\title{
Scalable Synthesis of Biologically Relevant Spirocyclic Pyrrolidines
}

Kostiantyn P. Melnykov, ${ }^{\mathrm{a}, \mathrm{b}}$ Artem N. Artemenko, ${ }^{\mathrm{a}}$ Bohdan O. Ivanenko, ${ }^{\mathrm{a}, \mathrm{b}}$ Yevhenii M. Sokolenko, ${ }^{\mathrm{a}}$ Pavel S. Nosik, ${ }^{\mathrm{a}, \mathrm{b}}$ Eugeniy N. Ostapchuk, $^{\mathrm{a}, \mathrm{b}}$ Oleksandr O. Grygorenko, ${ }^{\mathrm{a}, \mathrm{b}}$ Dmitriy M. Volochnyuk, ${ }^{\mathrm{b}, \mathrm{c}^{*}}$ Sergey V. Ryabukhin ${ }^{\mathrm{a}, \mathrm{b}^{*}}$

${ }^{a}$ Enamine Ltd., Chervonotkatska Street 78, Kyiv 02094, Ukraine, www.enamine.net

${ }^{b}$ Taras Shevchenko National University of Kyiv, Volodymyrska Street 64, Kyiv 01601, Ukraine

${ }^{c}$ Institute of Organic Chemistry, National Academy of Sciences of Ukraine, Murmanska Street 5, Kyiv 02660, Ukraine

\section{Supporting Information}

SI-1 to SI-2 Table of Contents

SI-3 to SI-22 Scheme (S1) and analytical data for the synthesis of 4-azaspiro[2.4]heptane hydrochloride 1a*HCl. Approach IV. (Figures S1-S20)

SI-23 to SI-30 Scheme (S2) and analytical data for the synthesis of 5-azaspiro[3.4] octane hydrochloride 16*HCl. Approach I. (Figures S21-S28)

SI-31 to SI-41 Scheme (S3) and analytical data for the synthesis of 5-azaspiro[3.4]octane hydrochloride 1b*HCl. Approach II. (Figures S29-S39)

SI-42 to SI-49 Scheme (S4) and analytical data for the synthesis of 1-azaspiro[4.4]nonane hydrochloride 1c*HCl. Approach I. (Figures S40-S47)

SI-50 to SI-57 Scheme (S5) and analytical data for the synthesis of 1-azaspiro[4.5]decane hydrochloride 1d*HCl. Approach I. (Figures S48-S55)

SI-58 to SI-66 Scheme (S6) and analytical data for the synthesis of 1-azaspiro[4.5]decane hydrochloride 1d*HCl. Approach II. (Figures S56-S64)

SI-67 to SI-74 Scheme (S7) and analytical data for the synthesis of 8-oxa-1-azaspiro[4.5]decane hydrochloride 1e*HCl. Approach I. (Figures S65-S72)

SI-75 to SI-82 Scheme (S8) and analytical data for the synthesis of 8-oxa-1-azaspiro[4.5]decane hydrochloride 1e*HCl. Approach II. (Figures S73-S80)

SI-83 to SI-94 Scheme (S9) and analytical data for the synthesis of 8-thia-1-azaspiro[4.5]decane hydrochloride 1f*HCl. Approach II. (Figures S81-S92)

SI-95 to SI-108 Scheme (S10) and analytical data for the synthesis of 8-thia-1-azaspiro[4.5]decane hydrochloride 1f*HCl. Approach III. (Figures S93-S106)

SI-109 to SI-117 Scheme (S11) and analytical data for the synthesis of 8-thia-1-azaspiro[4.5]decane 8,8-dioxide hydrochloride 1g*HCl. Approach I. (Figures S107-S115)

SI-118 to SI-125 Scheme (S12) and analytical data for the synthesis of 1-azaspiro[4.6]undecane hydrochloride 1h*HCl. Approach I. (Figures S116-S123)

SI-126 to SI-129 Scheme (S13) and analytical data for the synthesis of 7-oxa-1-azaspiro[4.4]nonane hydrochloride 1i*HCl. Approach I. (Figures S124-S127) 
SI-130 to SI-136 Scheme (S14) and analytical data for the synthesis of 7-oxa-1-azaspiro[4.5]decane 1j. Approach I. (Figures S128-S134)

SI-137 to SI-151 Scheme (S15) and analytical data for the synthesis of 7-thia-1-azaspiro[4.4]nonane hydrochloride 1k*HCl. Approach III. (Figures S135-S149).

SI-152 to SI-155 Scheme (S16) and analytical data for the synthesis of 7-thia-1-azaspiro[4.4]nonane 7,7-dioxide hydrochloride 1l*HCl. Approach III. (Figures S150-S153).

SI-156 to SI-169 Scheme (S17) and analytical data for the synthesis of 7-thia-1-azaspiro[4.5]decane hydrochloride 1m*HCl. Approach II. (Figures S154-S167).

SI-170 to SI-182 Scheme (S18) and analytical data for the synthesis of benzyl 7-thia-1-azaspiro[4.5]decane 7,7-dioxide hydrochloride 1n*HCl. Approach II. (Figures S168-S180).

SI-183 to SI-199 Scheme (S19) and analytical data for the synthesis of 8,8-difluoro-1-azaspiro[4.5]decane hydrochloride 1o*HCl. Approach II. (Figures S181-S197).

SI-200 to SI-218 Scheme (S20) and analytical data for the synthesis of tert-butyl 1,8-diazaspiro[4.5]decane-8-carboxylate 1p. Approach III. (Figures S198-S216).

SI-219 to SI-235 Scheme (S21) and analytical data for the synthesis of tert-butyl 1,7-diazaspiro[4.5]decane-7-carboxylate 1r. Approach III. (Figures S217-S233). 
Synthesis of 4-azaspiro[2.4]heptane hydrochloride (1a*HCl). Approach IV.

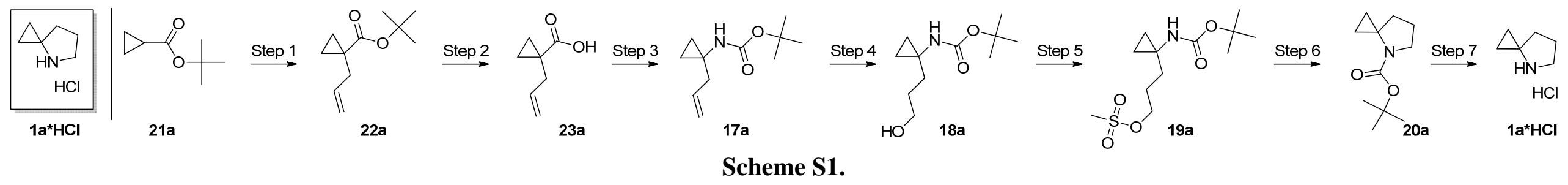

Figure S1. ${ }^{1} \mathrm{H}$ NMR spectrum of the compound 22a.

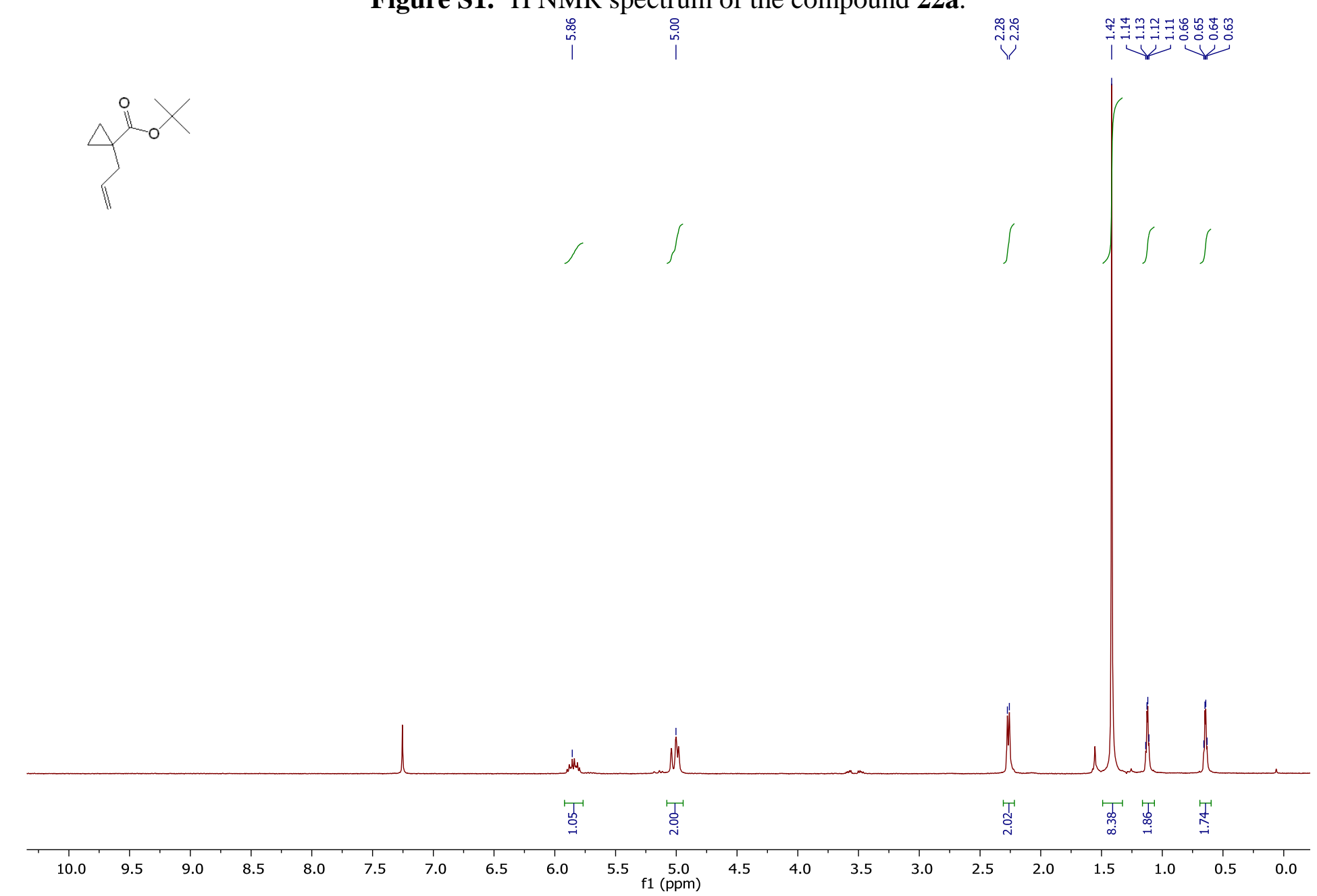


Figure S2. ${ }^{13} \mathrm{C}$ NMR spectrum of the compound 22a.
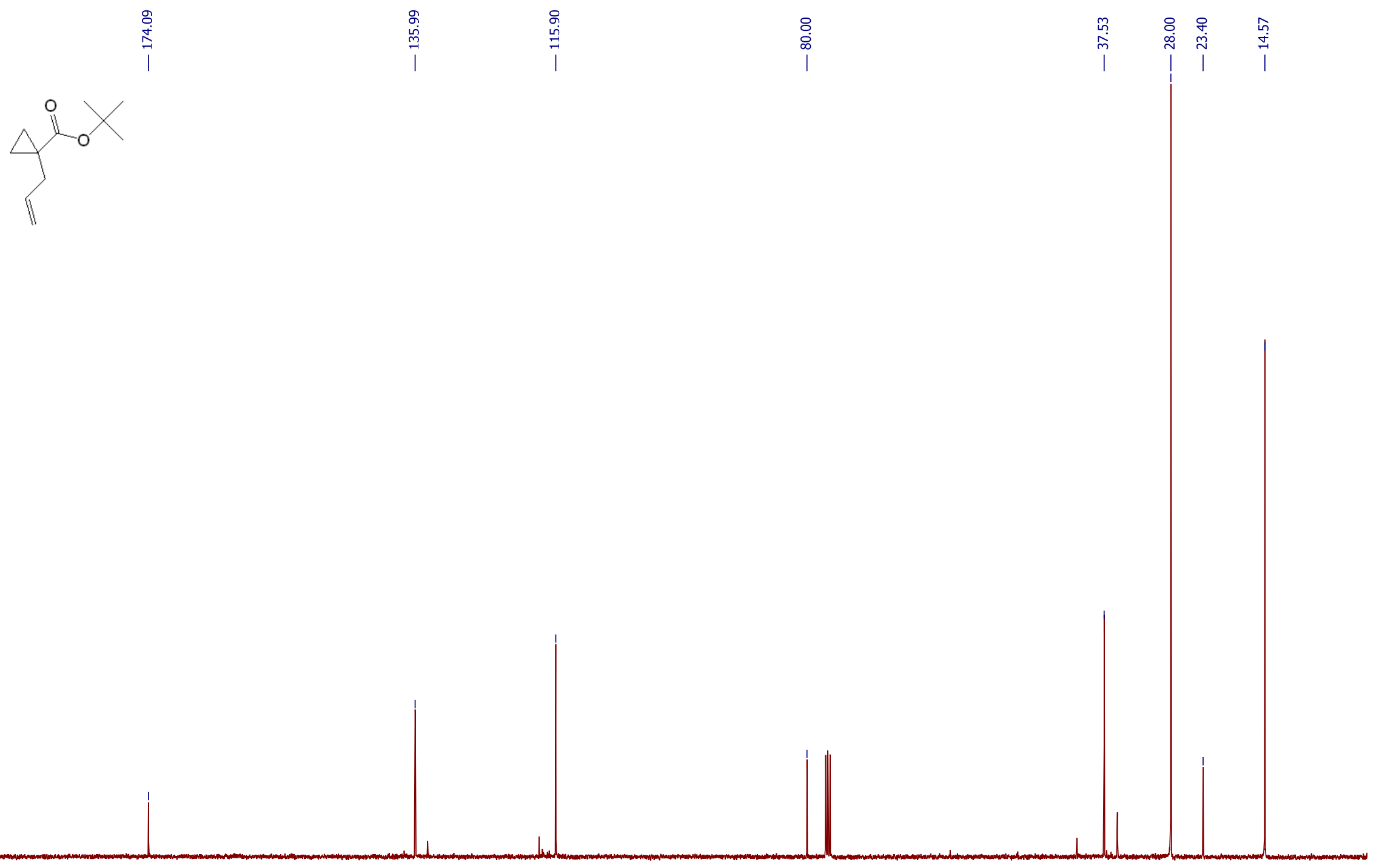
Figure S3. Mass spectrum of the compound 22a.

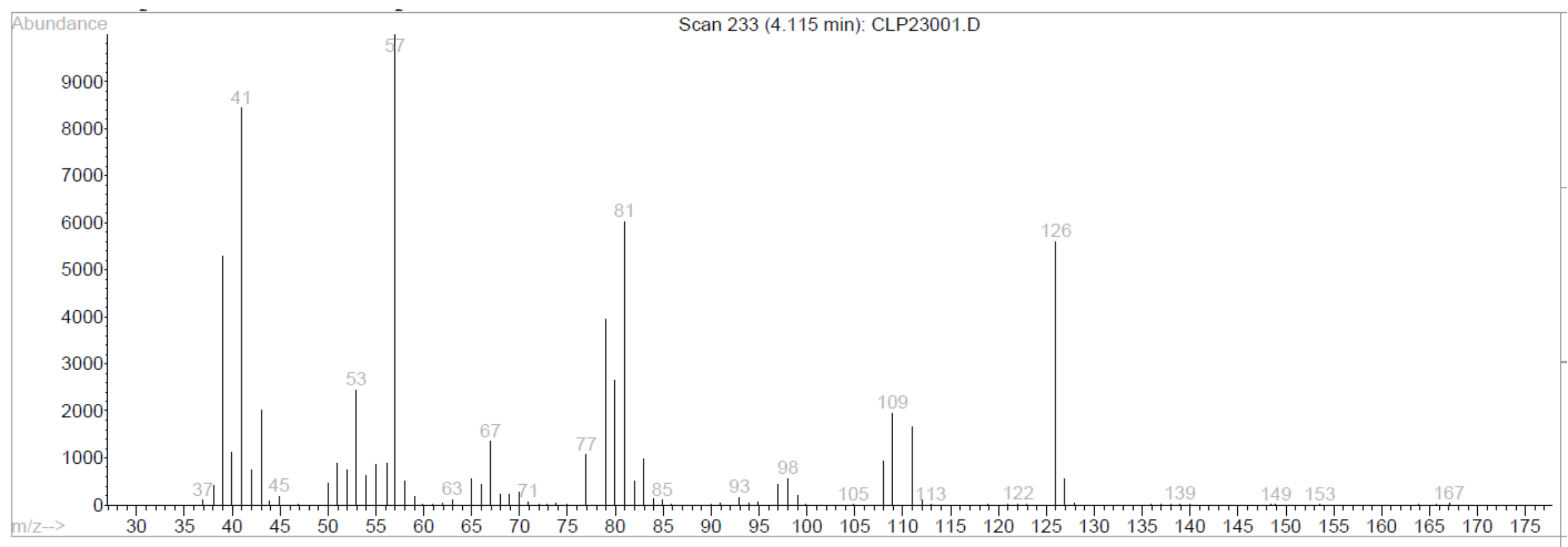


Figure S4. ${ }^{1} \mathrm{H}$ NMR spectrum of the compound 23a.

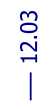
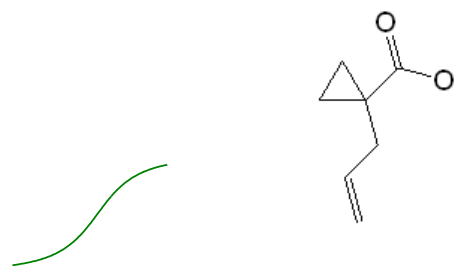

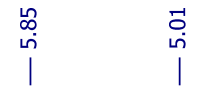

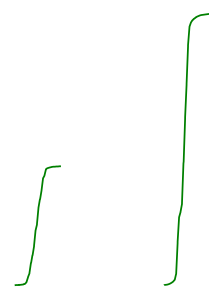

$$
\text { in }
$$
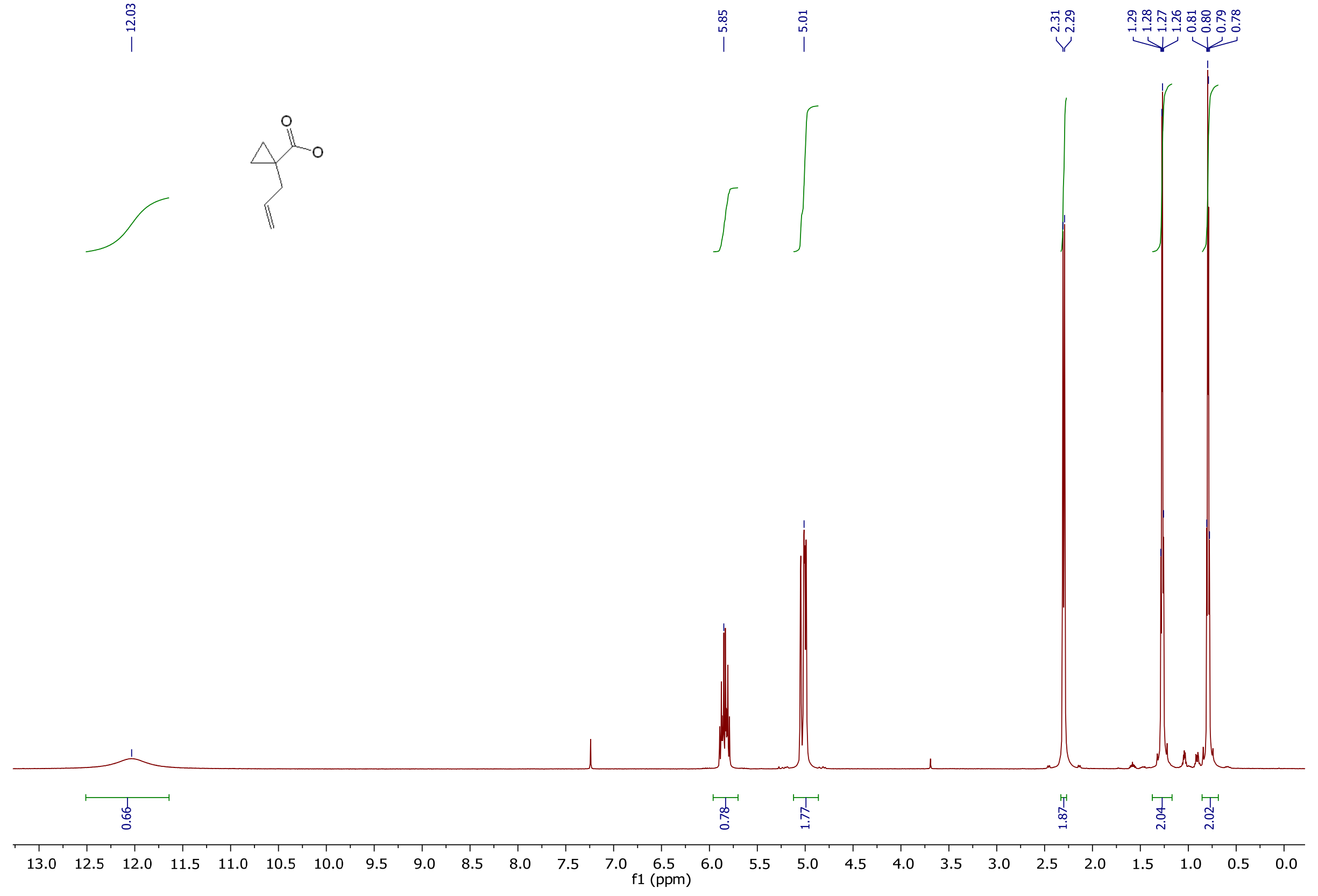
Figure S5. ${ }^{13} \mathrm{C}$ NMR spectrum of the compound 23a.
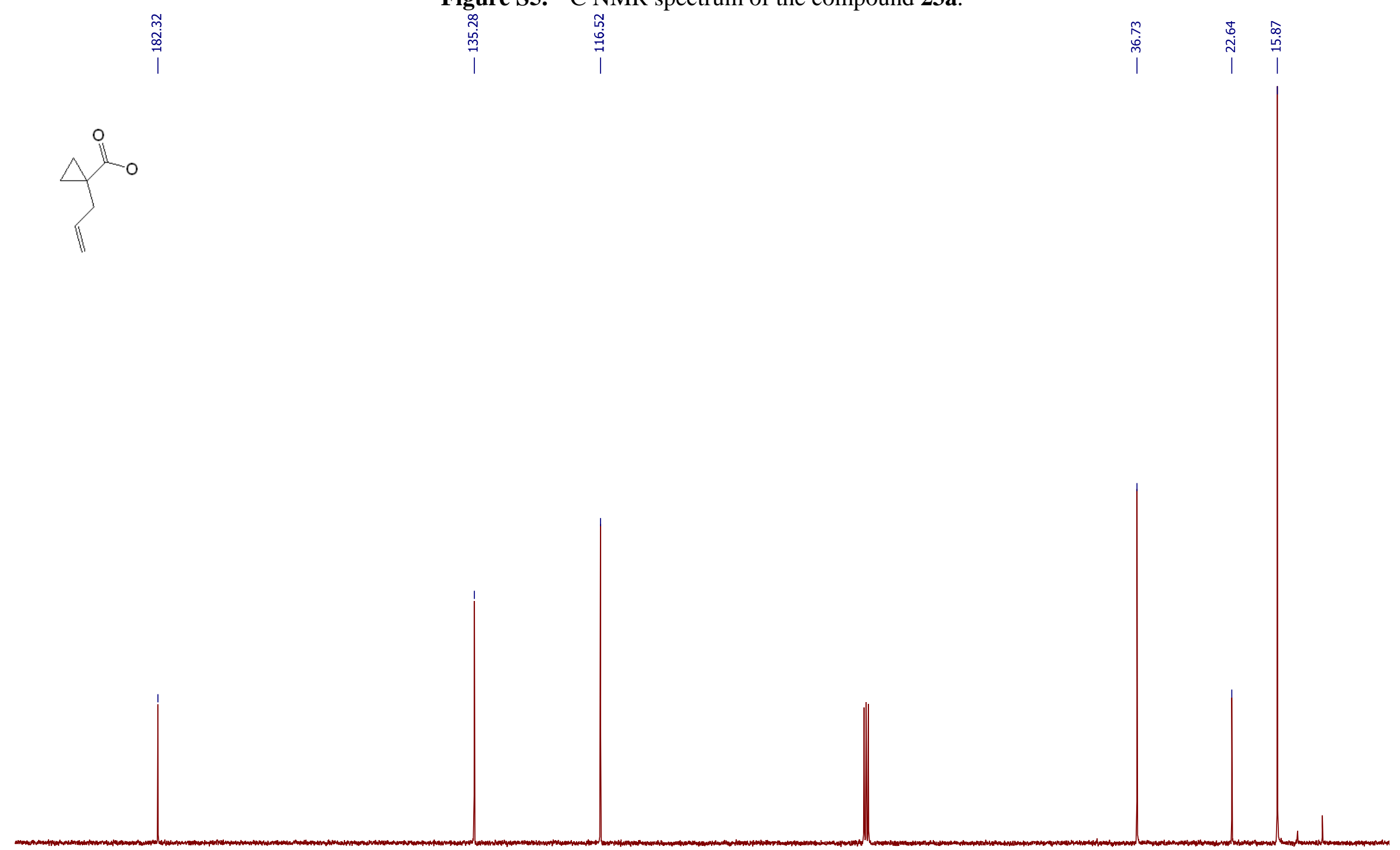
Figure S6. Mass spectrum of the compound 23a.

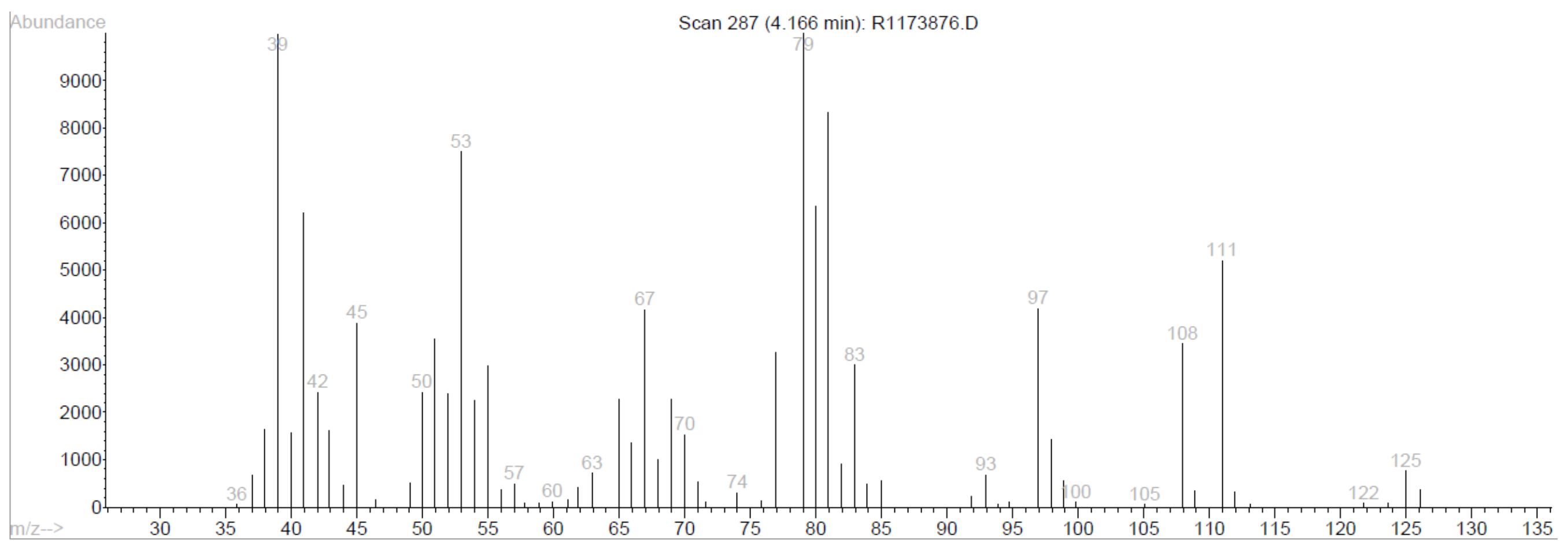


Figure S7. ${ }^{1} \mathrm{H}$ NMR spectrum of the compound $\mathbf{1 7 a}$.

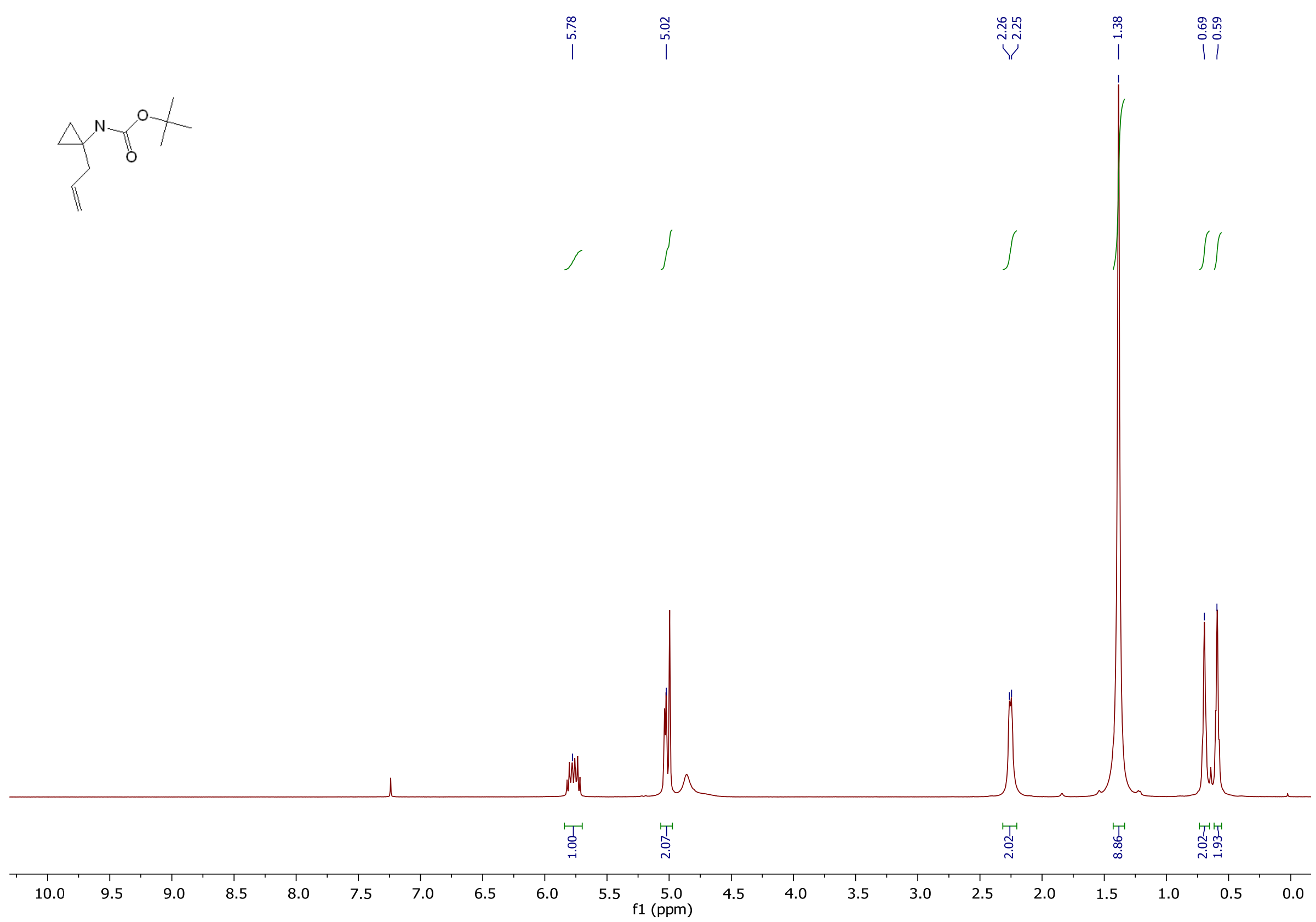


Figure S8. ${ }^{13} \mathrm{C}$ NMR spectrum of the compound 17a.

।

$\Delta_{0}^{N-a / t}$

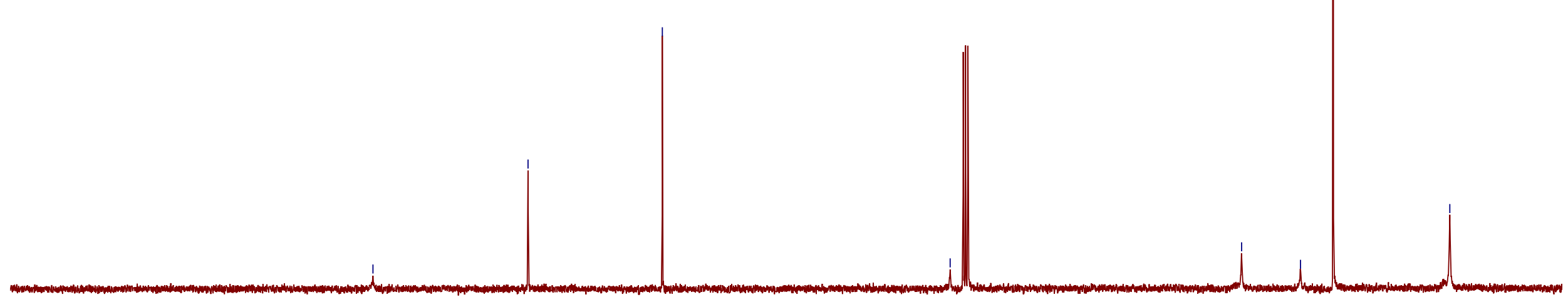


Figure S9. Mass spectrum of the compound 17a.

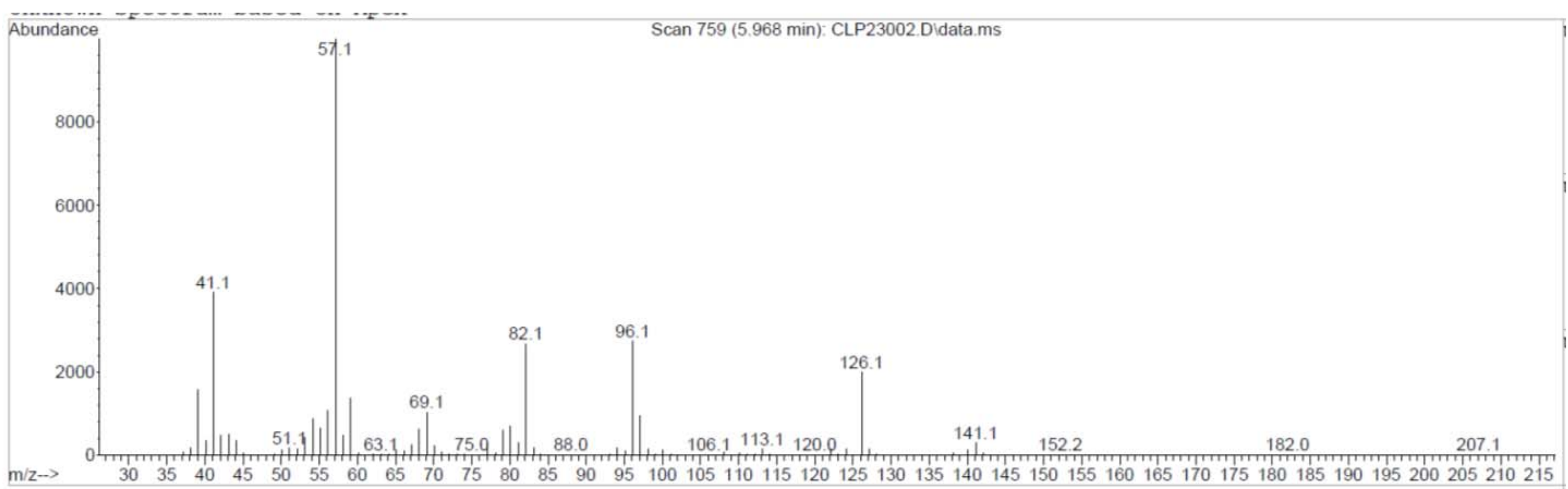


Figure S10. ${ }^{1} \mathrm{H}$ NMR spectrum of the compound 18a.
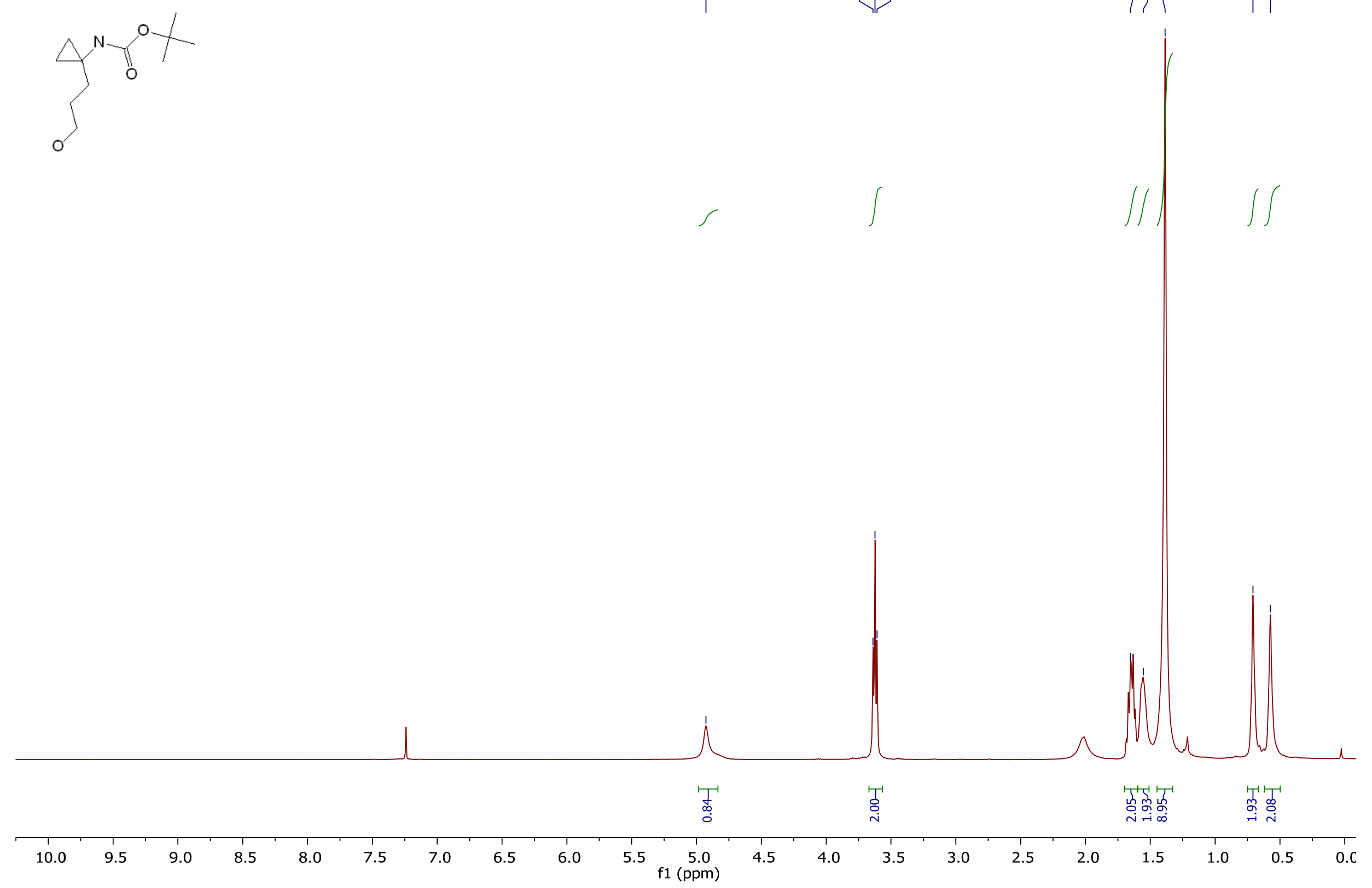
Figure S11. ${ }^{13} \mathrm{C}$ NMR spectrum of the compound 18a.
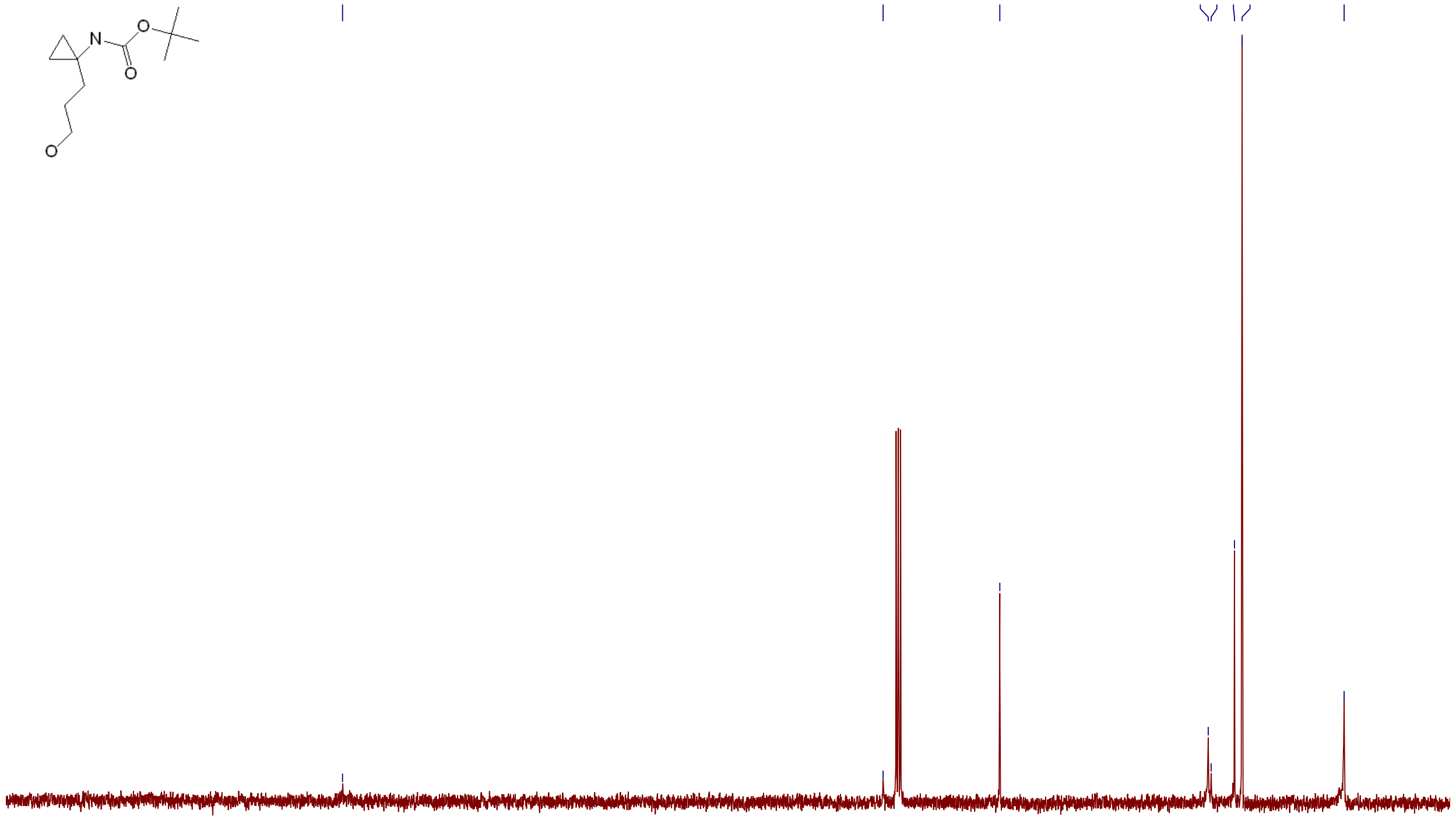
Figure S12. Mass spectrum of the compound 18a.

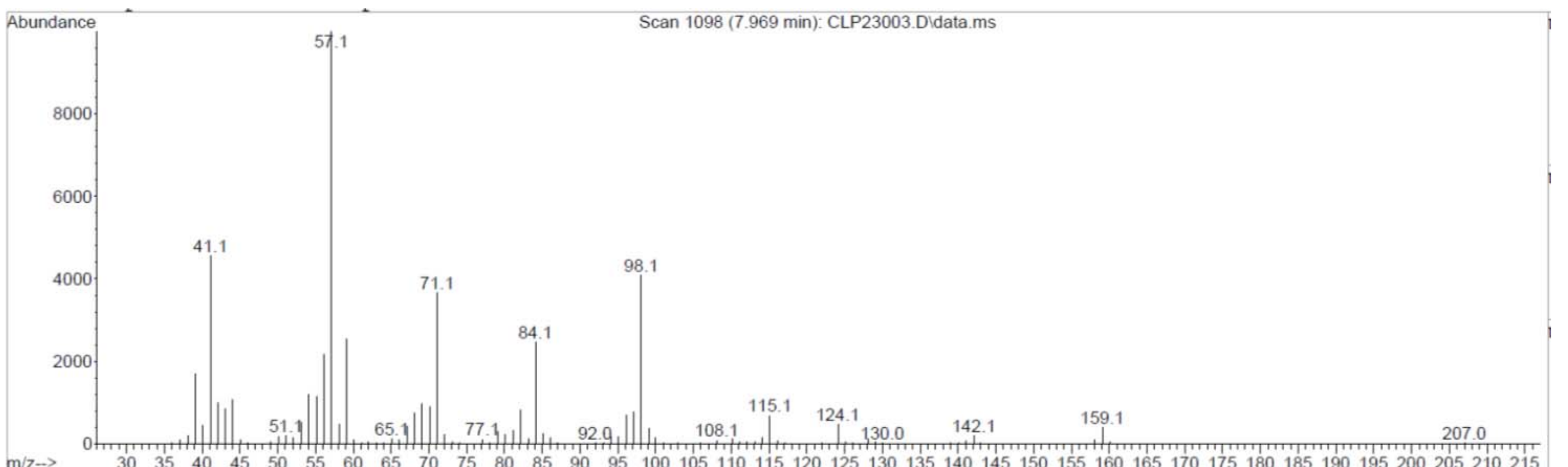


Figure S13. ${ }^{1} \mathrm{H}$ NMR spectrum of the compound 19a.

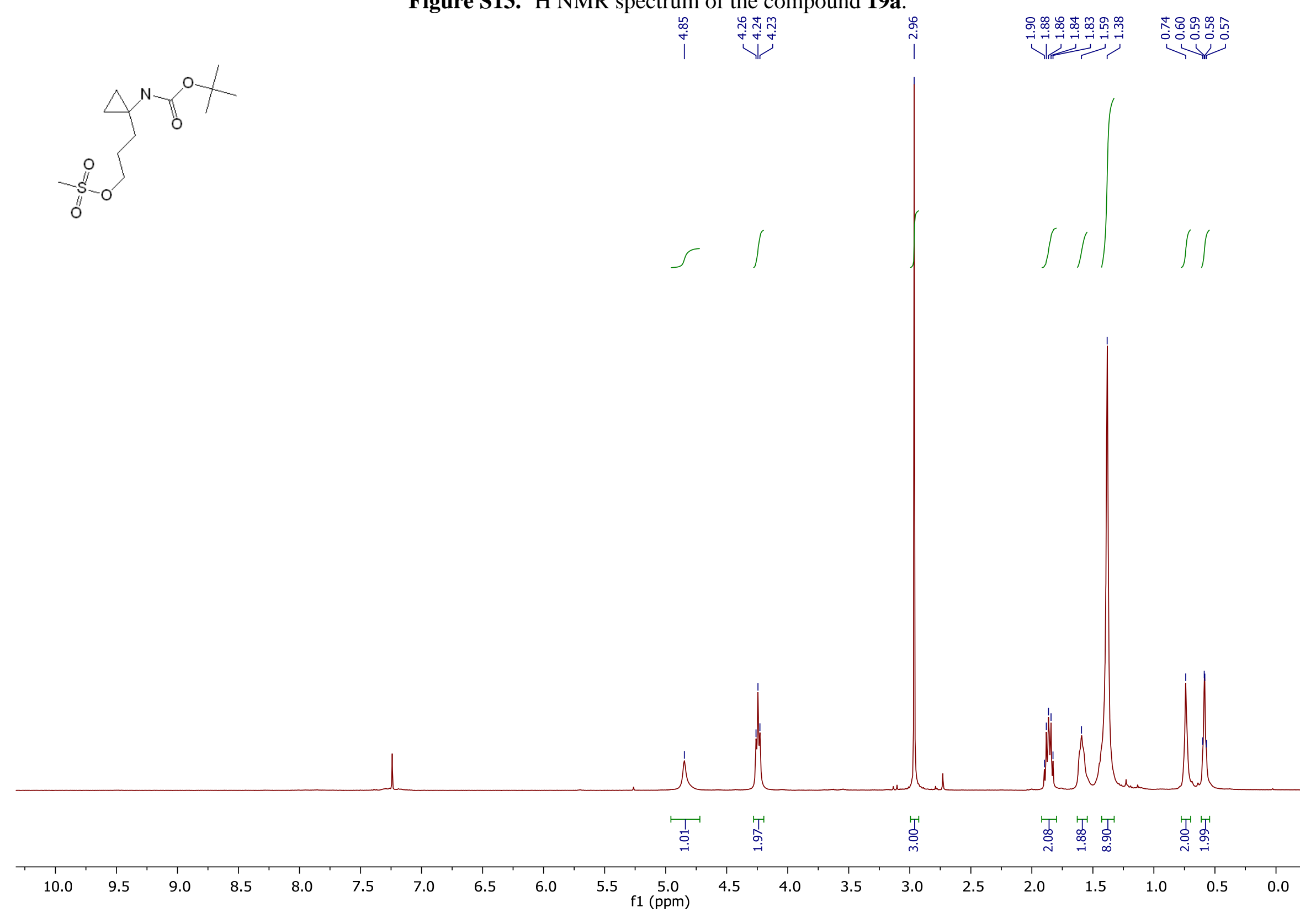


Figure S14. ${ }^{13} \mathrm{C}$ NMR spectrum of the compound 19a.
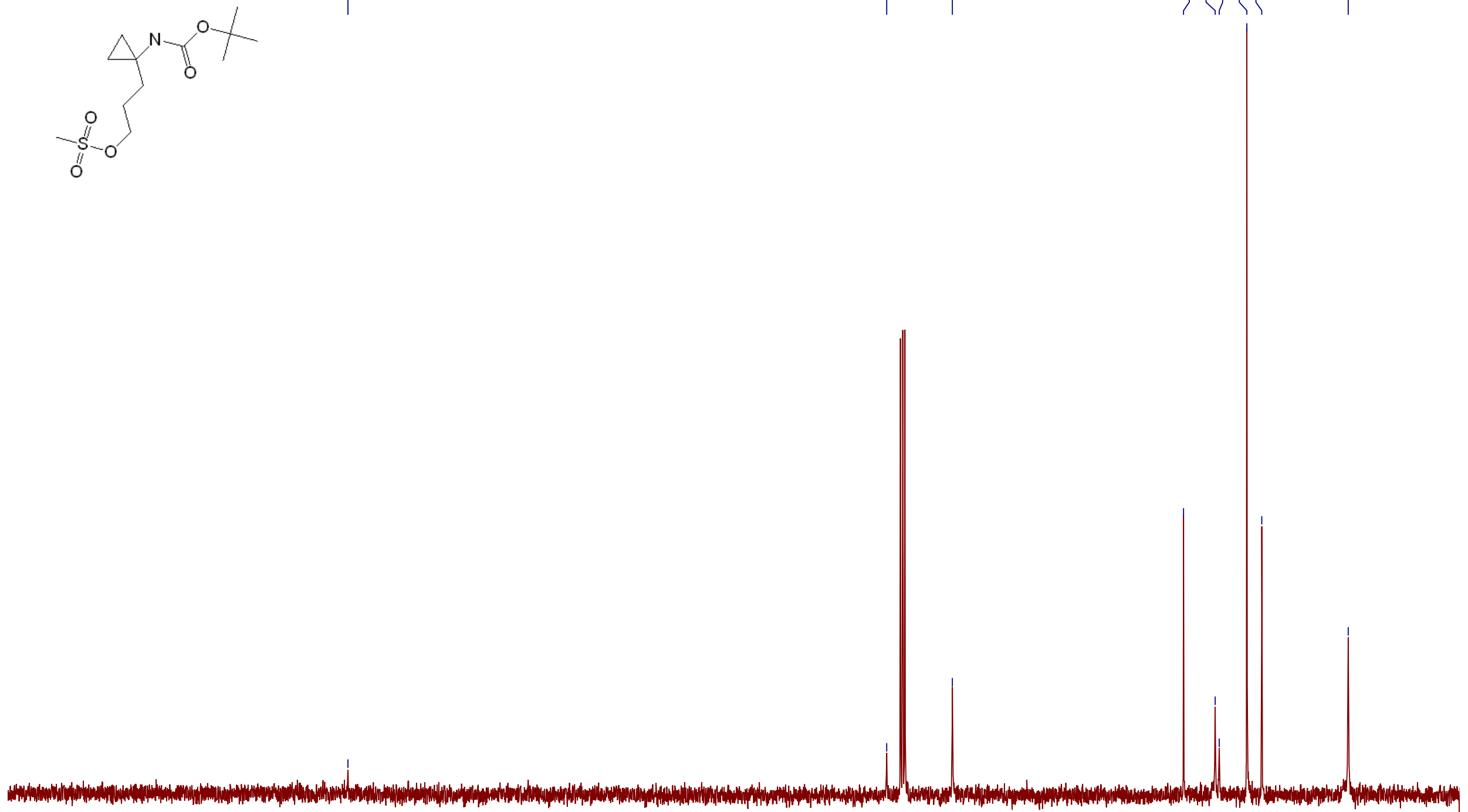
Figure S15. Mass spectrum of the compound 19a.

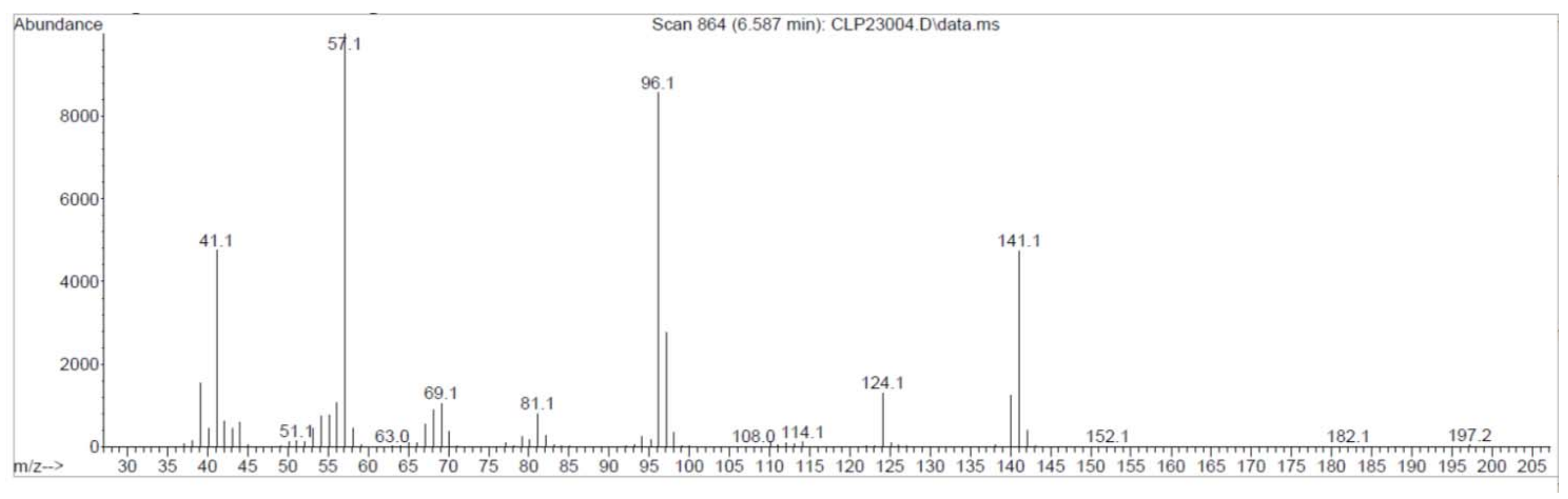


Figure S16. ${ }^{1} \mathrm{H}$ NMR spectrum of the compound 20a.

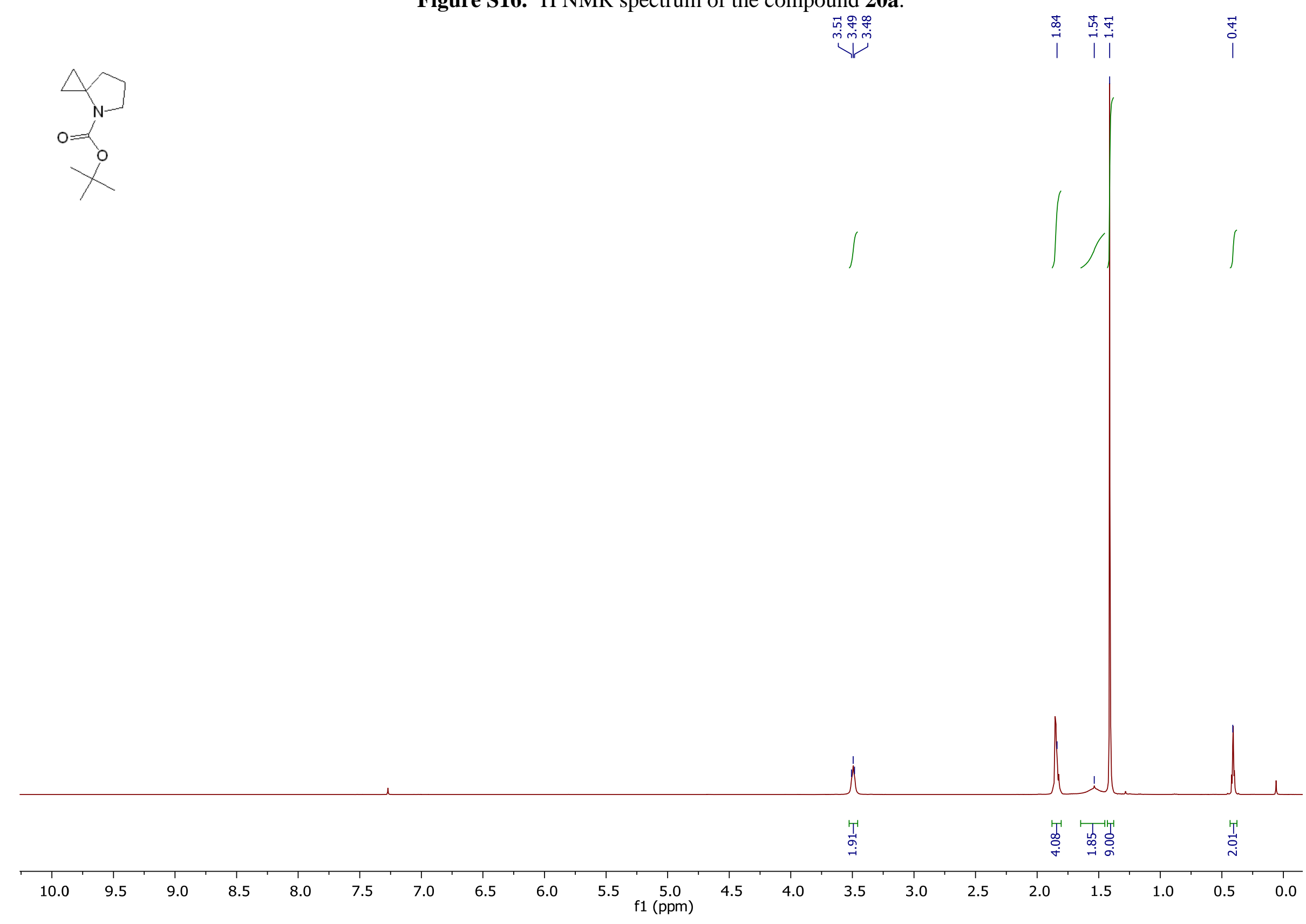


Figure S17. ${ }^{13} \mathrm{C}$ NMR spectrum of the compound 20a.

兽

$$
\underset{\substack{\llcorner \\\infty}}{\substack{\infty \\ \mid}}
$$

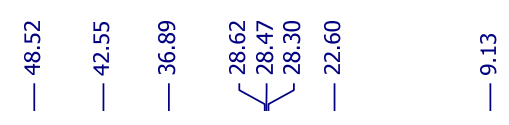<smiles>CC(C)(C)OC(=O)N1CCCC12CC2</smiles>

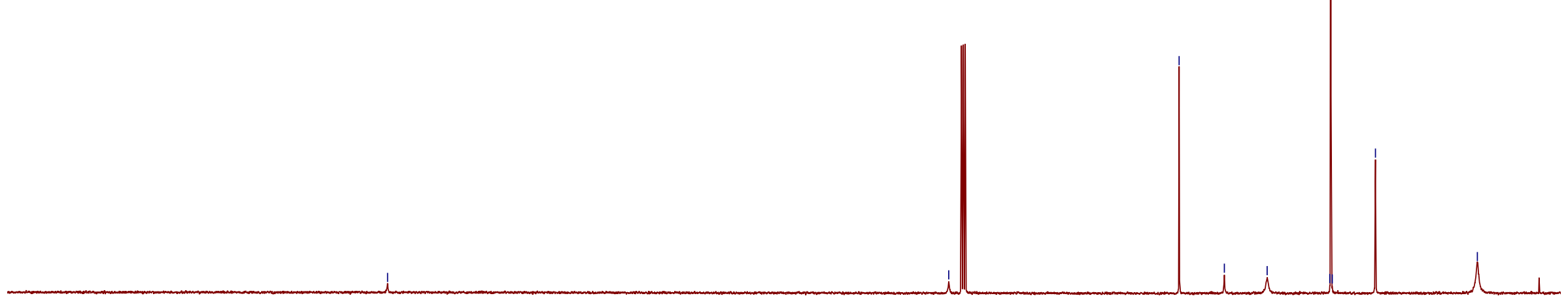


Figure S18. Mass spectrum of the compound 20a.

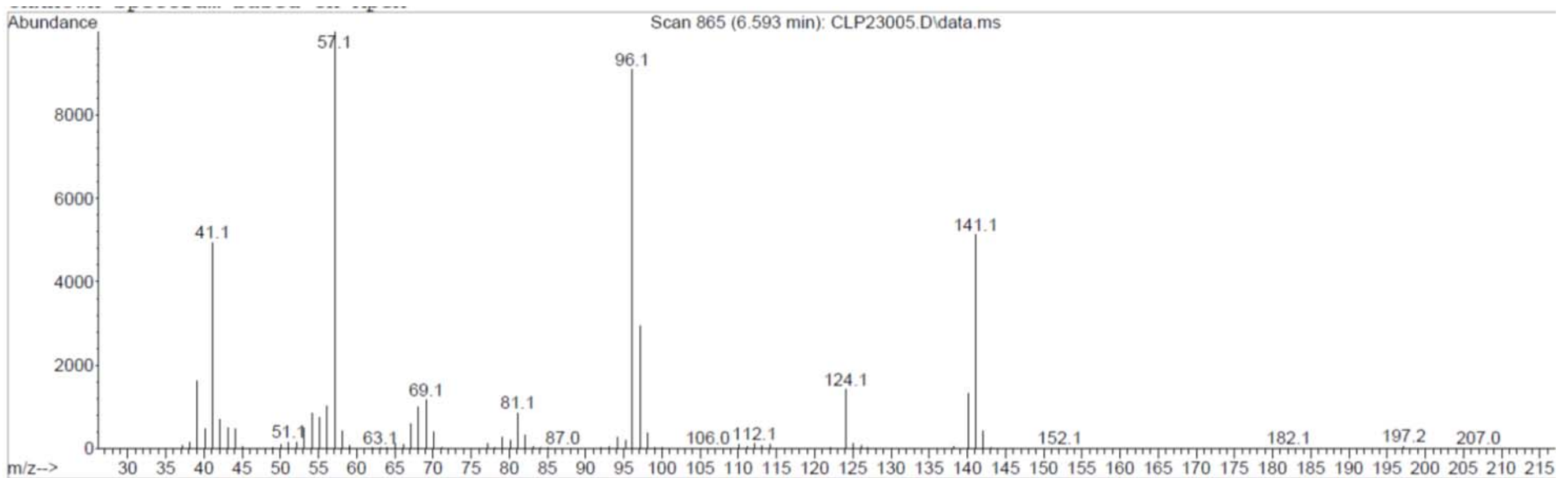


Figure S19. ${ }^{1} \mathrm{H}$ NMR spectrum of the compound $1 \mathbf{a}^{*} \mathbf{H C l}$.

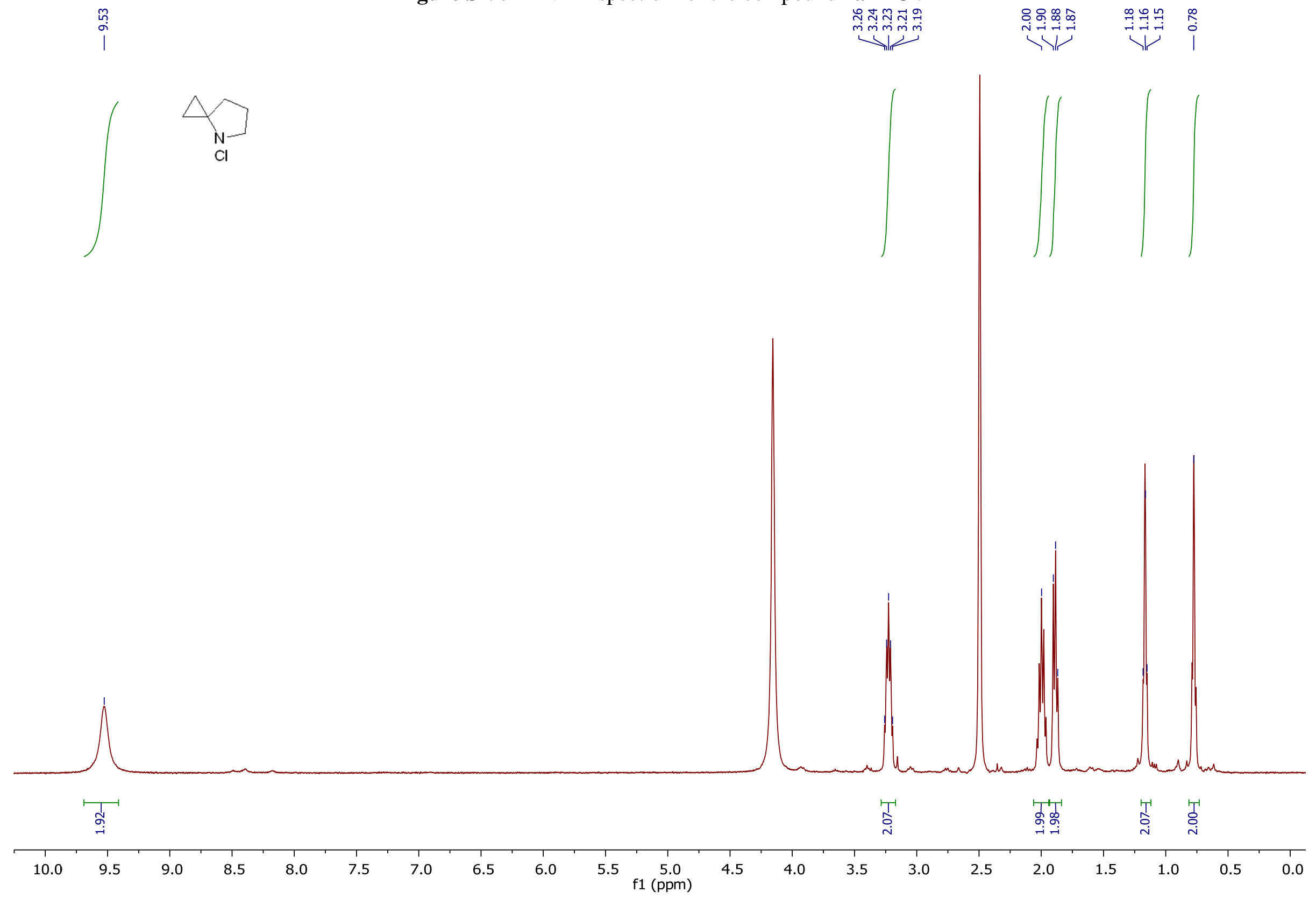


Figure S20. ${ }^{13} \mathrm{C}$ NMR spectrum of the compound $\mathbf{1 a}{ }^{*} \mathbf{H C l}$. 
Synthesis of 5-azaspiro[3.4]octane hydrochloride (1b*HCl). Approach I.

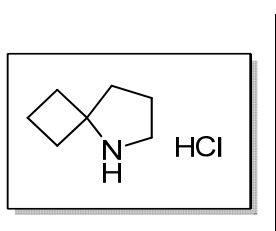

$1 b^{\star} \mathrm{HCl}$

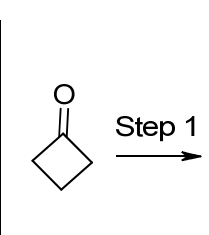

2b

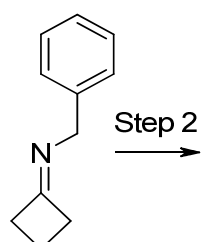

$3 b$

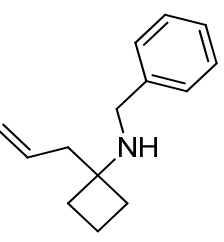

$\mathbf{4 b}$

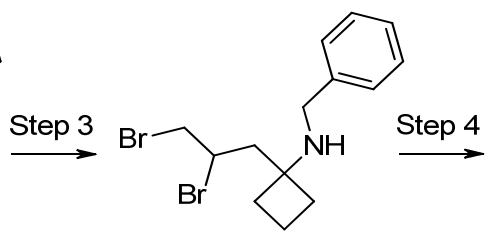

$5 \mathbf{b}$

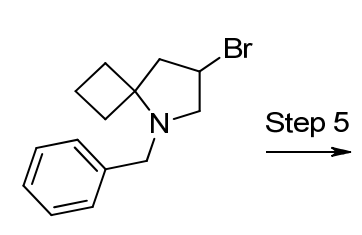

$6 b$

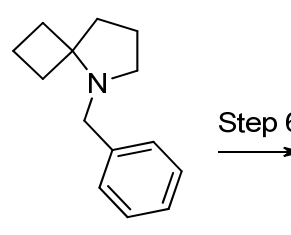

$7 \mathbf{b}$
Step 6<smiles>ClC1CCCC12CCC2</smiles>

$1 b^{*} \mathrm{HCl}$

Scheme S2

Figure S21. ${ }^{1} \mathrm{H}$ NMR spectrum of the compound $\mathbf{4 b}$.

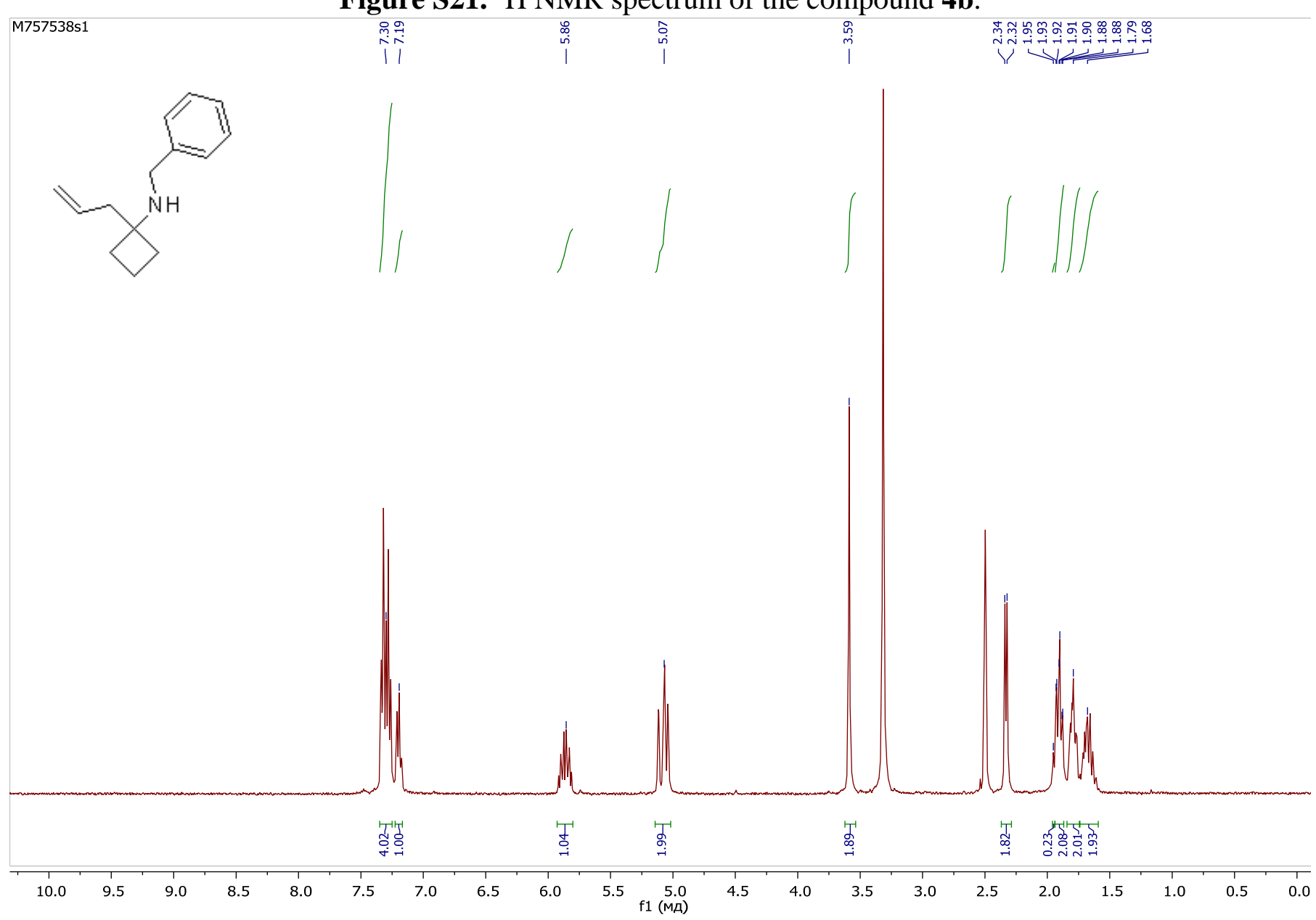


Figure S22. ${ }^{13} \mathrm{C}$ NMR spectrum of the compound $\mathbf{4 b}$.

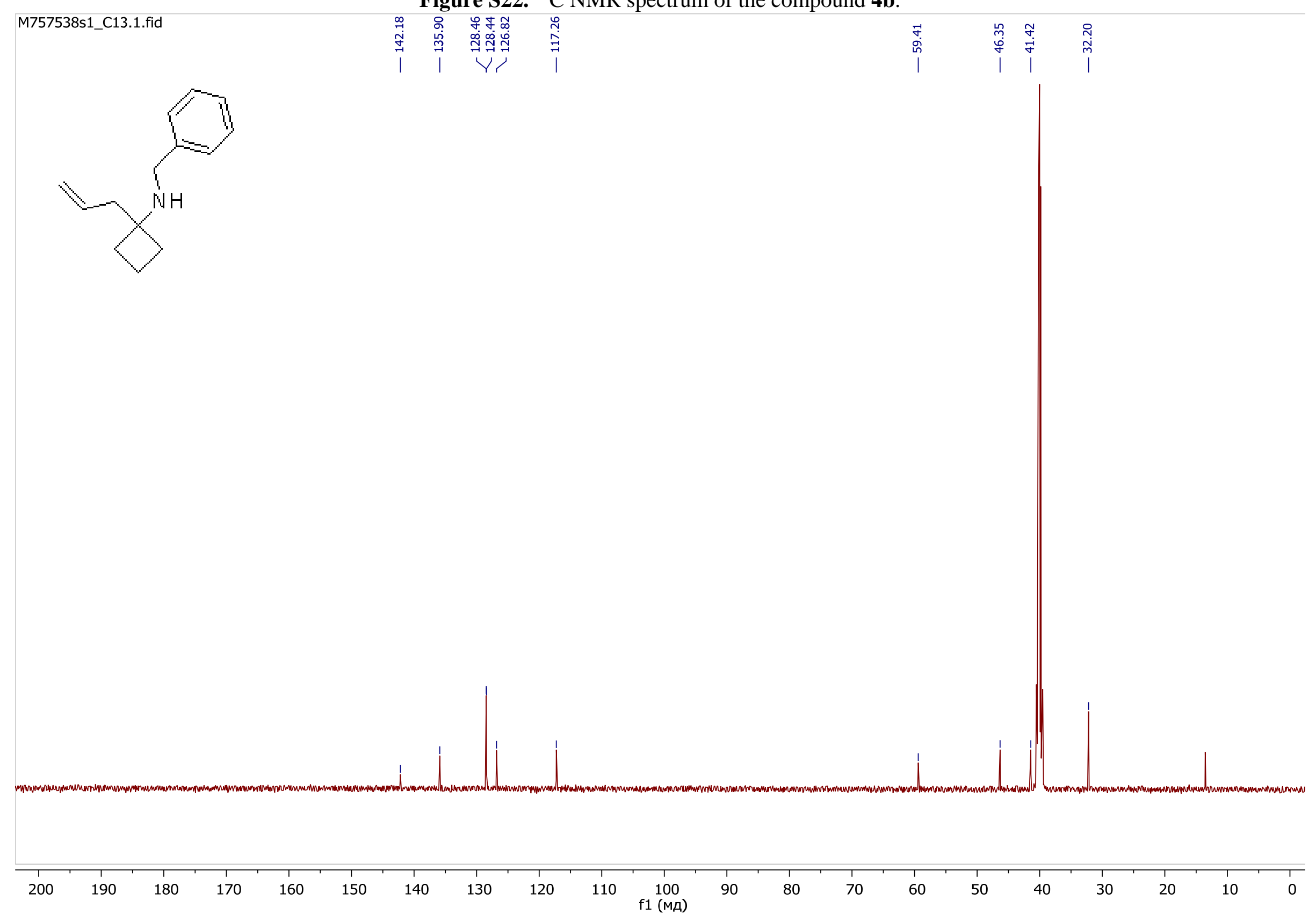


Figure S23. ${ }^{1} \mathrm{H}$ NMR spectrum of the compound $\mathbf{6 b}$.

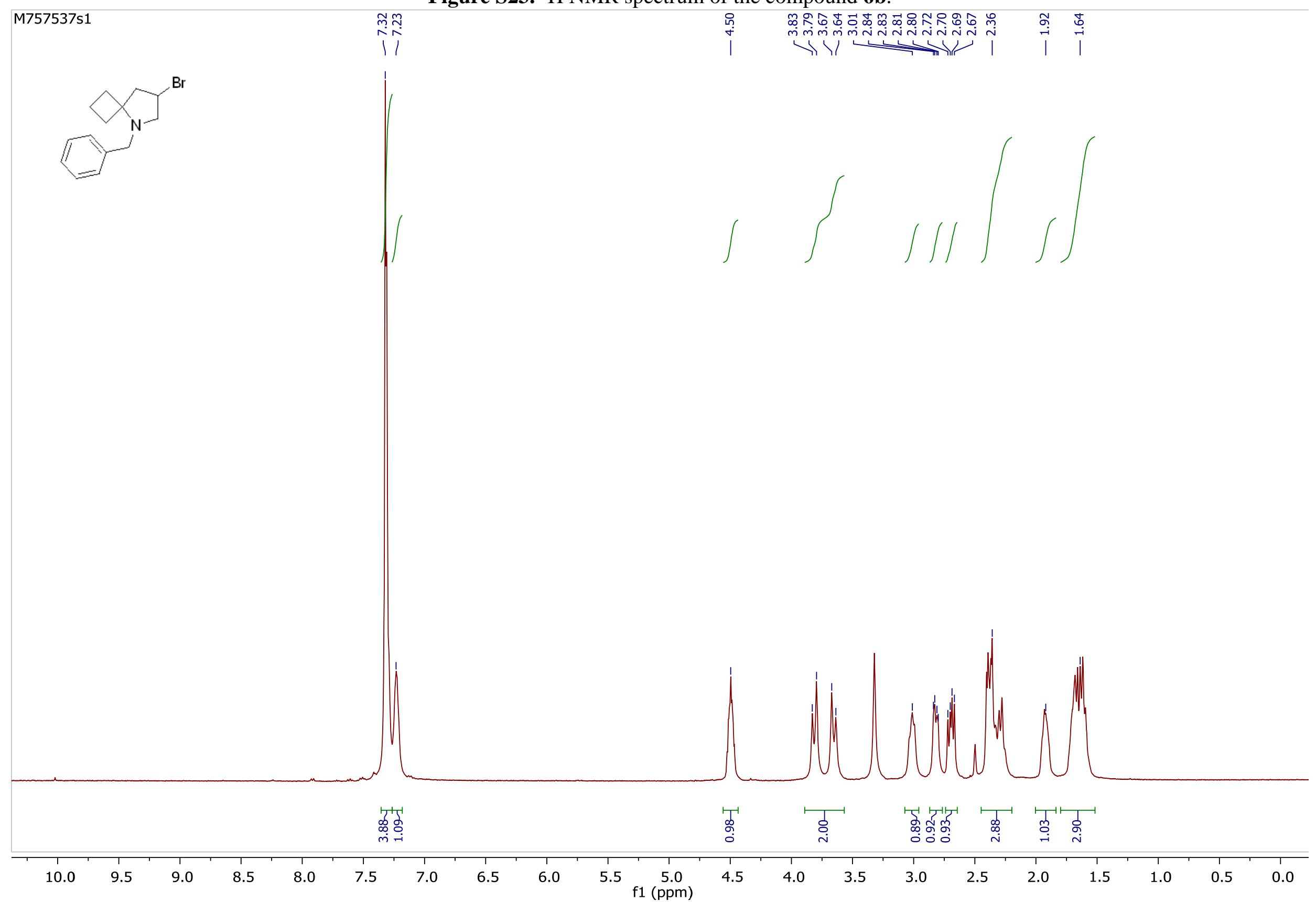


Figure S24. ${ }^{13} \mathrm{C}$ NMR spectrum of the compound $\mathbf{6 b}$.

M757537s1_C13

Automated Probe tuning parameter

$\mathrm{ft}$

l

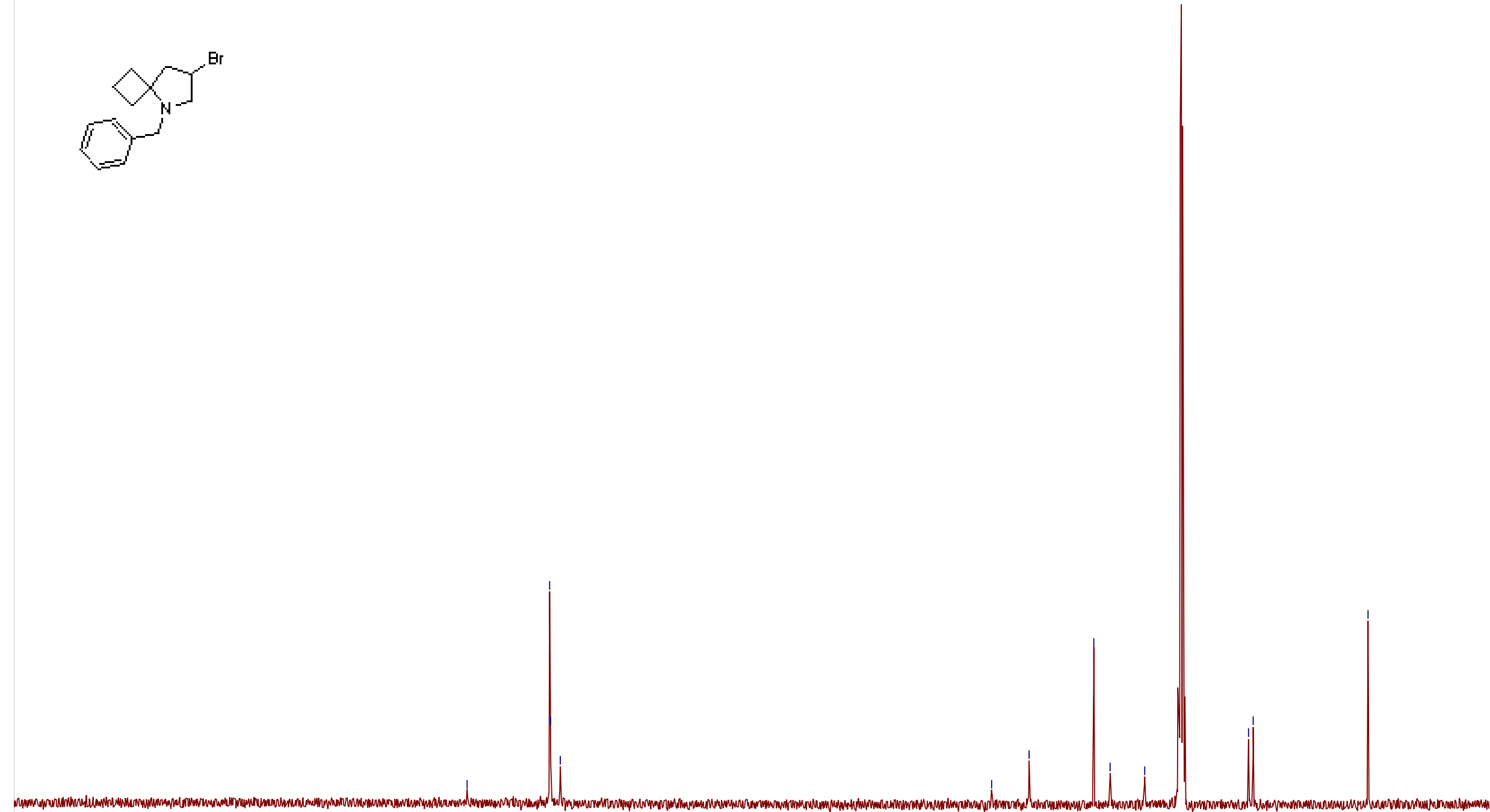

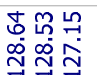

Y

\begin{tabular}{|c|c|c|c|c|c|c|c|c|c|c|c|c|c|c|c|c|c|c|c|}
\hline 200 & $\begin{array}{c}1 \\
190\end{array}$ & 180 & 170 & $\begin{array}{c}1 \\
160\end{array}$ & 150 & 140 & 130 & 120 & 110 & $\begin{array}{c}100 \\
\text { f1 (MA) }\end{array}$ & 90 & 80 & 70 & & 50 & 40 & 30 & 20 & 10 \\
\hline
\end{tabular}


Figure S25. ${ }^{1} \mathrm{H}$ NMR spectrum of the compound $\mathbf{7 b}$.

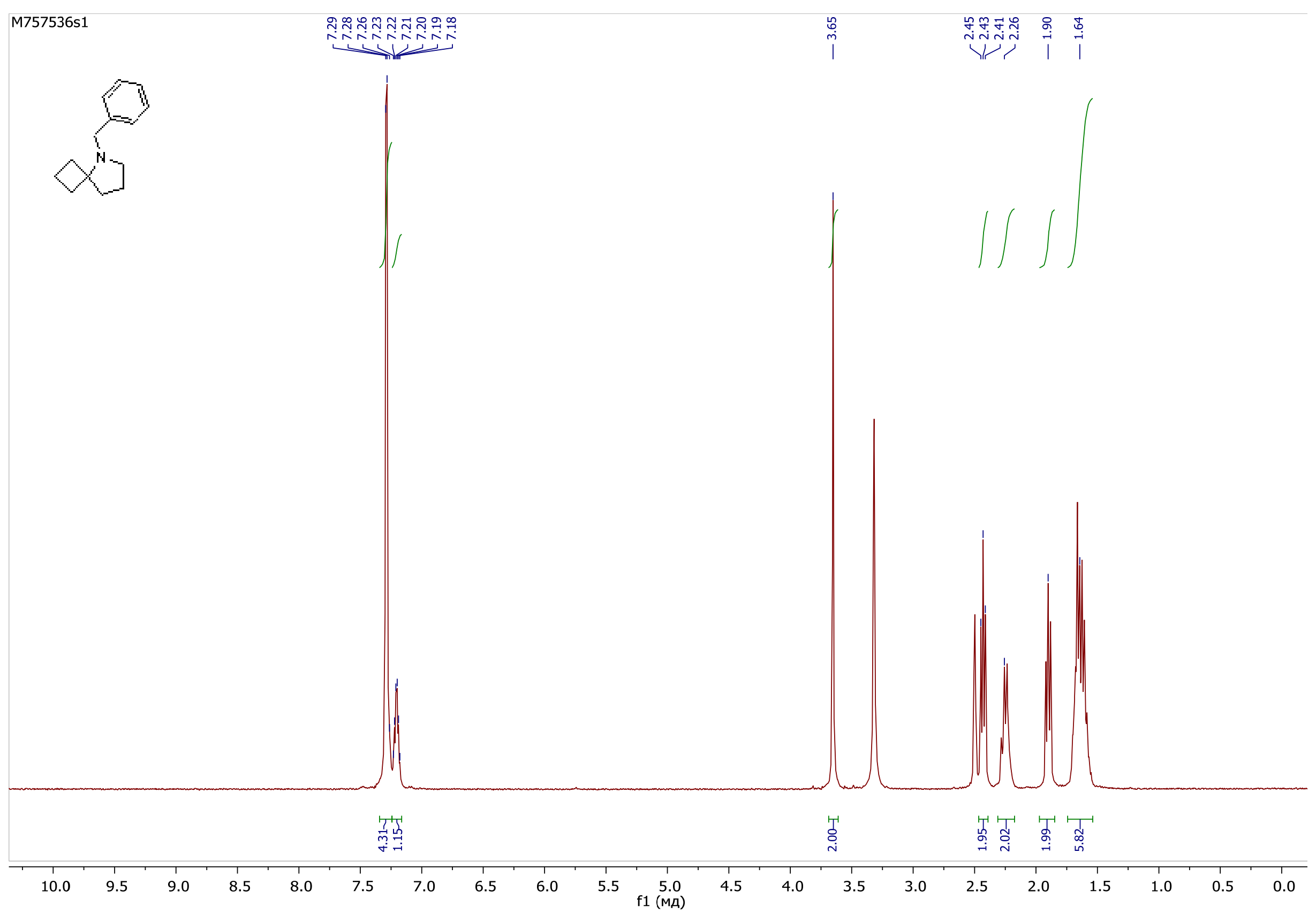


Figure S26. ${ }^{13} \mathrm{C}$ NMR spectrum of the compound $\mathbf{7 b}$.

M757536s1_C13.1.fid

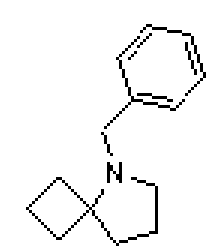

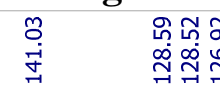

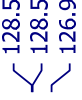

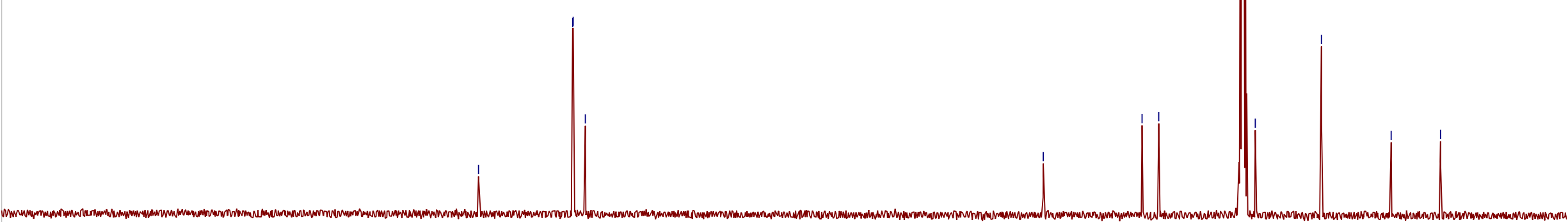


Figure S27. ${ }^{1} \mathrm{H}$ NMR spectrum of the compound $\mathbf{1 b} * \mathbf{H C l}$.

R847966尺

STANDARPD PROTON PARAMETERS

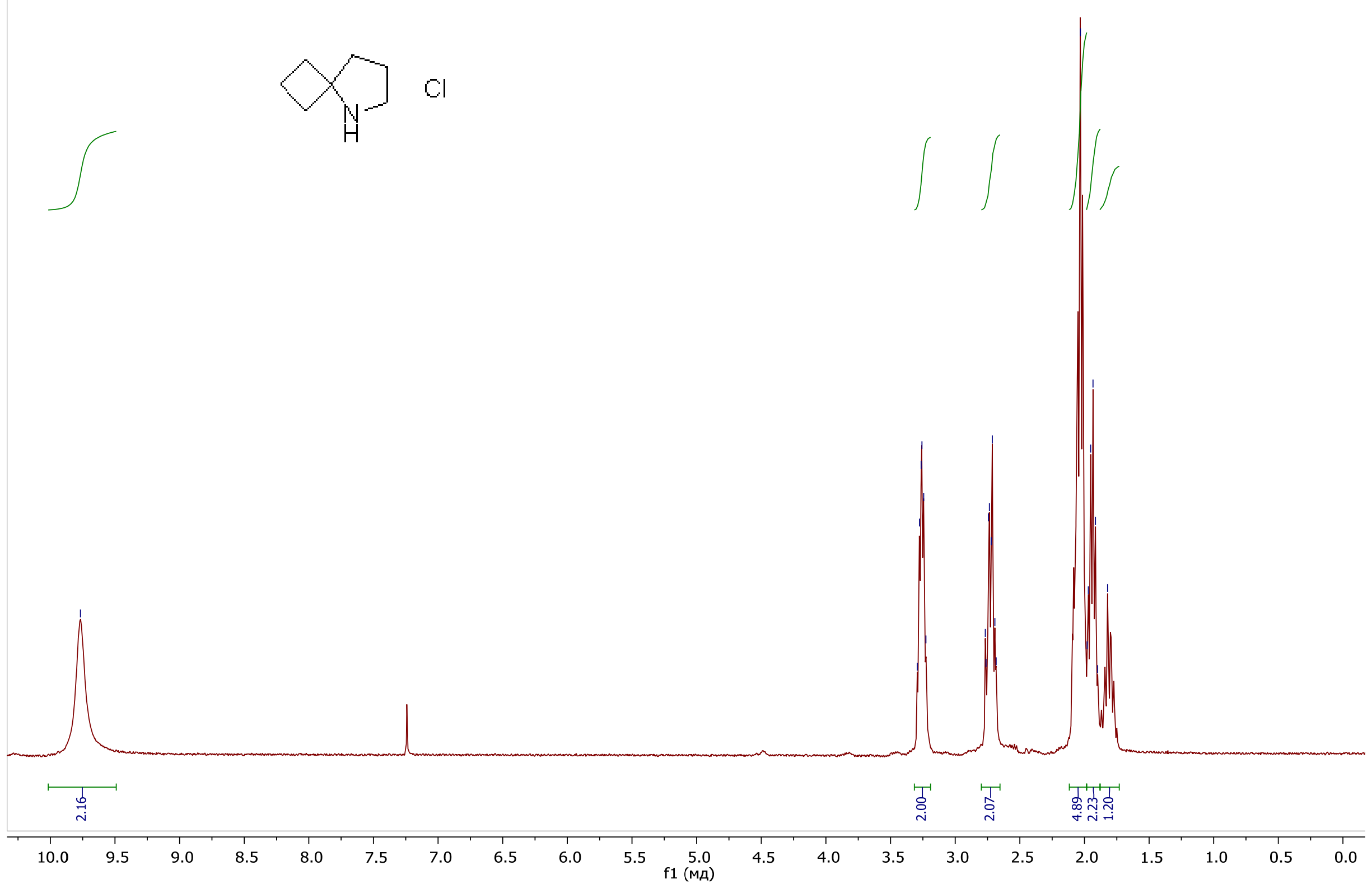

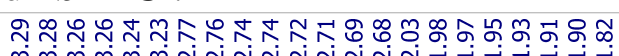


Figure S28. ${ }^{13} \mathrm{C}$ NMR spectrum of the compound $\mathbf{1 b} * \mathbf{H C l}$.

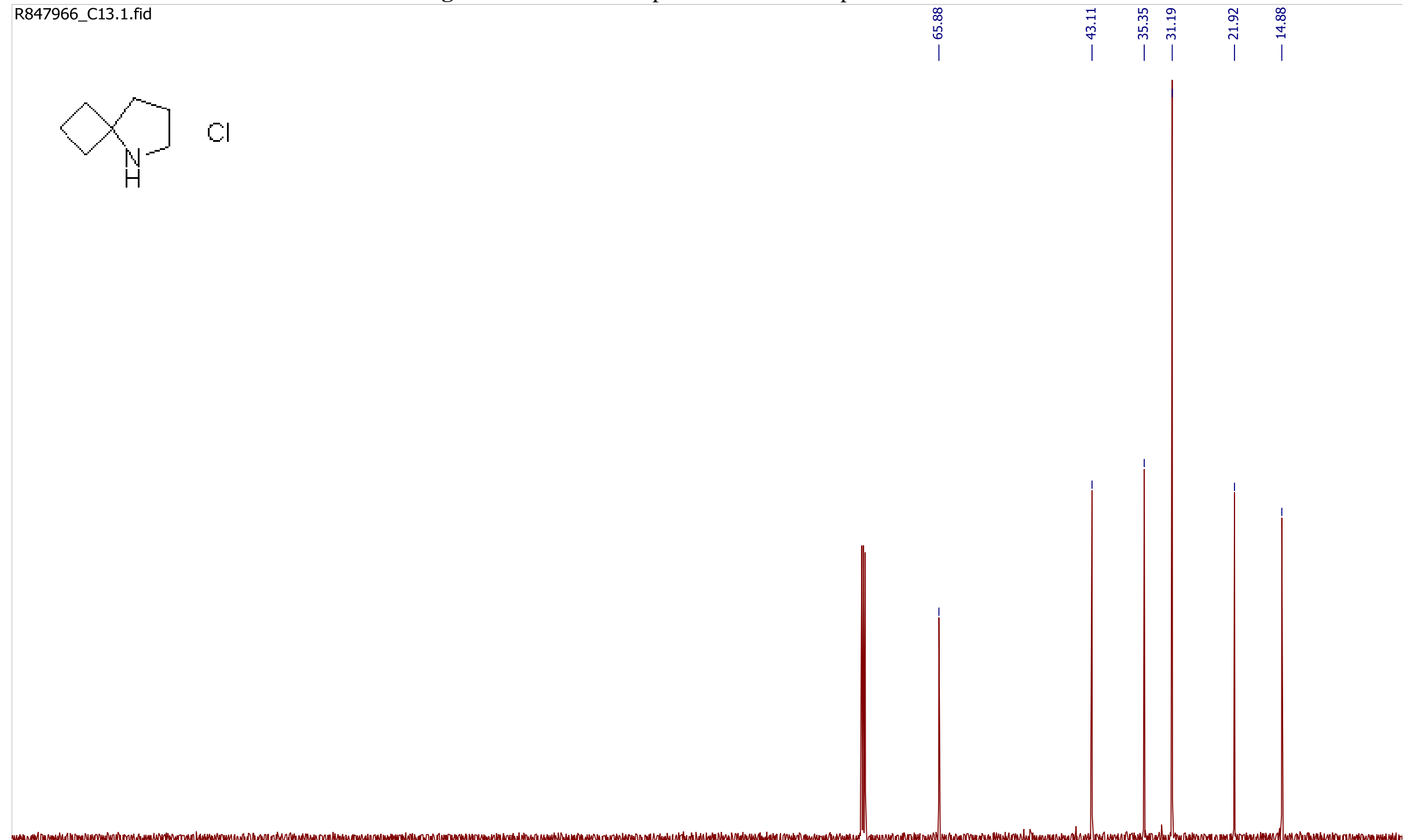

\begin{tabular}{|c|c|c|c|c|c|c|c|c|c|c|c|c|c|c|c|c|c|c|c|c|}
\hline 200 & $\begin{array}{l}1 \\
190\end{array}$ & 180 & $\begin{array}{c}1 \\
170\end{array}$ & 160 & 150 & 140 & 130 & 120 & 110 & $\begin{array}{c}1 \\
100\end{array}$ & 90 & 80 & 70 & 60 & $\frac{1}{50}$ & 40 & 13 & 20 & 10 & 1 \\
\hline 200 & 190 & 180 & $1 / 0$ & 160 & 150 & 140 & 130 & 120 & 110 & $\mathrm{f} 1$ (MA) & 90 & 80 & 10 & 60 & 50 & 40 & 30 & 20 & 10 & 0 \\
\hline
\end{tabular}


Synthesis of 5-azaspiro[3.4]octane hydrochloride (1b*HCl). Approach II.

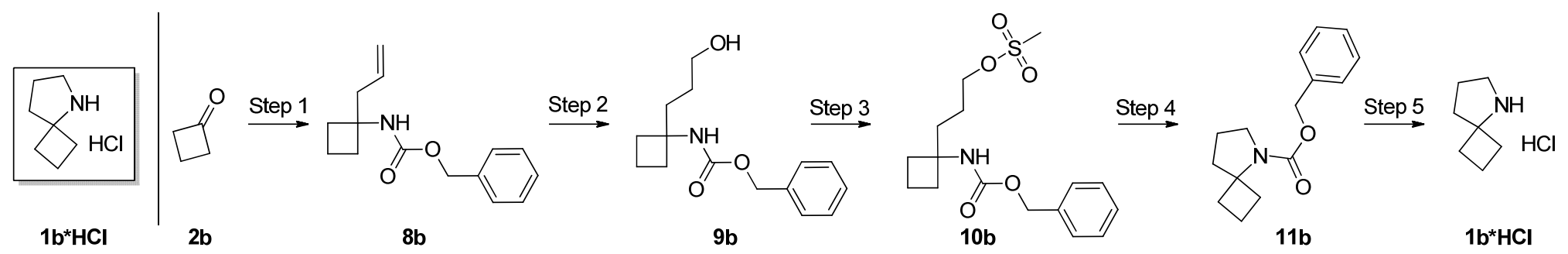

Scheme S3

Figure S29. ${ }^{1} \mathrm{H}$ NMR spectrum of the compound $\mathbf{8 b}$.

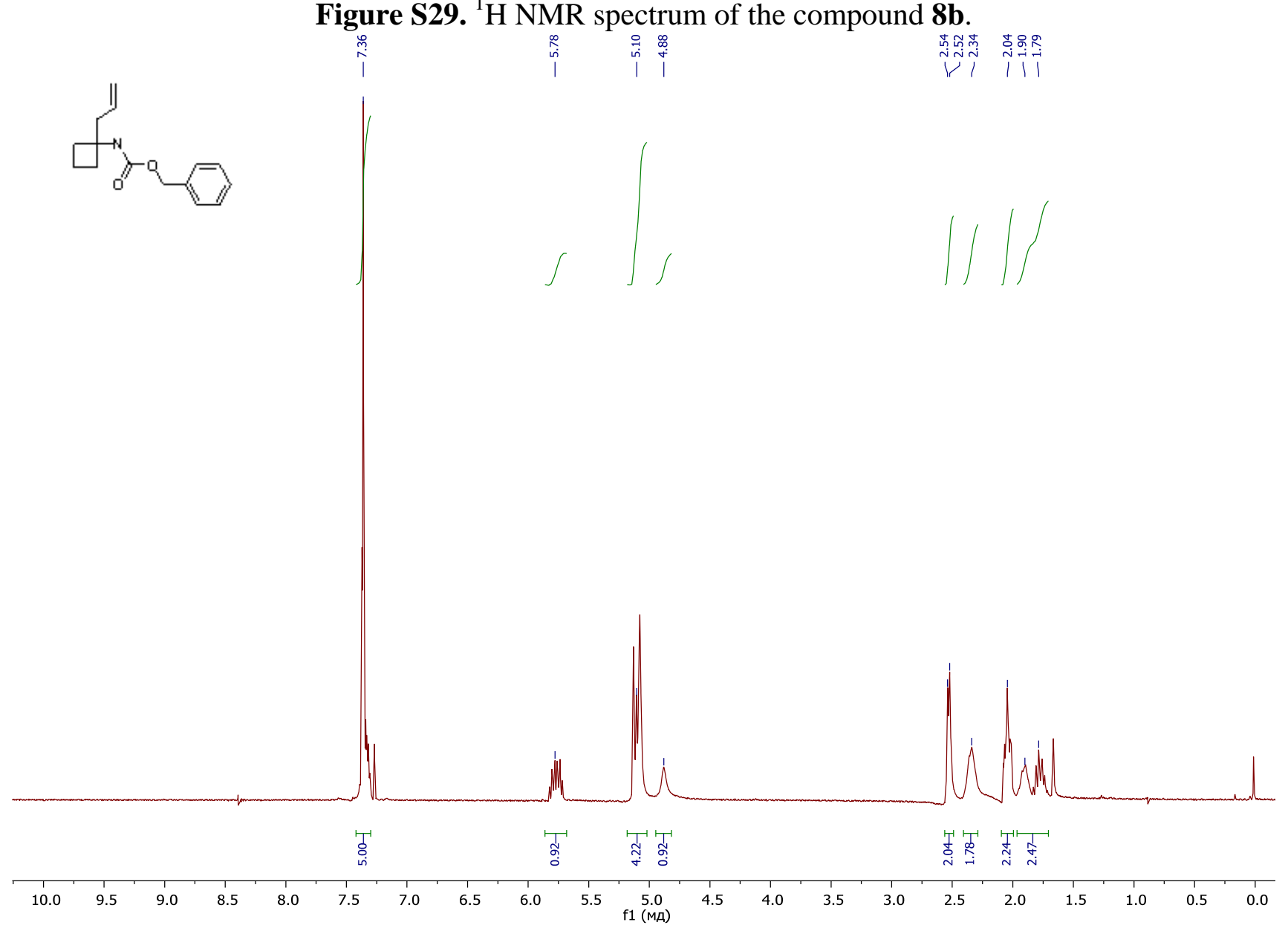


SI-32

Figure S30. ${ }^{13} \mathrm{C}$ NMR spectrum of the compound $8 \mathbf{b}$.

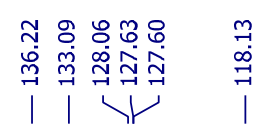

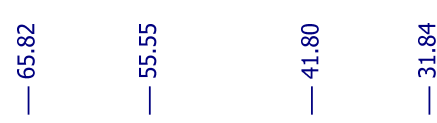

$\stackrel{\text { बे }}{\stackrel{9}{7}}$
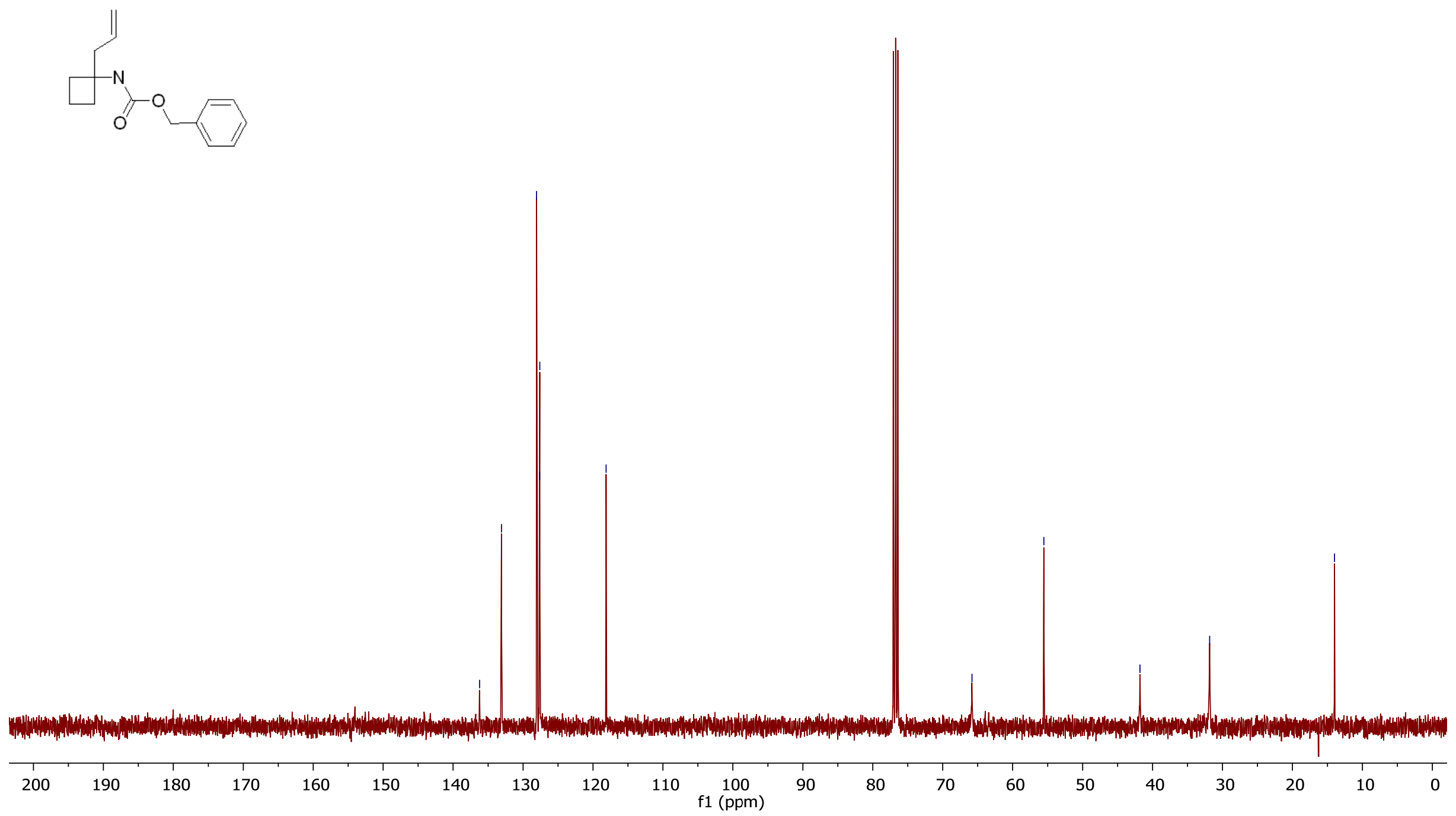
Figure S31. Mass spectrum of the compound $\mathbf{8 b}$.

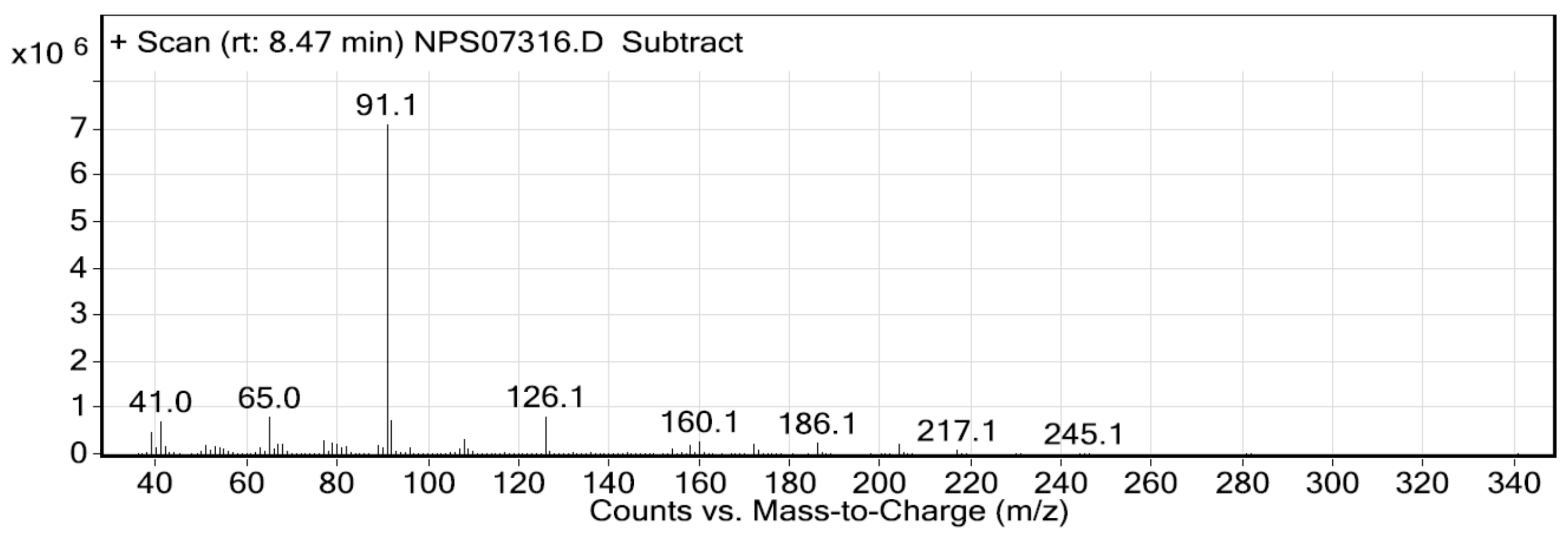


Figure S32. ${ }^{1} \mathrm{H}$ NMR spectrum of the compound $\mathbf{9 b}$.

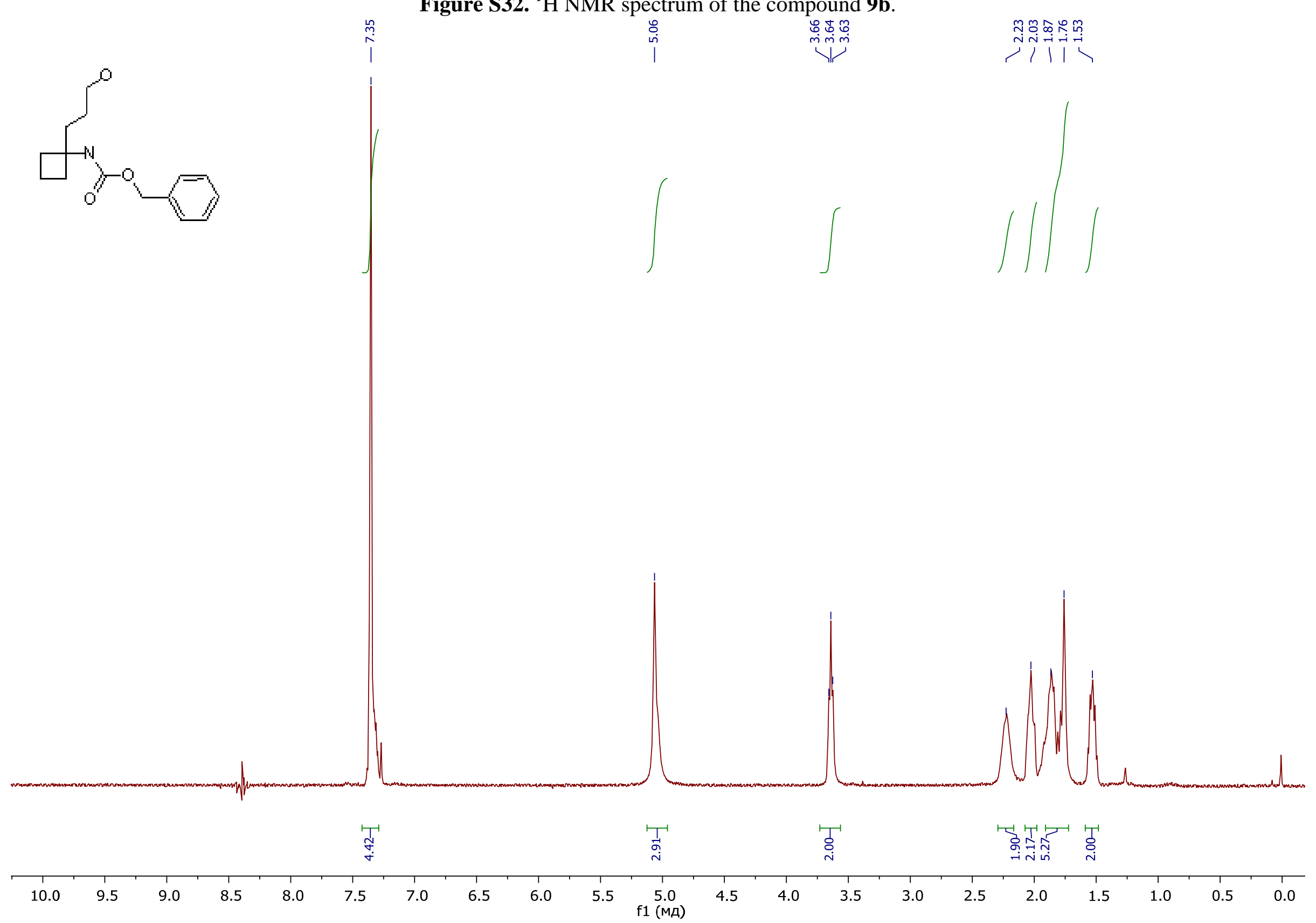


Figure S33. ${ }^{13} \mathrm{C}$ NMR spectrum of the compound $\mathbf{9 b}$.

空
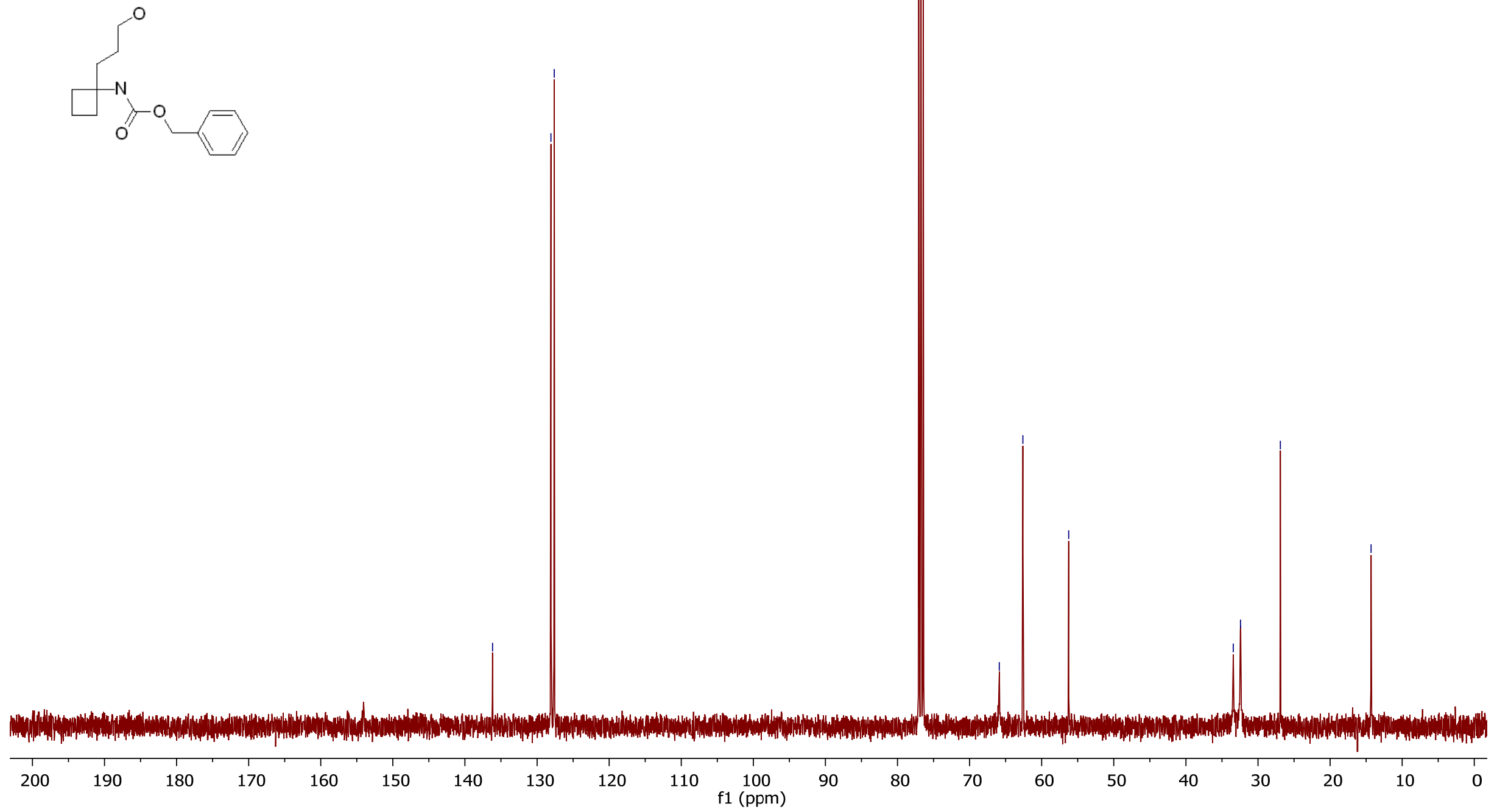
Figure S34. Mass spectrum of the compound $\mathbf{9 b}$.

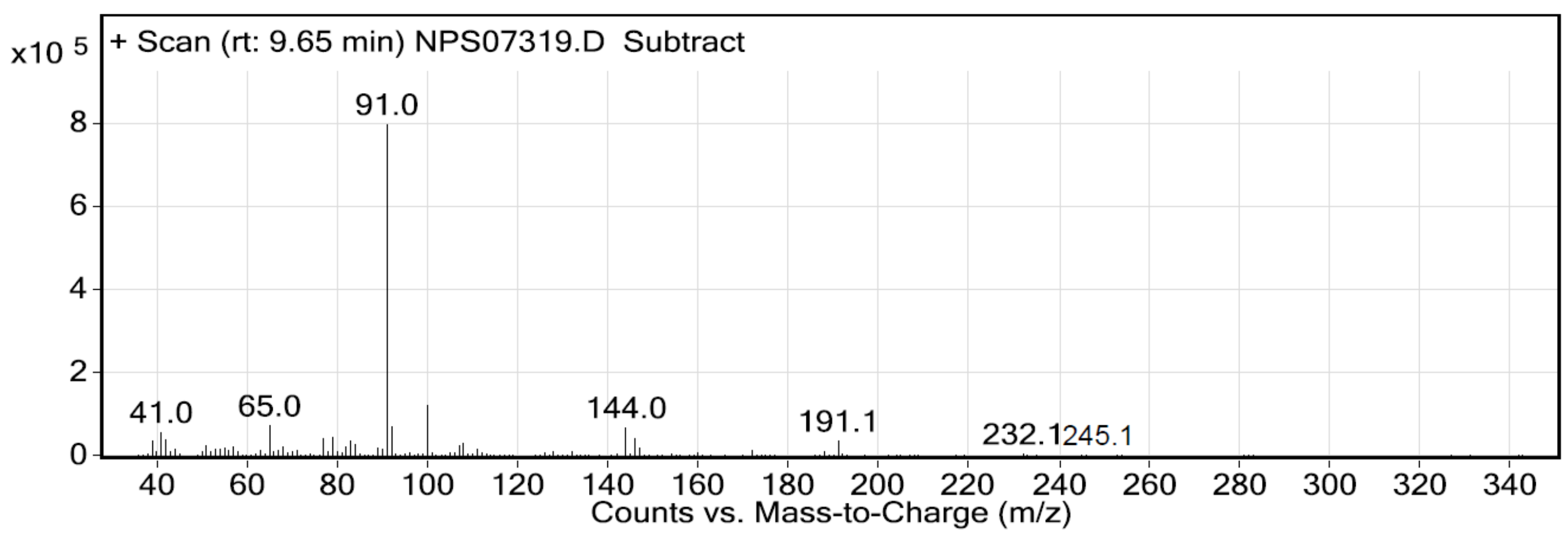




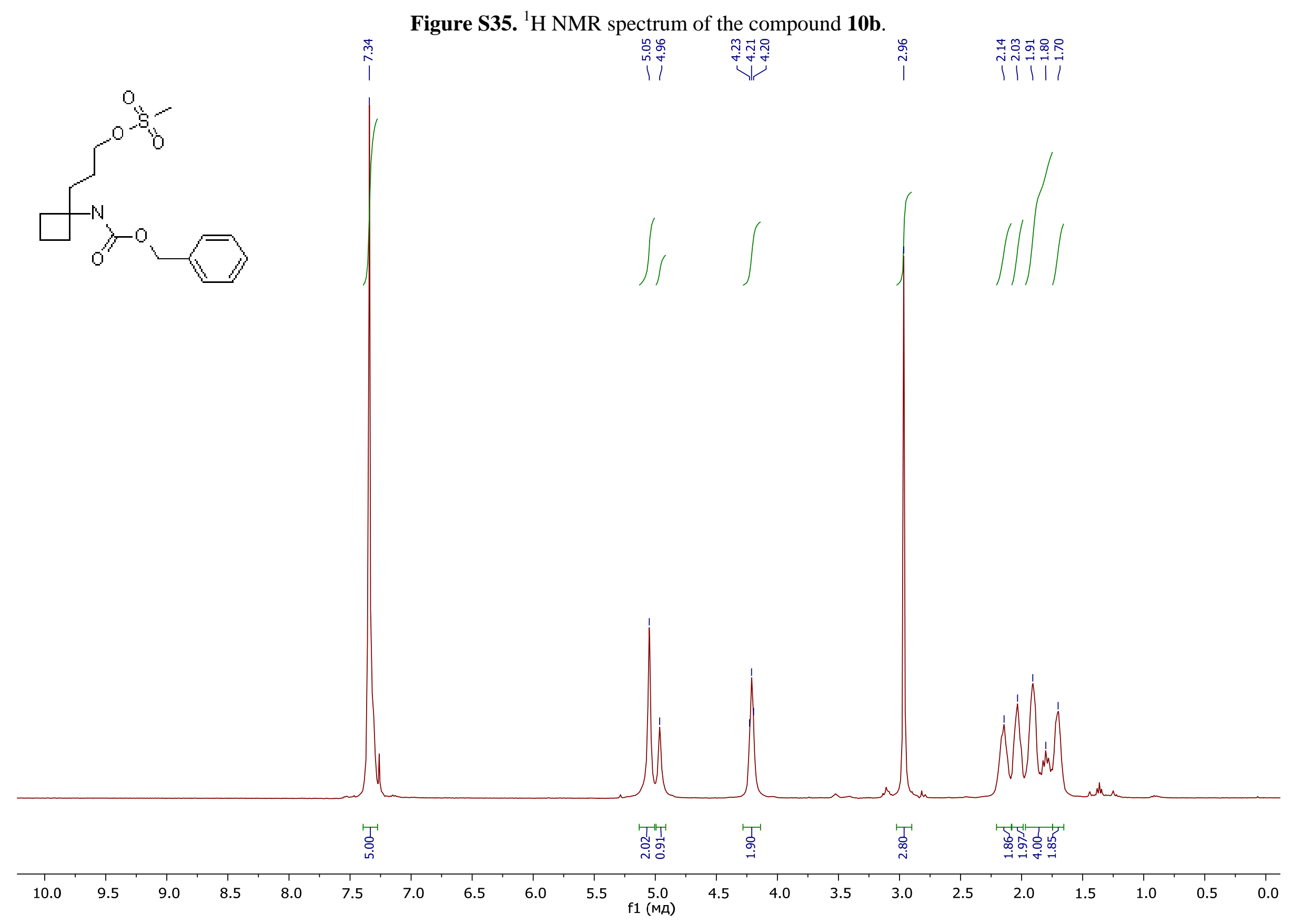


Figure S36. ${ }^{13} \mathrm{C}$ NMR spectrum of the compound $\mathbf{1 0 b}$.

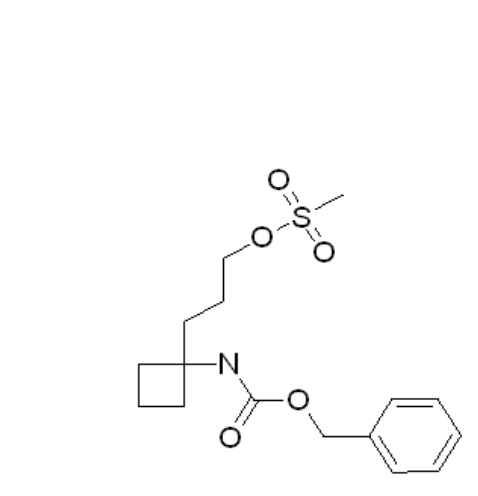

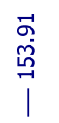

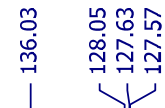

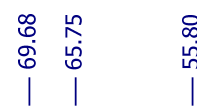

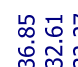

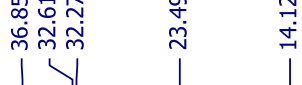

|

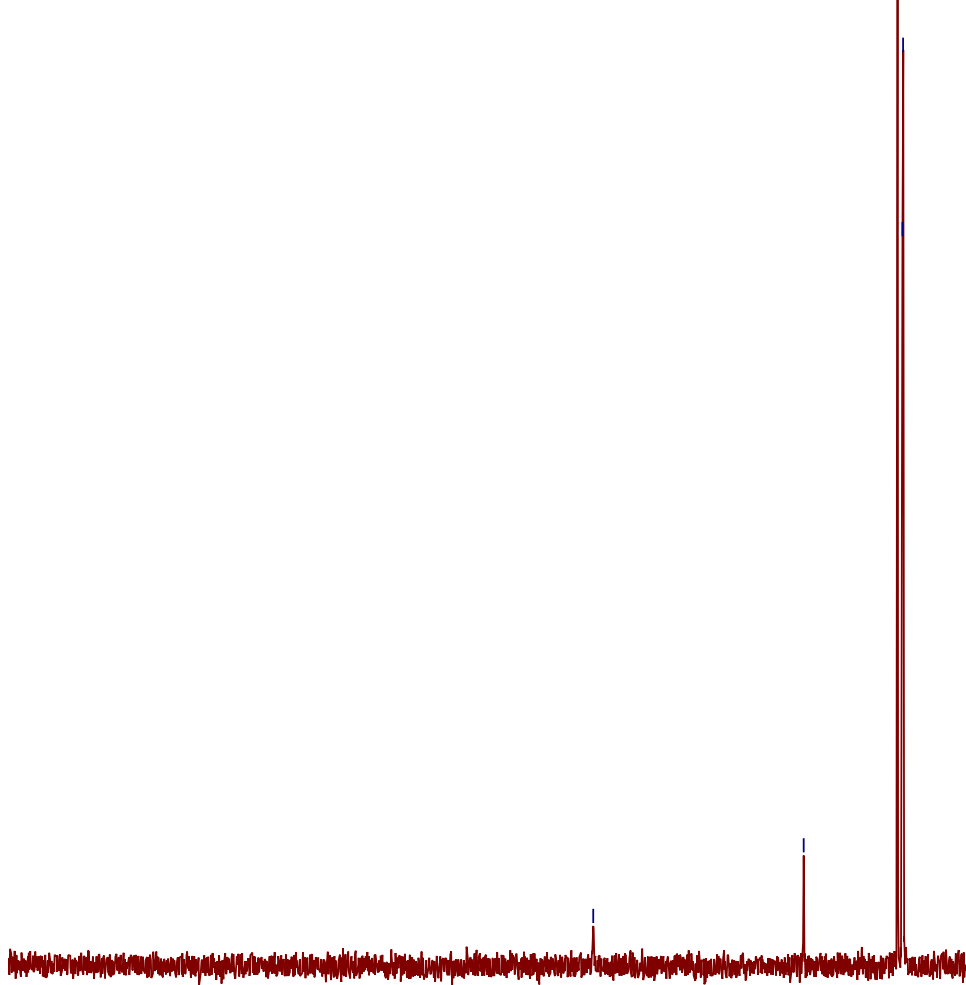


Figure S37. ${ }^{1} \mathrm{H}$ NMR spectrum of the compound $\mathbf{1 1 b}$.

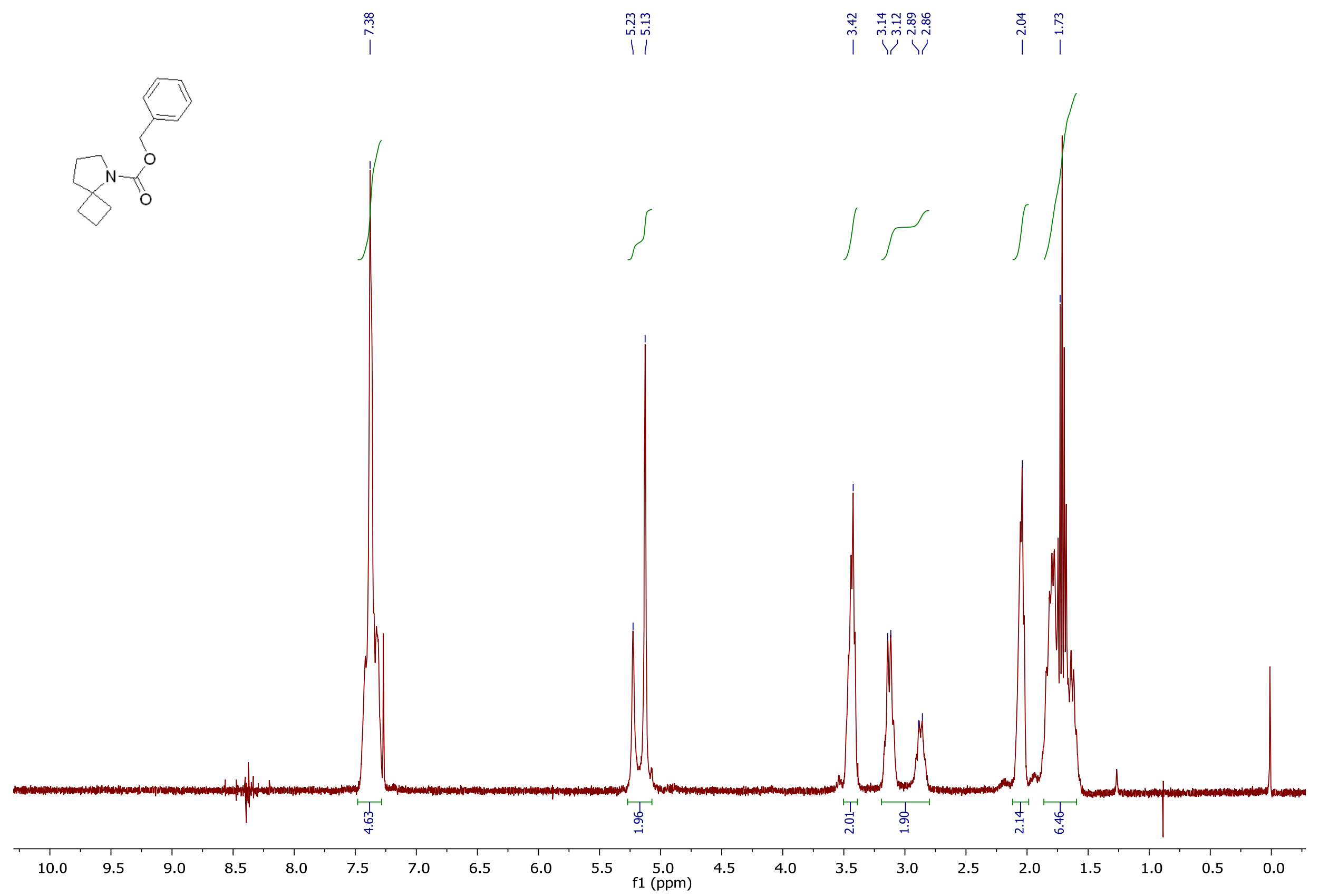


Figure S38. ${ }^{13} \mathrm{C}$ NMR spectrum of the compound $\mathbf{1 1 b}$.
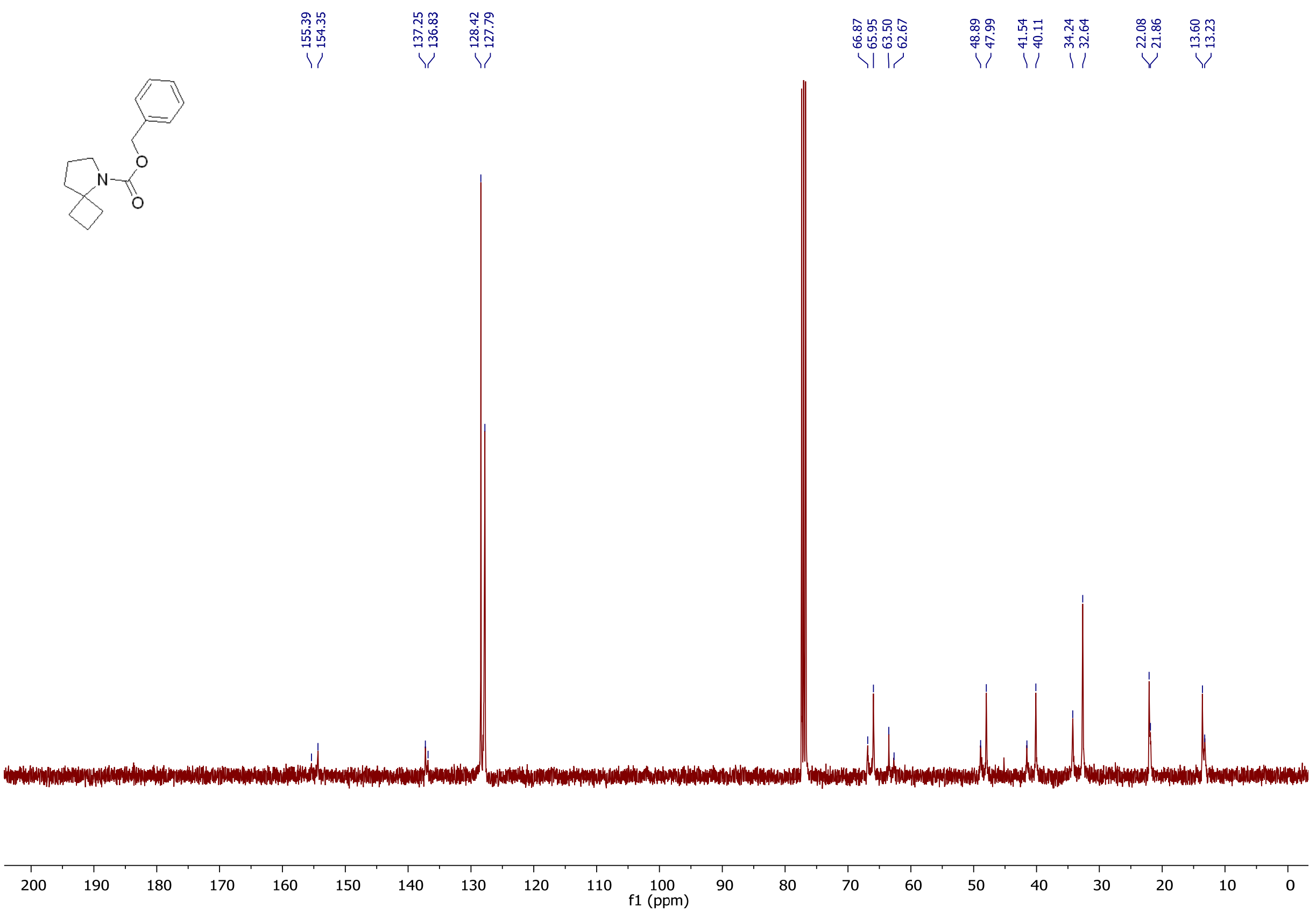
Figure S39. Mass spectrum of the compound $\mathbf{1 1 b}$.

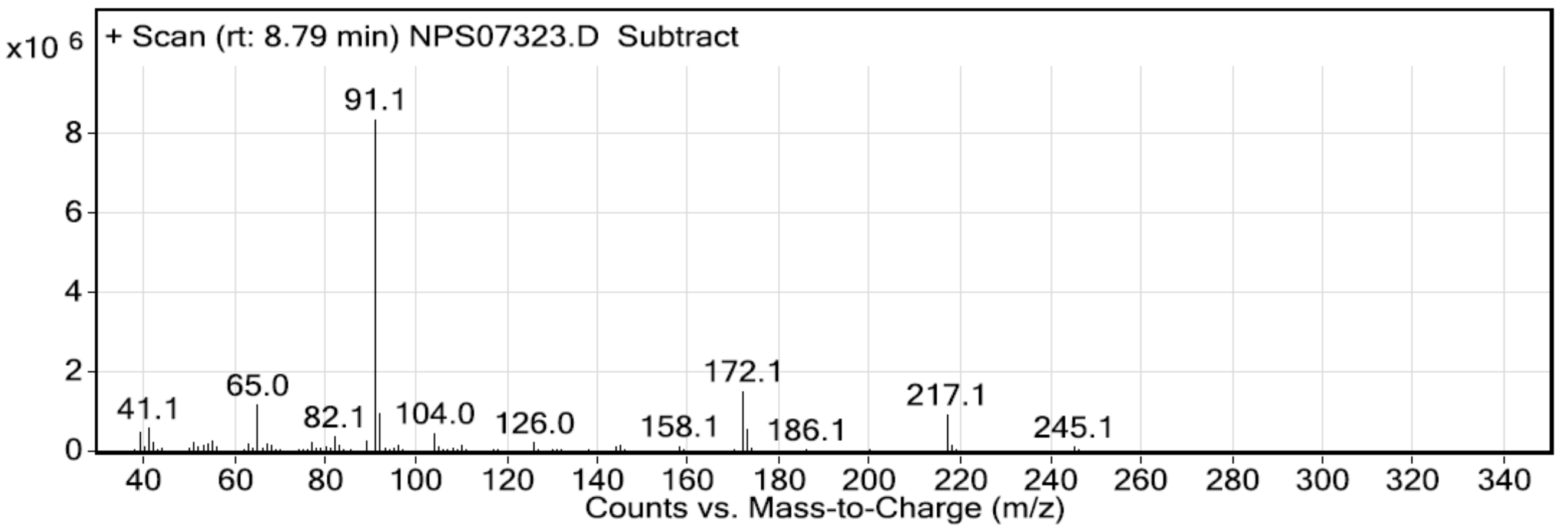


Synthesis of 1-azaspiro[4.4]nonane hydrochloride (1c*HCl). Approach I.

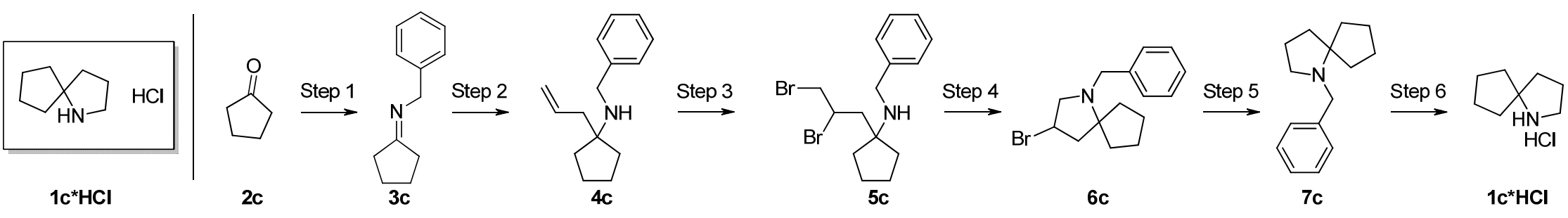

Figure S40. ${ }^{1} \mathrm{H}$ NMR spectrum of the compound 4c.

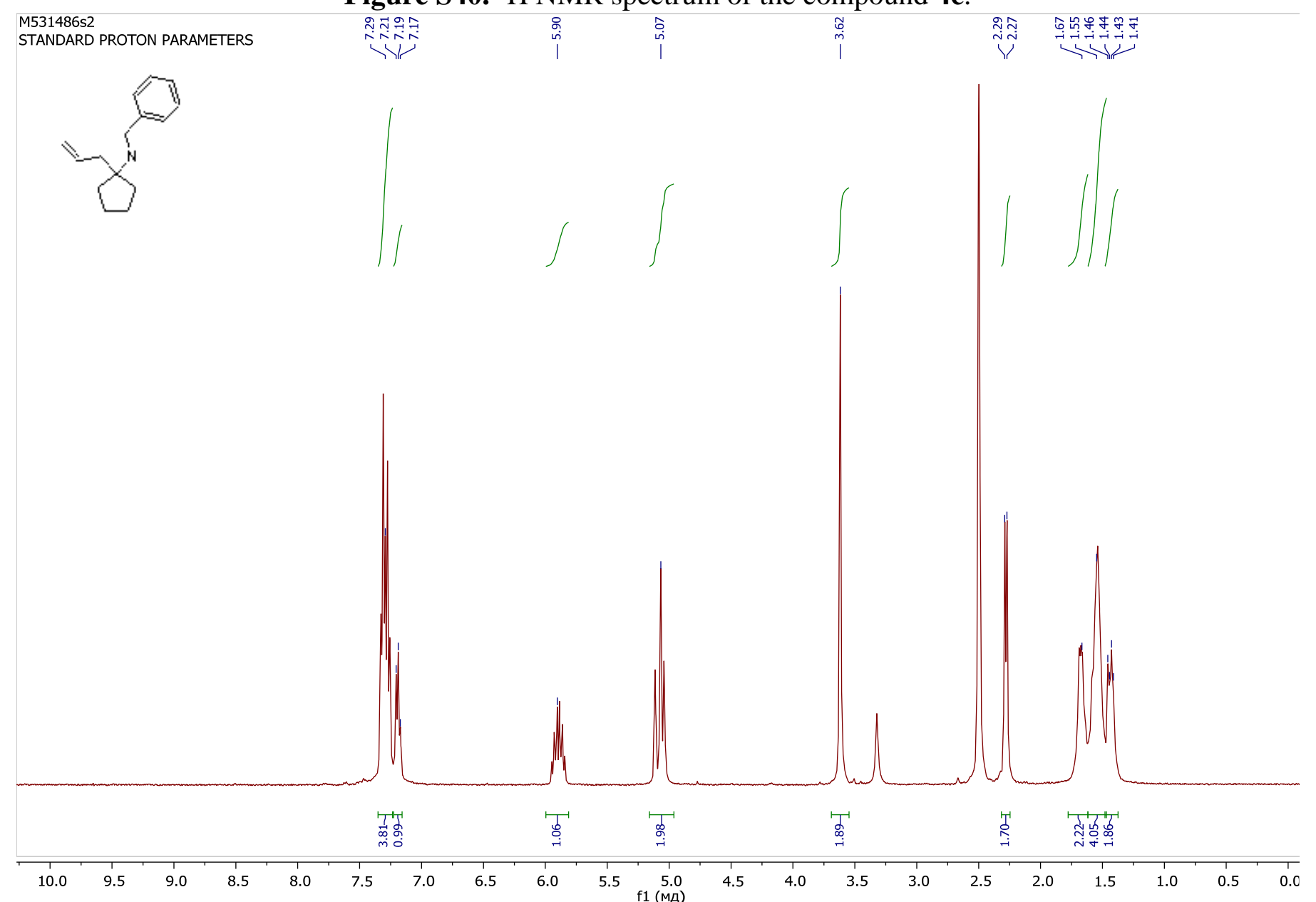


Figure S41. ${ }^{13} \mathrm{C}$ NMR spectrum of the compound 4c.
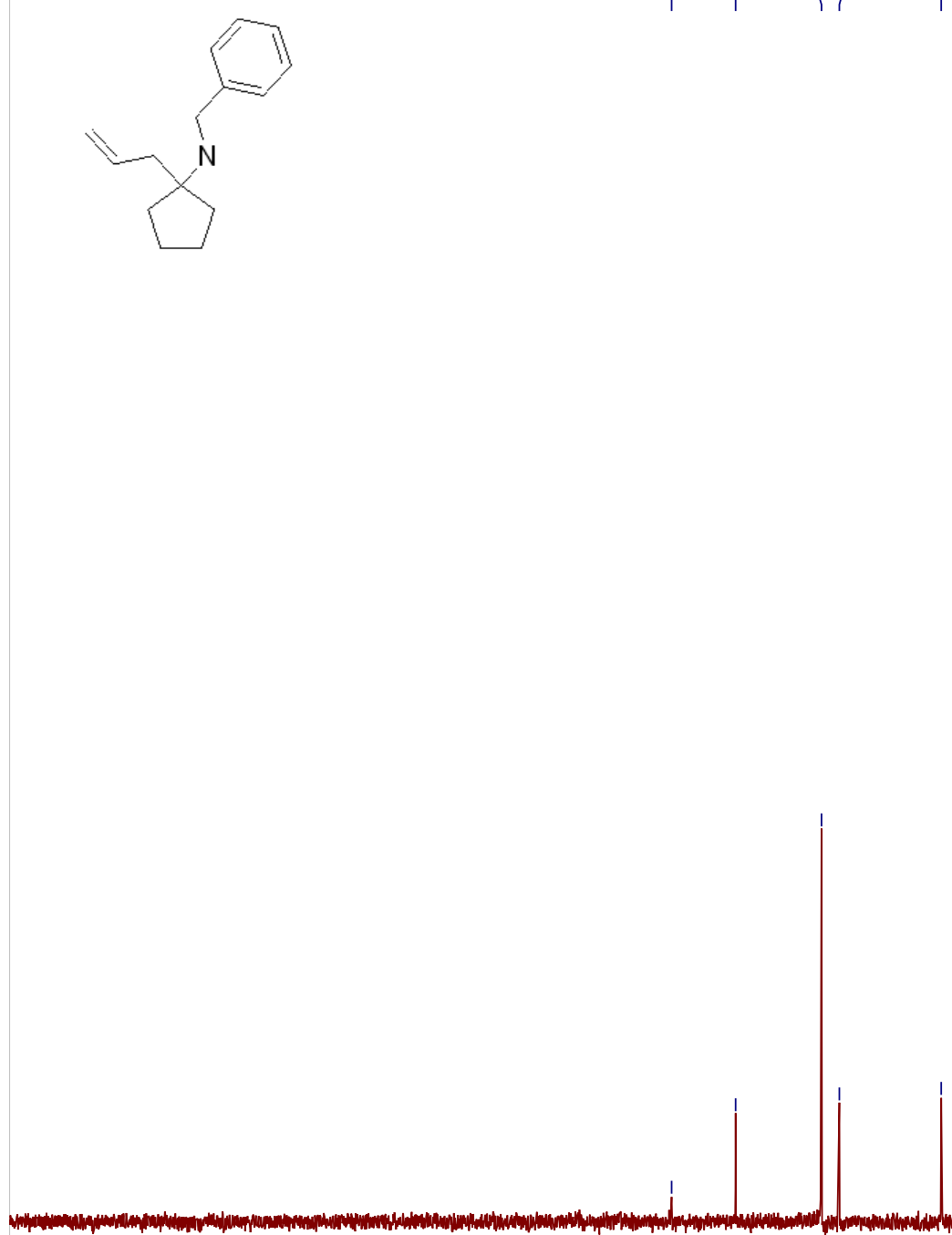
Figure S42. ${ }^{1} \mathrm{H}$ NMR spectrum of the compound $\mathbf{6 c}$.

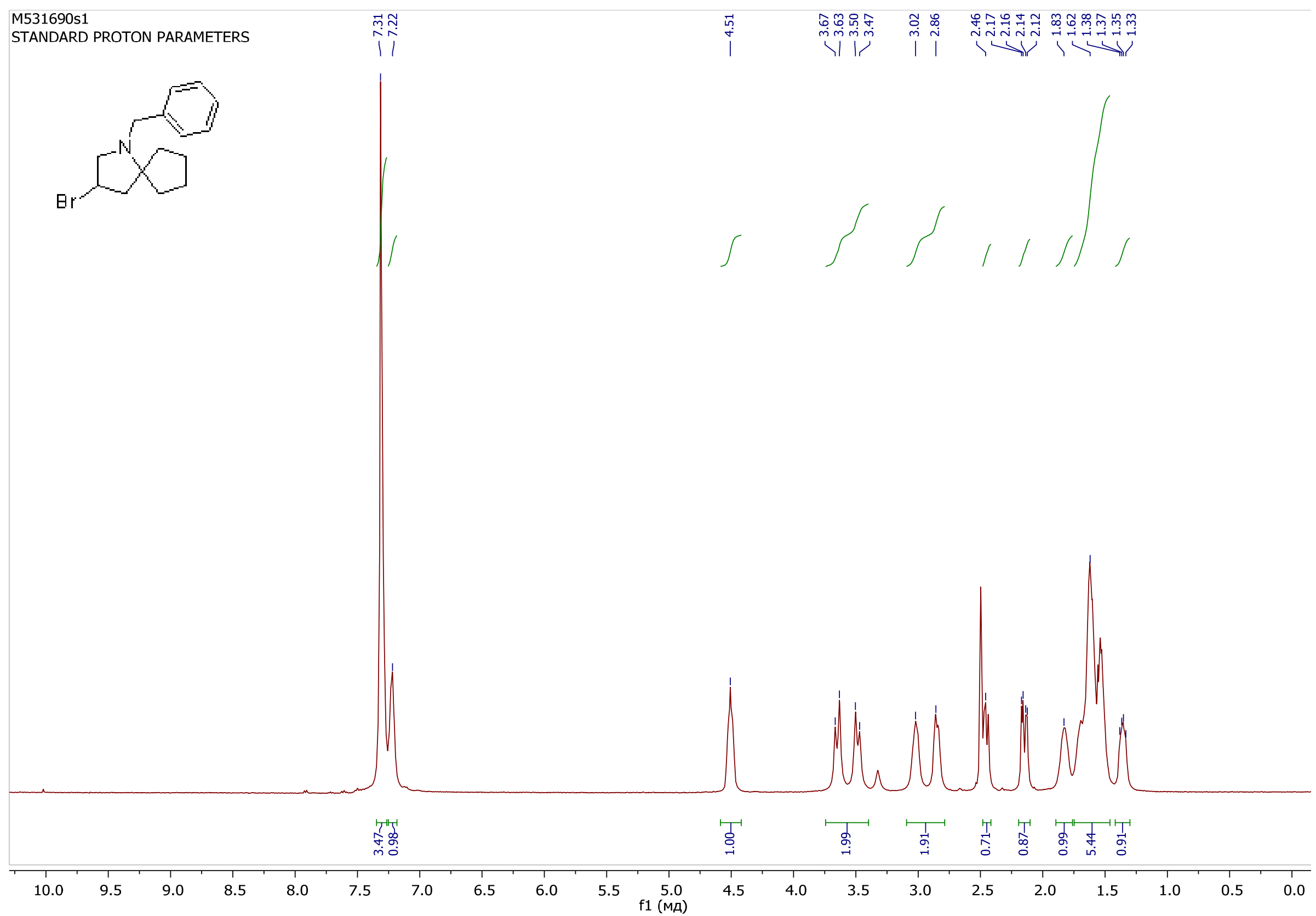


M531690s1_C13.1.fid

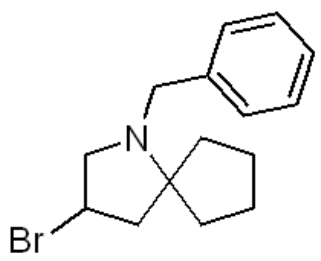

Figure S43. ${ }^{13} \mathrm{C}$ NMR spectrum of the compound $\mathbf{6 c}$.

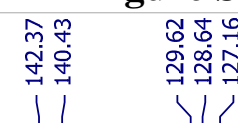
$\stackrel{\substack{+i}}{i}$

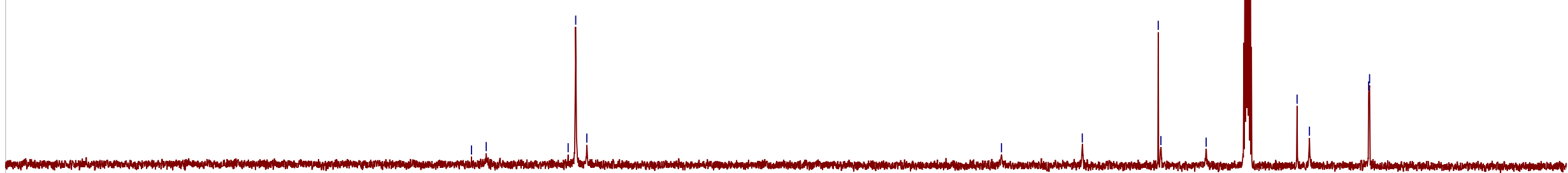


Figure S44. ${ }^{1} \mathrm{H}$ NMR spectrum of the compound 7c.

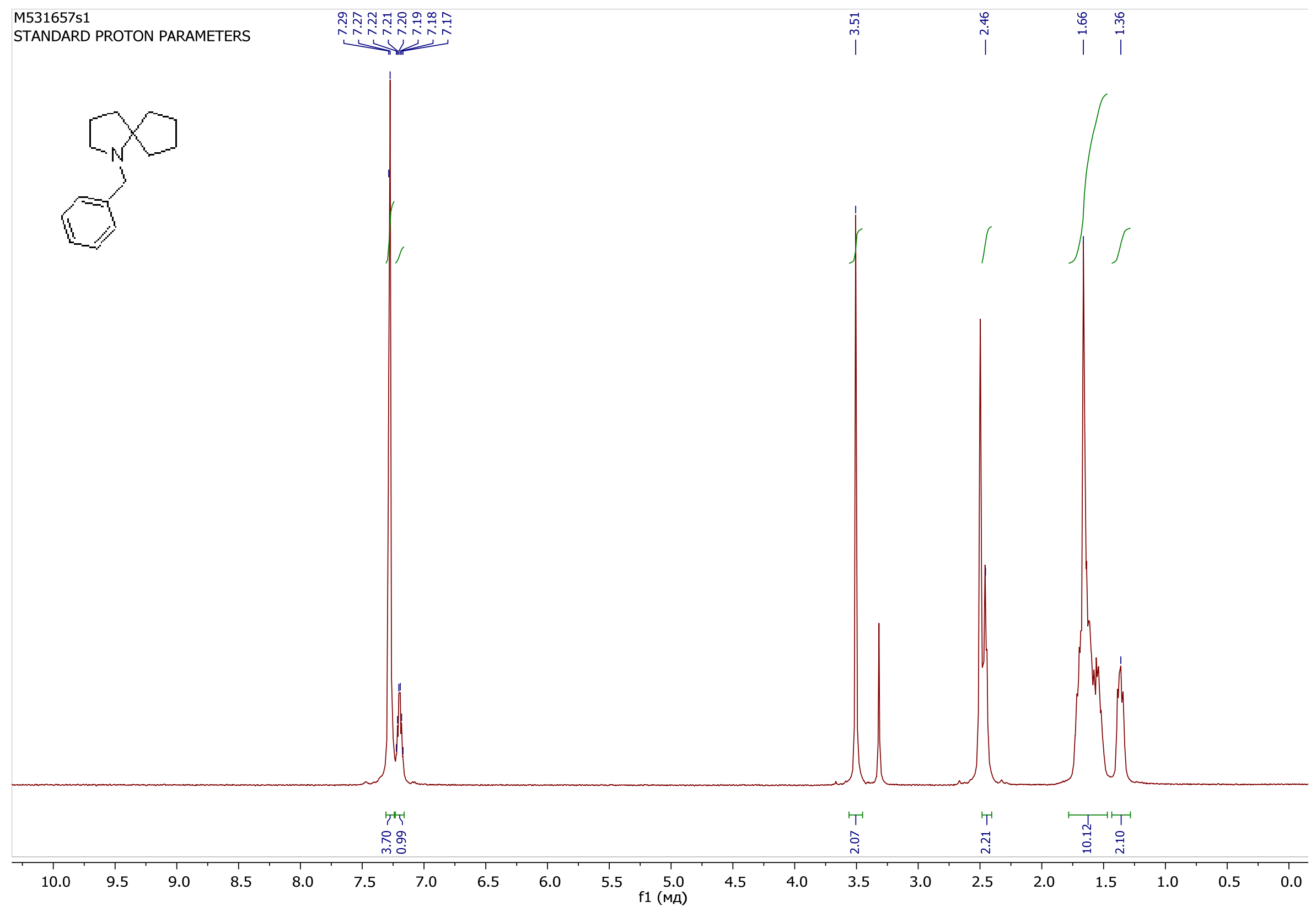


Figure S45. ${ }^{13} \mathrm{C}$ NMR spectrum of the compound $7 \mathrm{c}$.

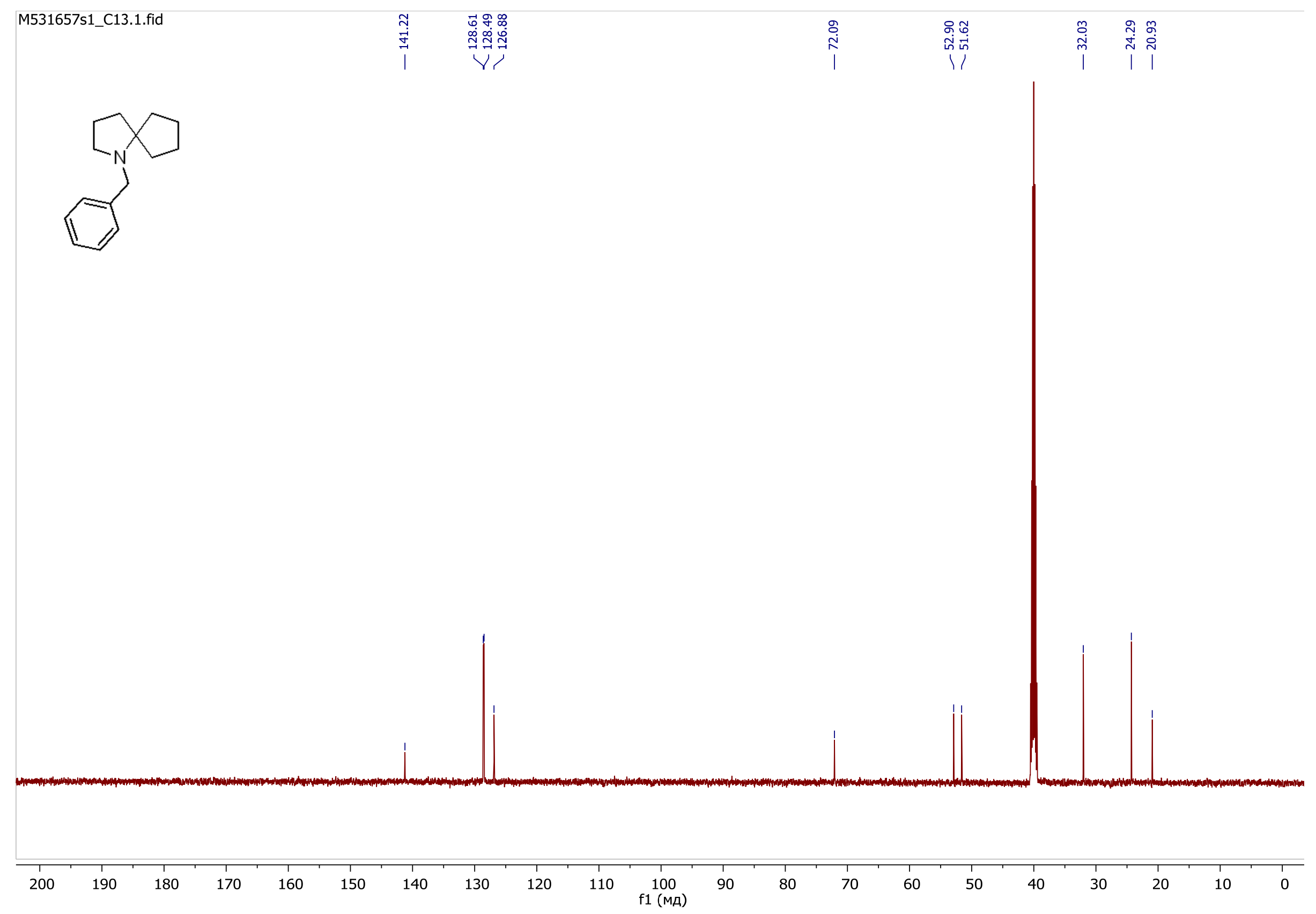


Figure S46. ${ }^{1} \mathrm{H}$ NMR spectrum of the compound $1 \mathbf{c}^{*} \mathbf{H C l}$.

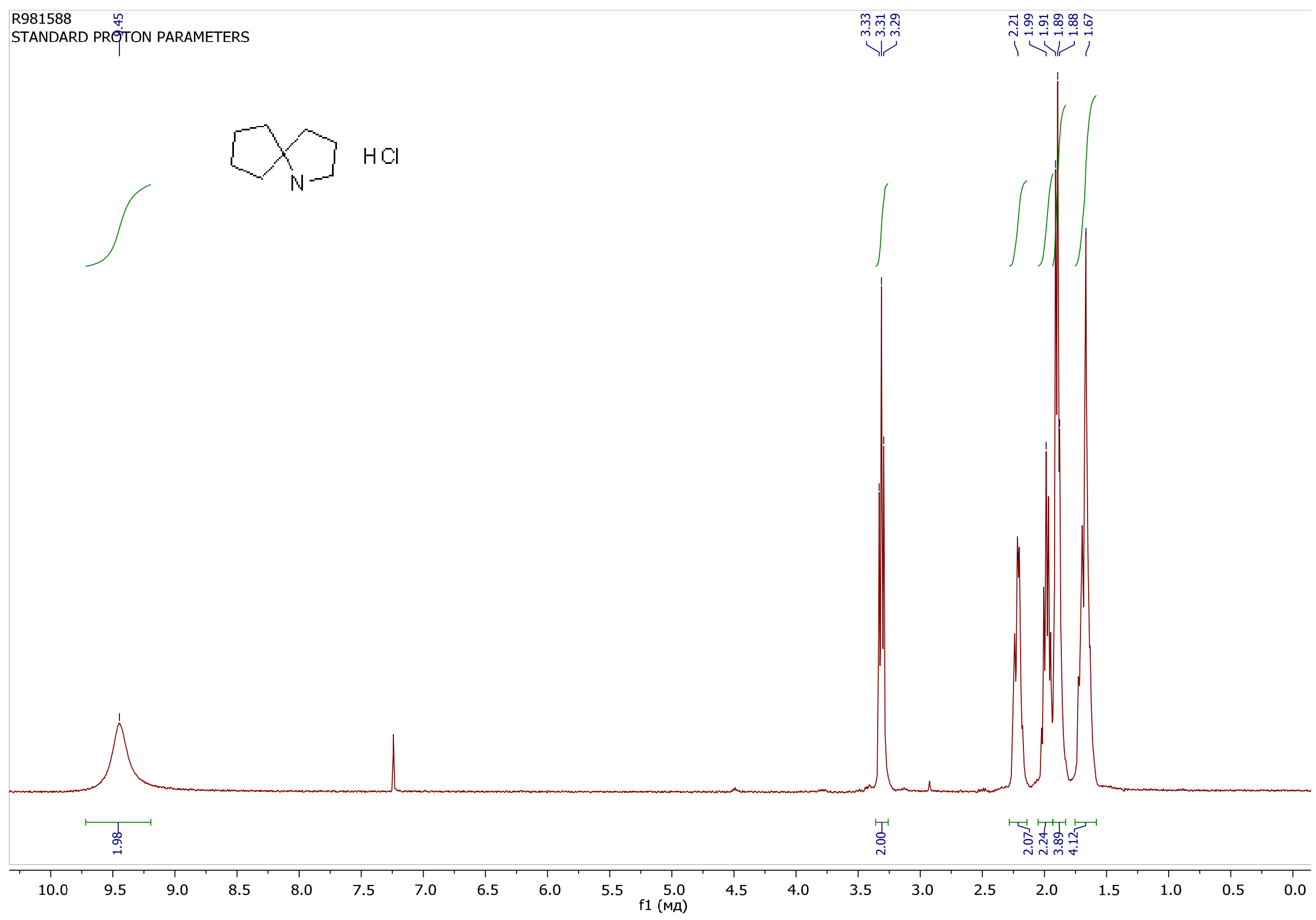


Figure S47. ${ }^{13} \mathrm{C}$ NMR spectrum of the compound $\mathbf{1 c} * \mathbf{H C l}$.

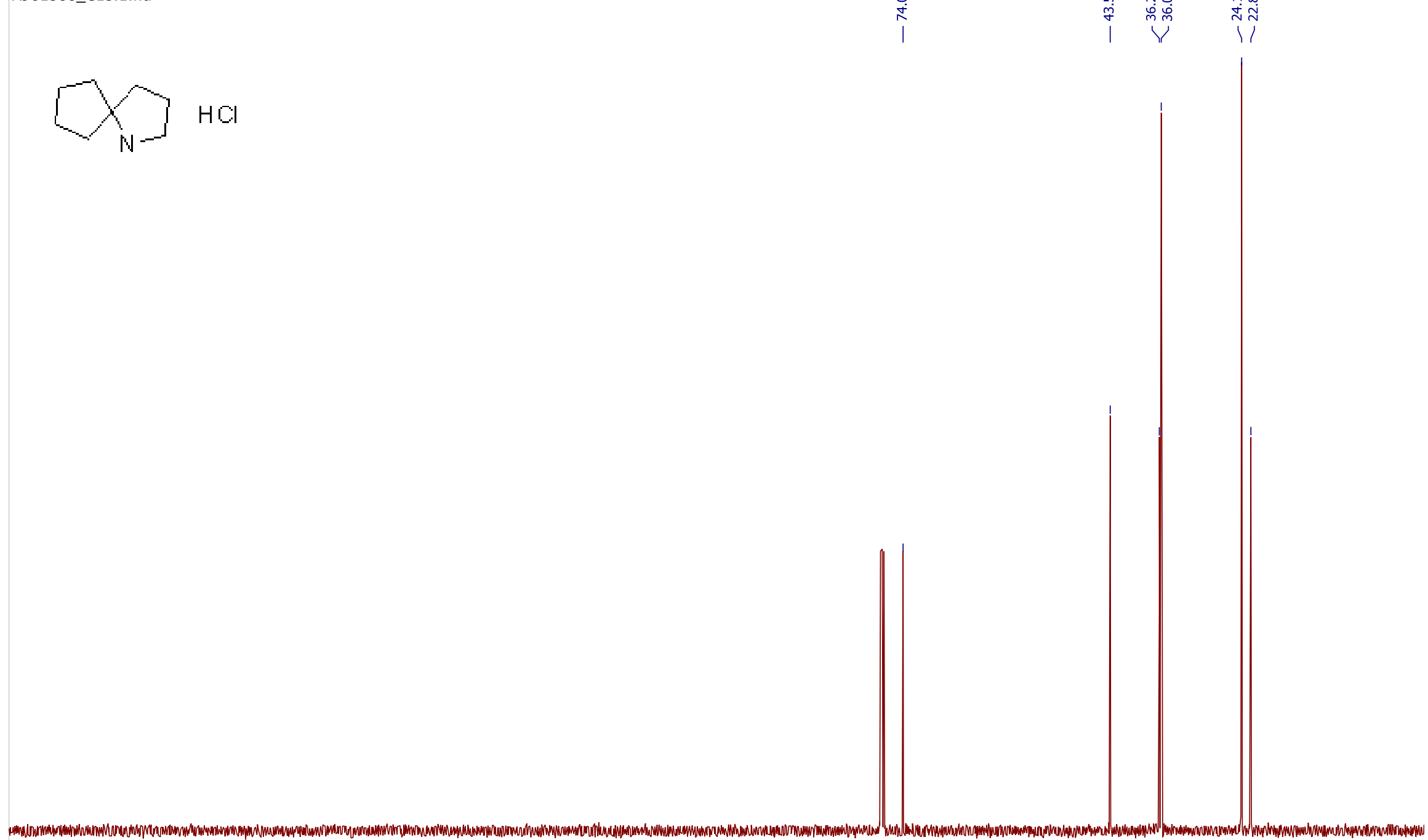

\begin{tabular}{|c|c|c|c|c|c|c|c|c|c|c|c|c|c|c|c|c|c|c|c|c|}
\hline 200 & 190 & 180 & 170 & 160 & 150 & 140 & 130 & 120 & 110 & 100 & 90 & 80 & 70 & 60 & 50 & 40 & 30 & 20 & 10 & 0 \\
\hline
\end{tabular}


Synthesis of 1-azaspiro[4.5]decane hydrochloride (1d*HCl). Approach I.

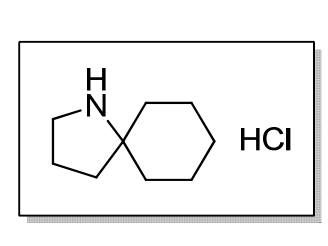

$1 d^{*} \mathrm{HCl}$

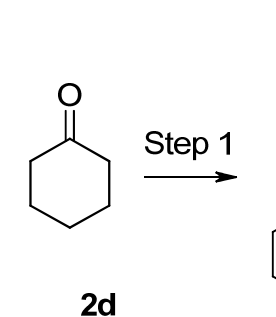

2d

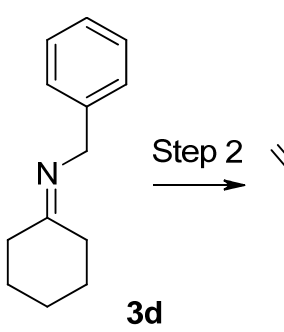

3d

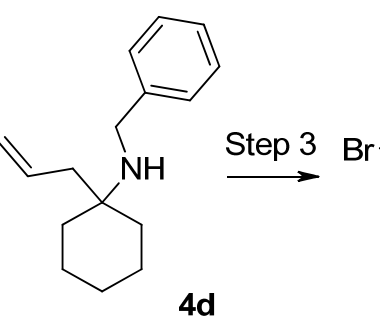

4d

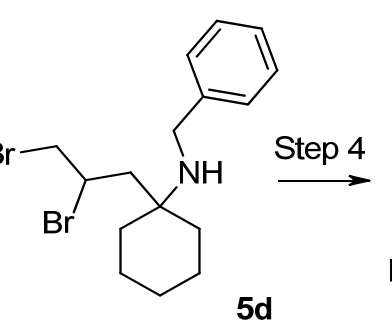

$5 d$

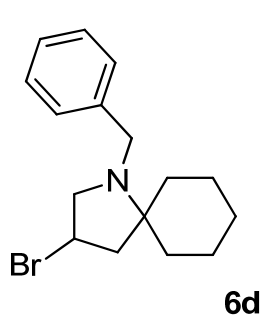

$6 d$
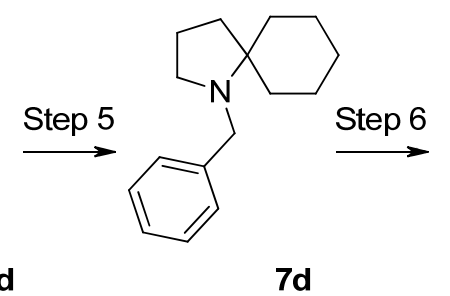

Step 6

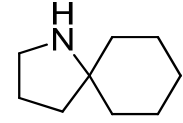

7d

$1 d^{*} \mathrm{HCl}$
$\mathrm{HCl}$

Scheme S5.

Figure S48. ${ }^{1} \mathrm{H}$ NMR spectrum of the compound $\mathbf{4 d}$.

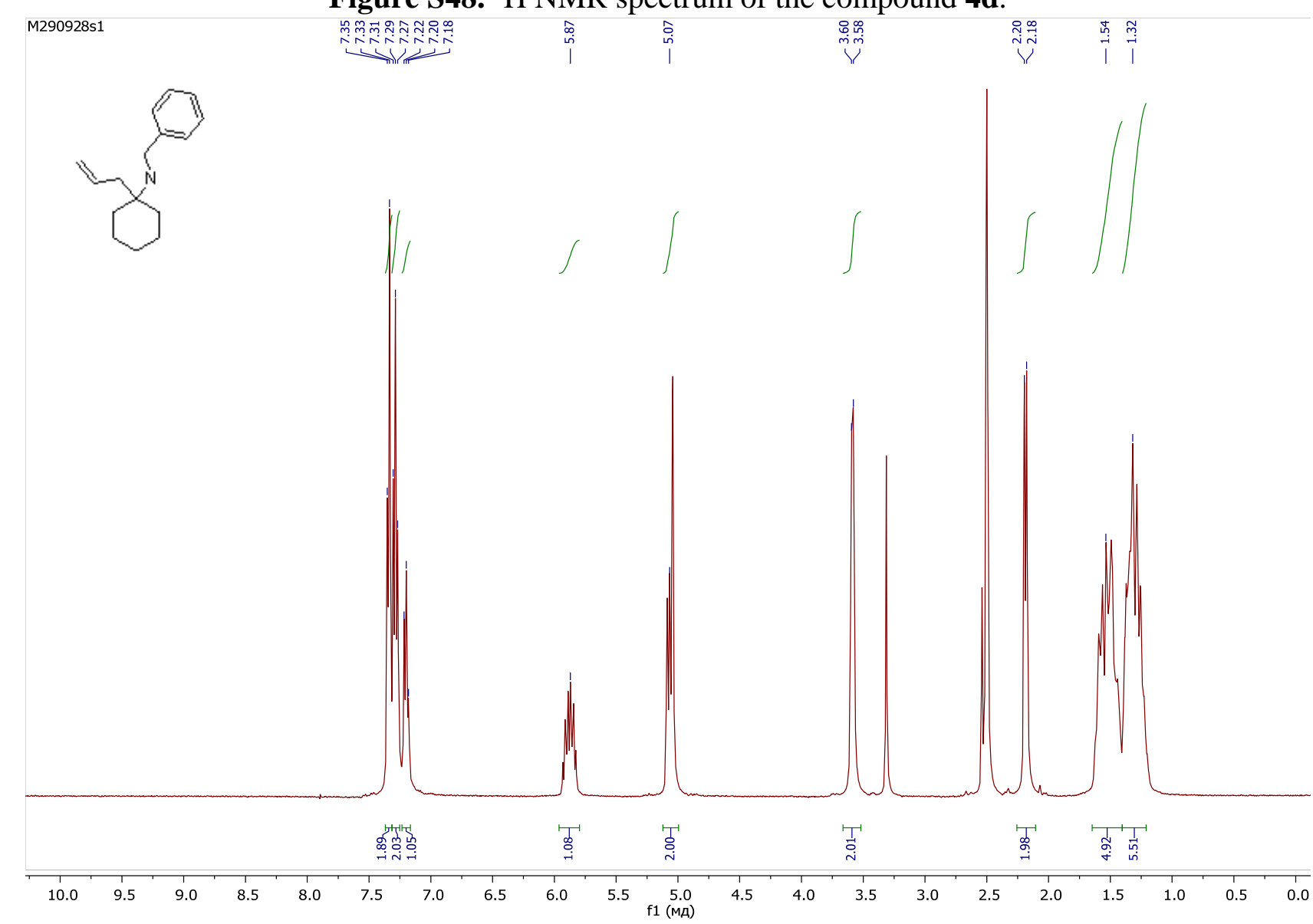


Figure S49. ${ }^{13} \mathrm{C}$ NMR spectrum of the compound $\mathbf{4 d}$.

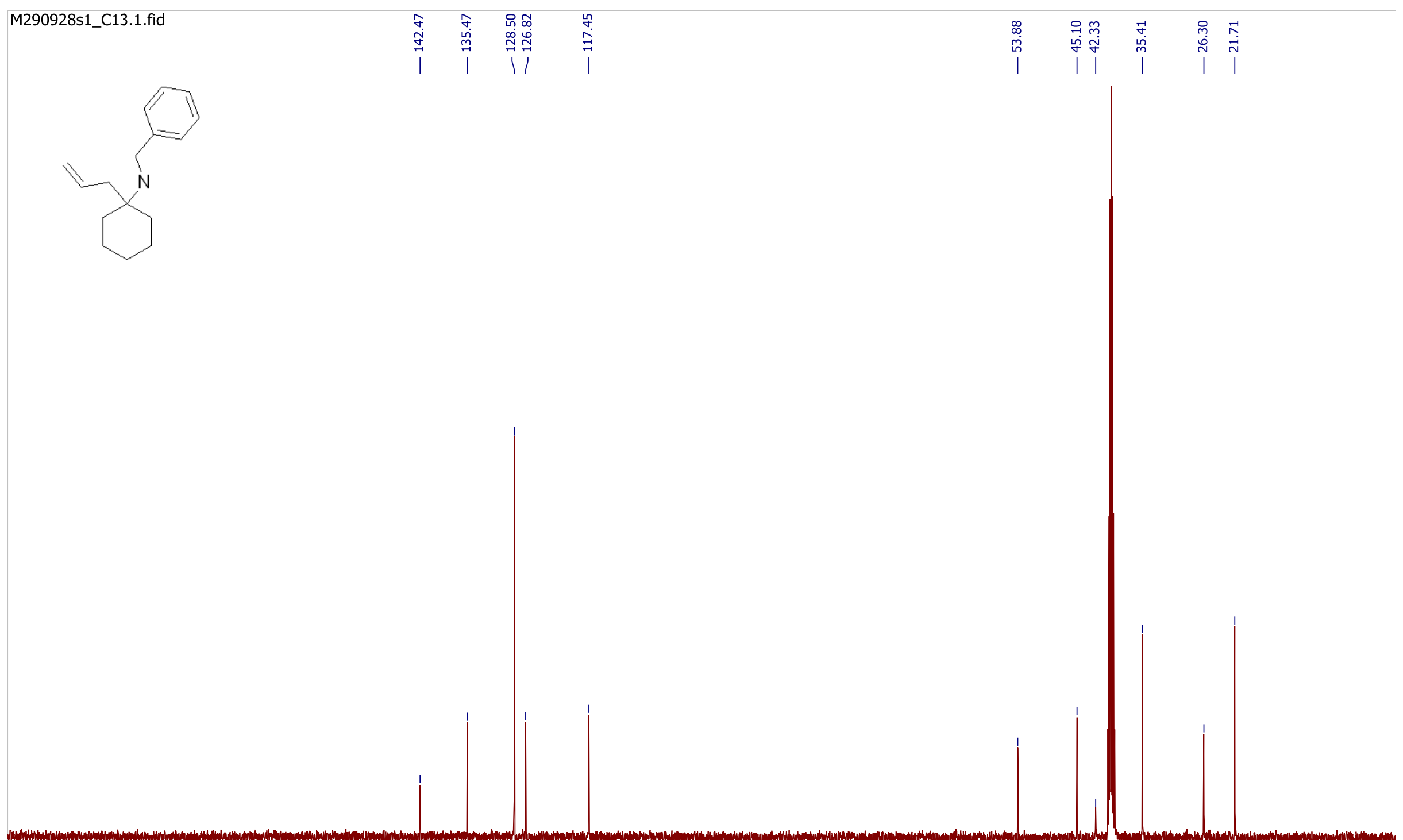

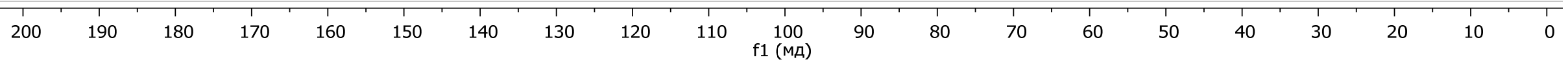


Figure S50. ${ }^{1} \mathrm{H}$ NMR spectrum of the compound $\mathbf{6 d}$.

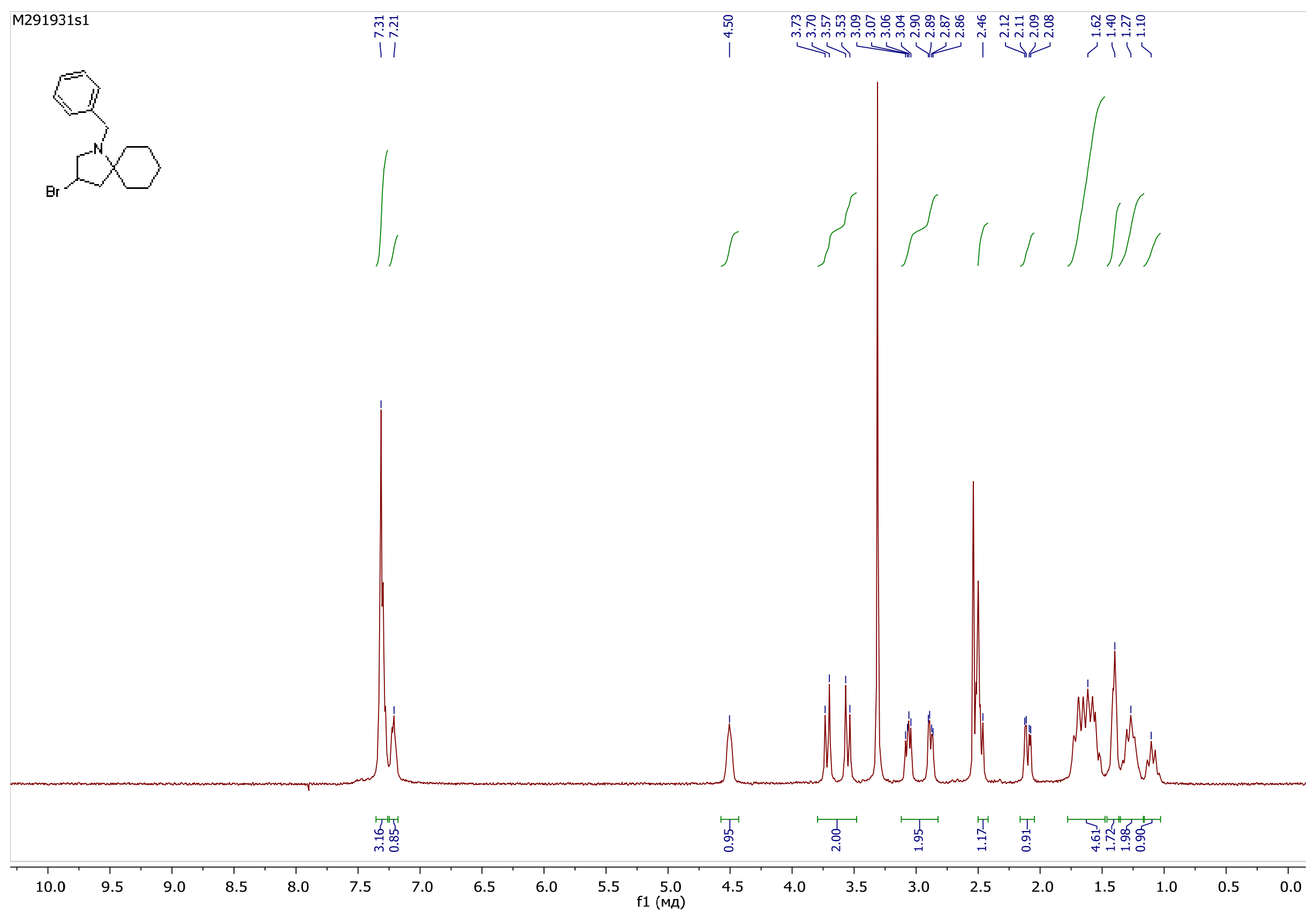


Figure S51. ${ }^{13} \mathrm{C}$ NMR spectrum of the compound $\mathbf{6 d}$.
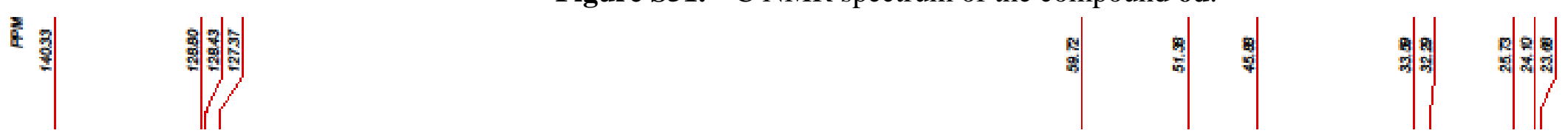

m291931C13.fid

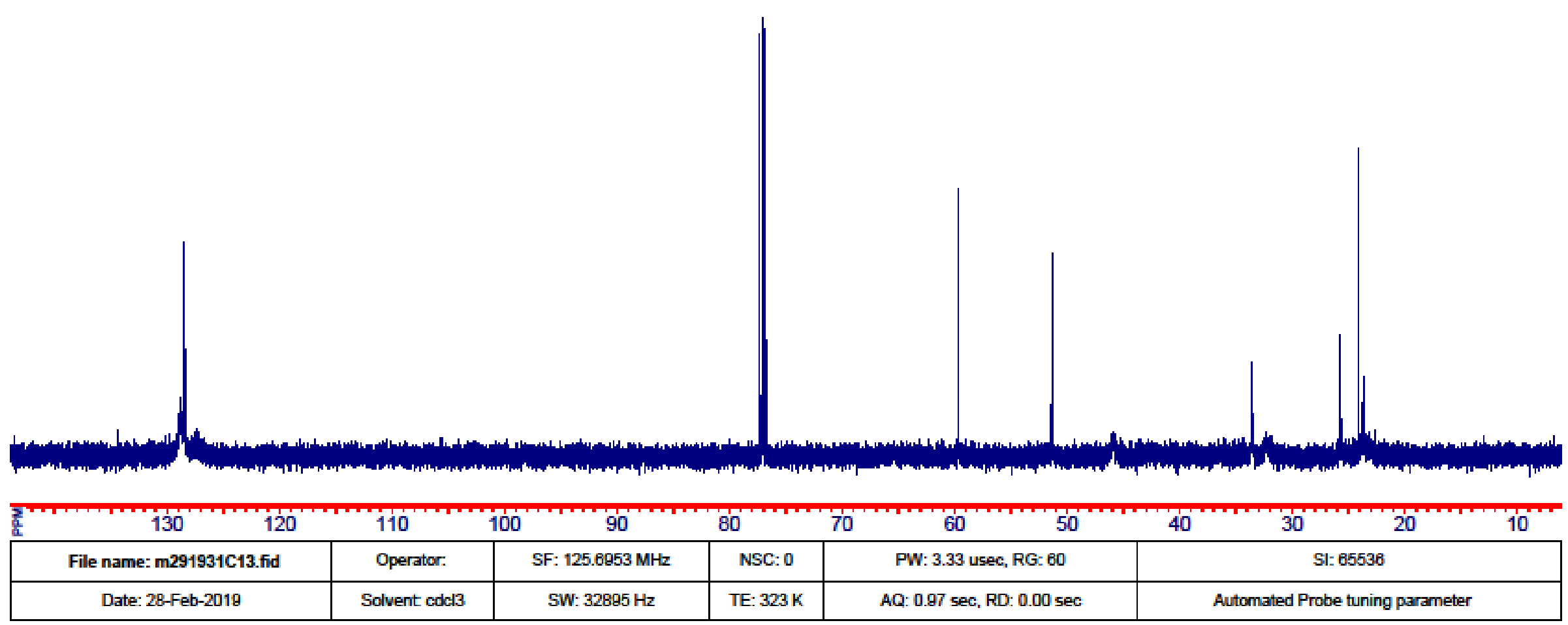


Figure S52. ${ }^{1} \mathrm{H}$ NMR spectrum of the compound $\mathbf{7 d}$.

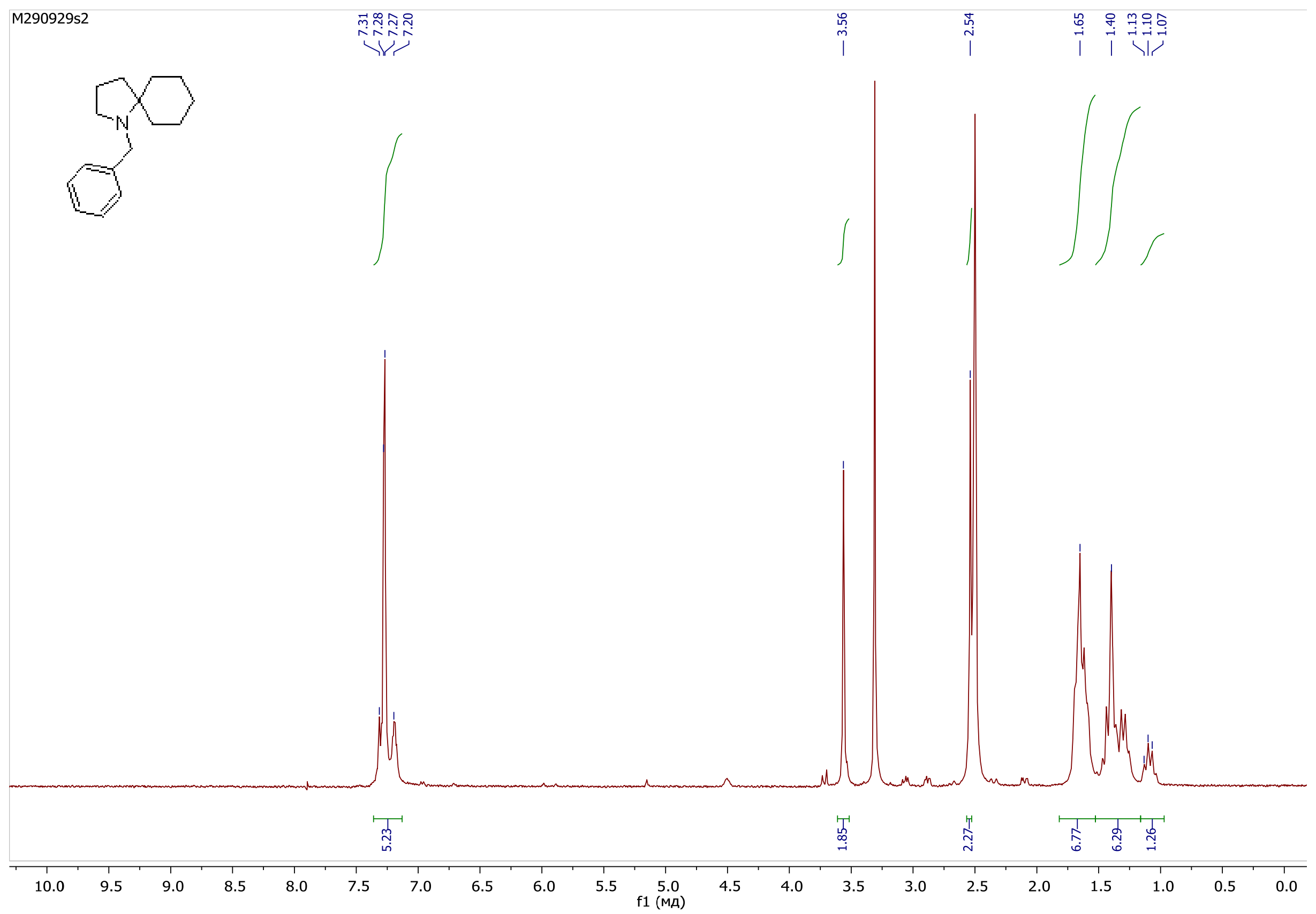


Figure S53. ${ }^{13} \mathrm{C}$ NMR spectrum of the compound 7d.

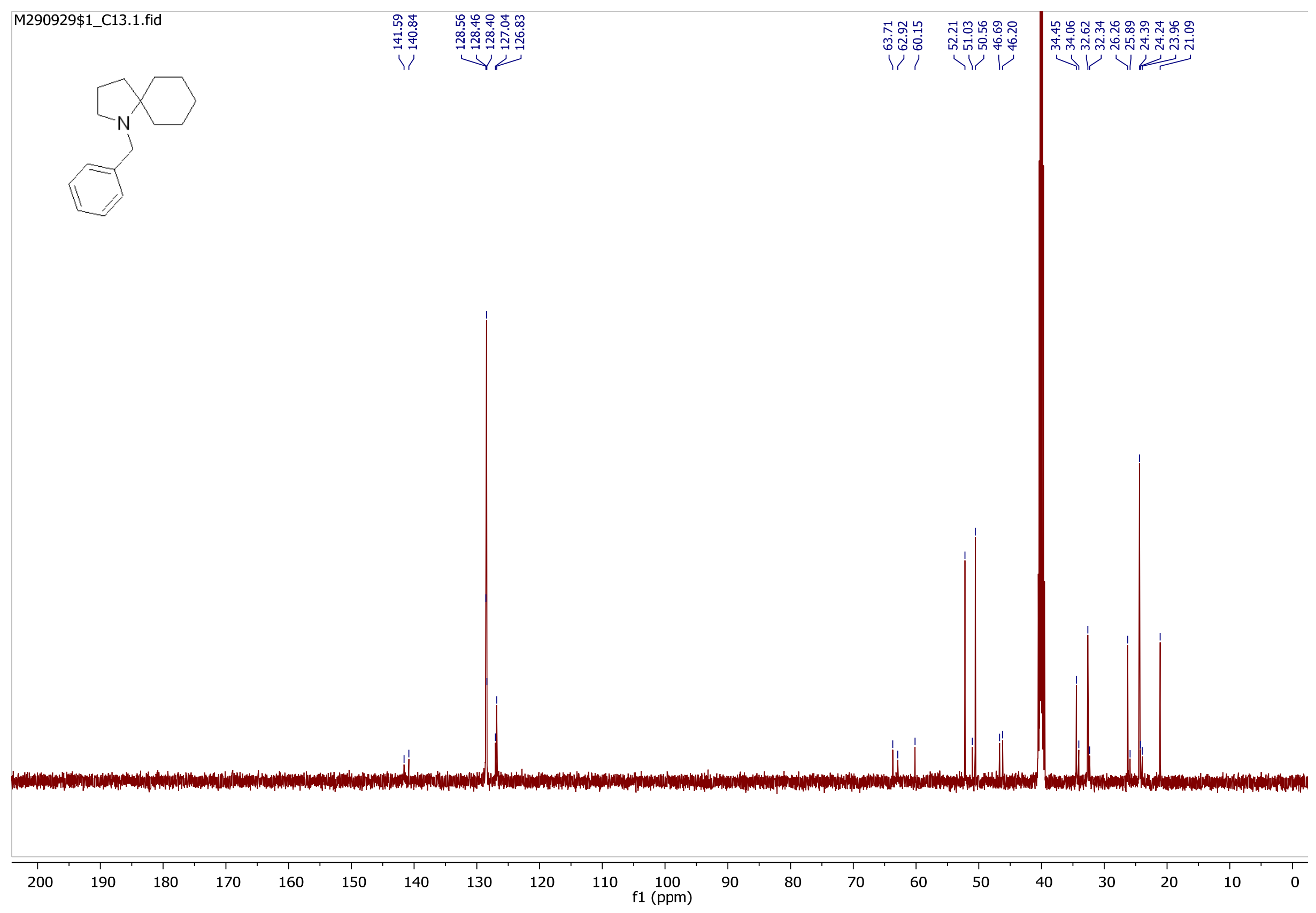


Figure S54. ${ }^{1} \mathrm{H}$ NMR spectrum of the compound $1 \mathbf{d}^{*} \mathbf{H C l}$.

R18546

STANDARD PROOTON PARAMETERS

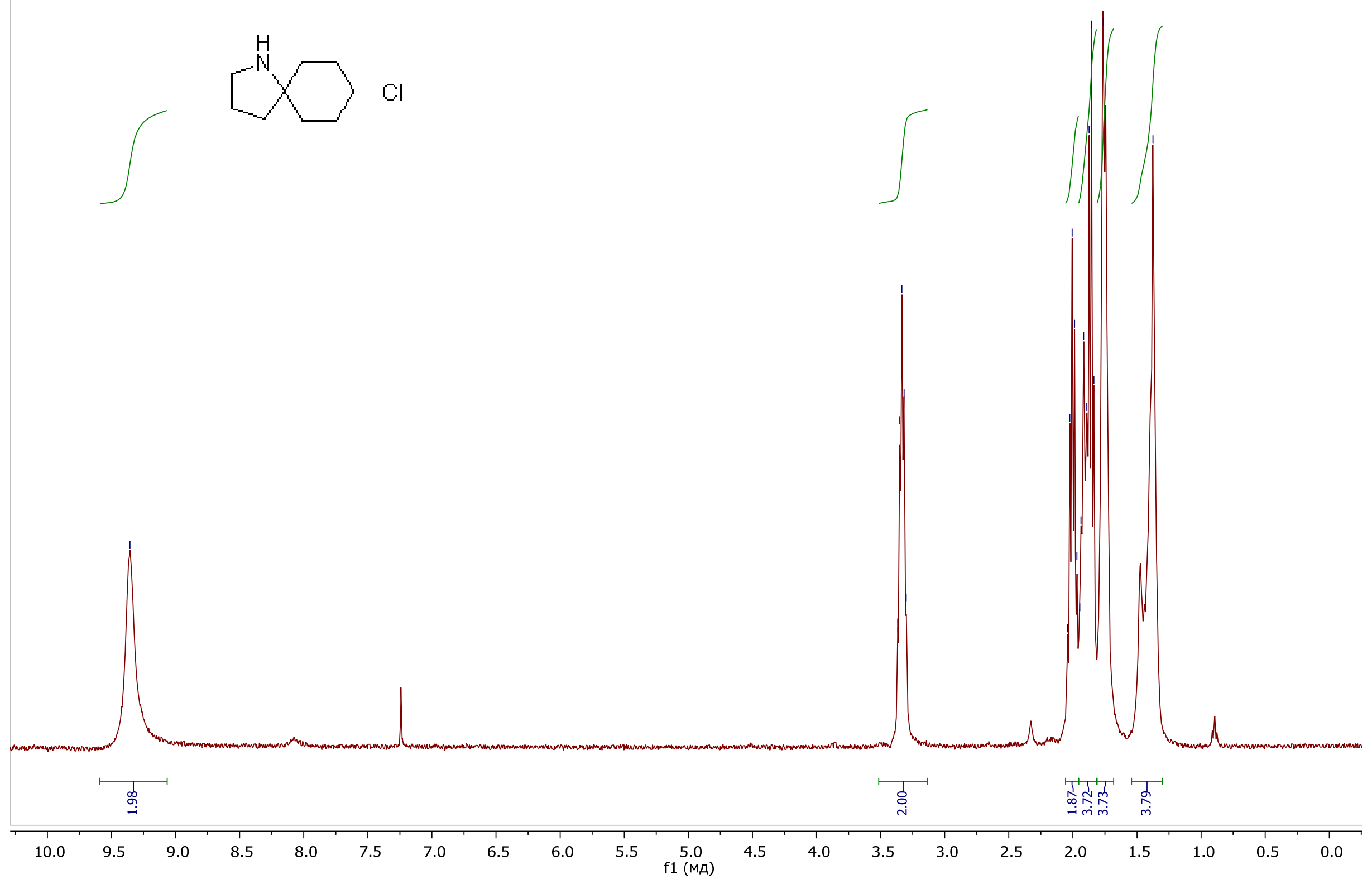


Figure S55. ${ }^{13} \mathrm{C}$ NMR spectrum of the compound $\mathbf{1 d} * \mathbf{H C l}$.

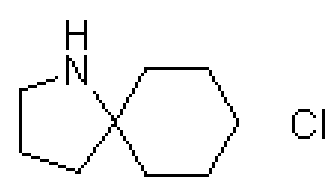

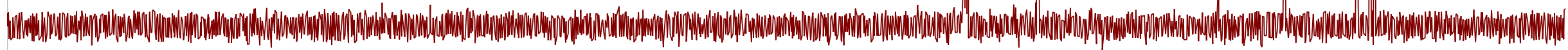


Synthesis of 1-azaspiro[4.5]decane hydrochloride (1d*HCl). Approach II.

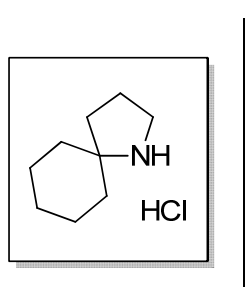

$1 d^{*} \mathrm{HCl}$

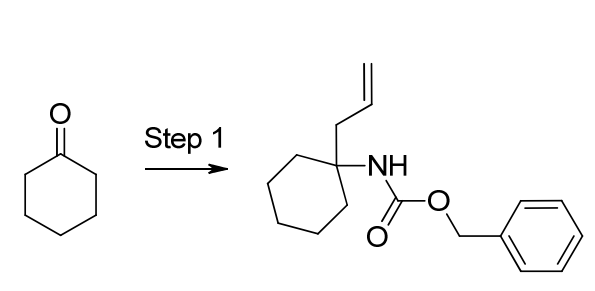

8d

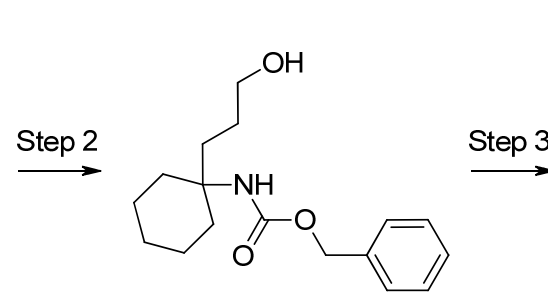

9d

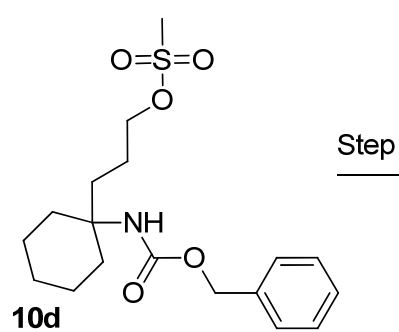

10d

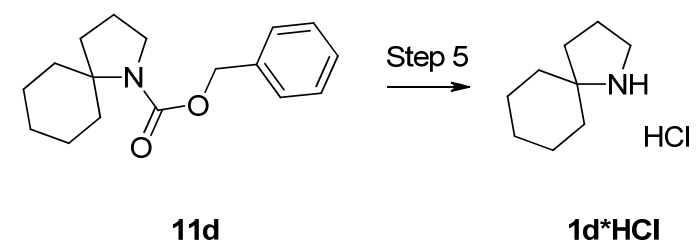

$1 d^{*} \mathrm{HCl}$

Scheme S6.

Figure S56. ${ }^{1} \mathrm{H}$ NMR spectrum of the compound $8 d$.

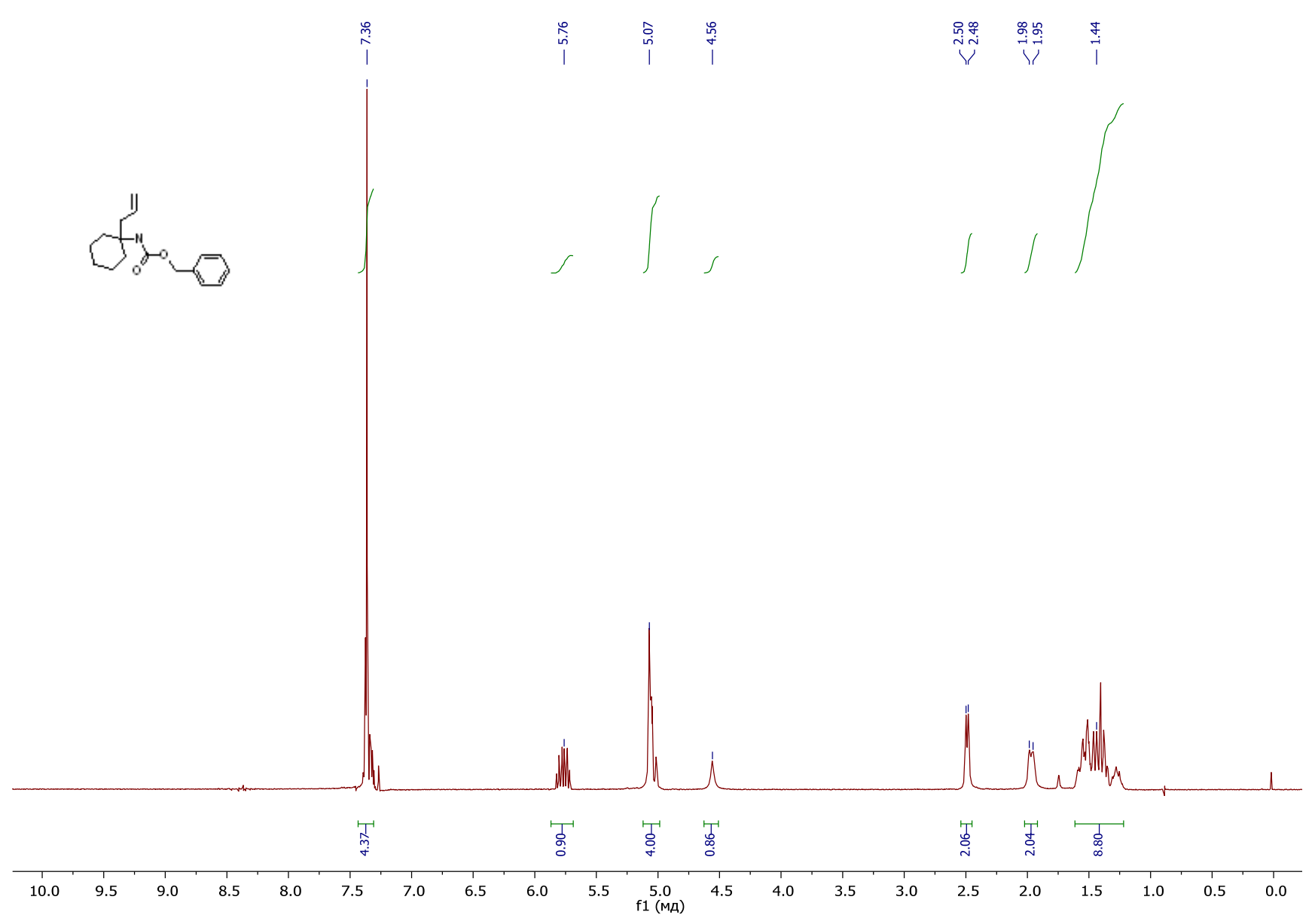


Figure S57. ${ }^{13} \mathrm{C}$ NMR spectrum of the compound $8 d$.

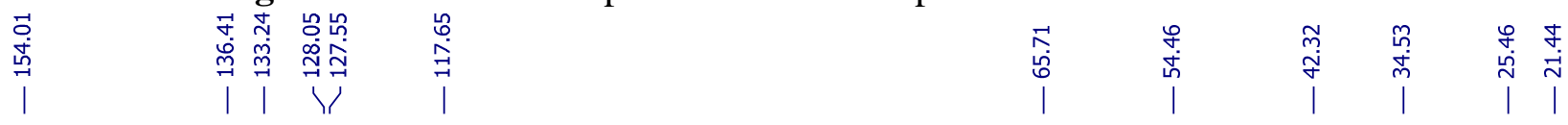

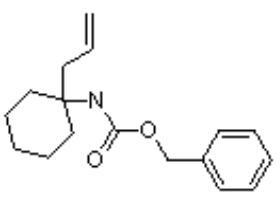




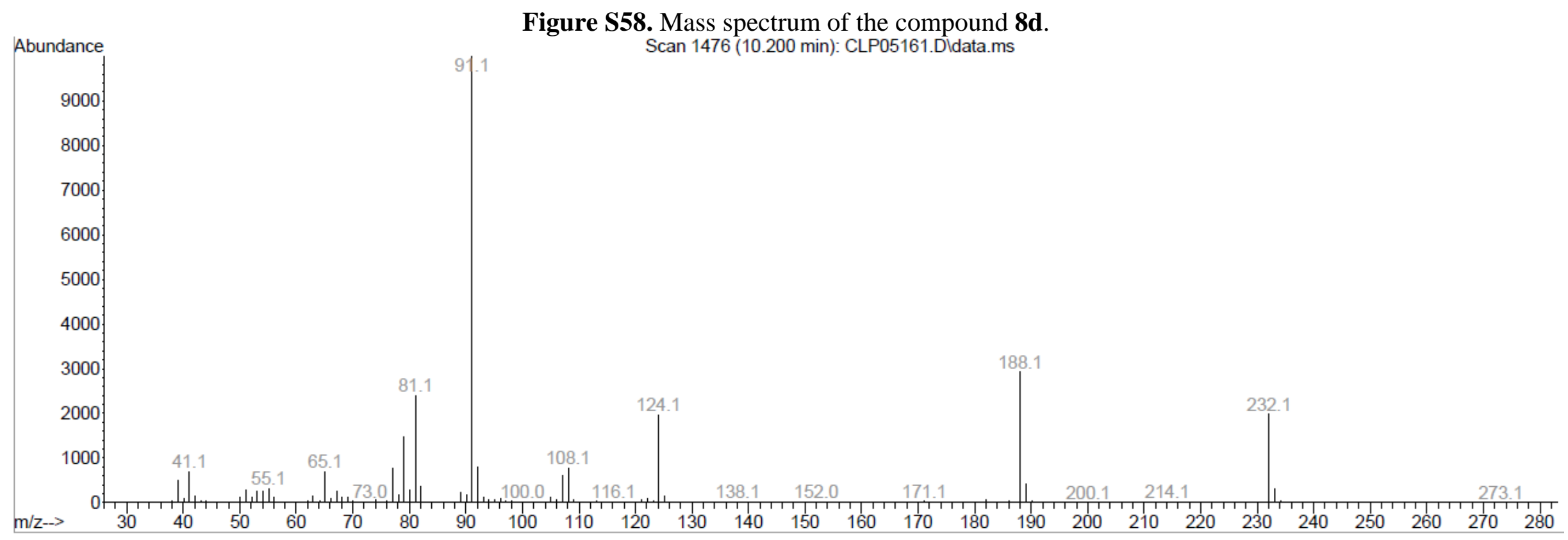


Figure S59. ${ }^{1} \mathrm{H}$ NMR spectrum of the compound 9d.

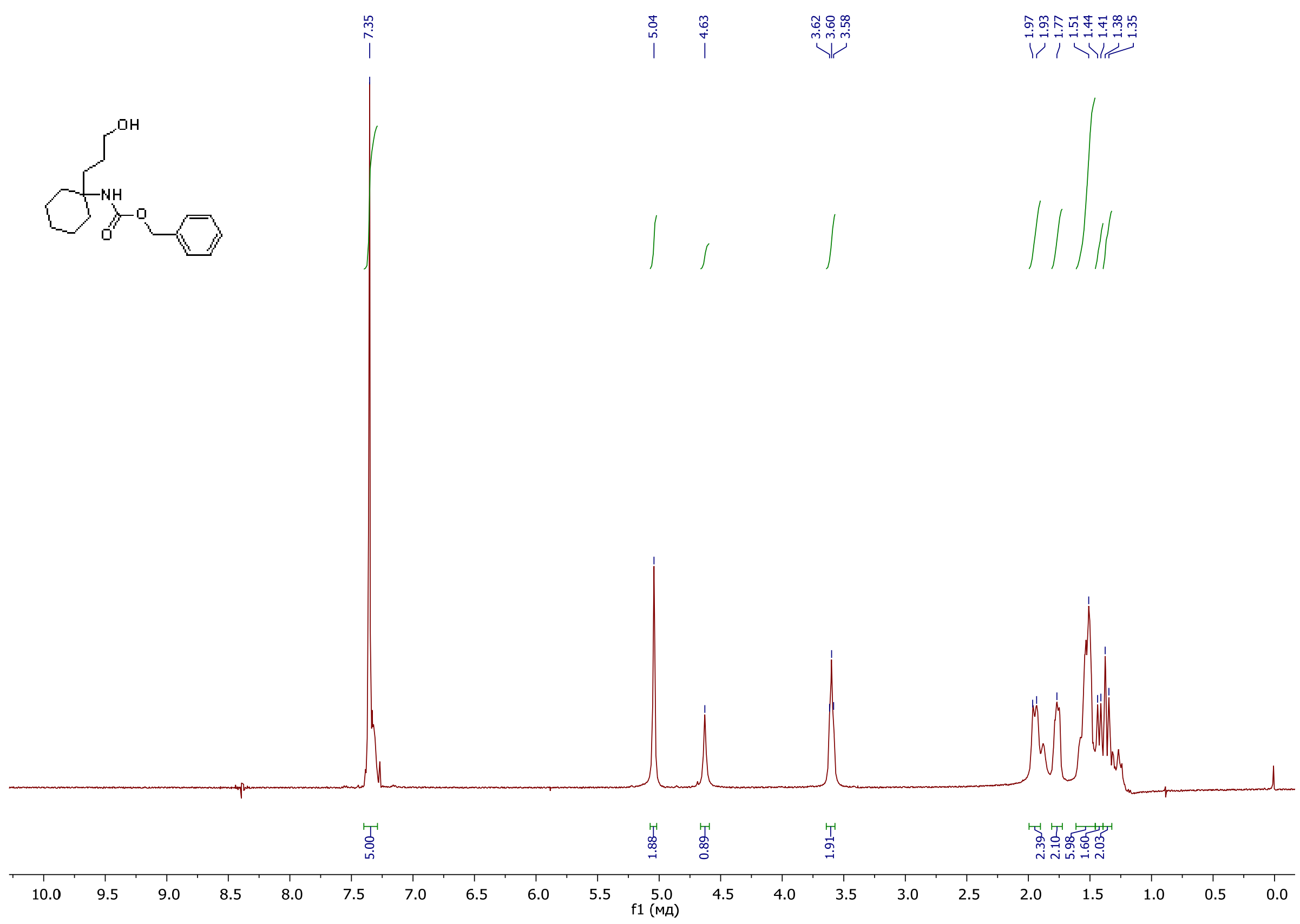


Figure S60. ${ }^{13} \mathrm{C}$ NMR spectrum of the compound 9d.

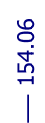

尊

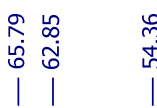

约

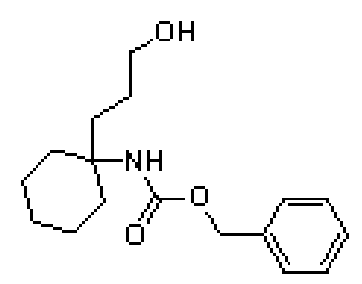

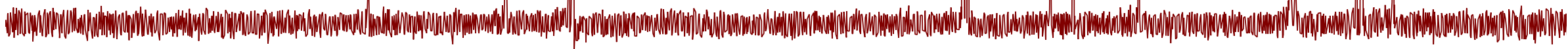

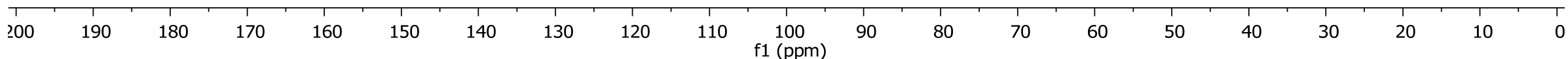


Figure S61. ${ }^{1} \mathrm{H}$ NMR spectrum of the compound $10 d$.

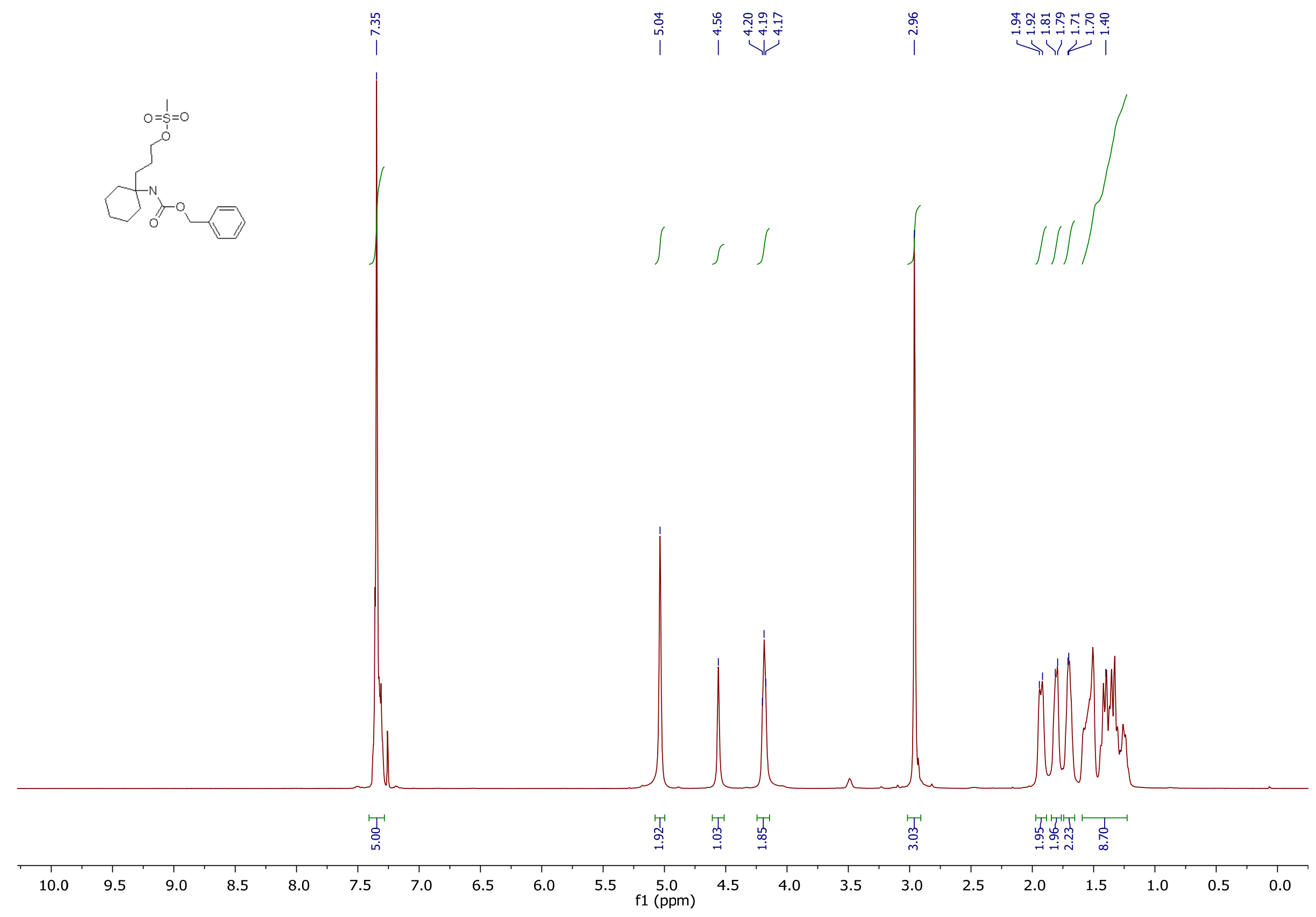


Figure S62. ${ }^{13} \mathrm{C}$ NMR spectrum of the compound 10d.

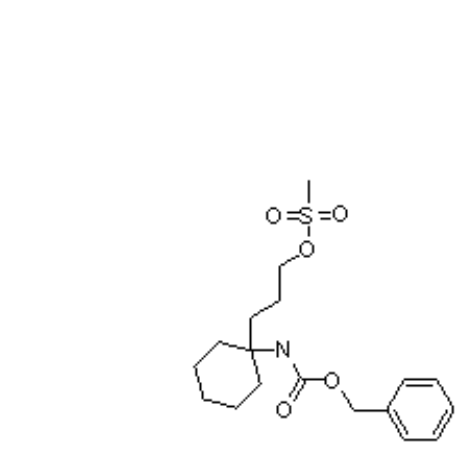

文

$i$

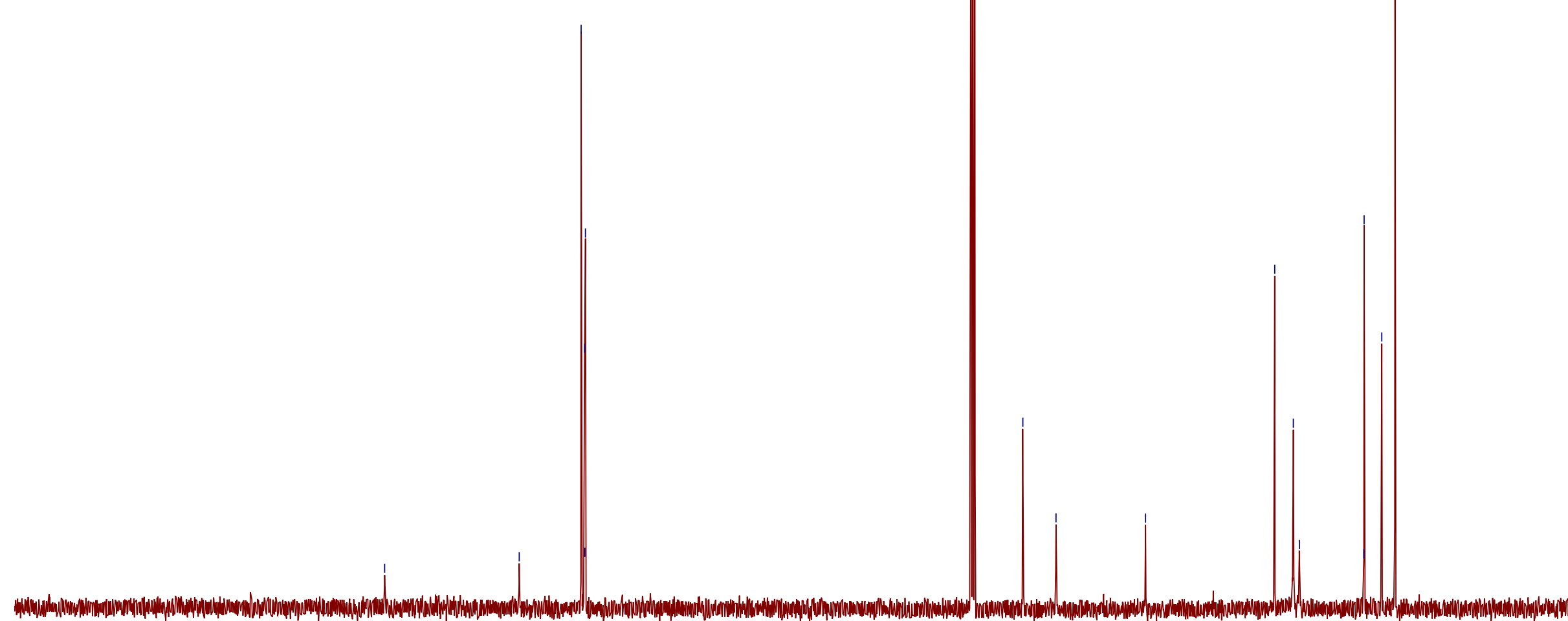




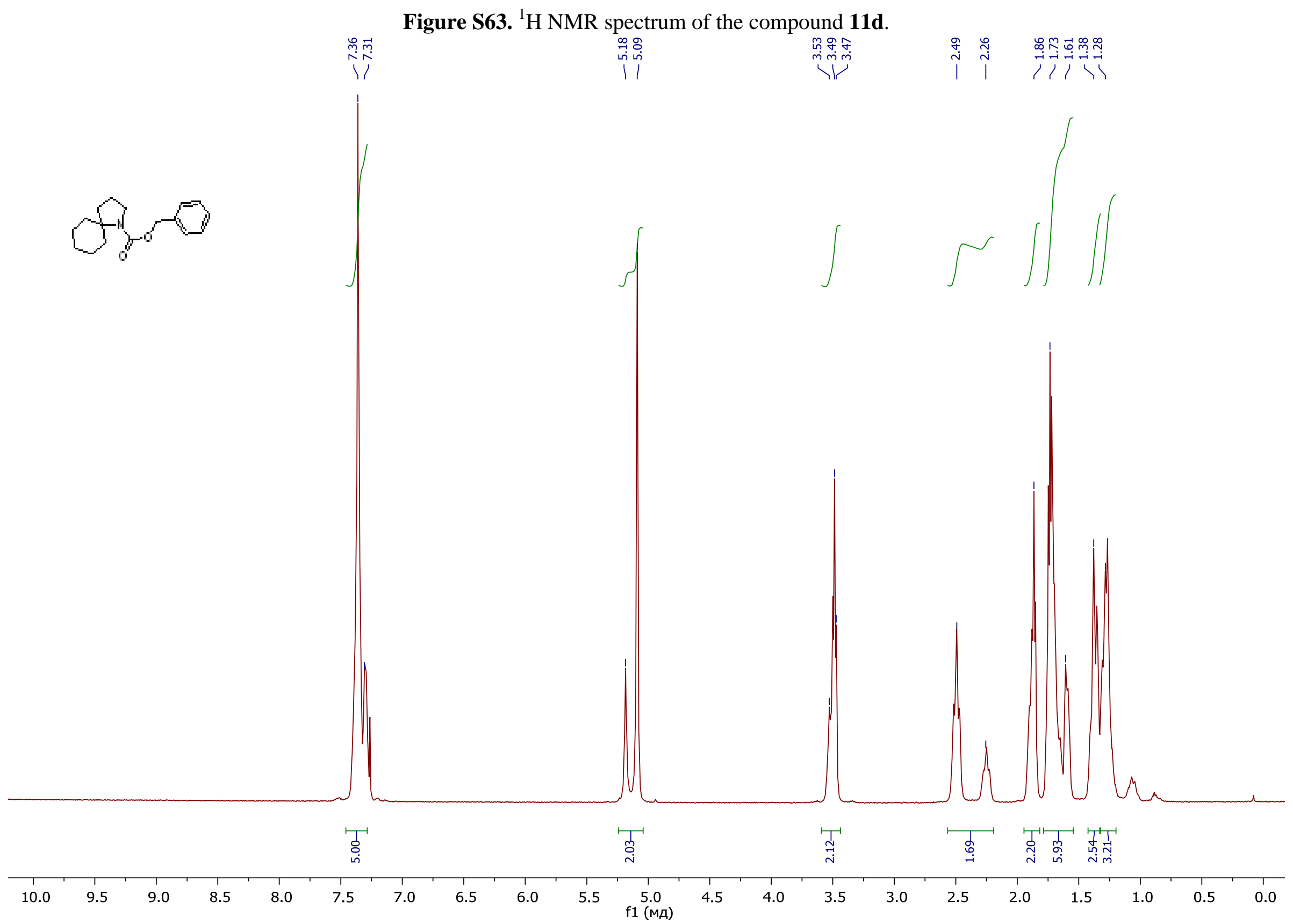


Figure S64. ${ }^{13} \mathrm{C}$ NMR spectrum of the compound 11d.

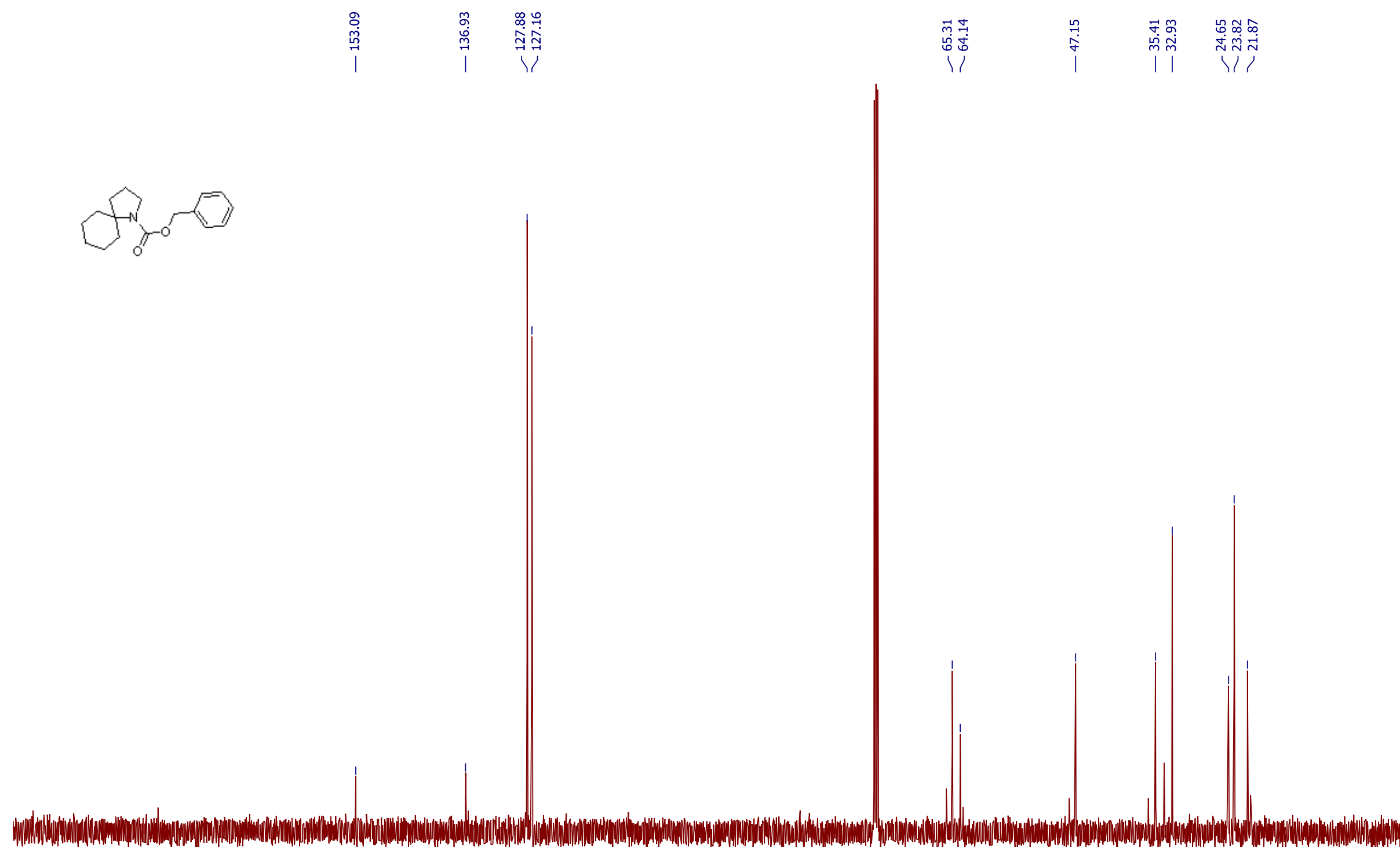

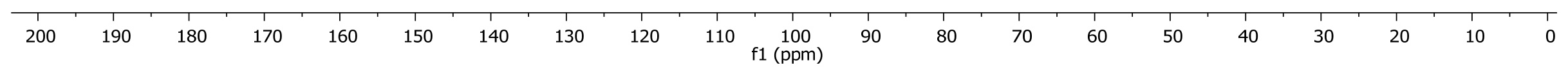


Synthesis of 8-oxa-1-azaspiro[4.5]decane hydrochloride (1e*HCl). Approach I.

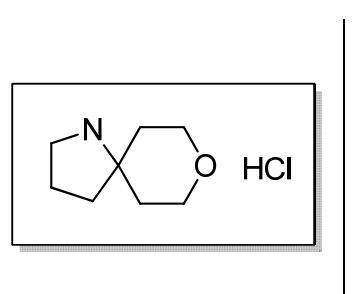

$1 \mathrm{e}^{*} \mathrm{HCl}$

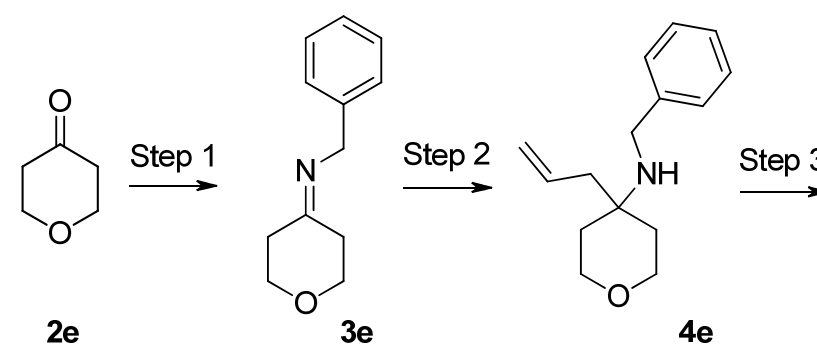

$3 e$

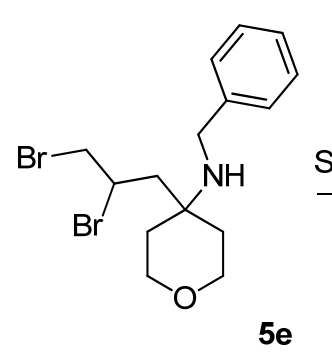

$5 e$

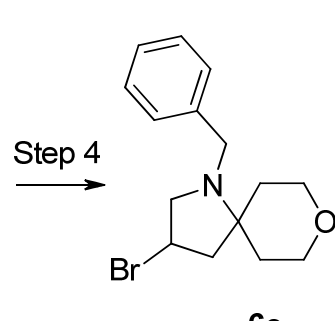

$6 e$

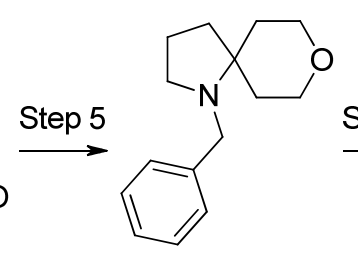

$7 e$
Step 6

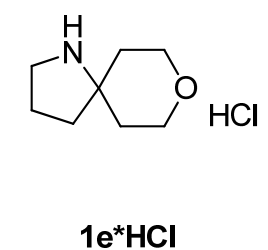

Scheme S7.

Figure S65. ${ }^{1} \mathrm{H}$ NMR spectrum of the compound $4 \mathbf{e}$.

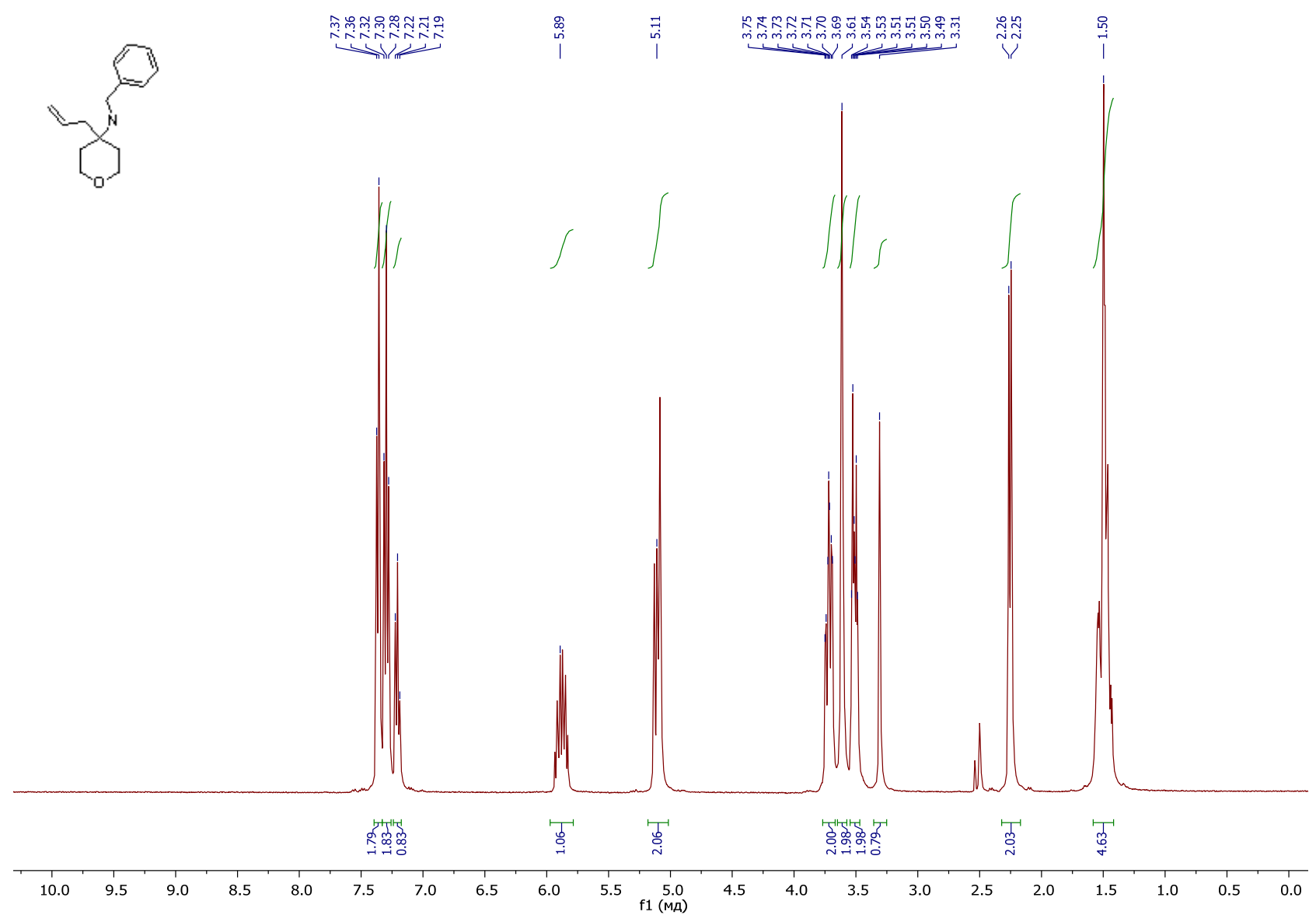


Figure S66. ${ }^{13} \mathrm{C}$ NMR spectrum of the compound $4 \mathbf{e}$.

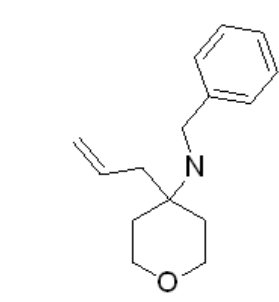

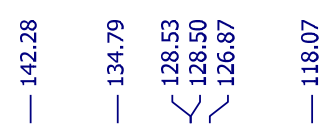

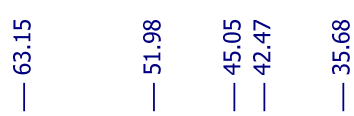

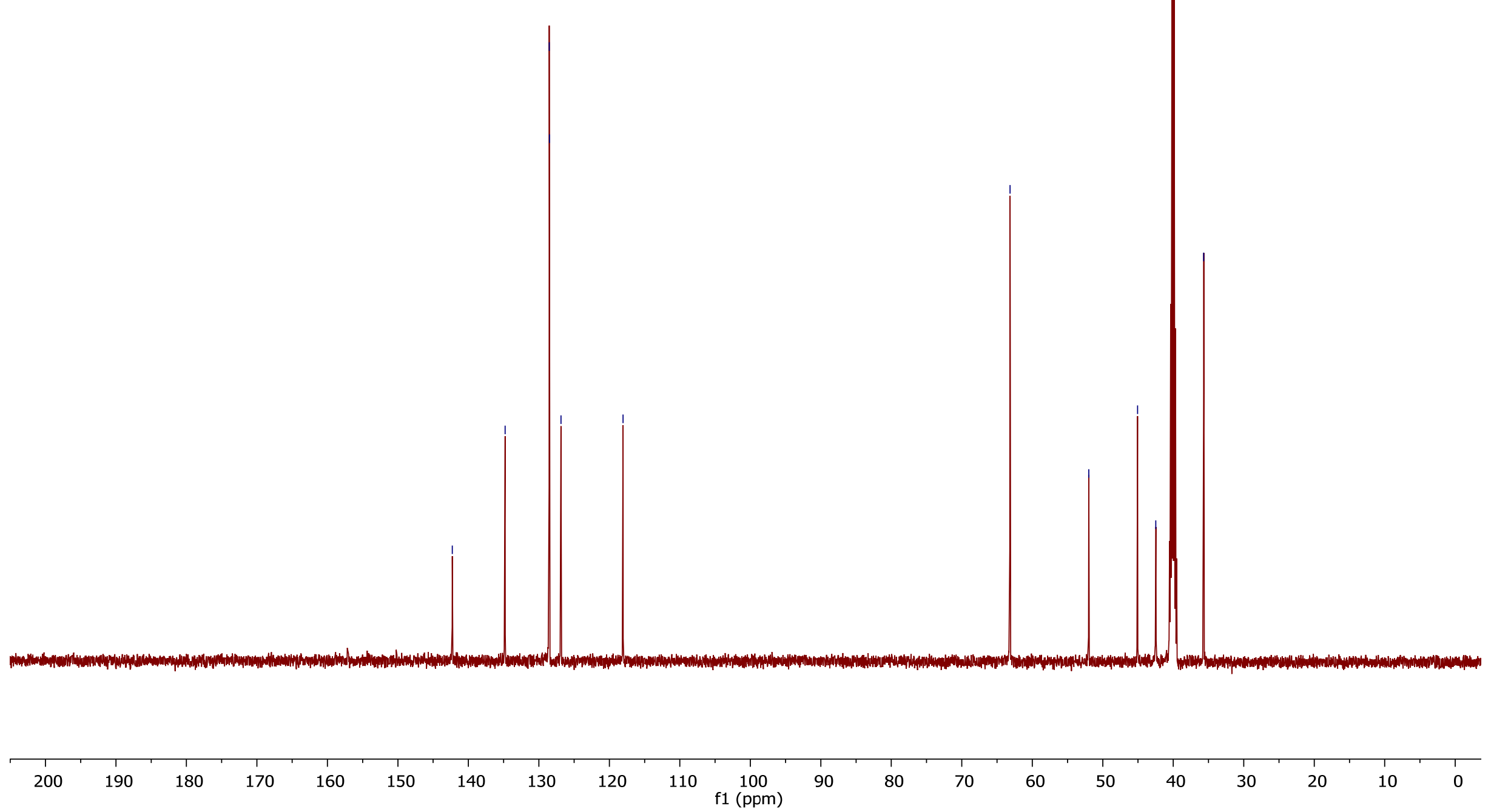


R1173233

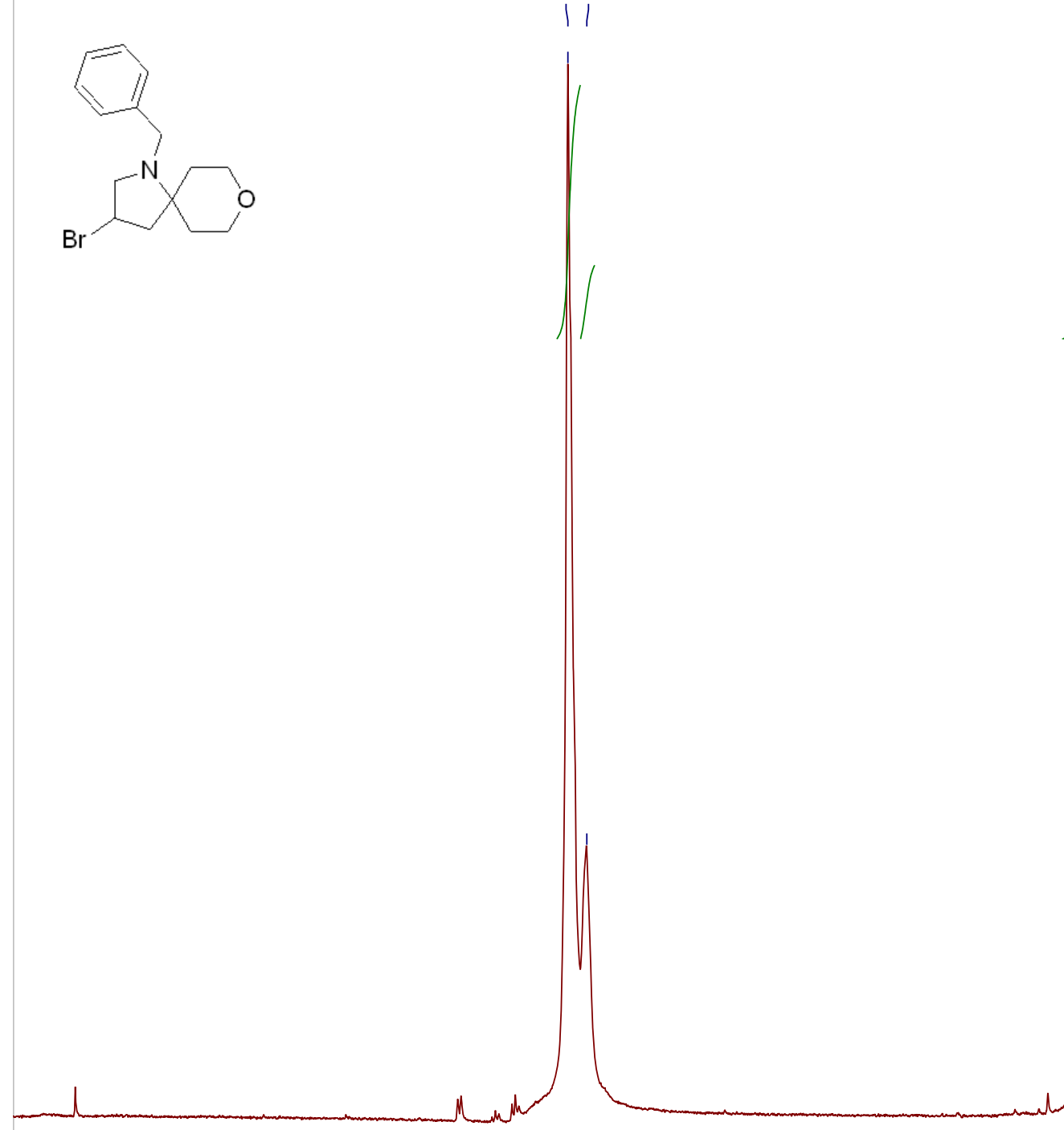

Figure S67. ${ }^{1} \mathrm{H}$ NMR spectrum of the compound $\mathbf{6 e}$.

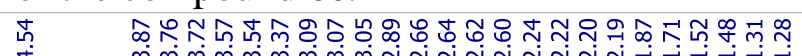

$\underbrace{m m}_{1}$
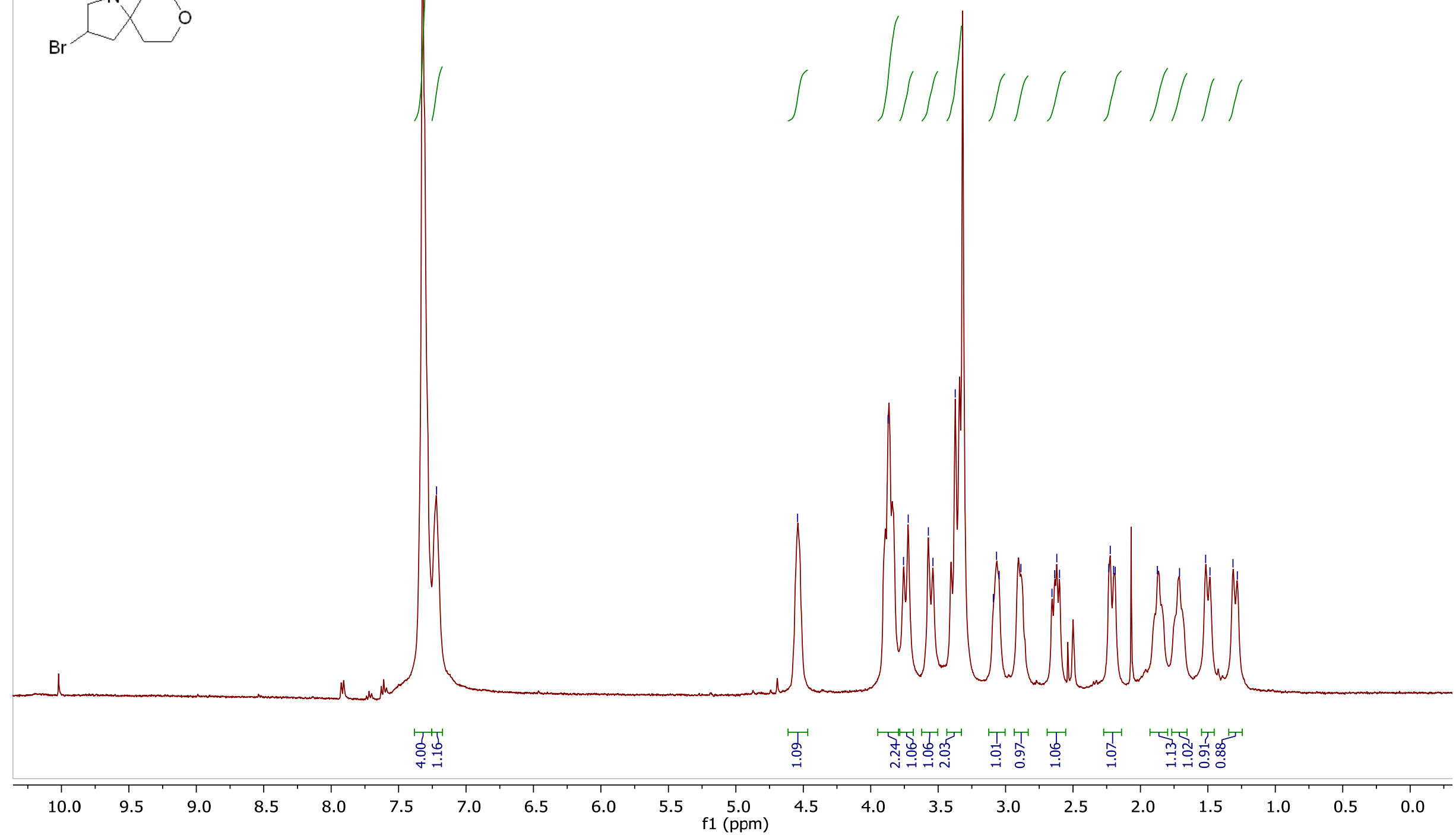
Figure S68. ${ }^{13} \mathrm{C}$ NMR spectrum of the compound 6 e.

R1173233_C13.1.fid

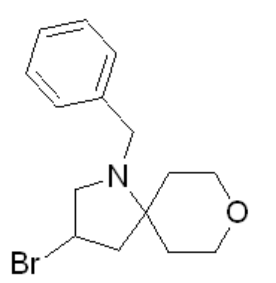

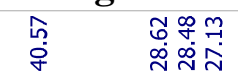

i

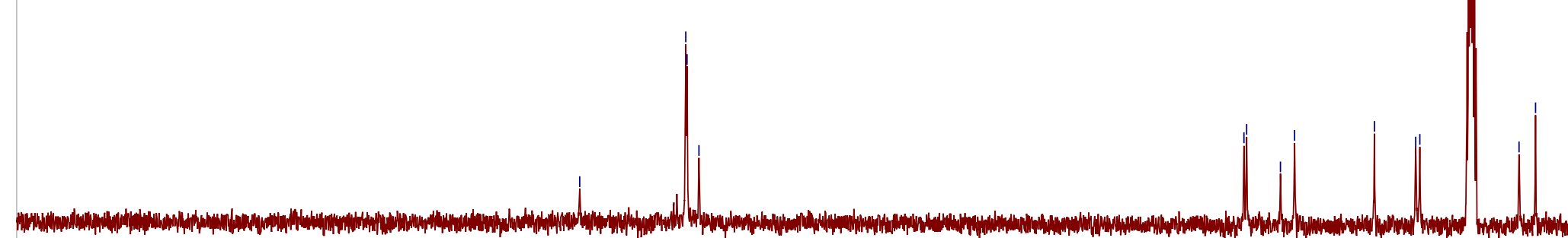




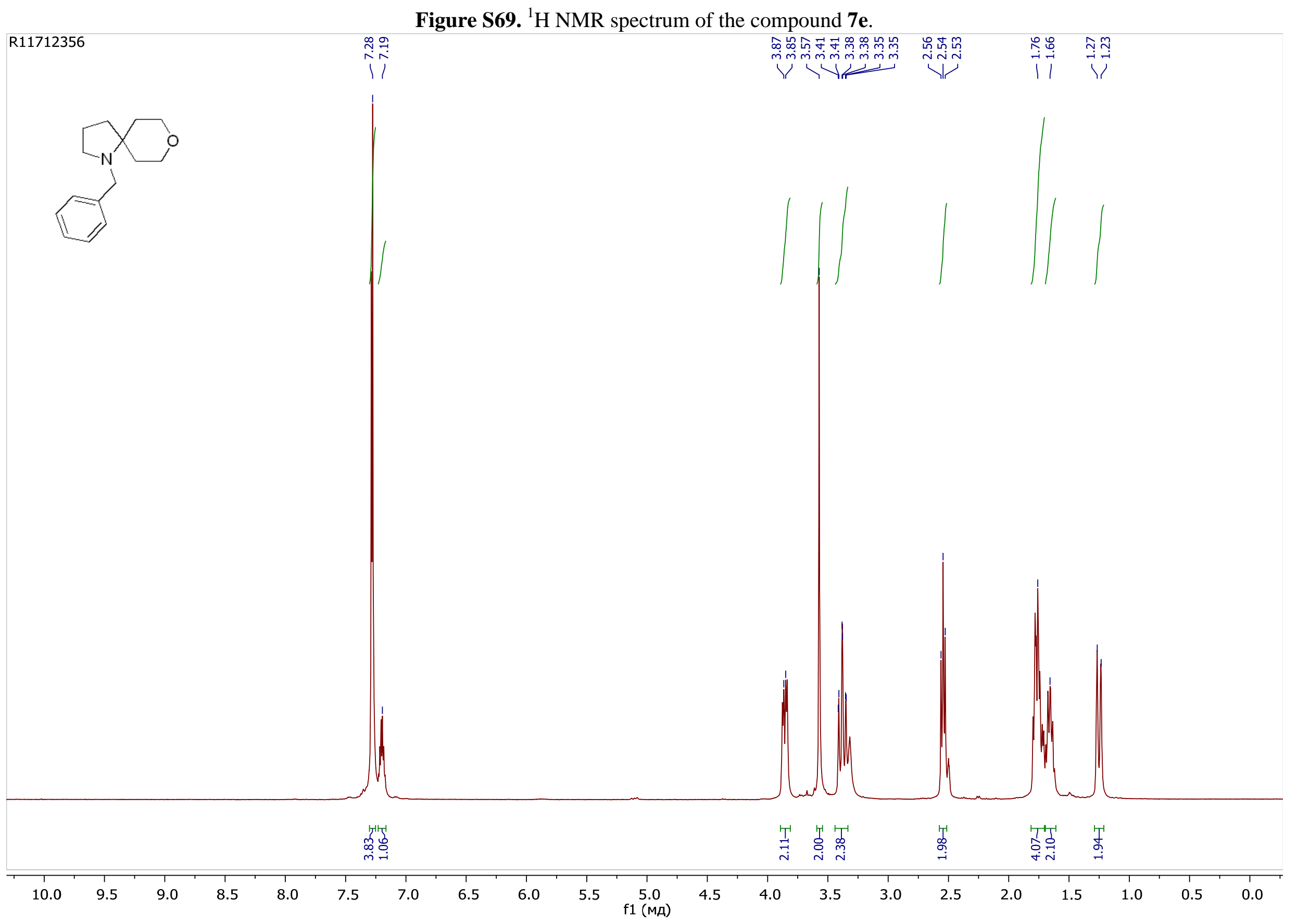


Figure S70. ${ }^{13} \mathrm{C}$ NMR spectrum of the compound $7 \mathbf{e}$.

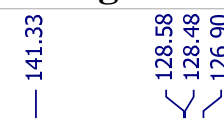

\&

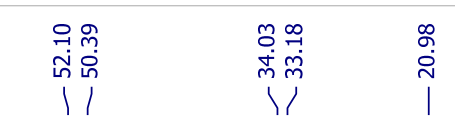
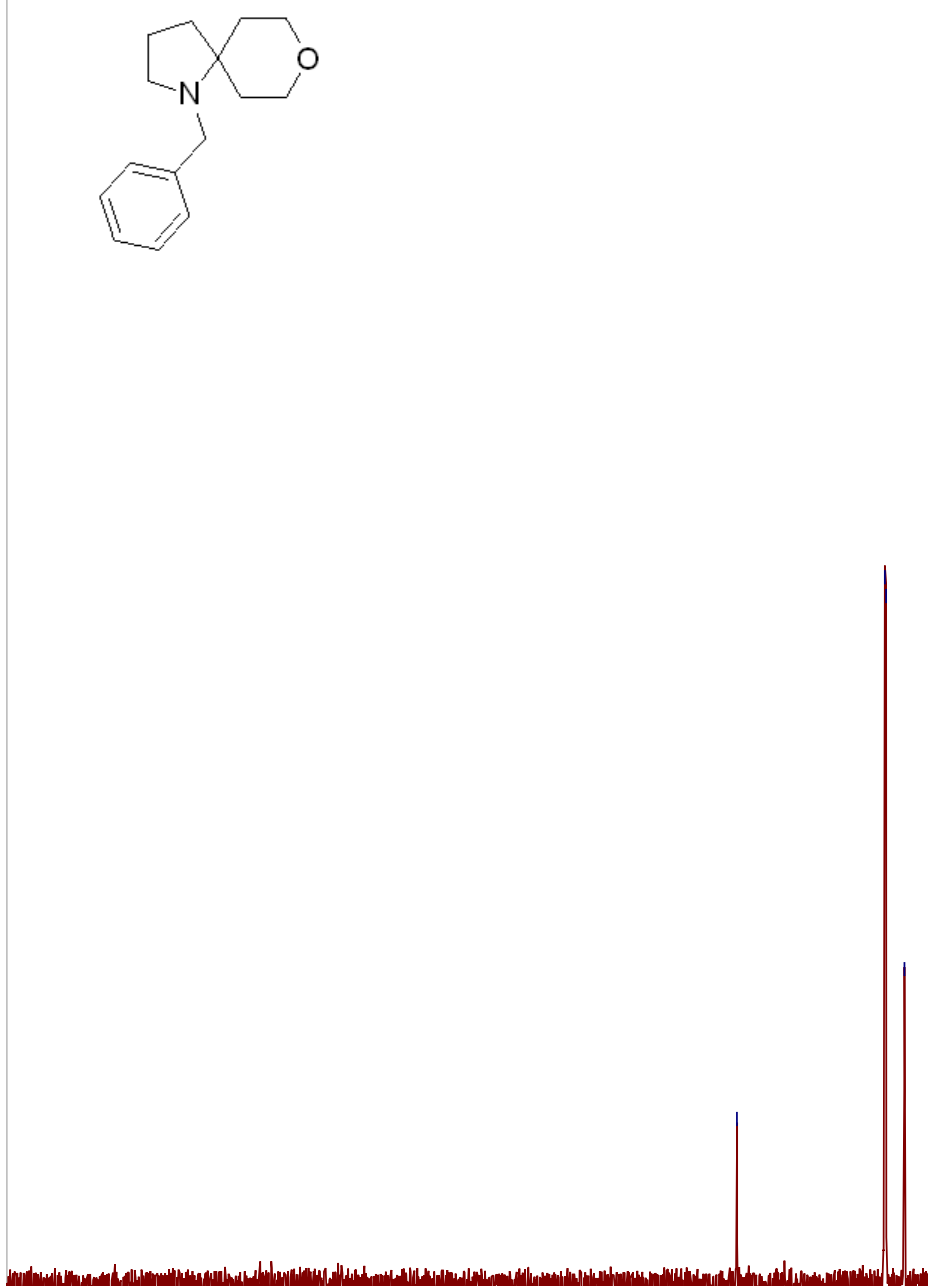
Figure S71. ${ }^{1} \mathrm{H}$ NMR spectrum of the compound $1 \mathbf{e}^{*} \mathbf{H C l}$.

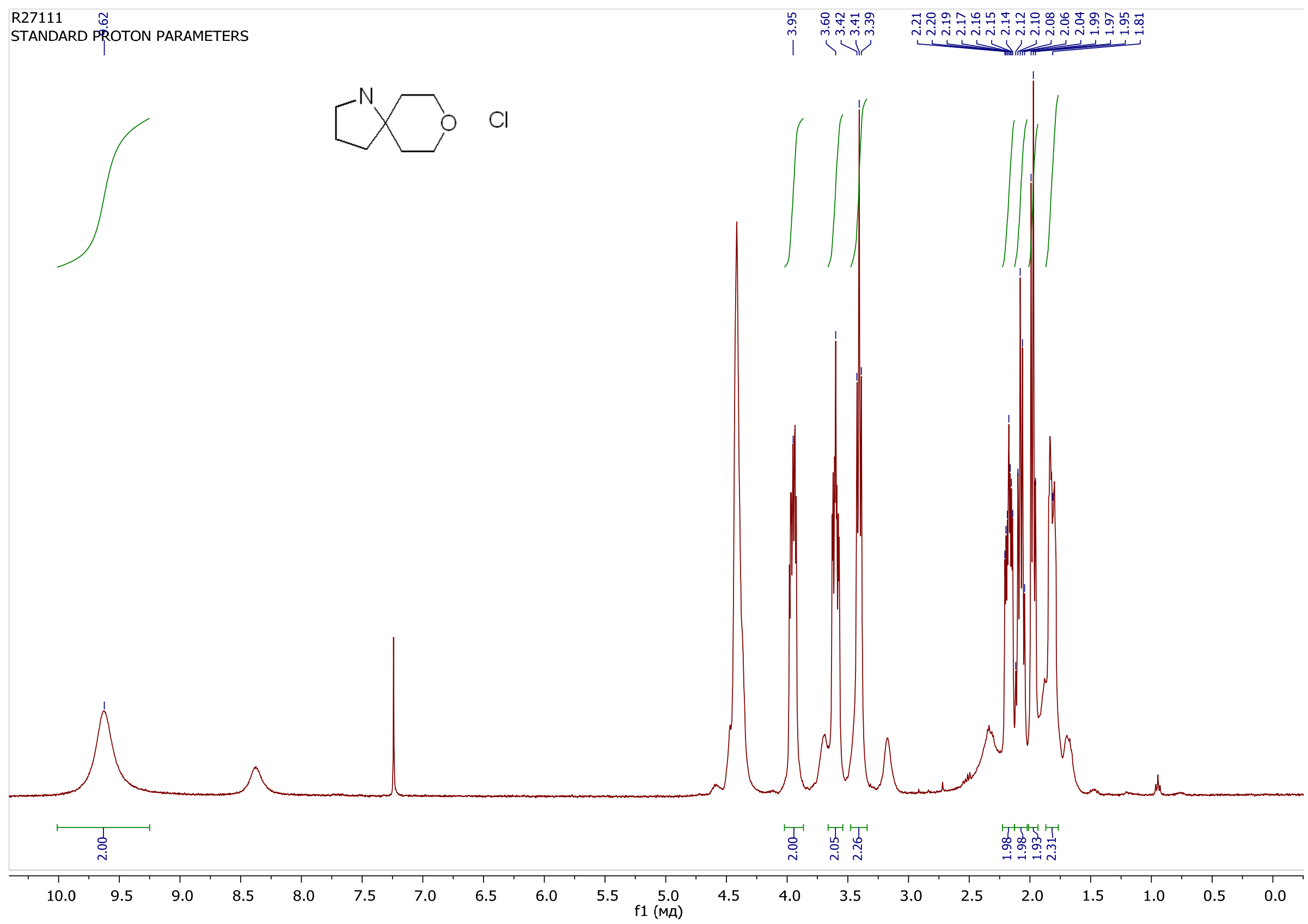


Figure S72. ${ }^{13} \mathrm{C}$ NMR spectrum of the compound $\mathbf{1 e} * \mathbf{H C l}$.

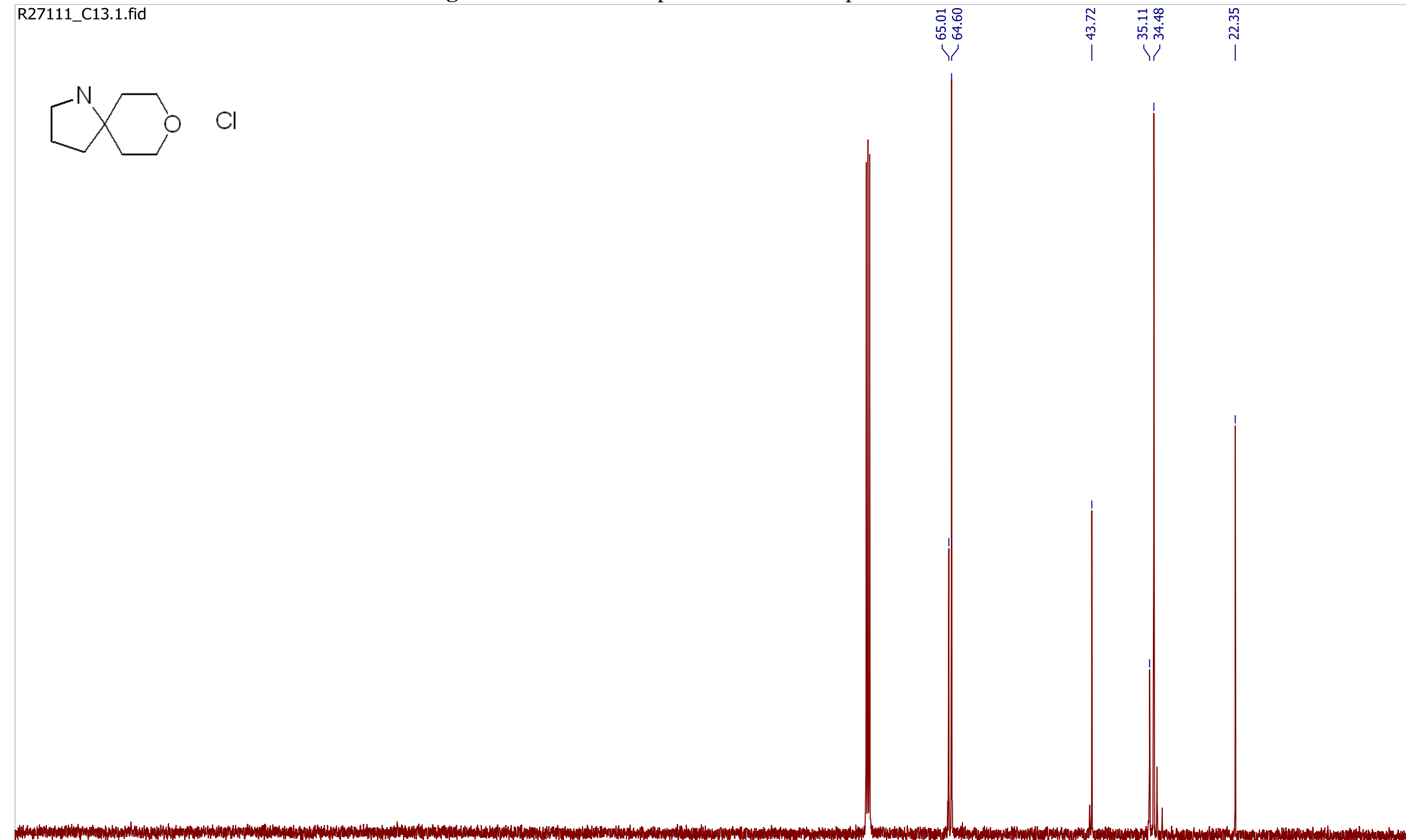

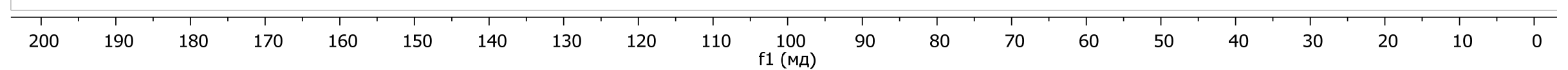


Synthesis of 1-chloro-8-oxa-1-azaspiro[4.5]decane (1e*HCl). Approach II.

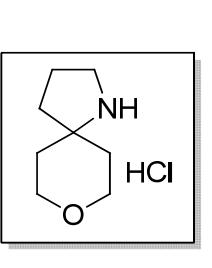

$1 \mathrm{e}^{\star} \mathrm{HCl}$

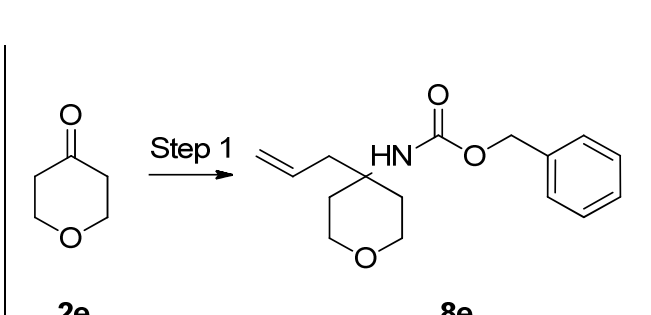

$8 \mathrm{e}$

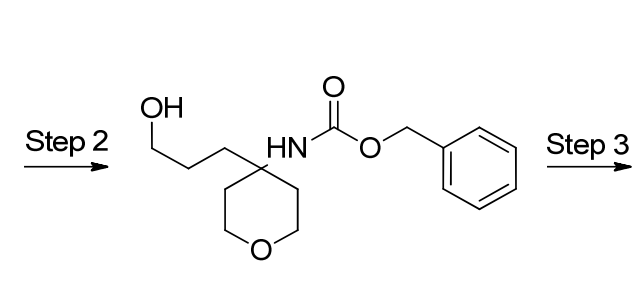

$9 e$

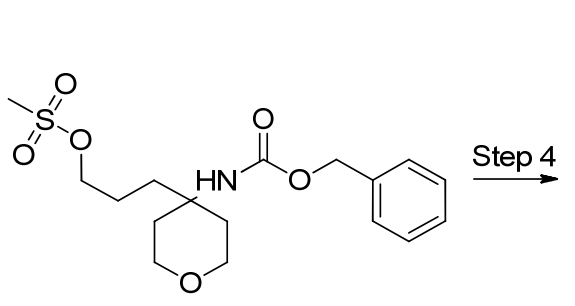

$10 \mathrm{e}$

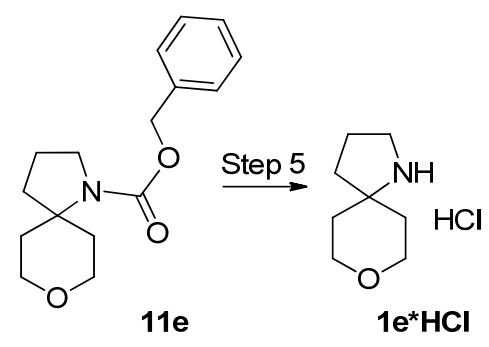

$11 \mathrm{e}$

Scheme S8.

Figure S73. ${ }^{1} \mathrm{H}$ NMR spectrum of the compound $8 \mathrm{e}$.

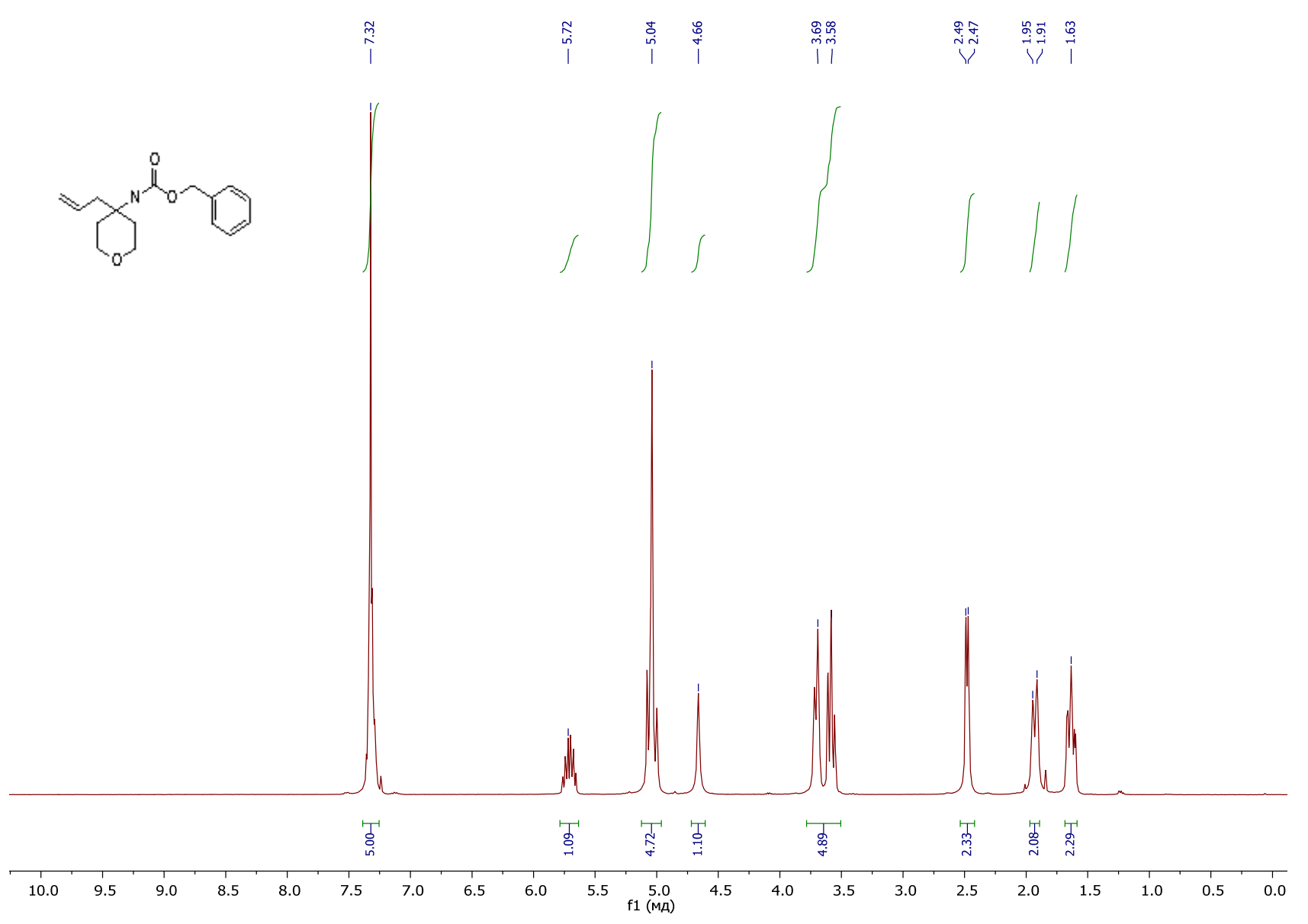


Figure S74. ${ }^{13} \mathrm{C}$ NMR spectrum of the compound $8 \mathrm{e}$.

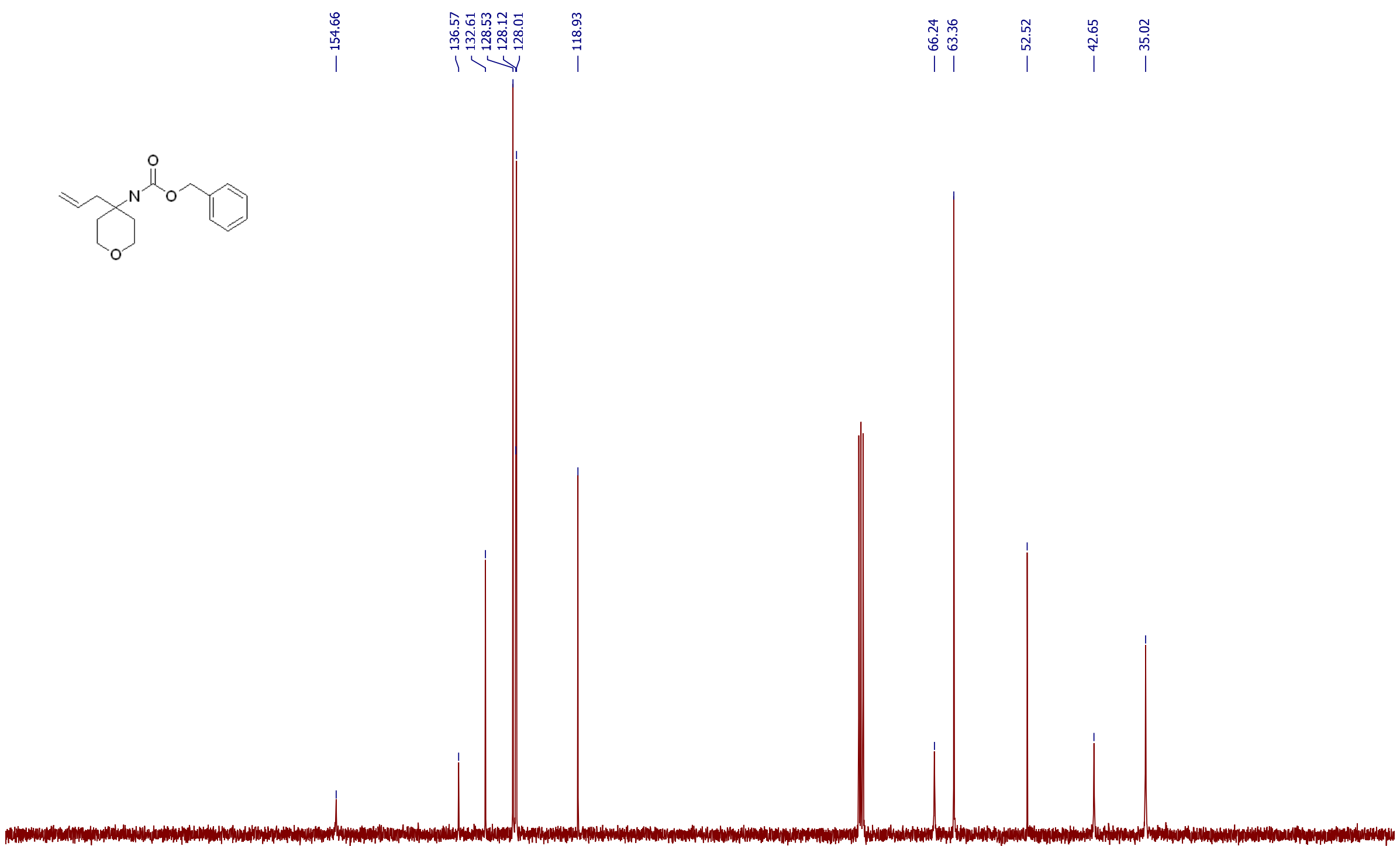


Figure S75. ${ }^{1} \mathrm{H}$ NMR spectrum of the compound $\mathbf{9 e}$.

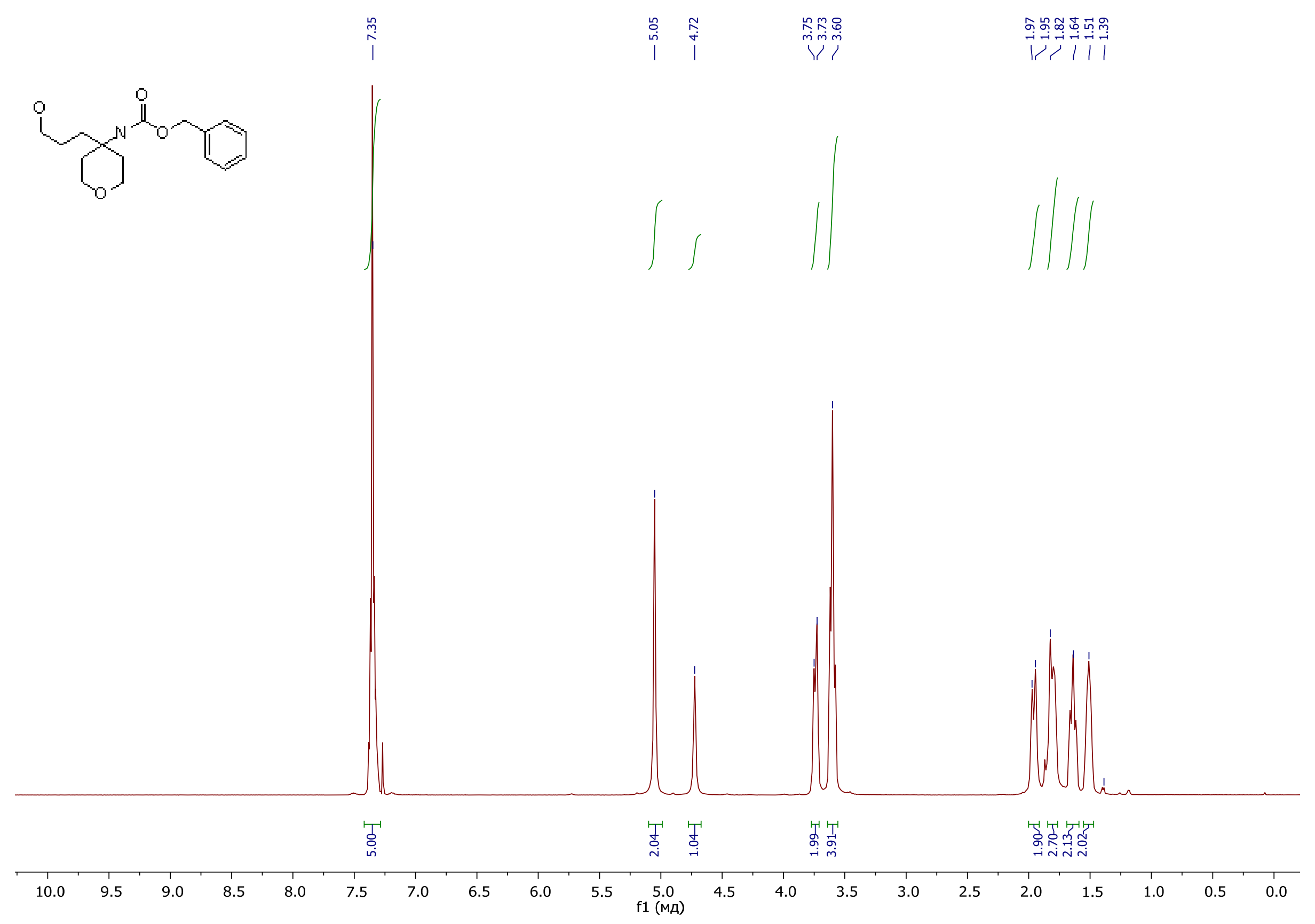


Figure S76. ${ }^{13} \mathrm{C}$ NMR spectrum of the compound $9 e$.

|

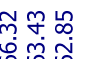

กิ่
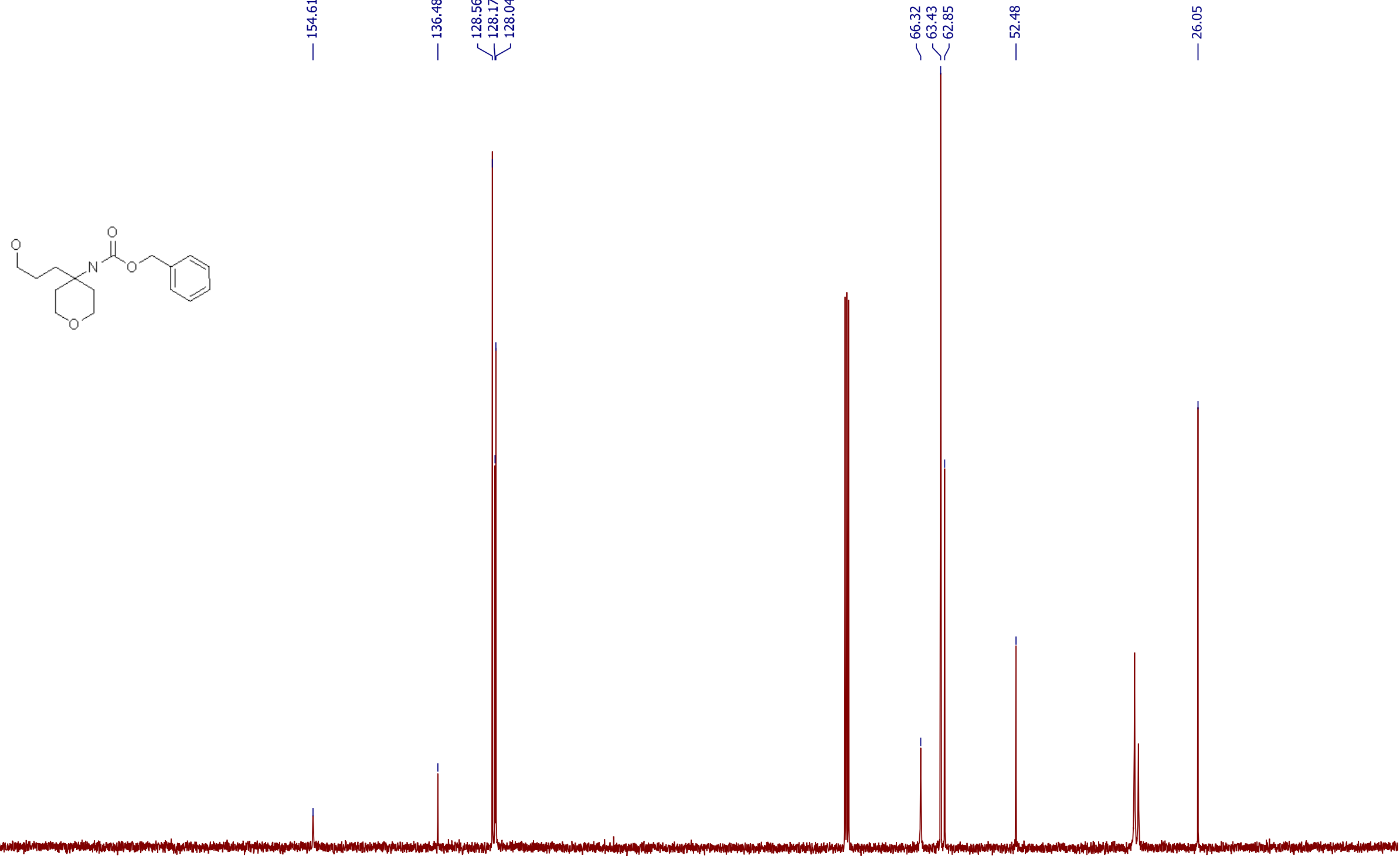
Figure S77. ${ }^{1} \mathrm{H}$ NMR spectrum of the compound 10e.
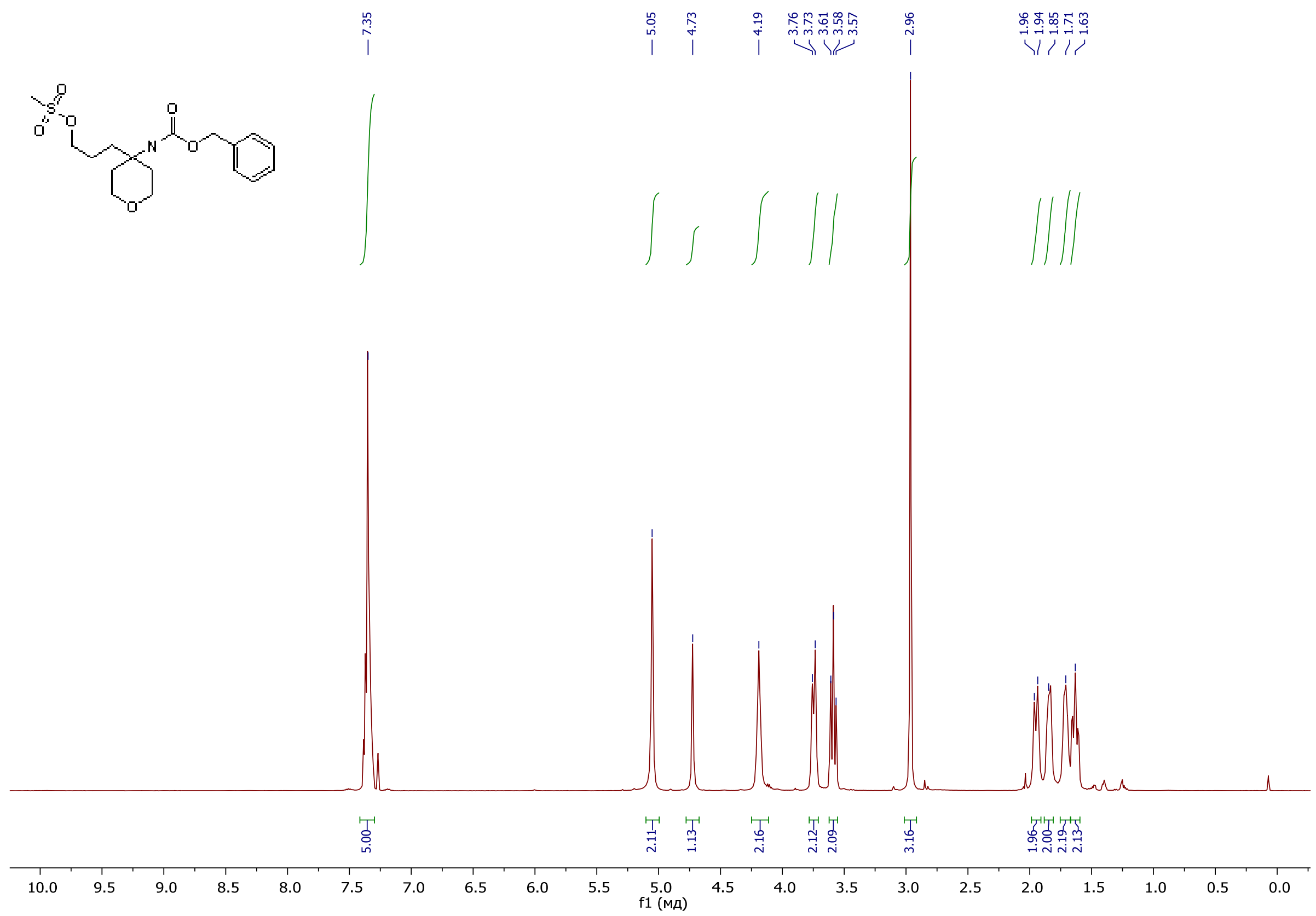
Figure S78. ${ }^{13} \mathrm{C}$ NMR spectrum of the compound 10e.

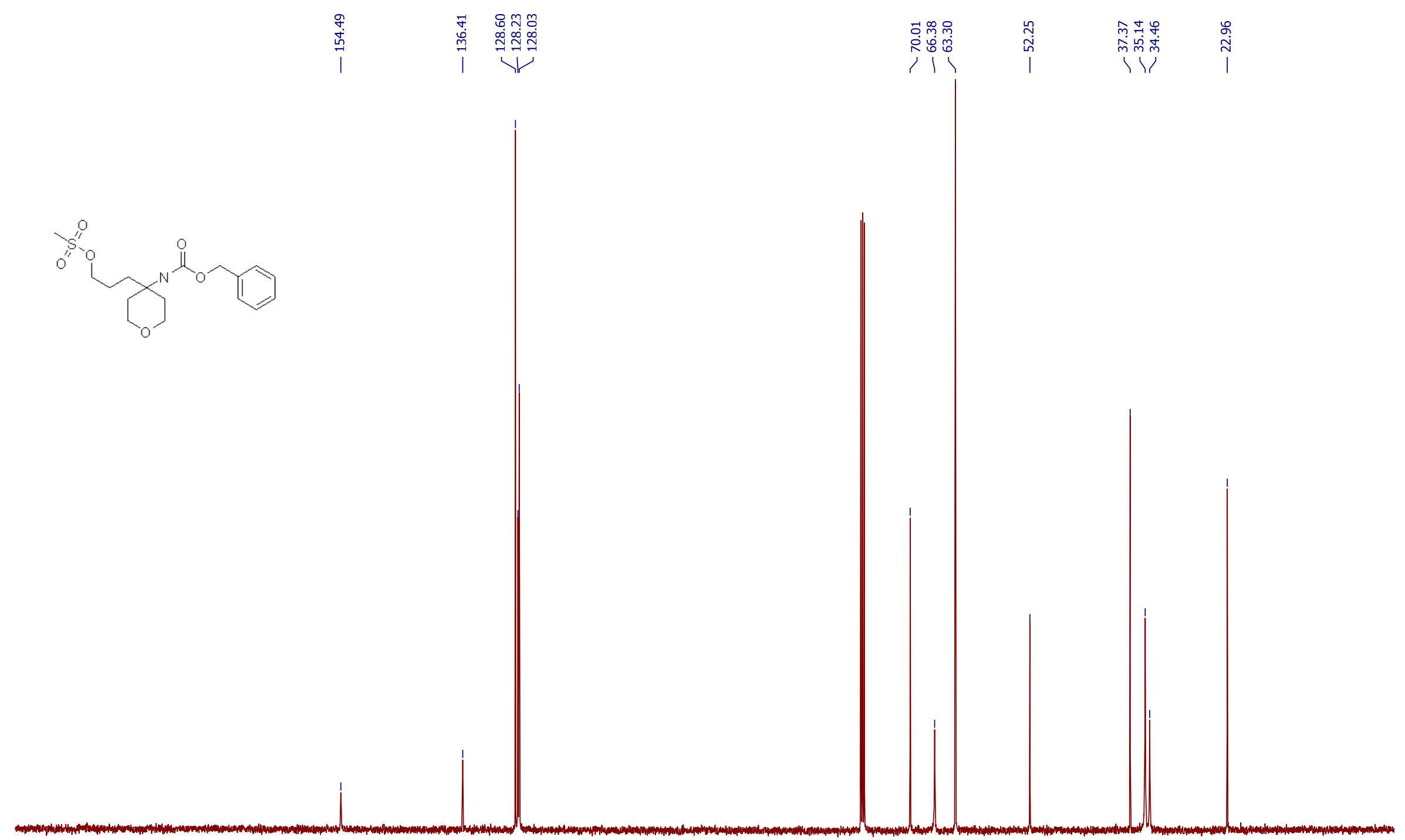

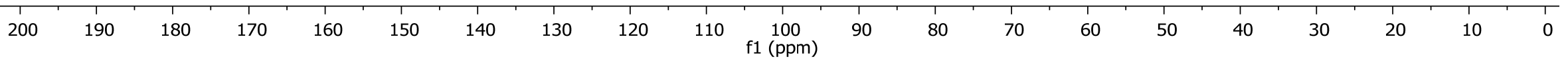


Figure S79. ${ }^{1} \mathrm{H}$ NMR spectrum of the compound $\mathbf{1 1 e}$.

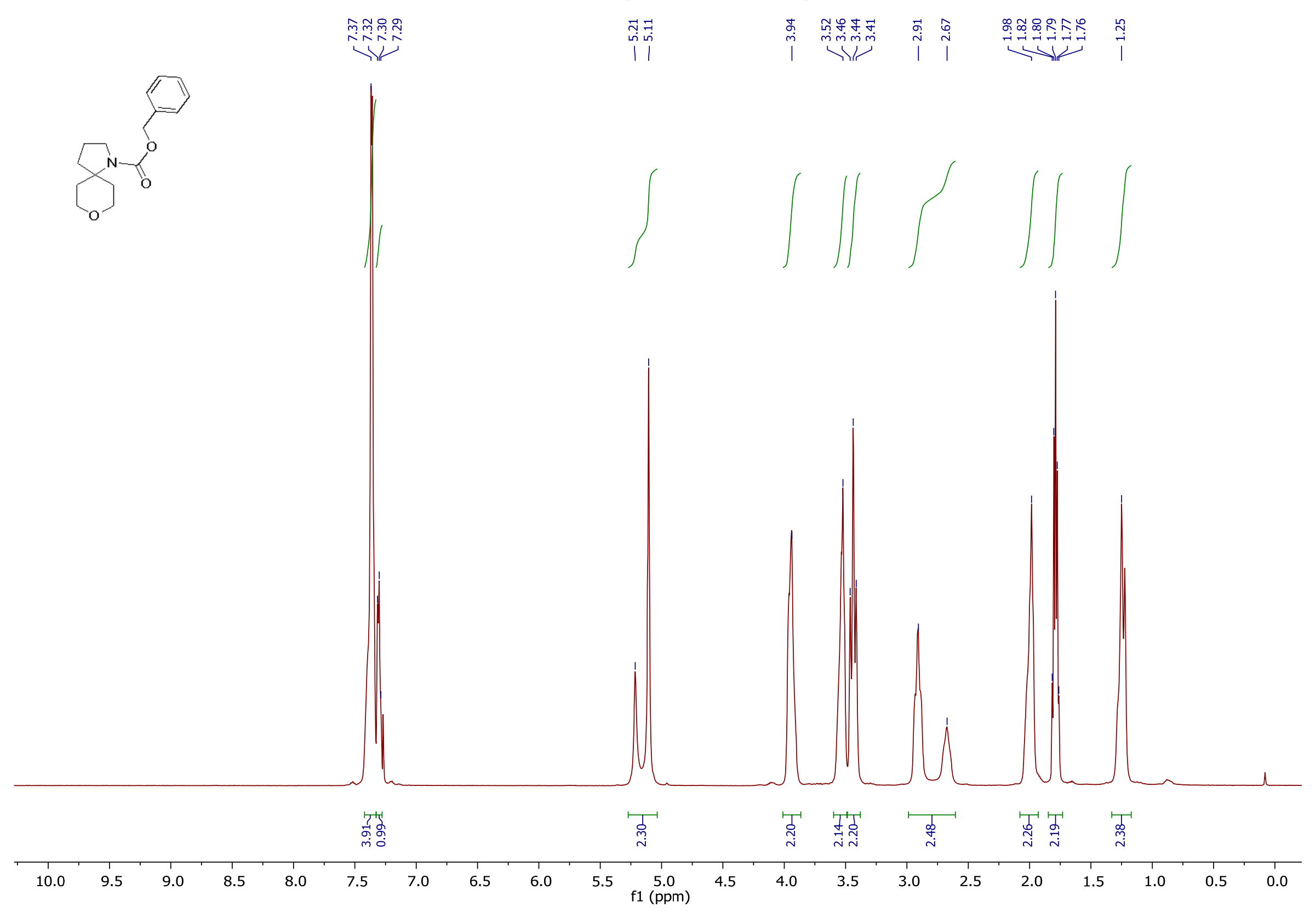


Figure S80. ${ }^{13} \mathrm{C}$ NMR spectrum of the compound $11 e$.

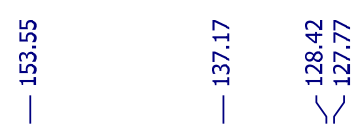

|l

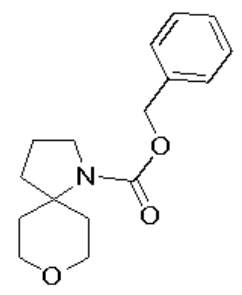

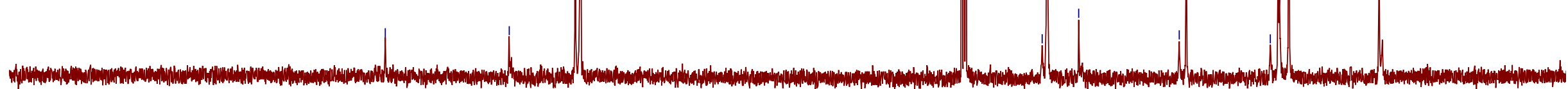

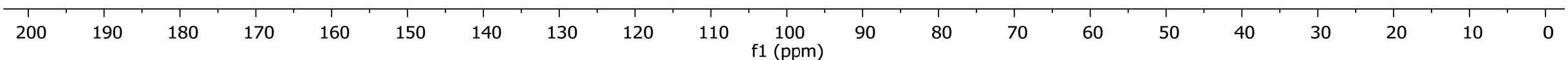


Synthesis of 8-thia-1-azaspiro[4.5]decane hydrochloride (1f*HCl). Approach II.

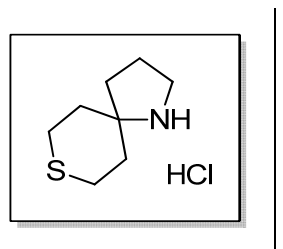

$1 f^{*} \mathrm{HCl}$

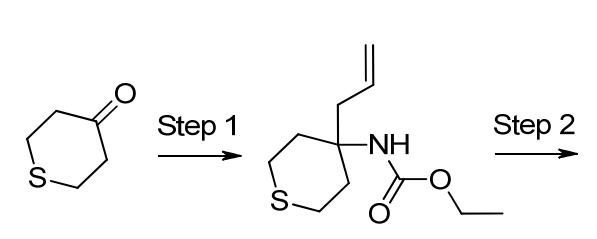

$2 \mathbf{f}$

$12 f$

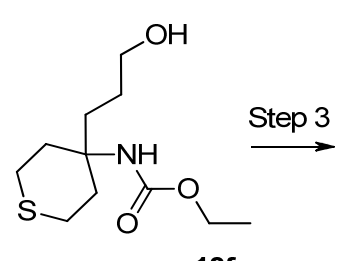

$13 f$

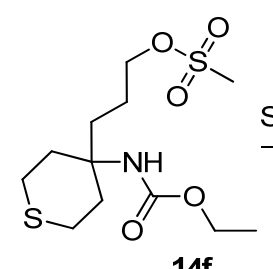

$14 f$ $\stackrel{\text { Step } 4}{\longrightarrow}$

$15 f$

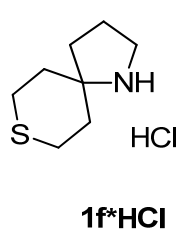

\section{Scheme S9}

Figure S81. ${ }^{1} \mathrm{H}$ NMR spectrum of the compound $\mathbf{1 2 f}$.

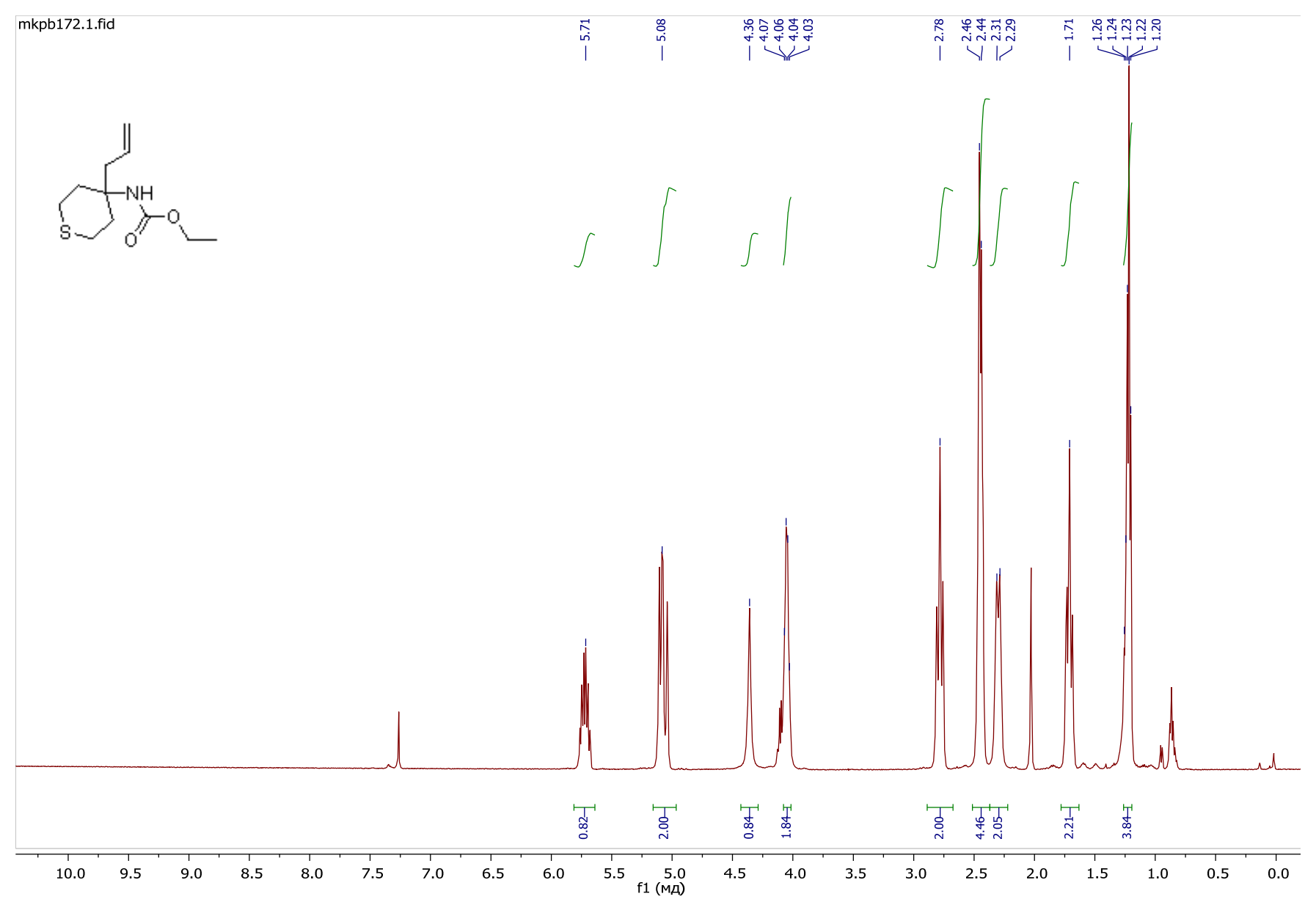


Figure S82. ${ }^{13} \mathrm{C}$ NMR spectrum of the compound $\mathbf{1 2 f}$.

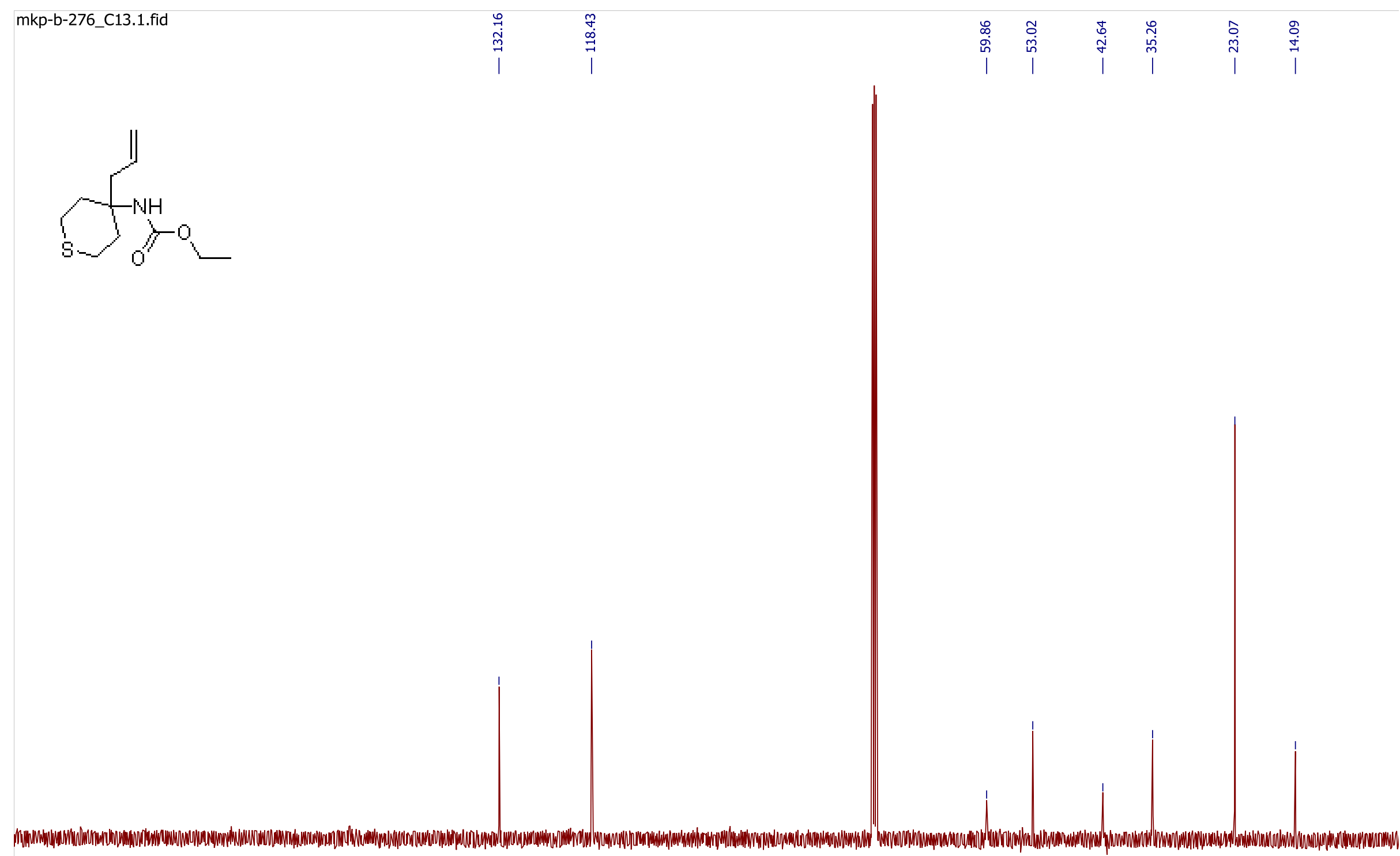

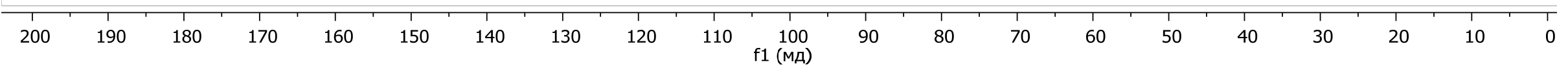


Figure S83. Mass spectrum of $\mathbf{1 2 f}$.

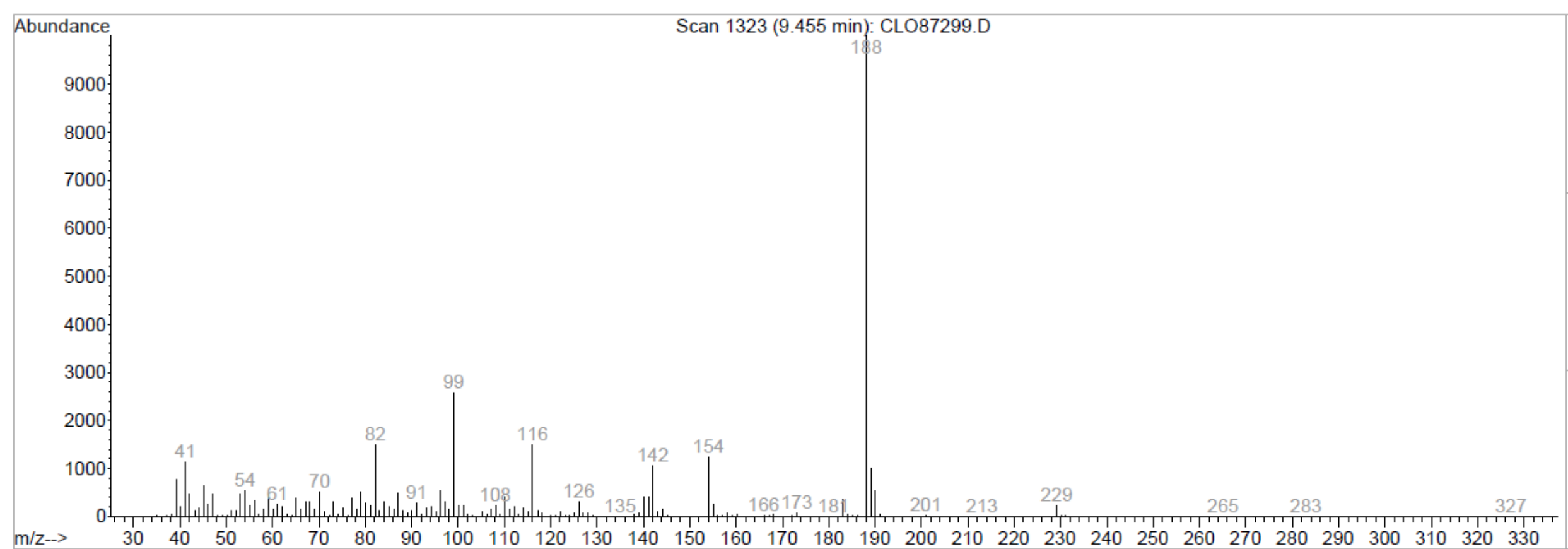


Figure S84. ${ }^{1} \mathrm{H}$ NMR spectrum of the compound $13 f$.

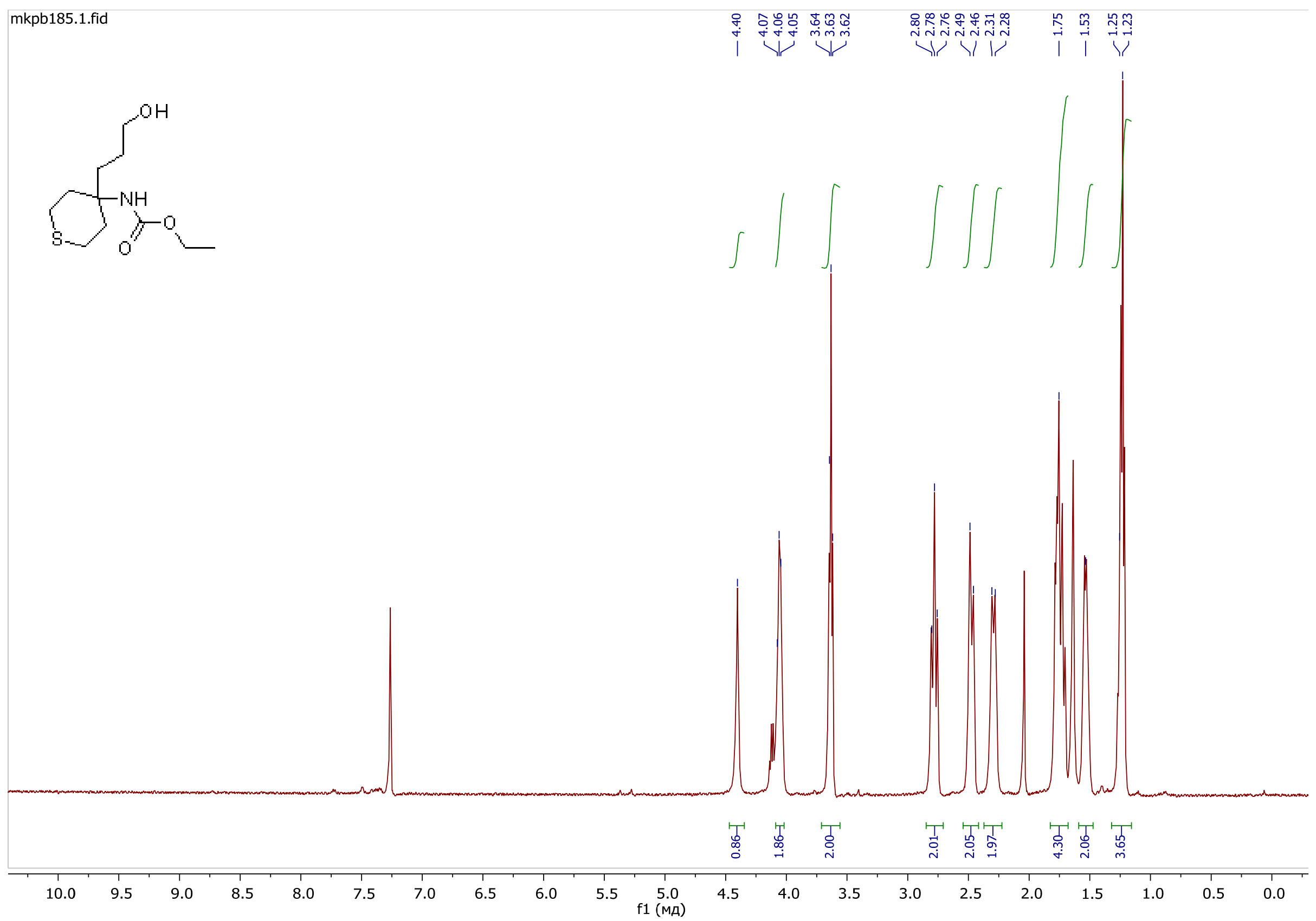


Figure S85. ${ }^{13} \mathrm{C}$ NMR spectrum of the compound $\mathbf{1 3 f}$.

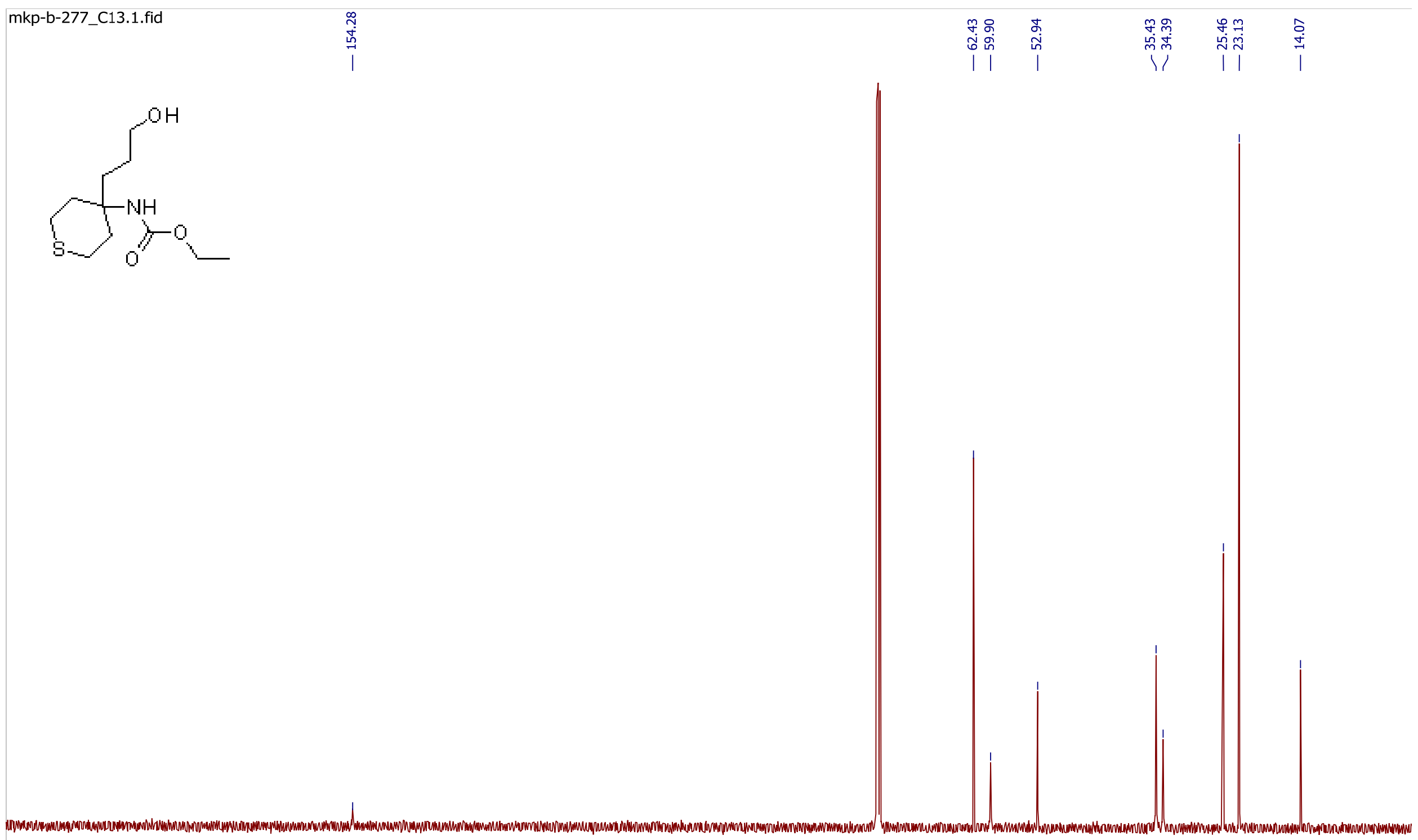

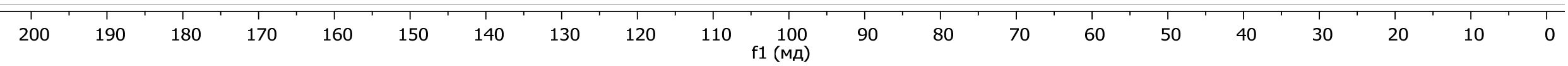


Figure S86. ${ }^{1} \mathrm{H}$ NMR spectrum of the compound $14 f$.

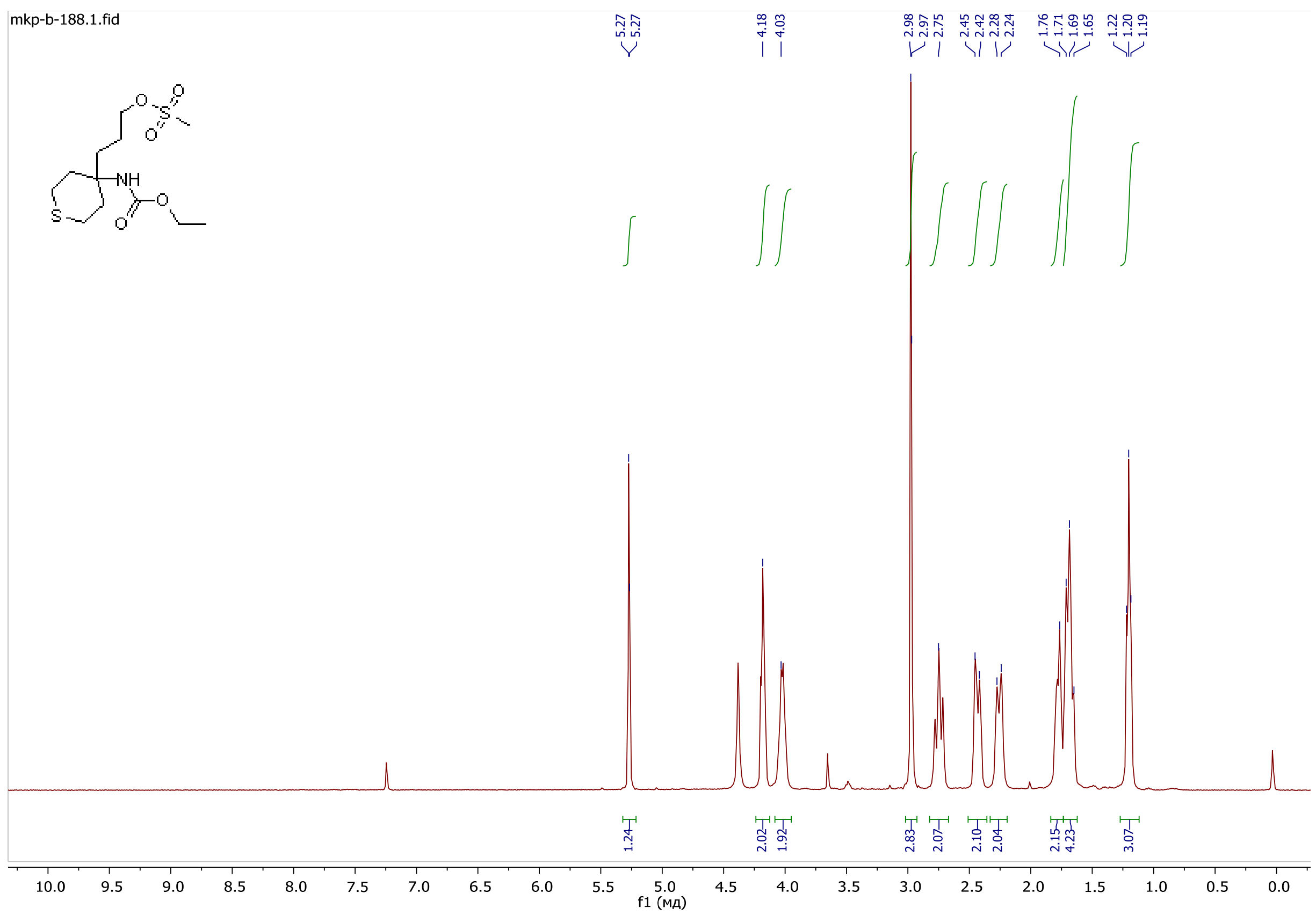


Figure S87. ${ }^{13} \mathrm{C}$ NMR spectrum of the compound $\mathbf{1 4 f}$.

mkp-b-278_c13.1.fid

\begin{tabular}{|c|c|c|c|c|c|}
\hline เீ & \% & $\stackrel{\pi}{\pi}$ & $\stackrel{L}{0}$ & 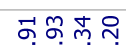 & $\tilde{0} 7$ \\
\hline 8 & กิ & กี่ & $\dot{f}$ & 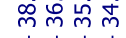 & ஸ் \\
\hline | & | & | & | & 1111 & V \\
\hline
\end{tabular}
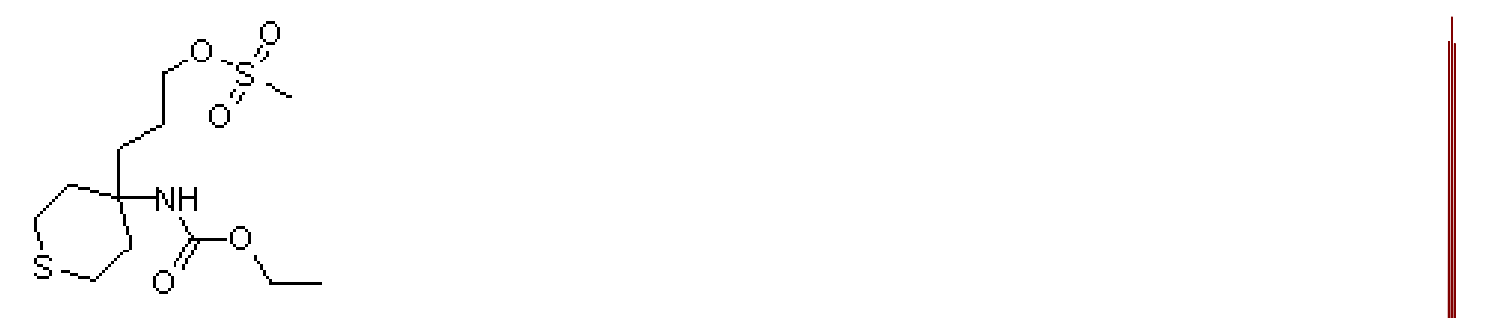

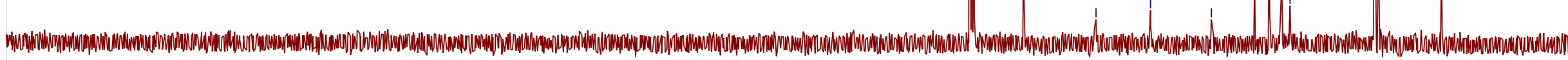

\begin{tabular}{|c|c|c|c|c|c|c|c|c|c|c|c|c|c|c|c|c|c|c|c|c|}
\hline 1 & & 1 & 1 & 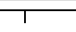 & & & 1 & 1 & 1 & & 1 & 1 & 1 & & & 1 & 1 & & & \\
\hline 200 & 190 & 180 & 170 & 160 & 150 & 140 & 130 & 120 & 110 & $\begin{array}{c}100 \\
\mathrm{f} 1 \text { (Mम) }\end{array}$ & 90 & 80 & 70 & 60 & 50 & 40 & 30 & 20 & 10 & 0 \\
\hline
\end{tabular}


Figure S88. ${ }^{1} \mathrm{H}$ NMR spectrum of the compound $15 f$.

mkpb200

new experiment

Combined from individual shim mapping experiments

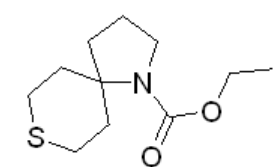

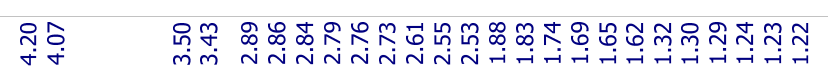

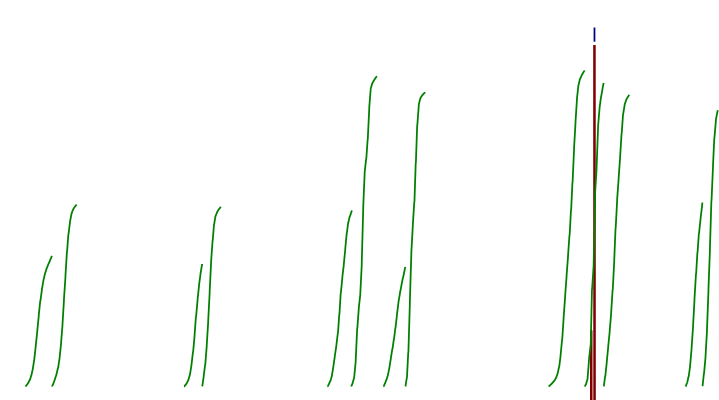

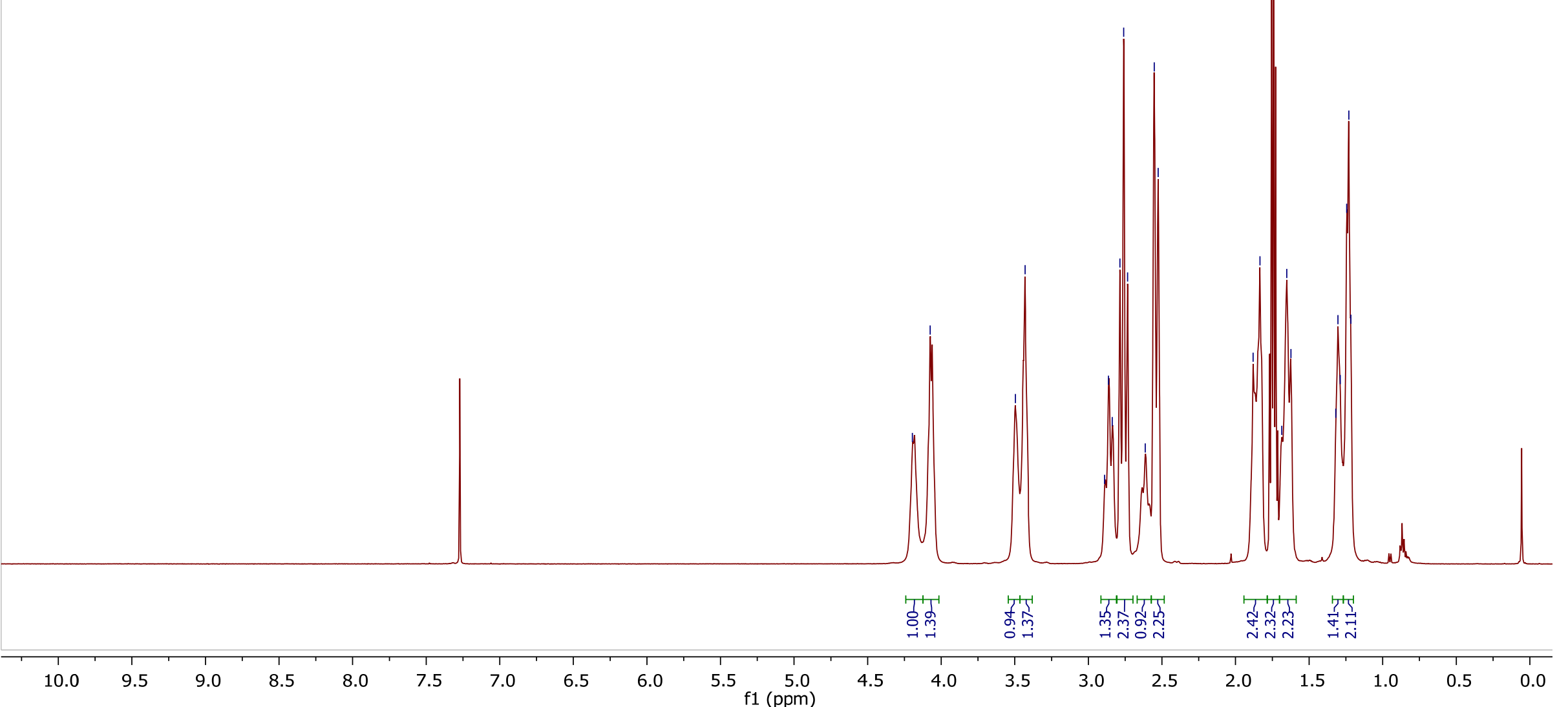


Figure S89. ${ }^{13} \mathrm{C}$ NMR spectrum of the compound $\mathbf{1 5 f}$.

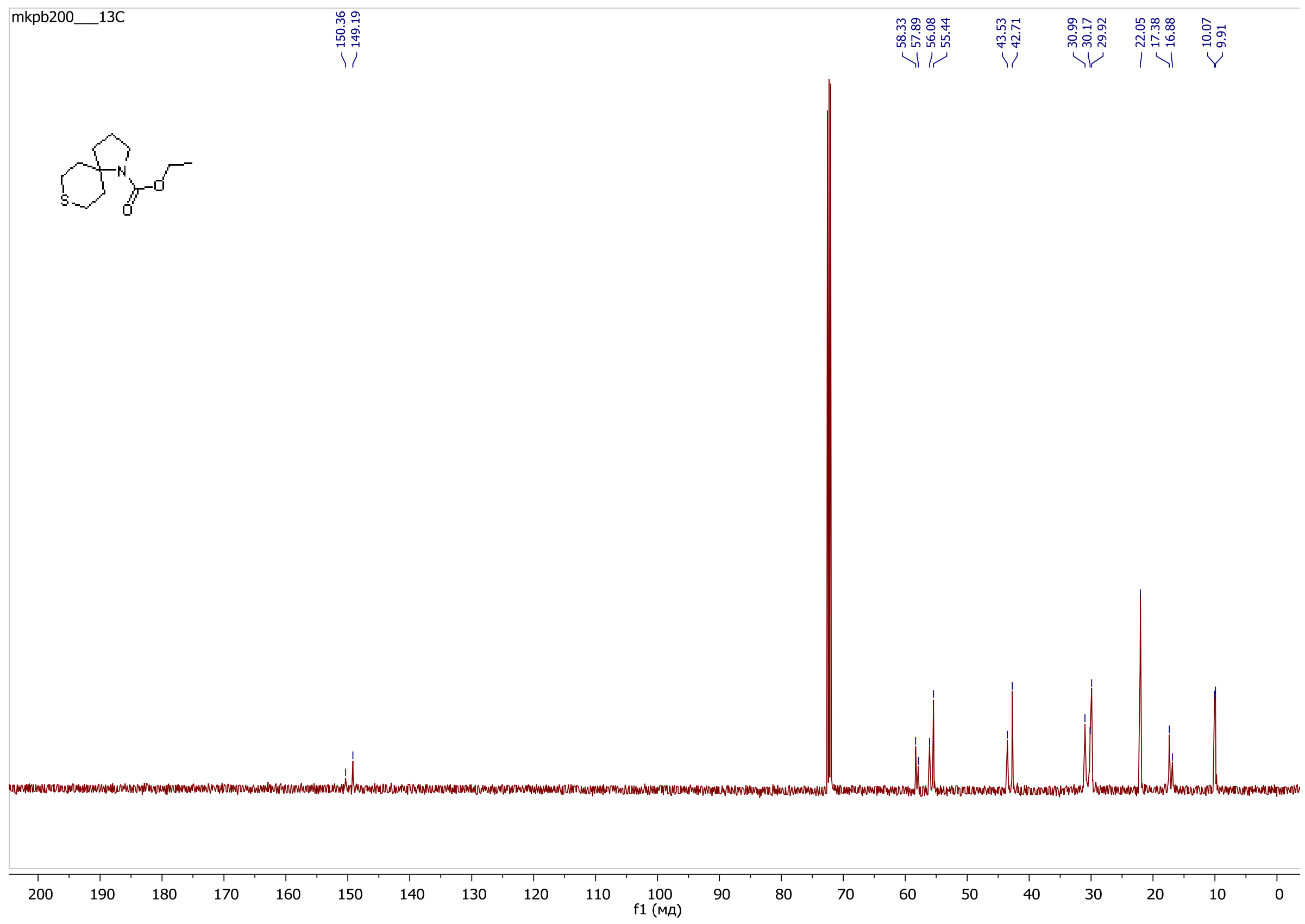


Figure S90. ${ }^{1} \mathrm{H}$ spectrum of the compound $\mathbf{1 f *} \mathbf{H C l}$.

$\vec{m}$

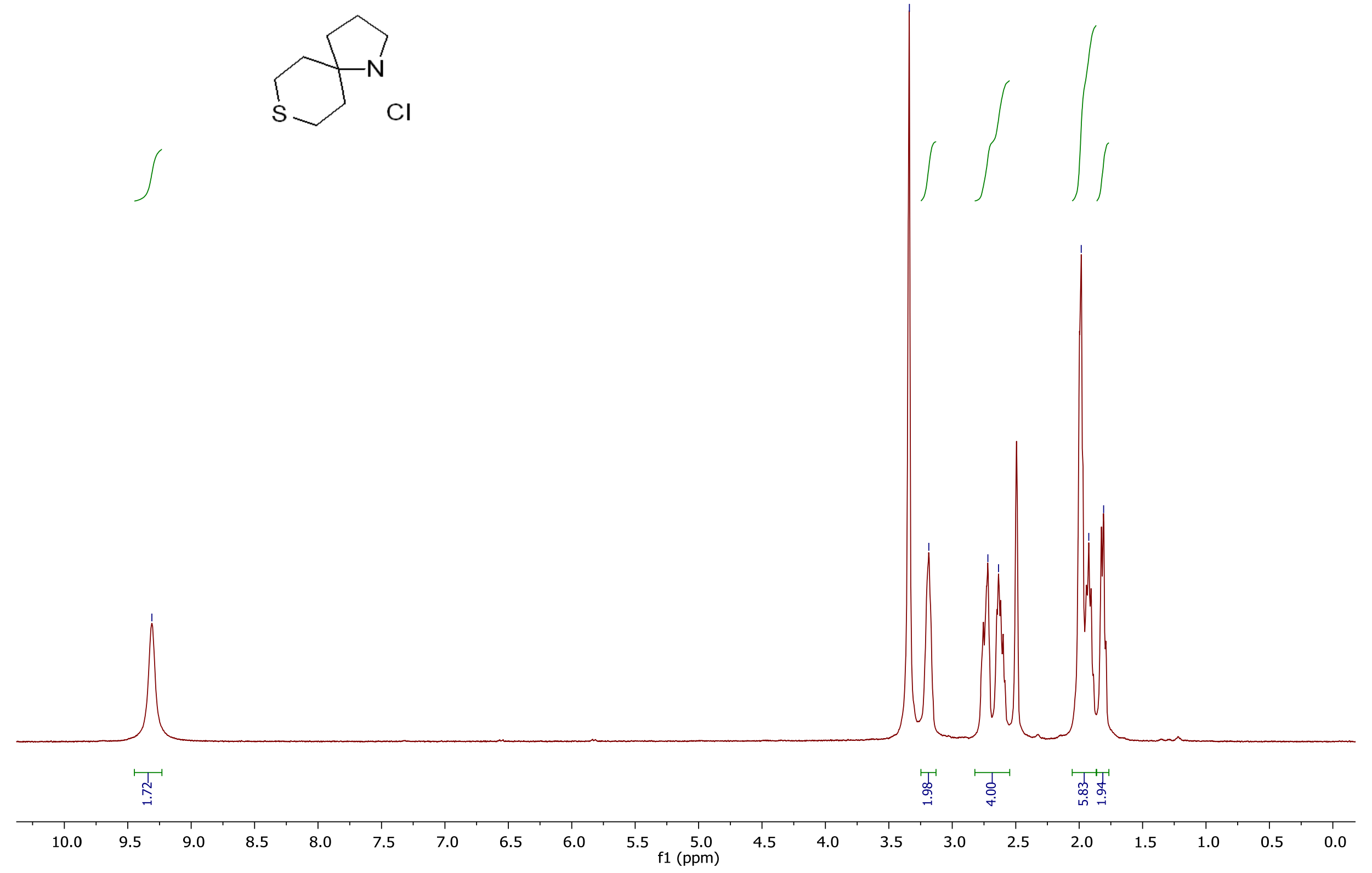

मे

W 
Figure S91. ${ }^{13} \mathrm{C}$ spectrum of the compound $\mathbf{1 f *} \mathbf{H C l}$.

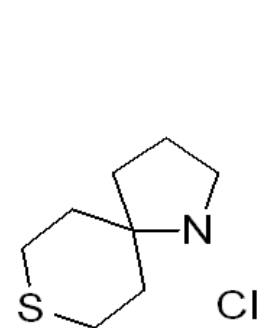

ar

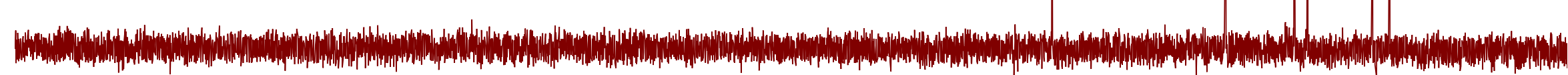


Figure S92. Mass spectrum of the compound 1f*HCl.

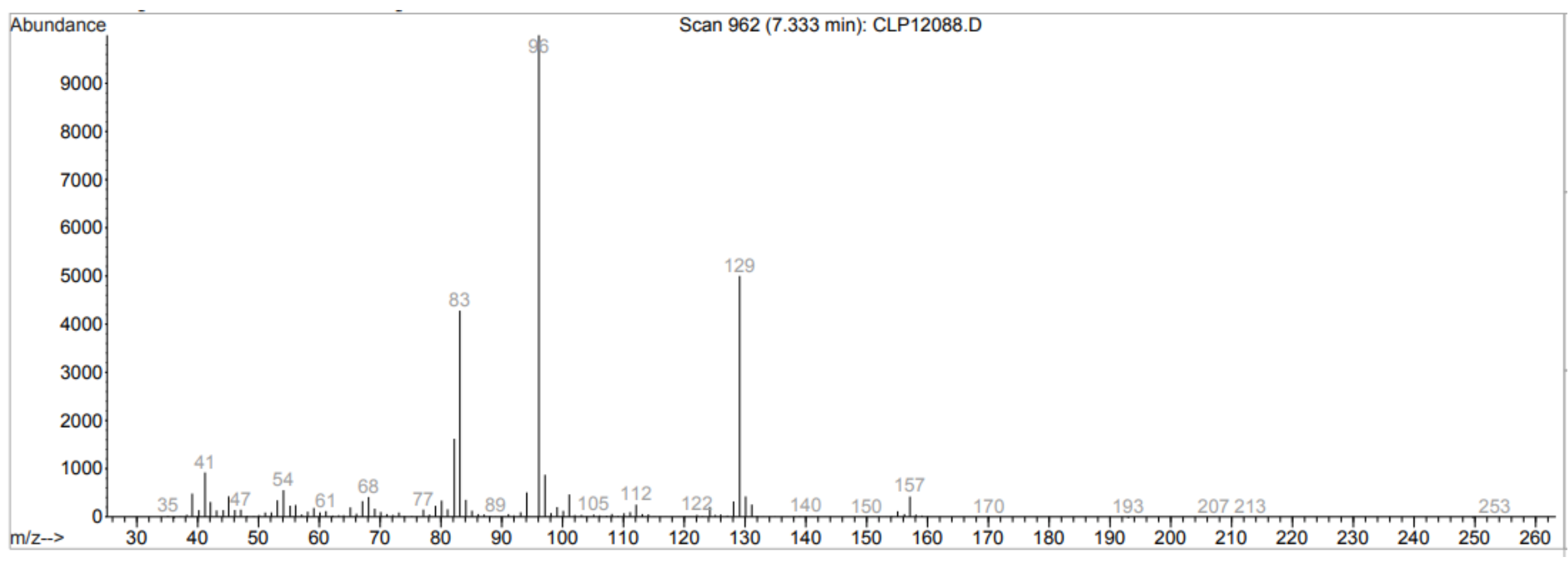


Synthesis of 8-thia-1-azaspiro[4.5]decane hydrochloride (1f*HCl). Approach III.

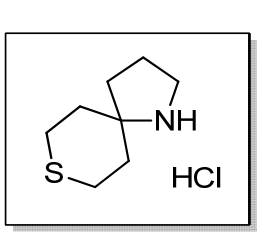

$1 f^{*} \mathrm{HCl}$

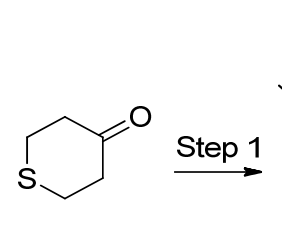

$2 \mathbf{f}$
$C_{S}^{\text {Step 2 }}$

$16 f$

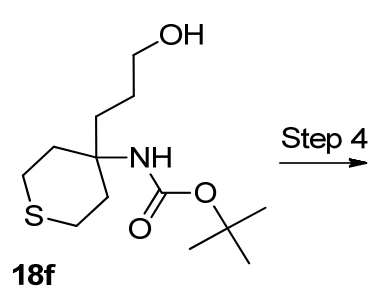

$18 f$

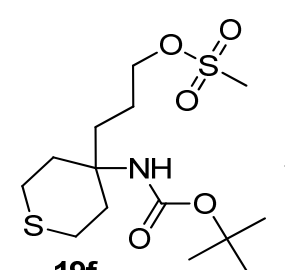

$19 f$

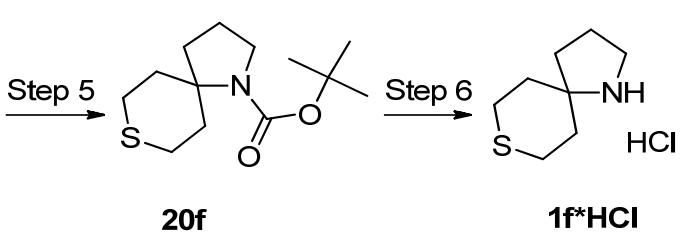

Scheme S10.

Figure S93. ${ }^{1} \mathrm{H}$ spectrum of the compound $\mathbf{1 6 f}$.
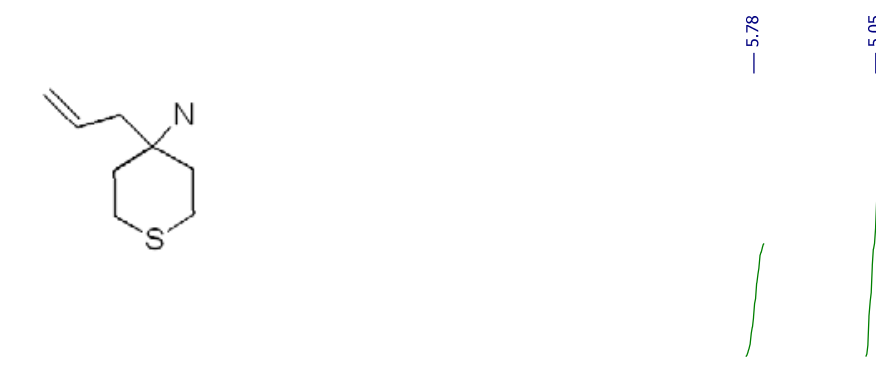

농

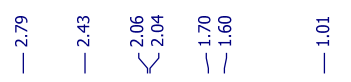
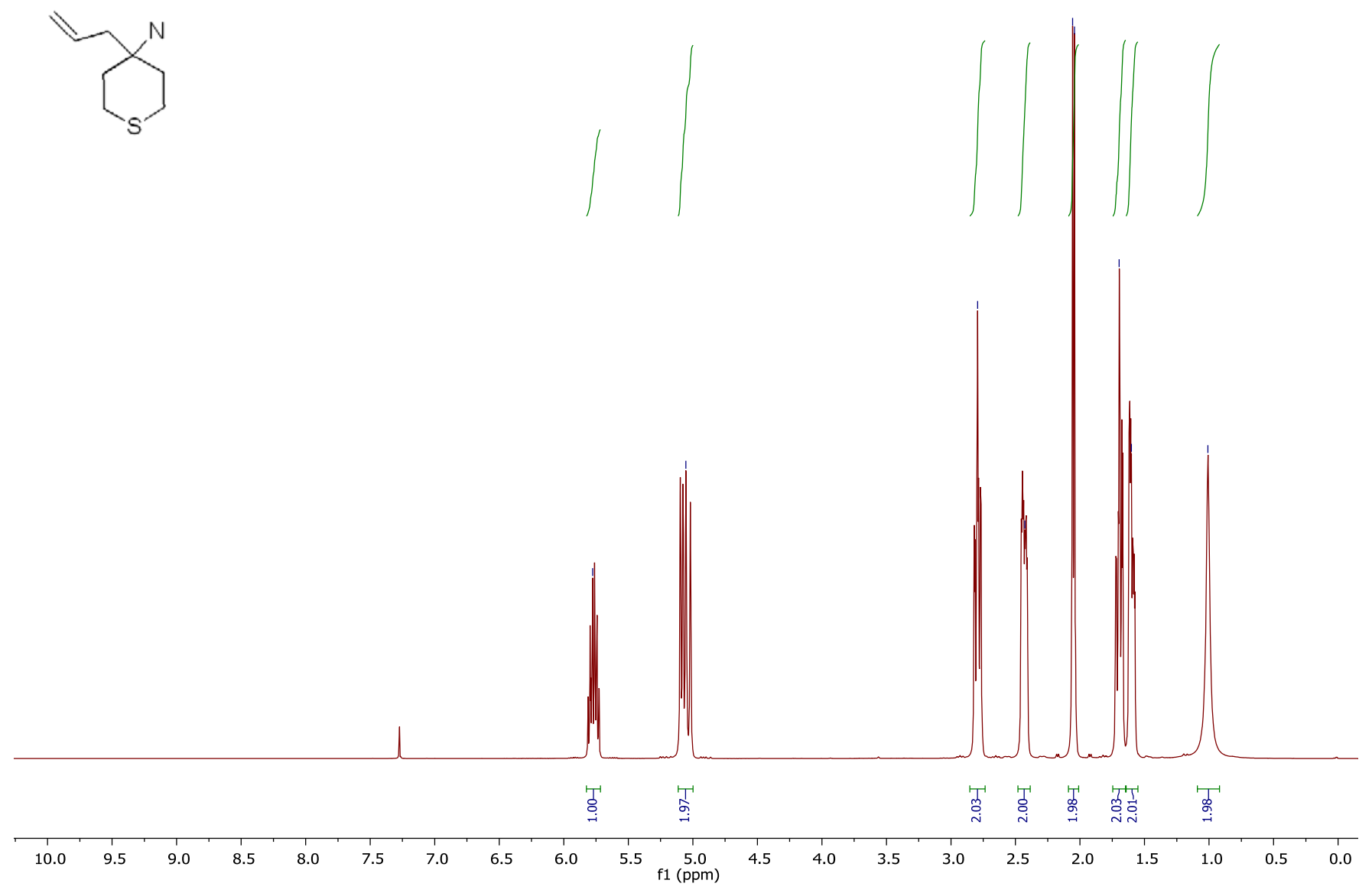
Figure S94. ${ }^{13} \mathrm{C}$ spectrum of the compound $\mathbf{1 6 f}$.
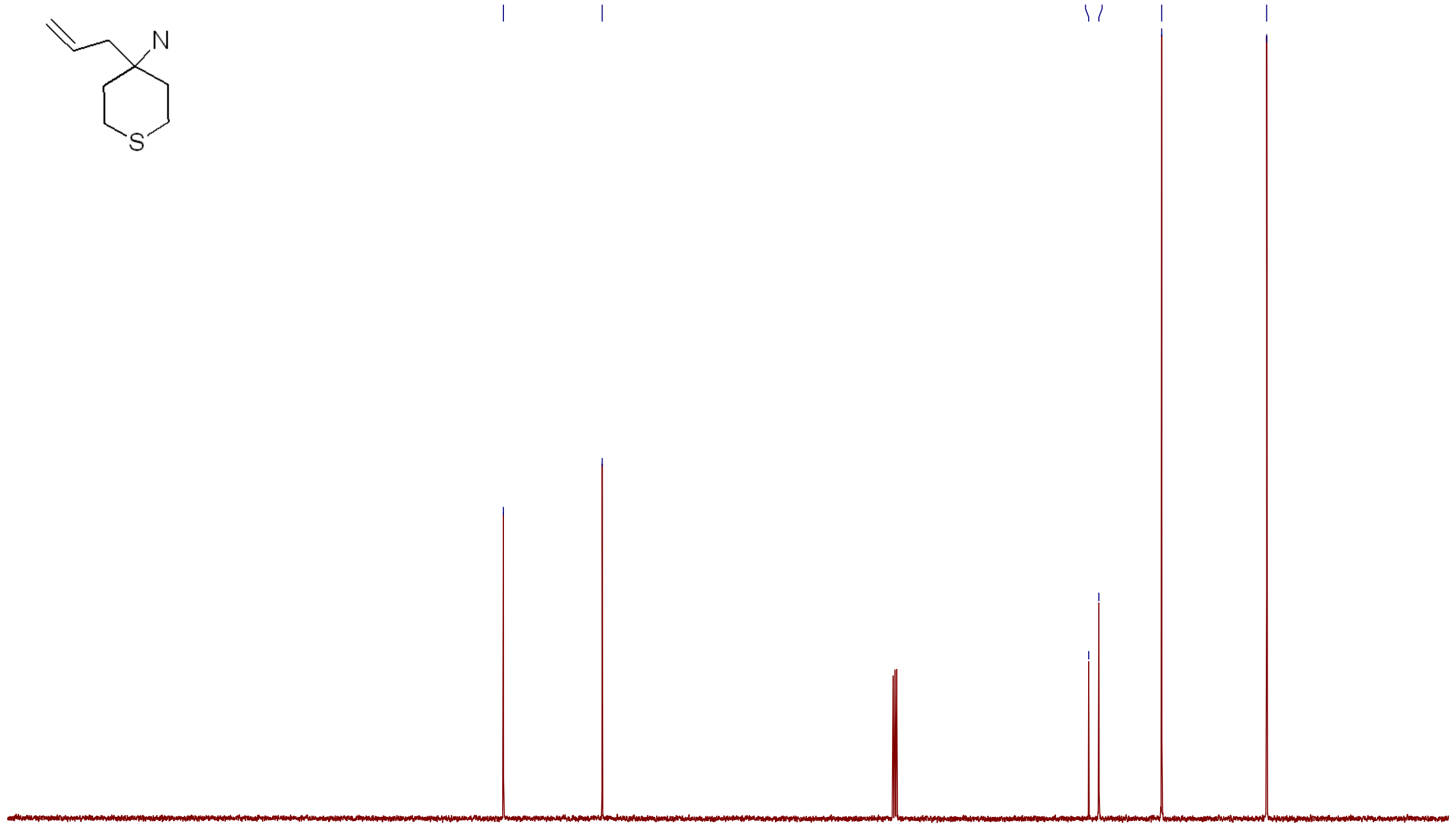
Figure S95. ${ }^{1} \mathrm{H}$ spectrum of the compound $\mathbf{1 7 f}$.

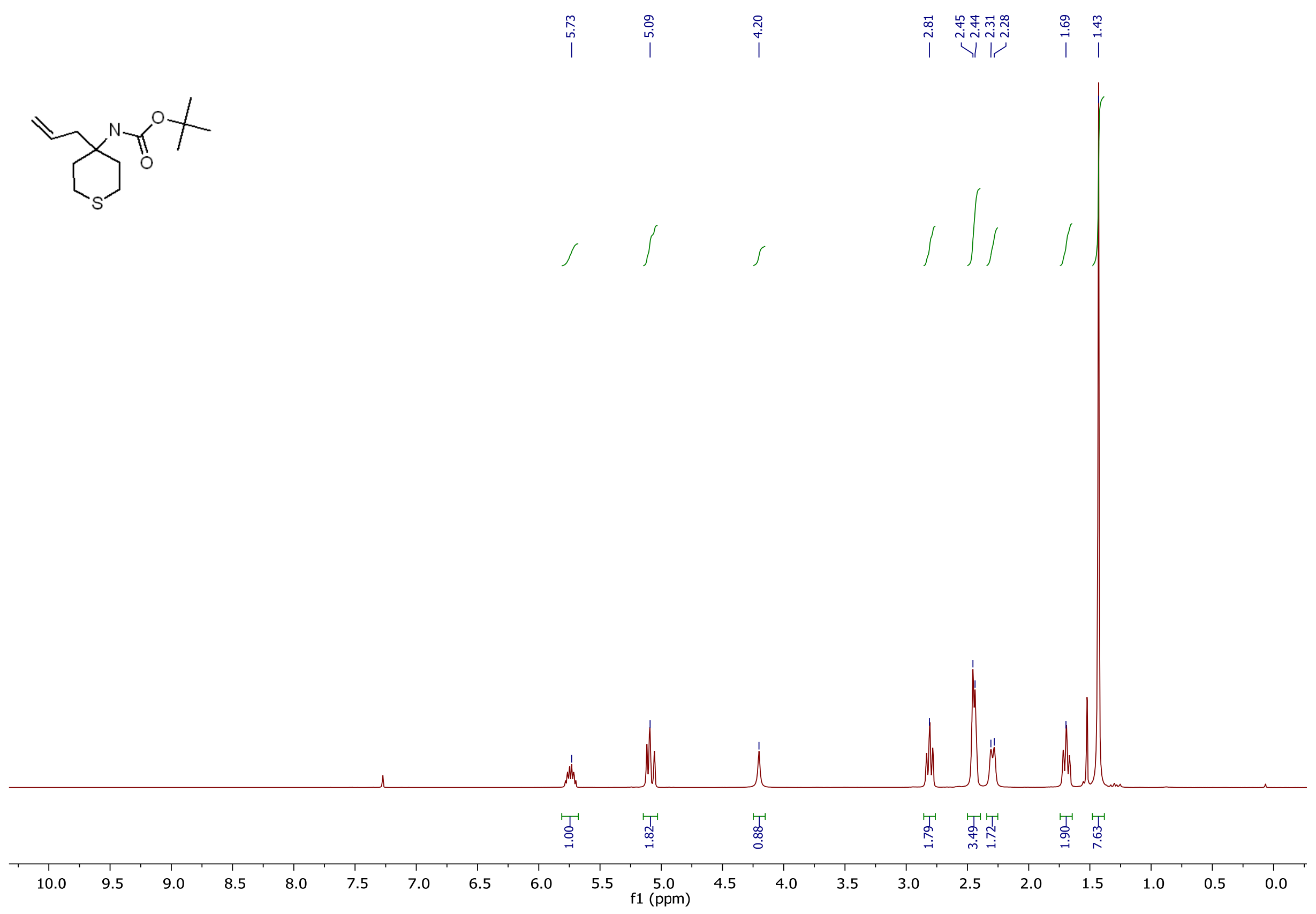


Figure S96. ${ }^{13} \mathrm{C}$ spectrum of the compound $\mathbf{1 7 f}$

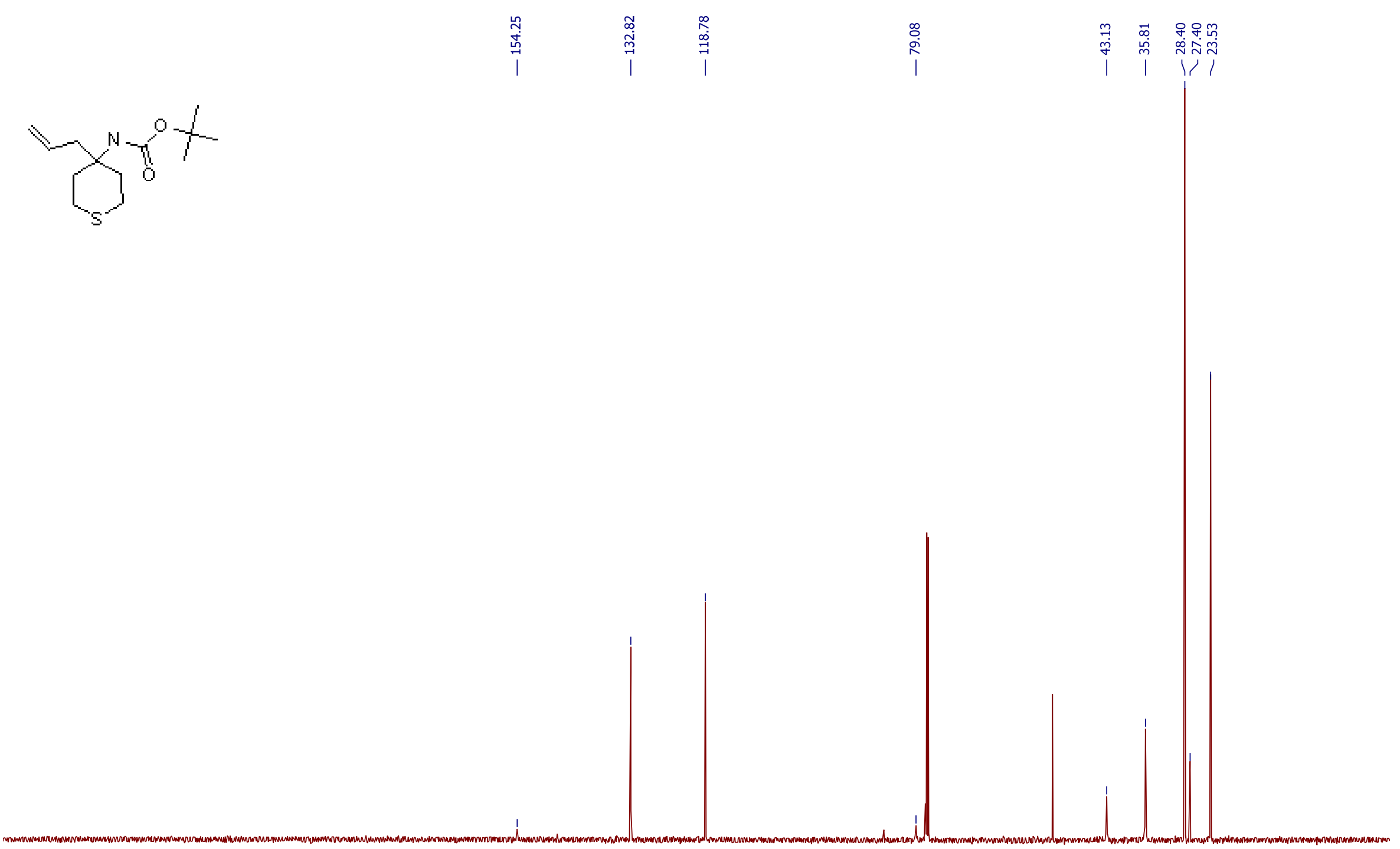

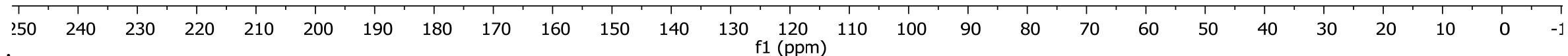


Figure S97. Mass spectrum of the compound $17 f$.

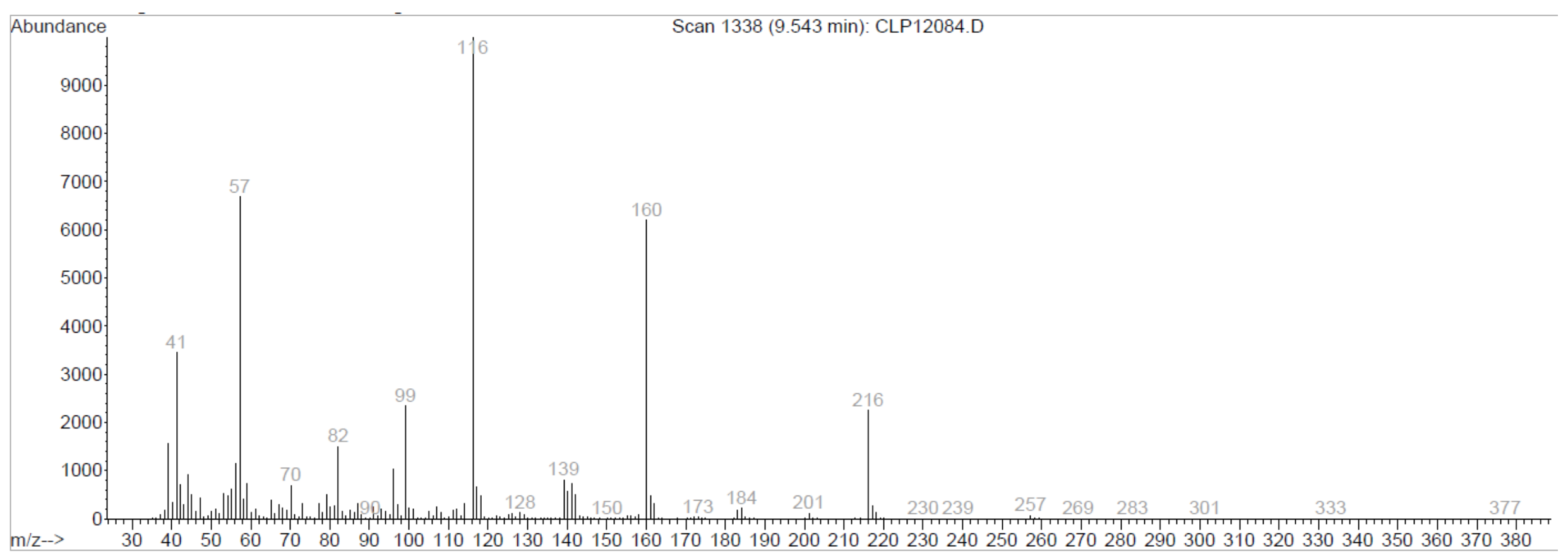


Figure S98. ${ }^{1} \mathrm{H}$ spectrum of the compound $\mathbf{1 8 f}$.

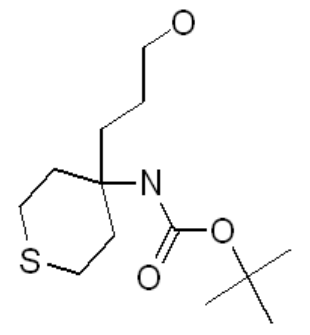

$$
\text { ஓ }
$$

๓ळळم

ปก)
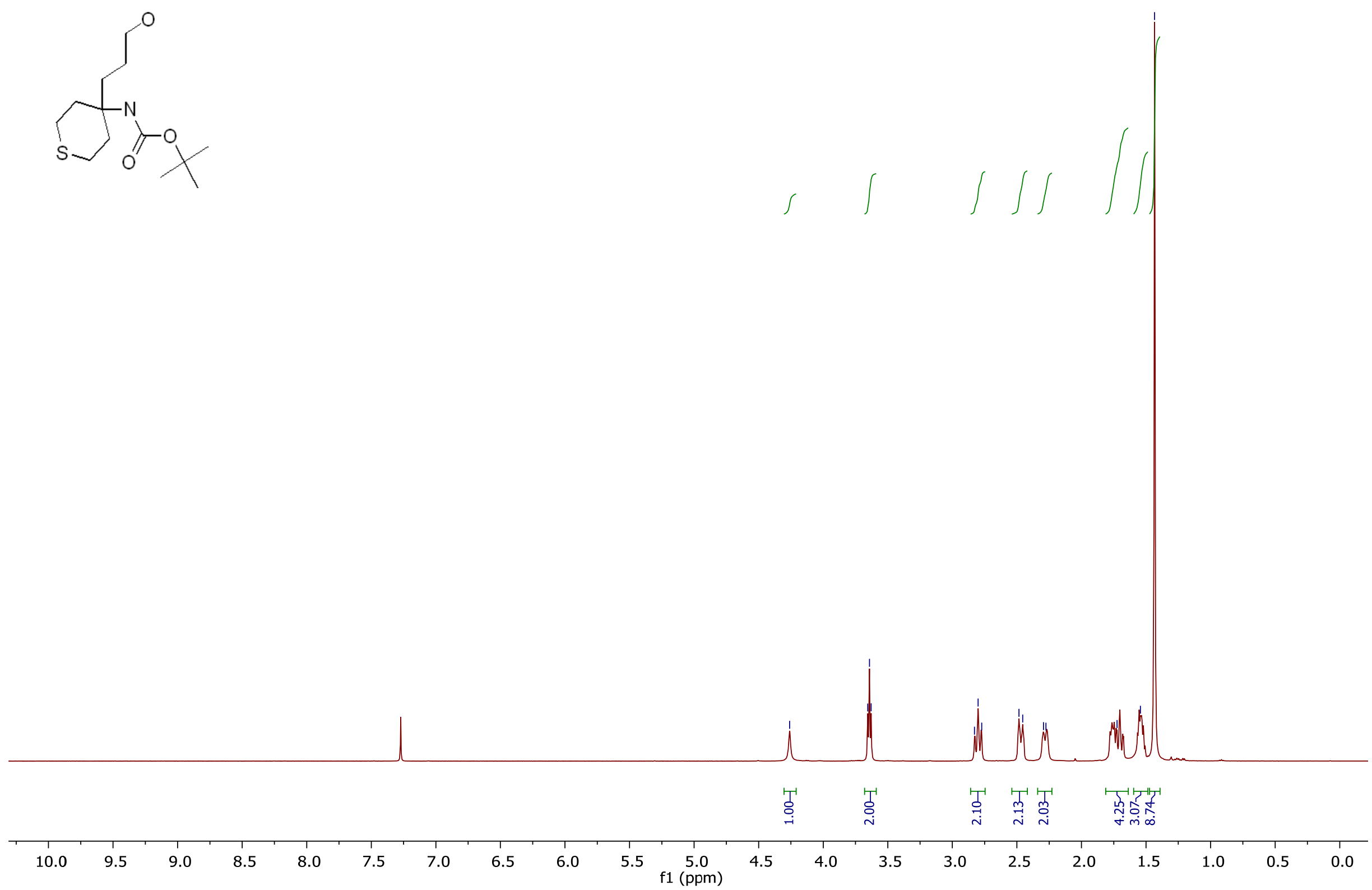
Figure S99. ${ }^{13} \mathrm{C}$ spectrum of the compound $\mathbf{1 8 f}$.

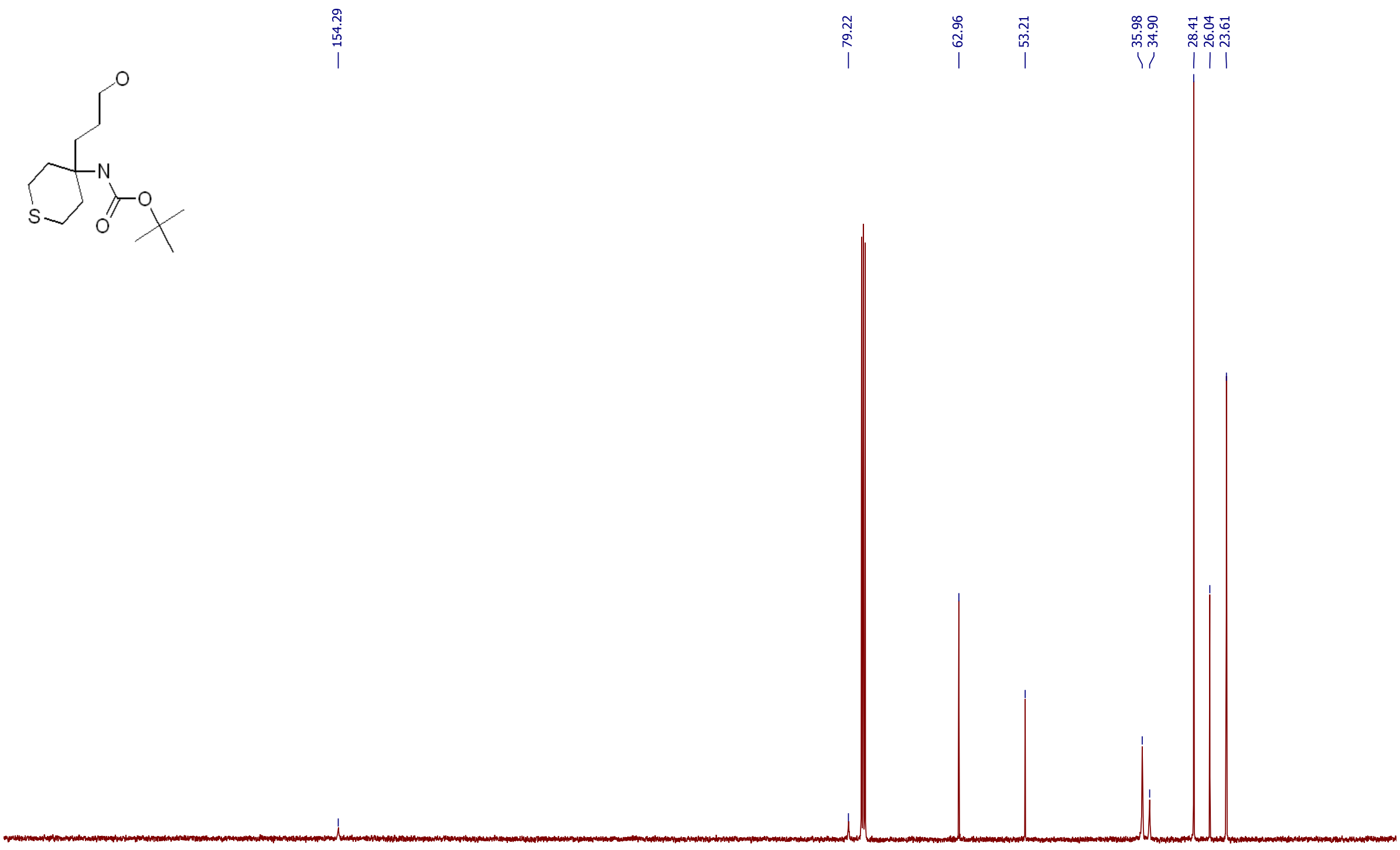

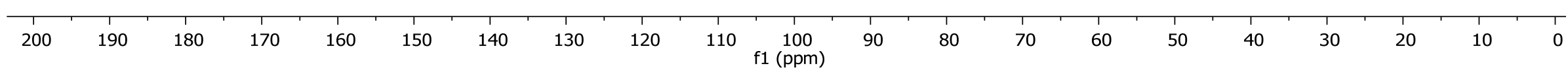


Figure S100. Mass spectrum of the compound 18f.

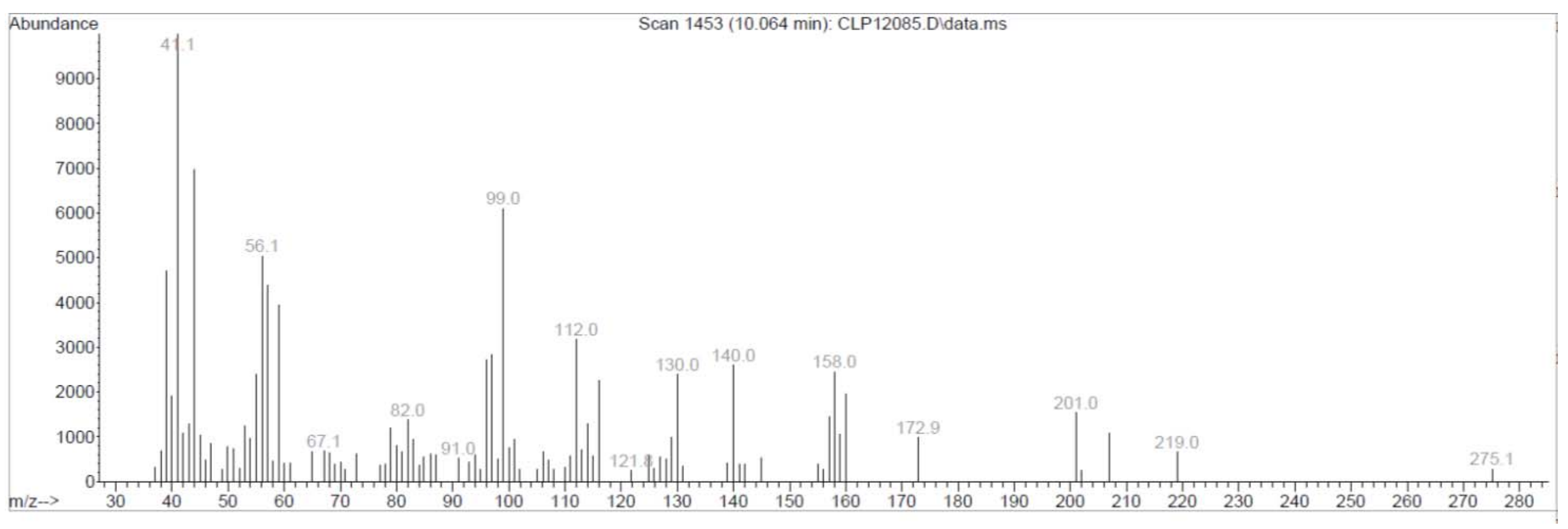


Figure S101. ${ }^{1} \mathrm{H}$ spectrum of the compound $19 f$.

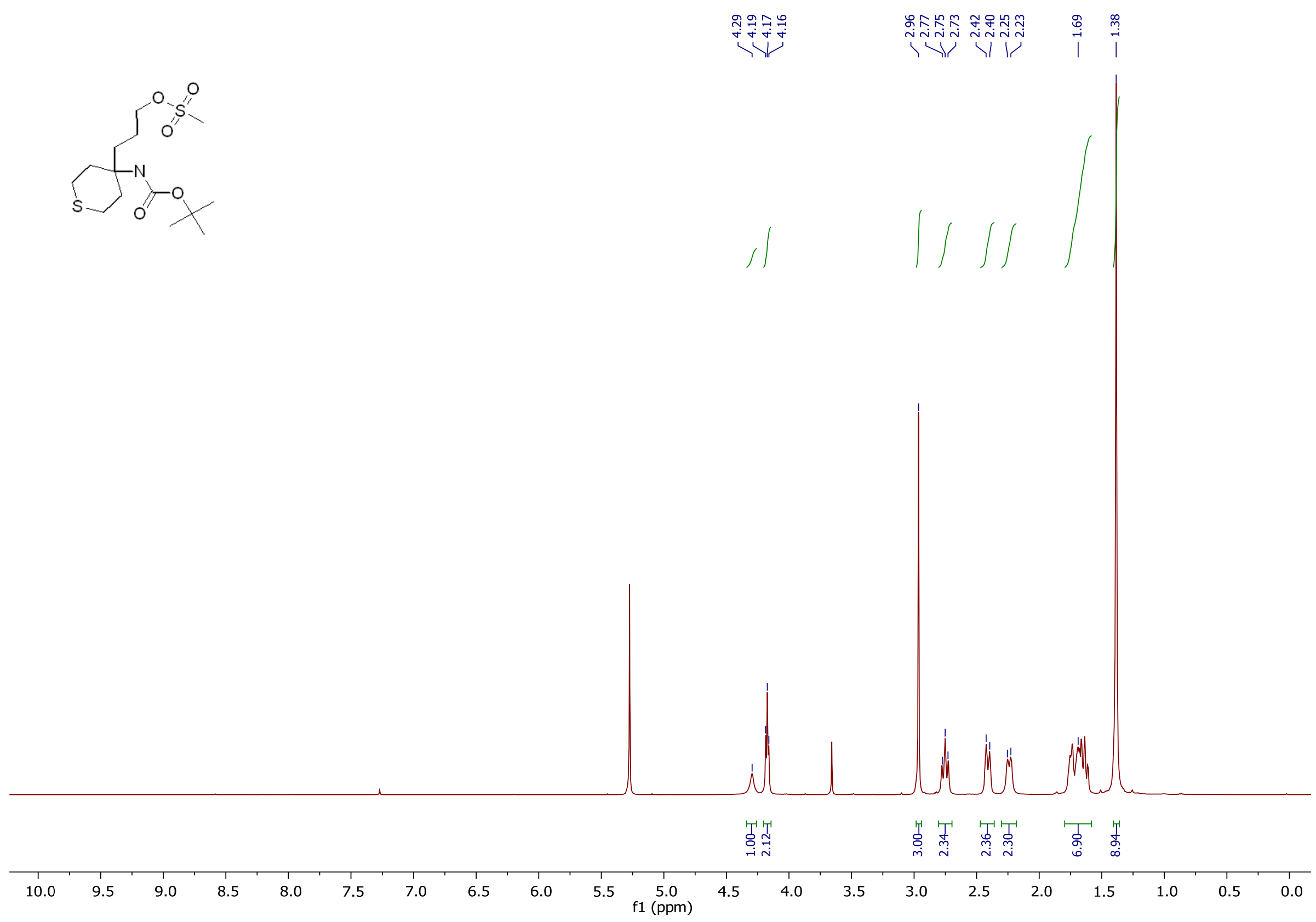


Figure S102. ${ }^{13} \mathrm{C}$ spectrum of the compound $\mathbf{1 9 f}$.

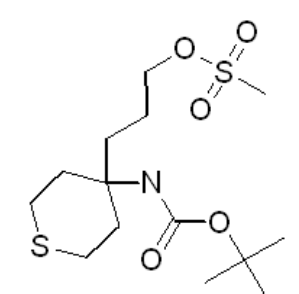

$$
\text { 梁 }
$$

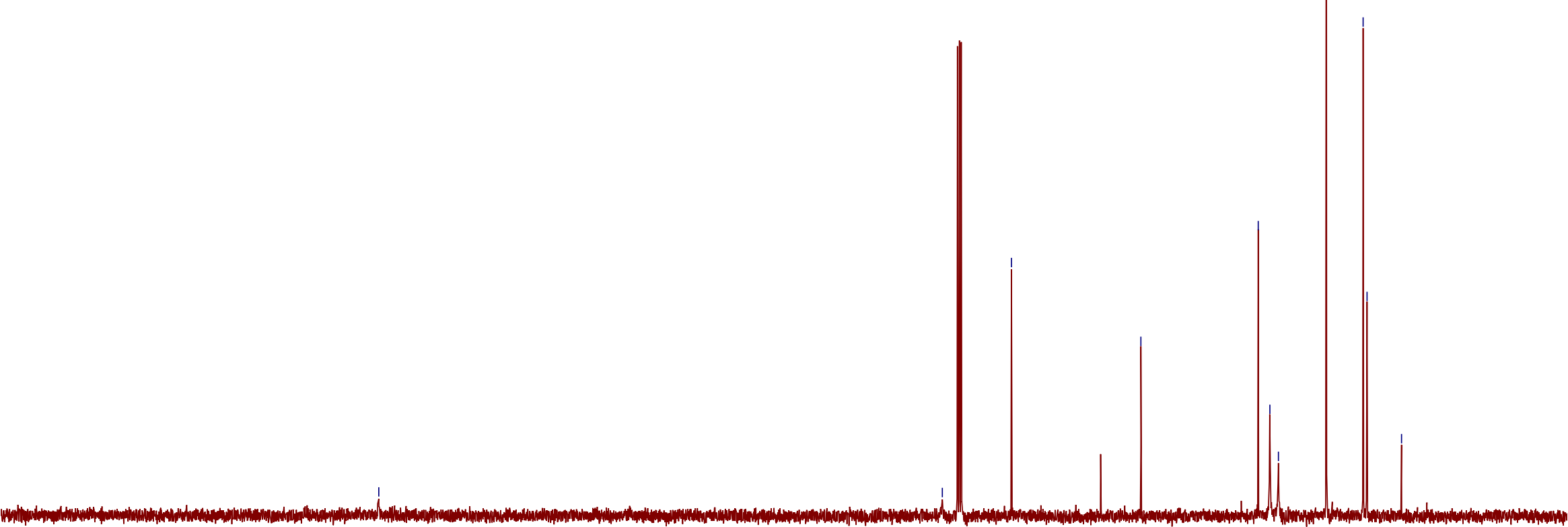


Figure S103. Mass spectrum of the compound 19f.

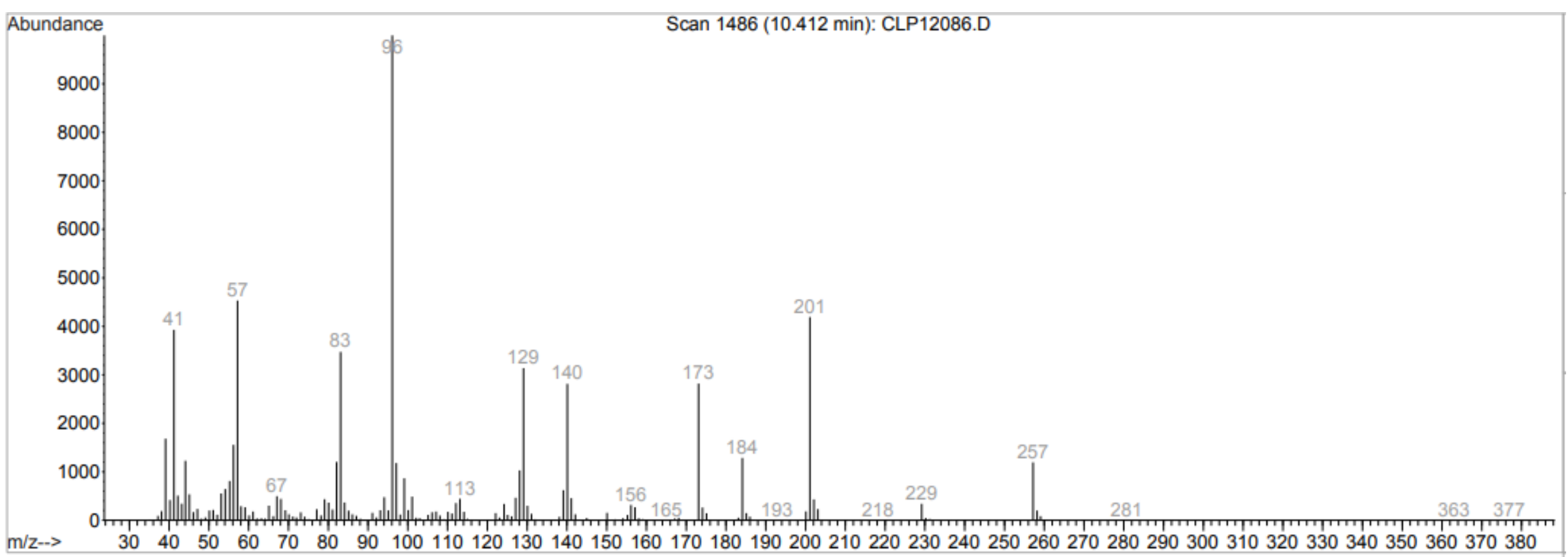


Figure S104. ${ }^{1} \mathrm{H}$ spectrum of the compound $20 f$.

䑻
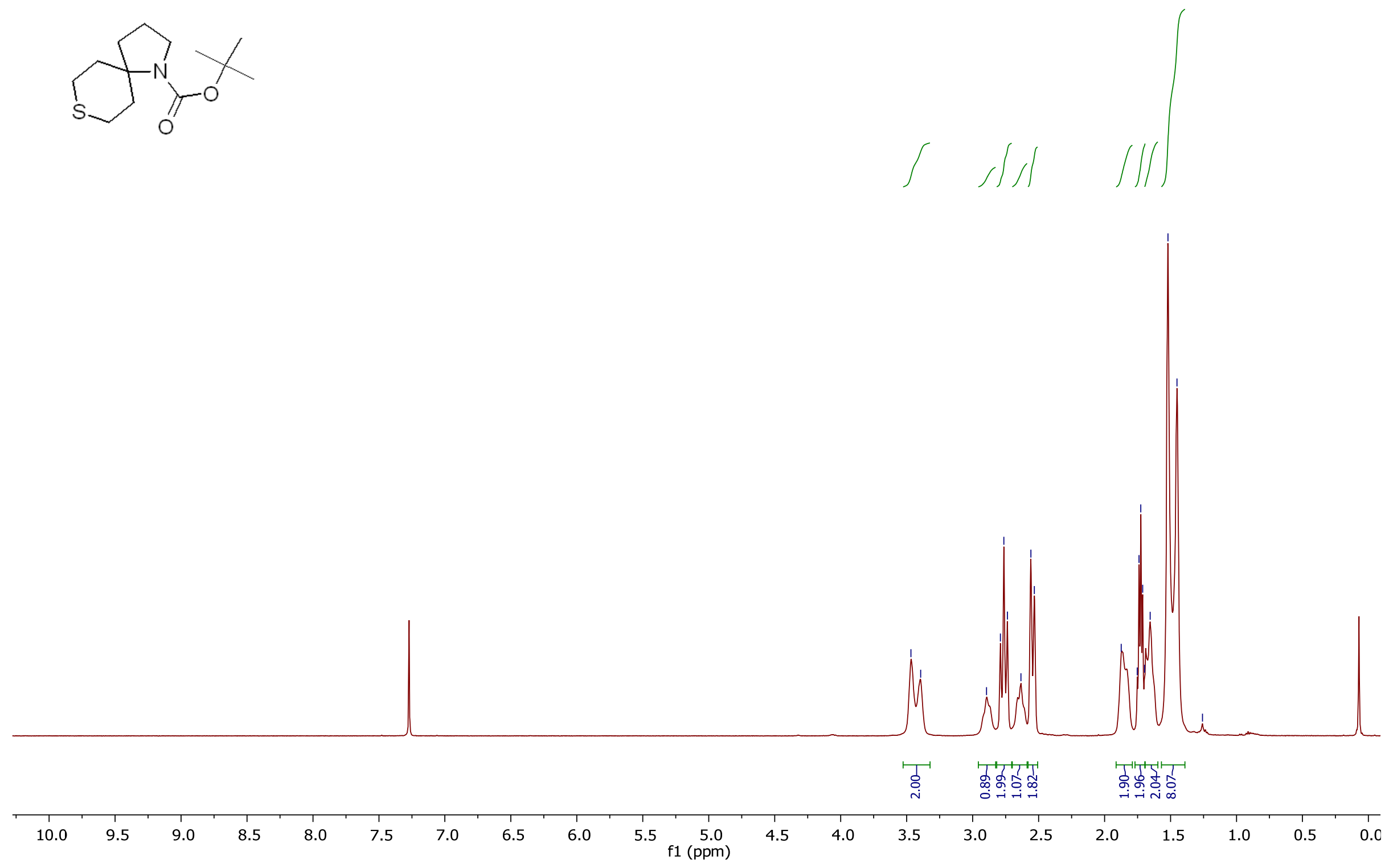
Figure S105. ${ }^{13} \mathrm{C}$ spectrum of the compound $20 \mathrm{f}$.

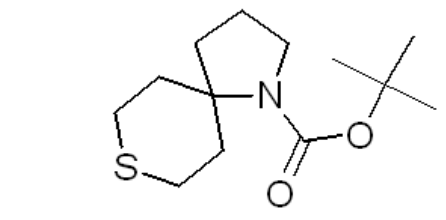

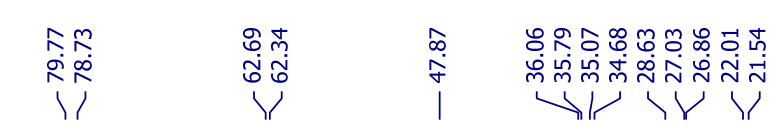
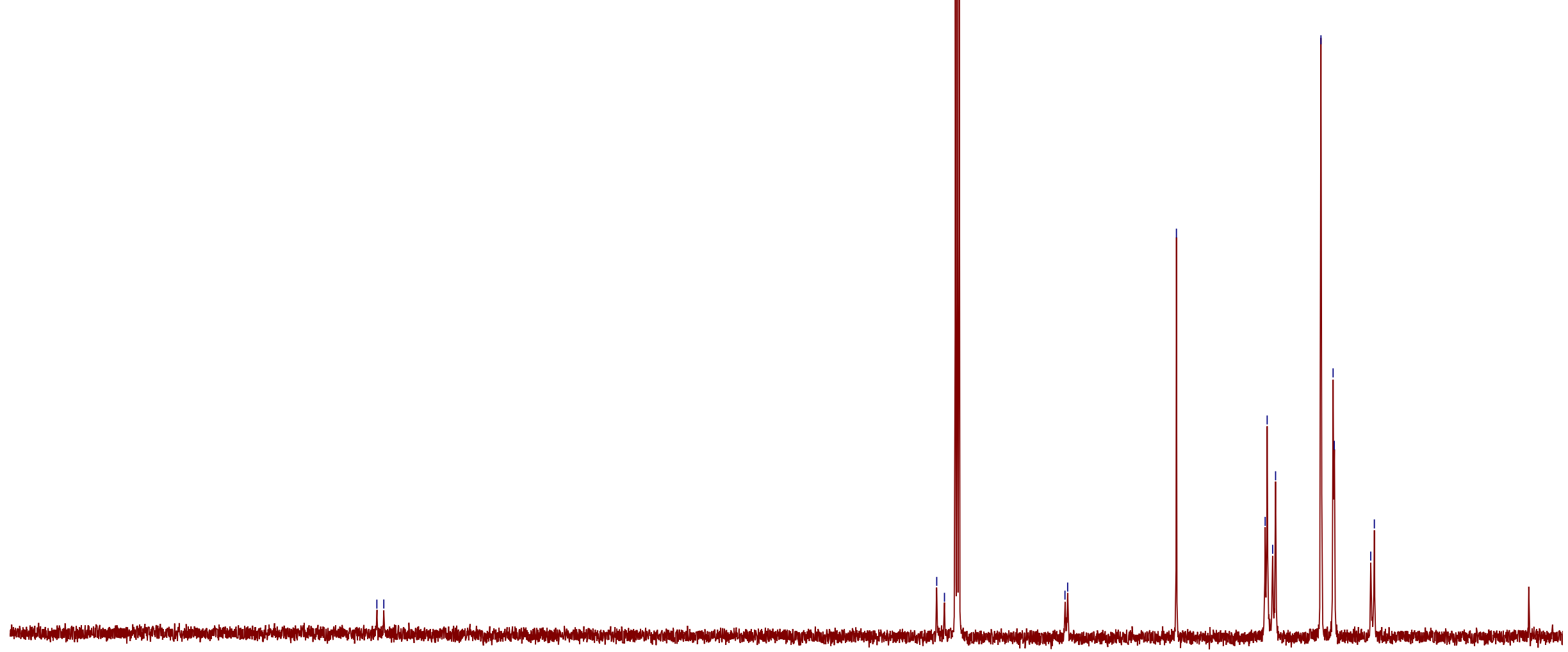
Figure S106. Mass spectrum of the compound 20f.

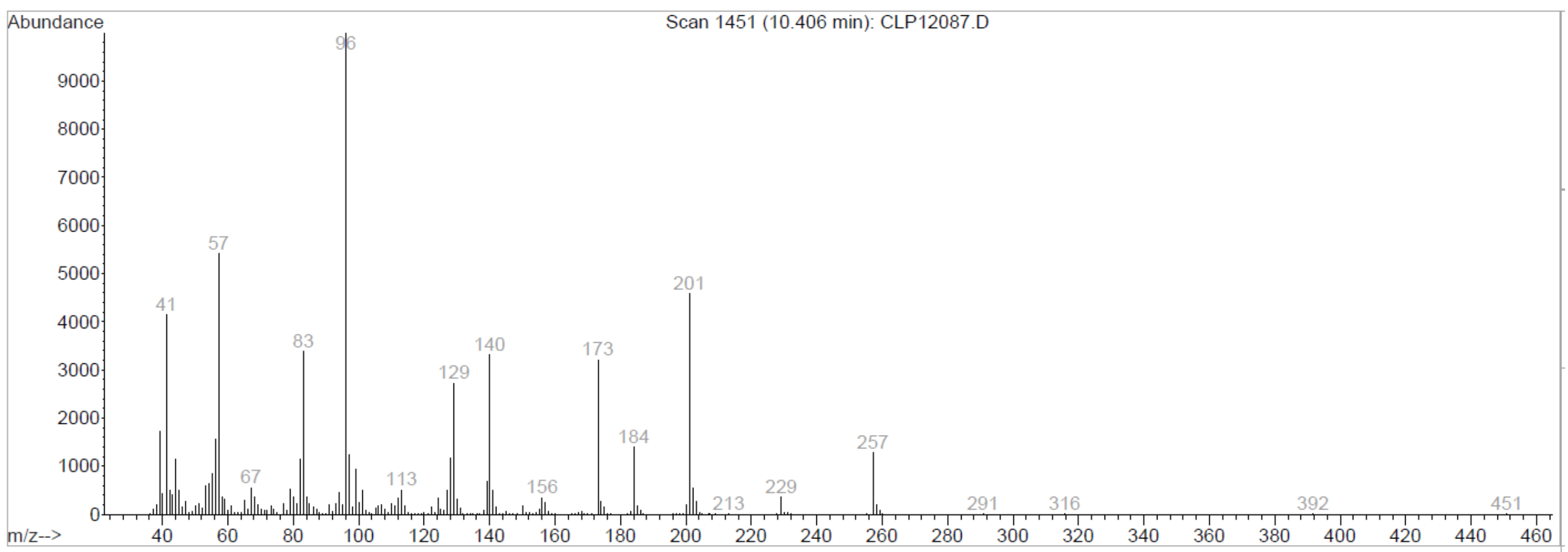


Synthesis of 8-thia-1-azaspiro[4.5]decane 8,8-dioxide hydrochloride (1g*HCl). Approach I.

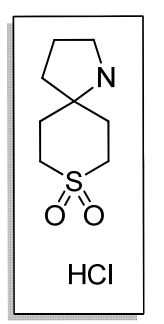

$1 g^{*} \mathrm{HCl}$

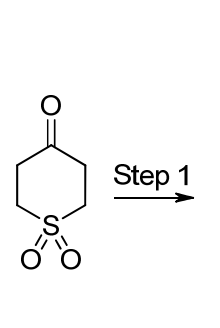

$2 \mathrm{~g}$

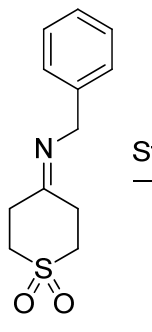

$3 \mathrm{~g}$

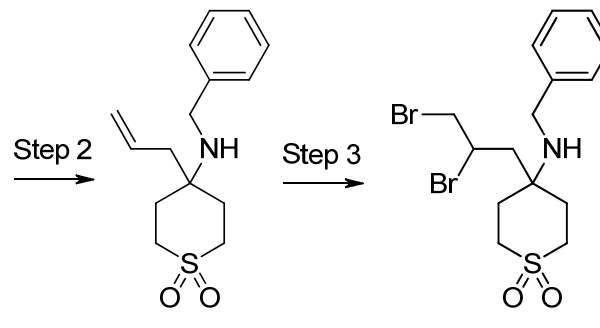

$4 \mathrm{~g}$

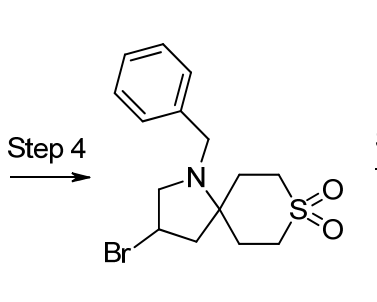

$6 \mathrm{~g}$

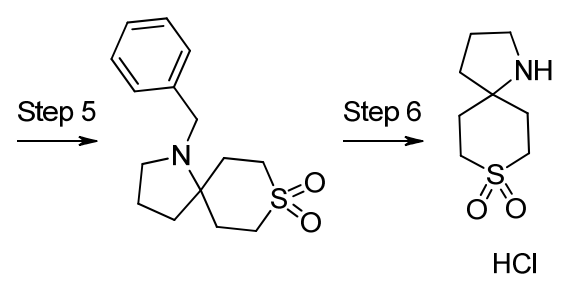

$7 g$

$1 \mathrm{~g}^{*} \mathrm{HCl}$

Scheme S11.

Figure S107. ${ }^{1} \mathrm{H}$ NMR spectrum of the compound $\mathbf{4 g}$.

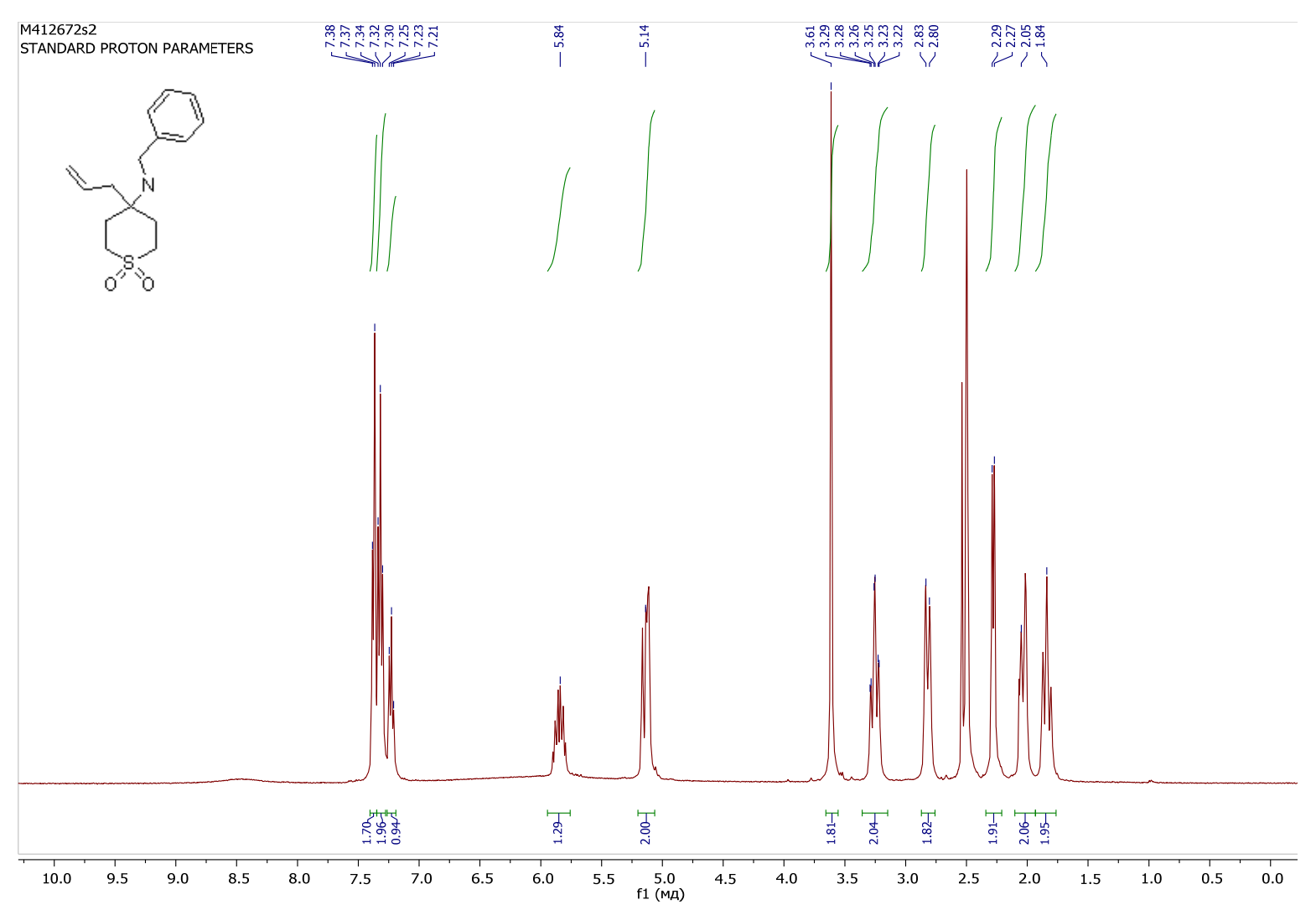


Figure S108. ${ }^{13} \mathrm{C}$ NMR spectrum of the compound $\mathbf{4 g}$.

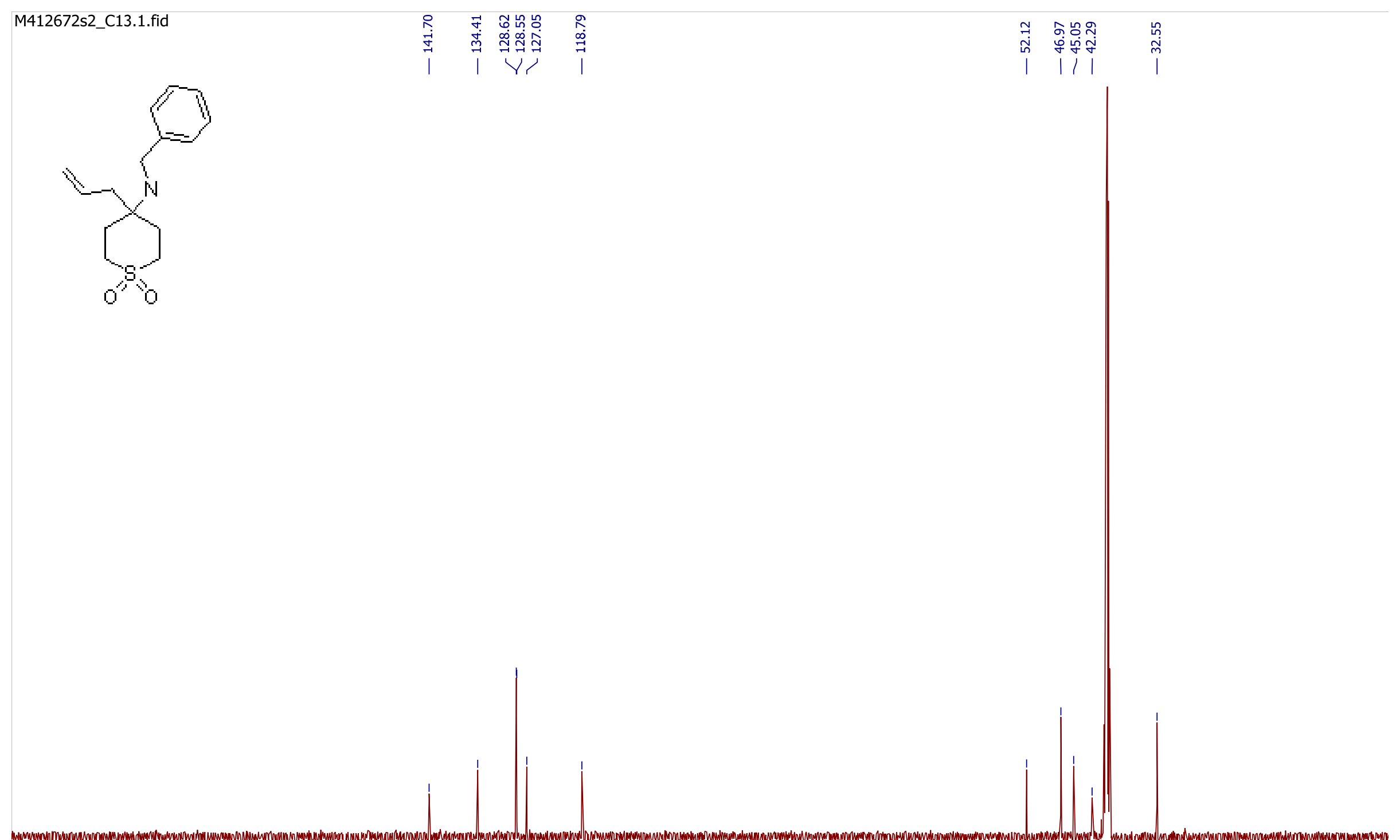

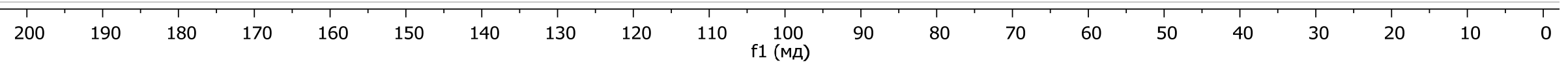


Figure S109. ${ }^{1} \mathrm{H}$ NMR spectrum of the compound $\mathbf{6 g}$.

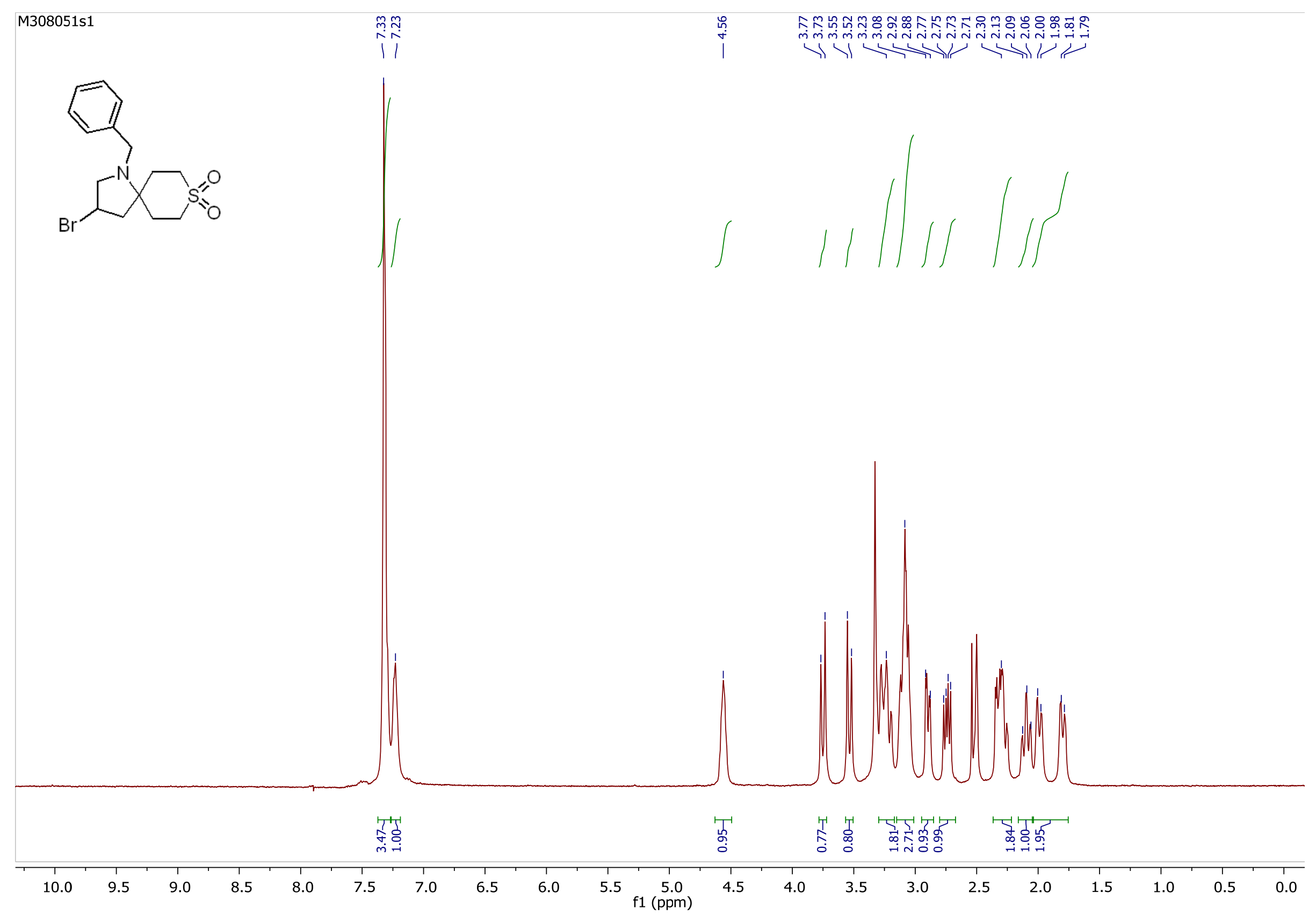


M308051s1 C13.1 fid

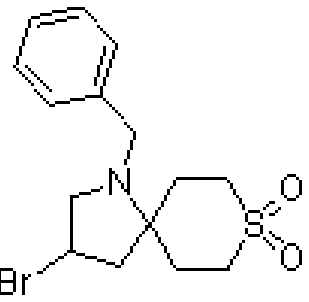

Figure S110. ${ }^{13} \mathrm{C}$ NMR spectrum of the compound $\mathbf{6 g}$.

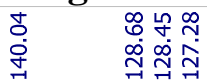

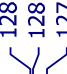

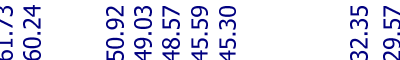

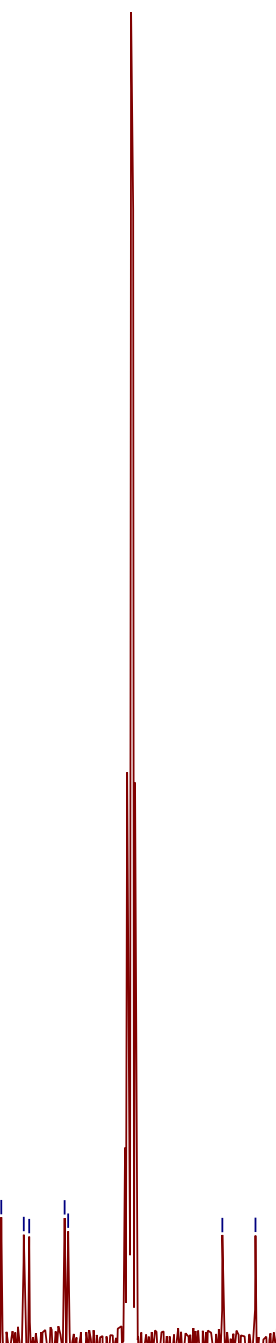

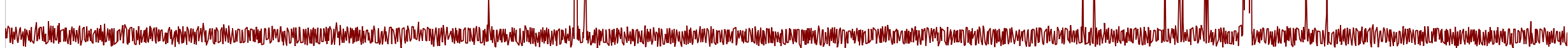

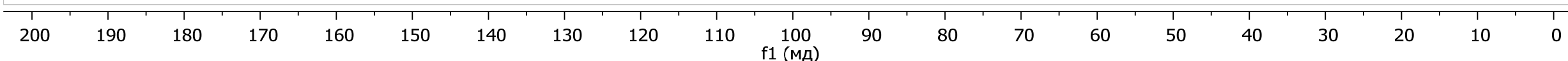


Figure S111. Mass spectrum of of the compound $\mathbf{6 g}$.

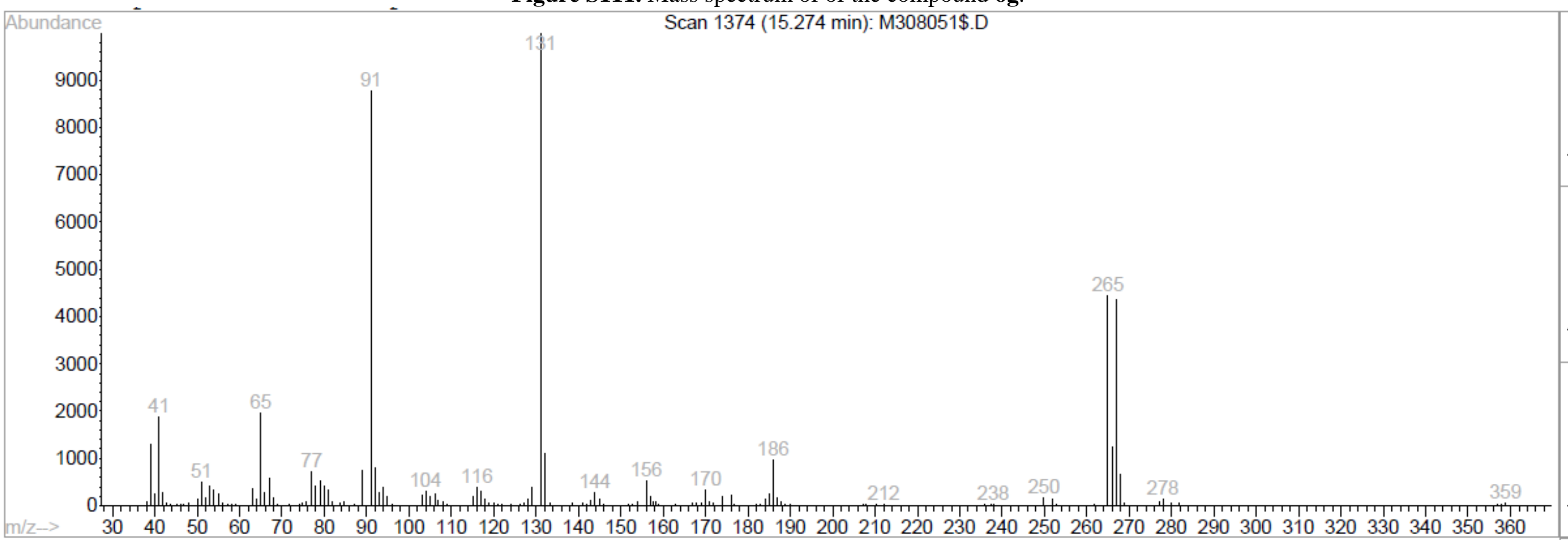


M588354s1

STANDARD PROTON PARAMETERS

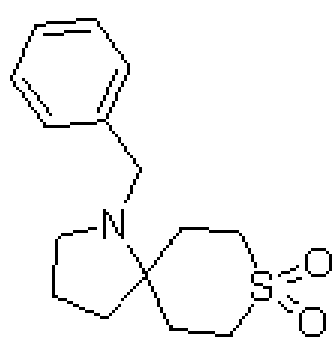

Figure S112. ${ }^{1} \mathrm{H}$ NMR spectrum of the compound $\mathbf{7 g}$. $\stackrel{\infty}{i} \underset{i}{i}$

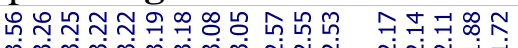

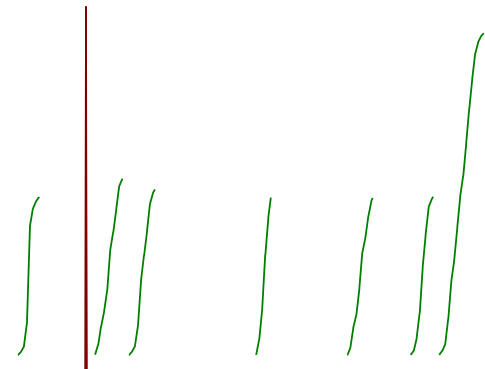

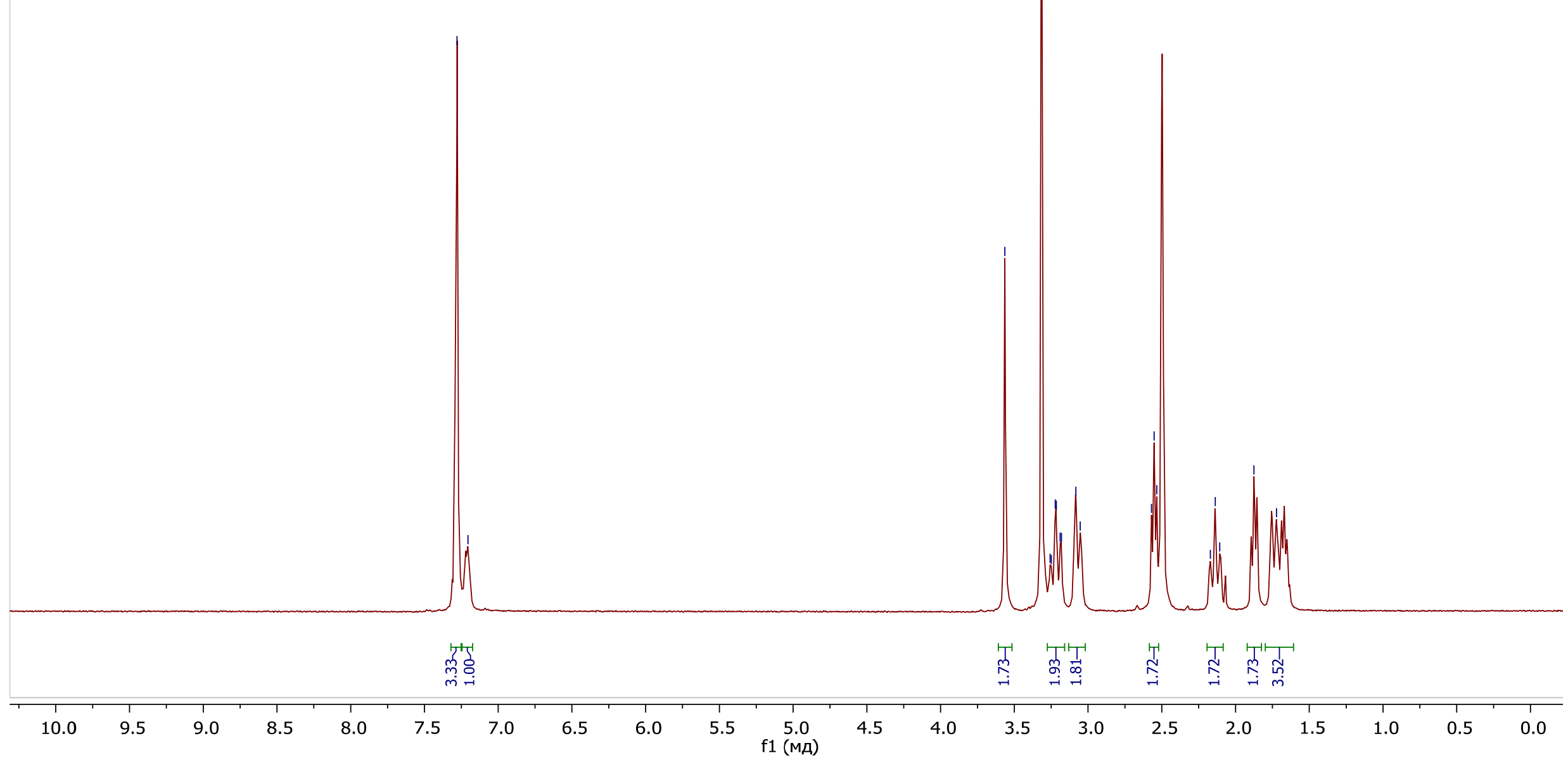


Figure S113. ${ }^{13} \mathrm{C}$ NMR spectrum of the compound $\mathbf{7 g}$.

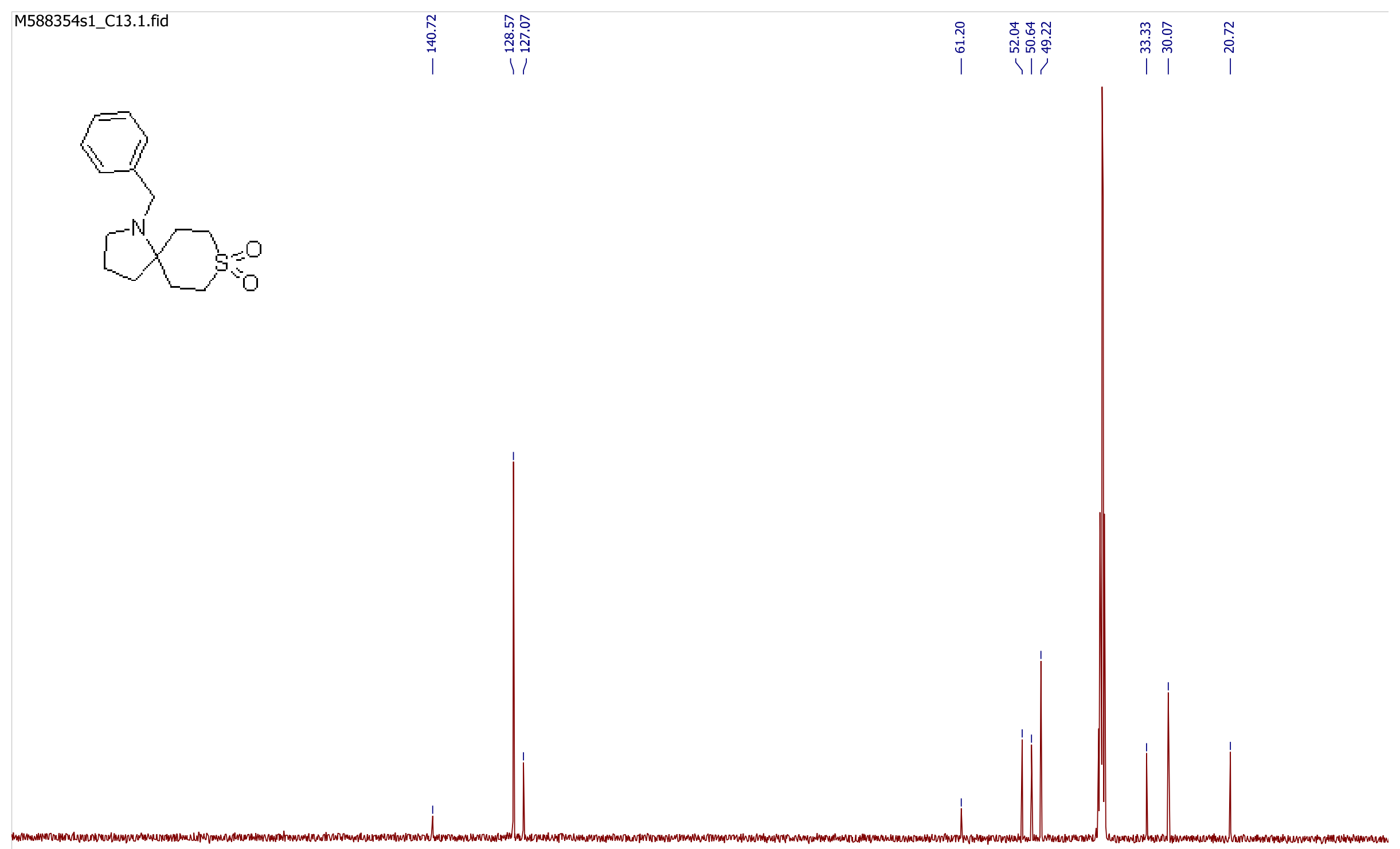

\begin{tabular}{|c|c|c|c|c|c|c|c|c|c|c|c|c|c|c|c|c|c|c|c|c|}
\hline 200 & $\begin{array}{c}1 \\
190\end{array}$ & $\begin{array}{c}1 \\
180\end{array}$ & 170 & $\begin{array}{c}1 \\
160\end{array}$ & $\begin{array}{c}1 \\
150\end{array}$ & 140 & 130 & $\begin{array}{c}1 \\
120\end{array}$ & 110 & 100 & 90 & 80 & 70 & 60 & 50 & 40 & 30 & 20 & 10 & $\begin{array}{l}1 \\
0\end{array}$ \\
\hline 200 & 190 & 180 & 170 & 100 & 150 & 140 & 130 & $1 \angle 0$ & 110 & f1 (Mд) & 90 & 80 & 10 & 00 & 50 & 40 & 30 & 20 & 10 & 0 \\
\hline
\end{tabular}


Figure S114. ${ }^{1} \mathrm{H}$ NMR spectrum of the compound $\mathbf{1}{ }^{*} \mathbf{H C l}$.

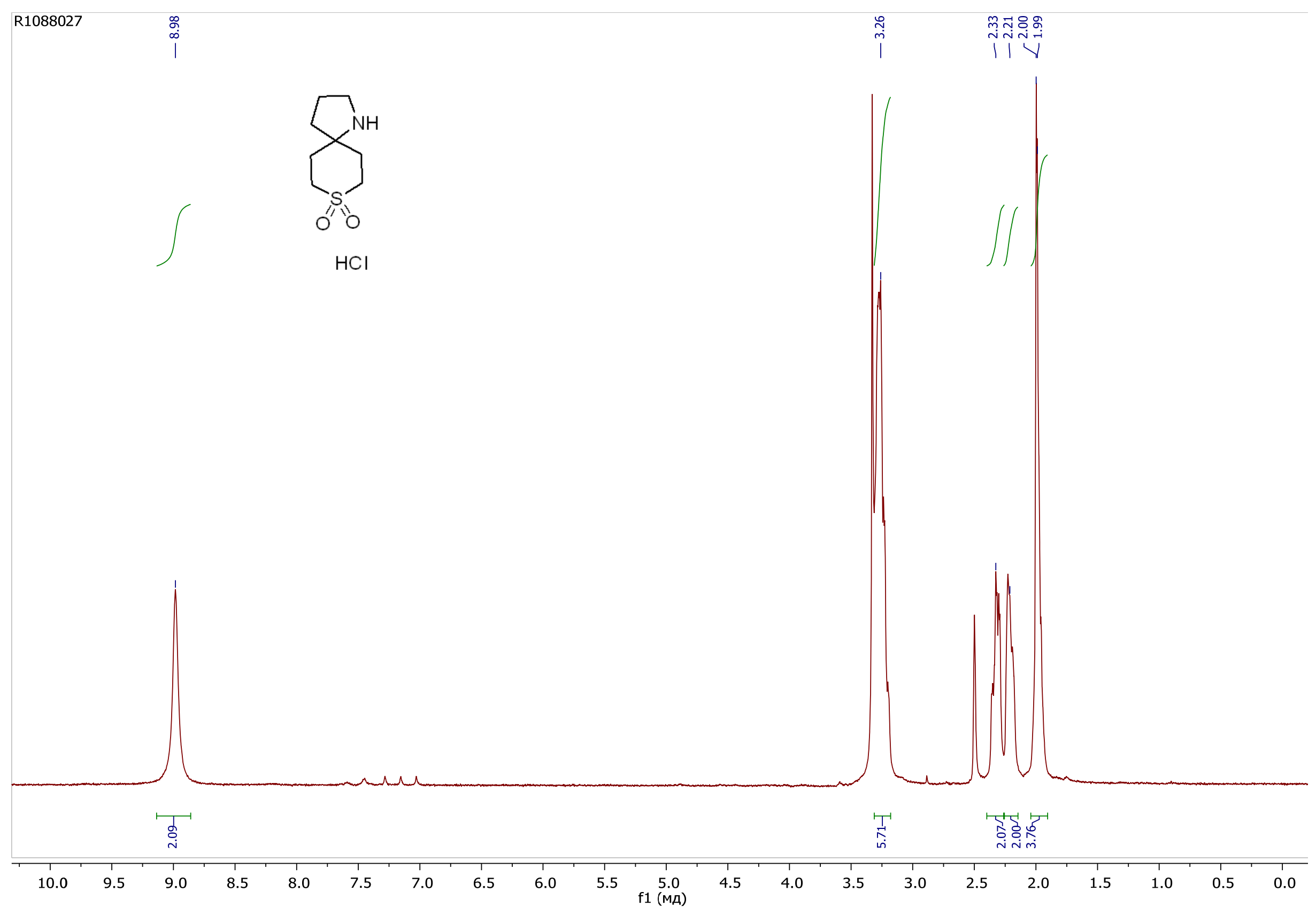


Figure S115. ${ }^{13} \mathrm{C}$ NMR spectrum of the compound $1 \mathbf{g} * \mathbf{H C l}$.

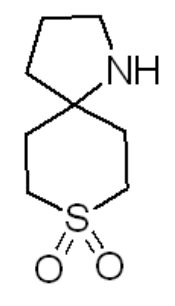

$\mathrm{HCl}$

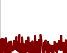

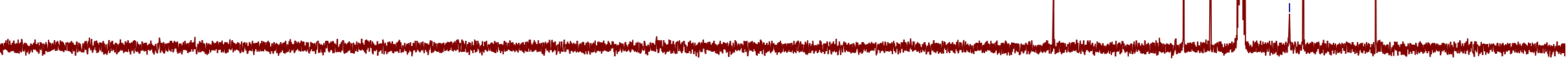

\begin{tabular}{|c|c|c|c|c|c|c|c|c|c|c|c|c|c|c|c|c|c|c|c|}
\hline 1 & 1 & 100 & 1 & 1 & 1 & 1 & 1 & 11 & 11 & 1 & 1 & 1 & & & 7 & & 13 & & 10 \\
\hline 200 & 190 & 180 & 170 & 160 & 150 & 140 & 130 & 120 & 110 & $\begin{array}{c}100 \\
\mathrm{f} 1(\mathrm{MA})\end{array}$ & 90 & 80 & 70 & 60 & 50 & 40 & 30 & 20 & 10 \\
\hline
\end{tabular}


Synthesis of 1-azaspiro[4.6]undecane hydrochloride (1h*HCl). Approach I.

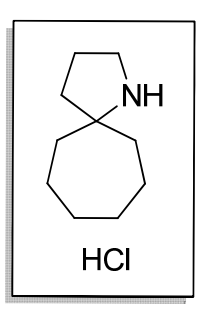

$1 \mathrm{~h}^{*} \mathrm{HCl}$

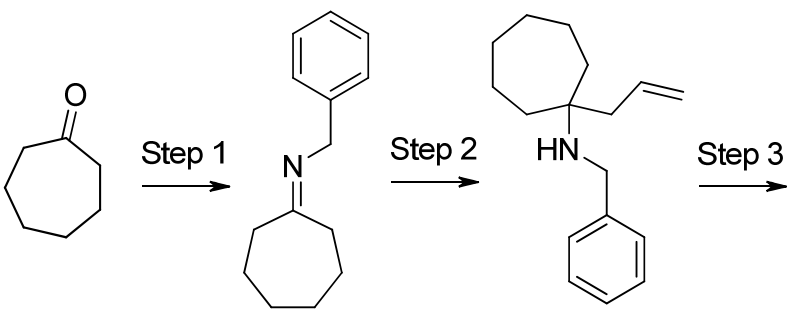

3h

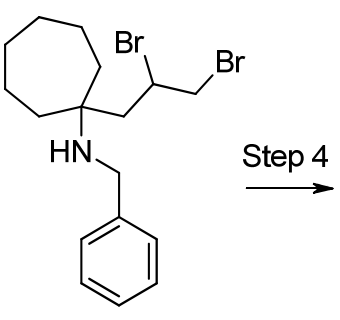

$5 \mathrm{~h}$

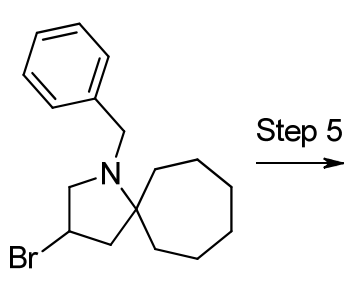

$6 \mathrm{~h}$

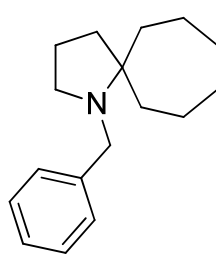

$7 \mathrm{~h}$

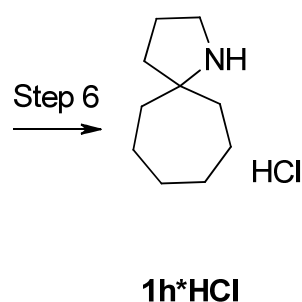

Scheme S12.

Figure S116. ${ }^{1} \mathrm{H}$ NMR spectrum of the compound $\mathbf{4 h}$.

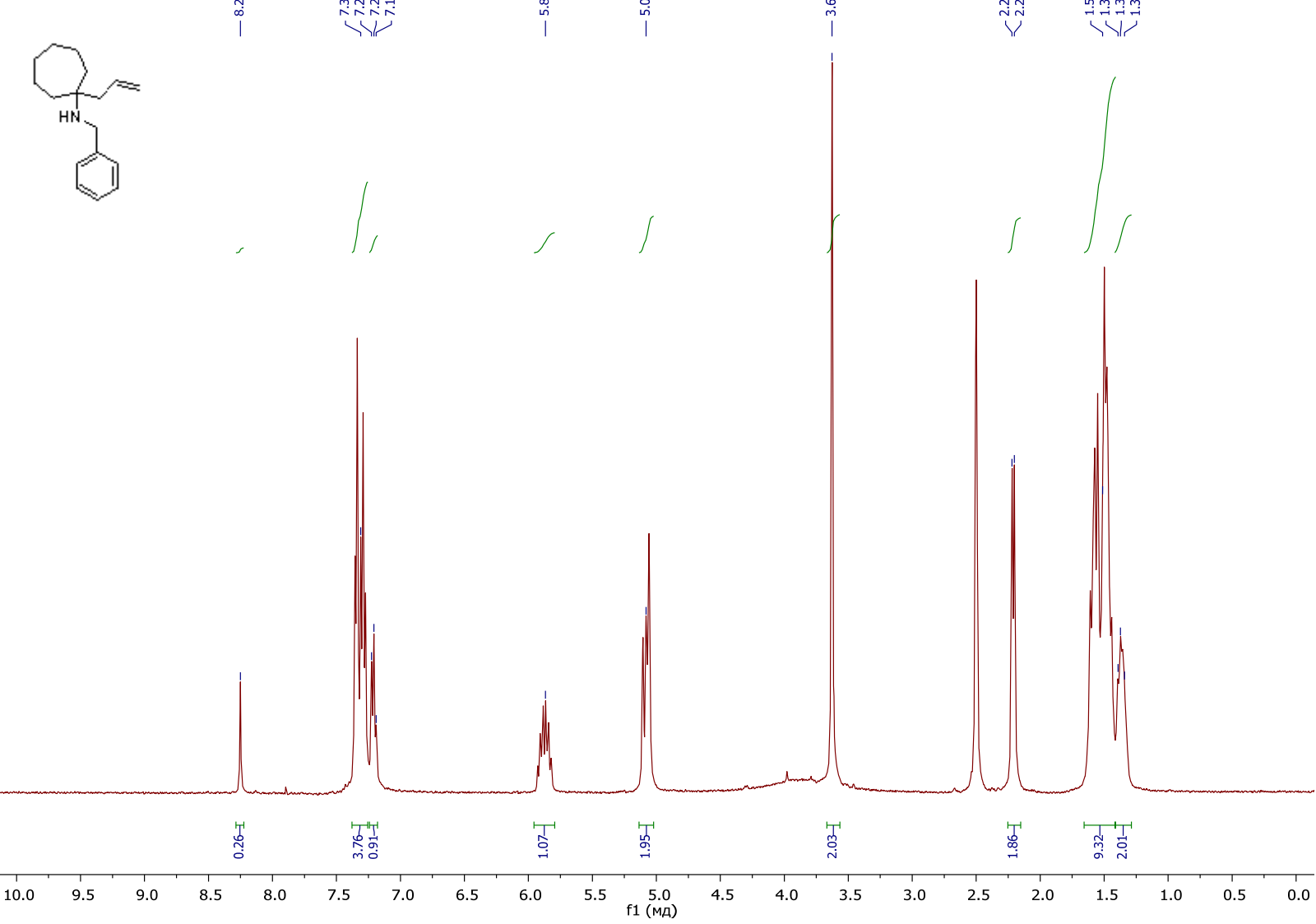


Figure S117. ${ }^{13} \mathrm{C}$ NMR spectrum of the compound $\mathbf{4 h}$.

|

|

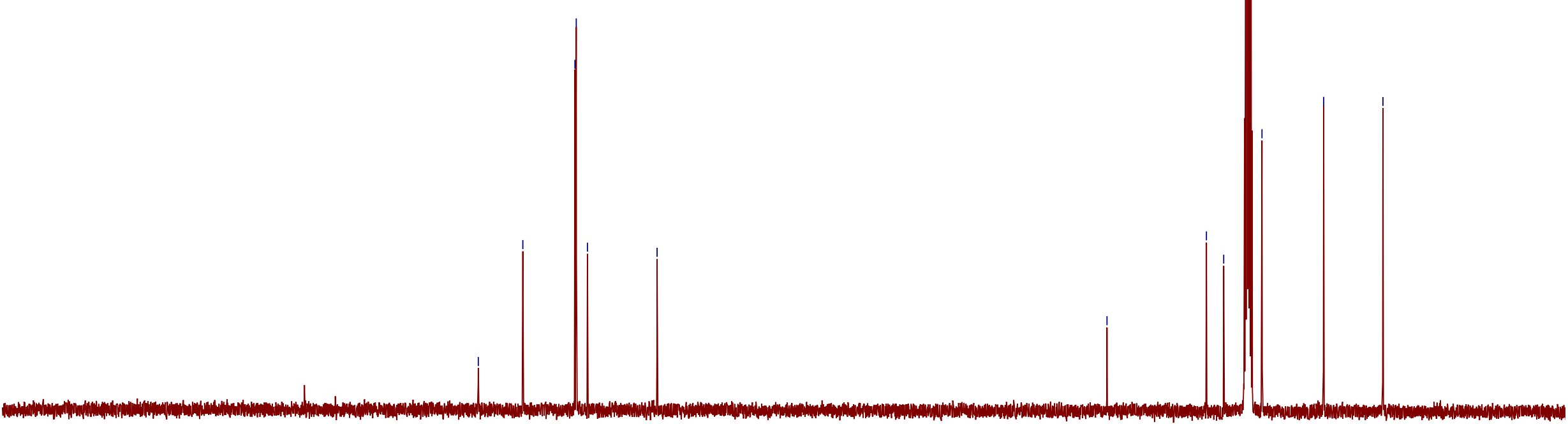


Figure S118. ${ }^{1} \mathrm{H}$ NMR spectrum of the compound $\mathbf{6 h}$.

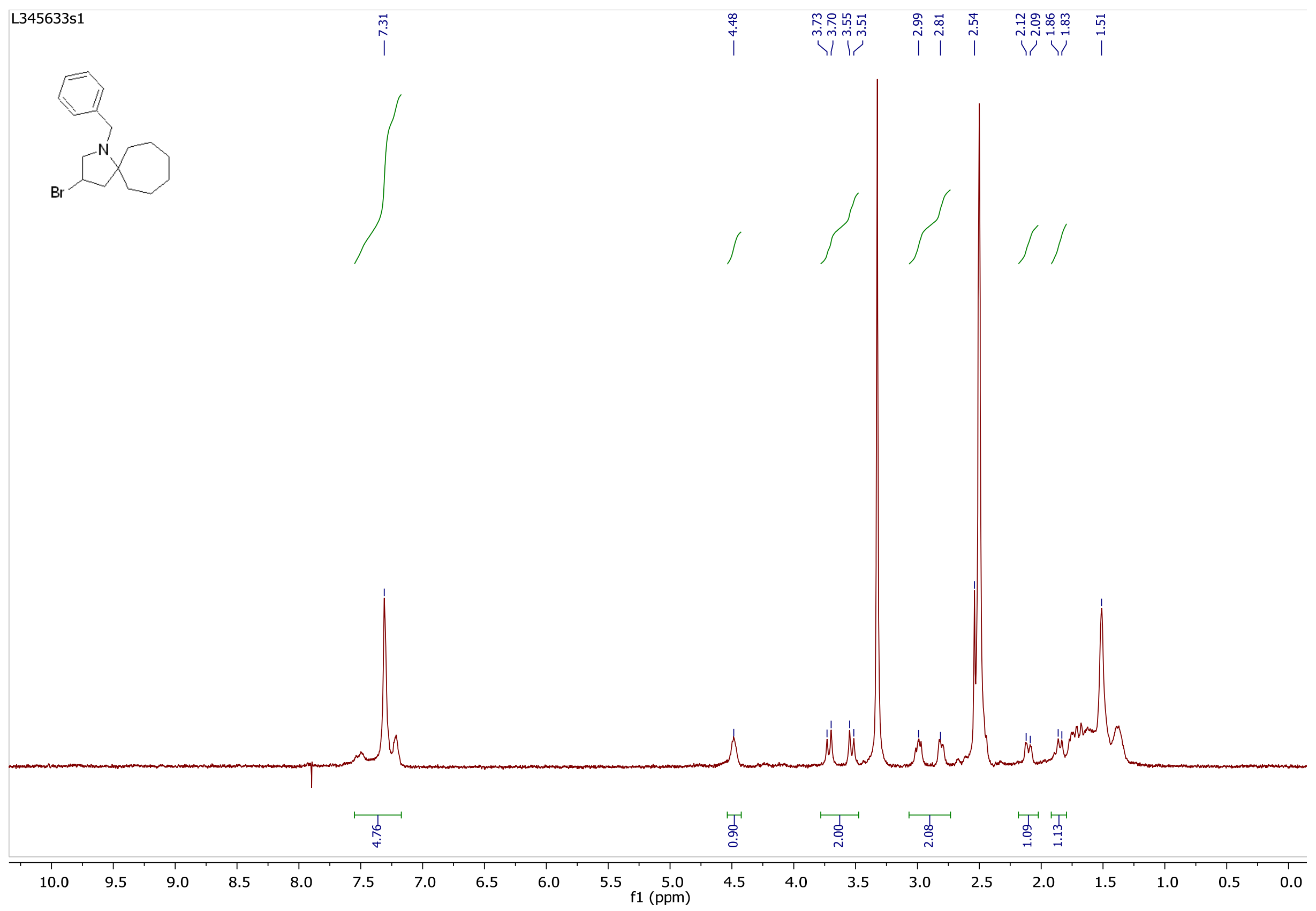


Figure S119. ${ }^{13} \mathrm{C}$ NMR spectrum of the compound $\mathbf{6 h}$.

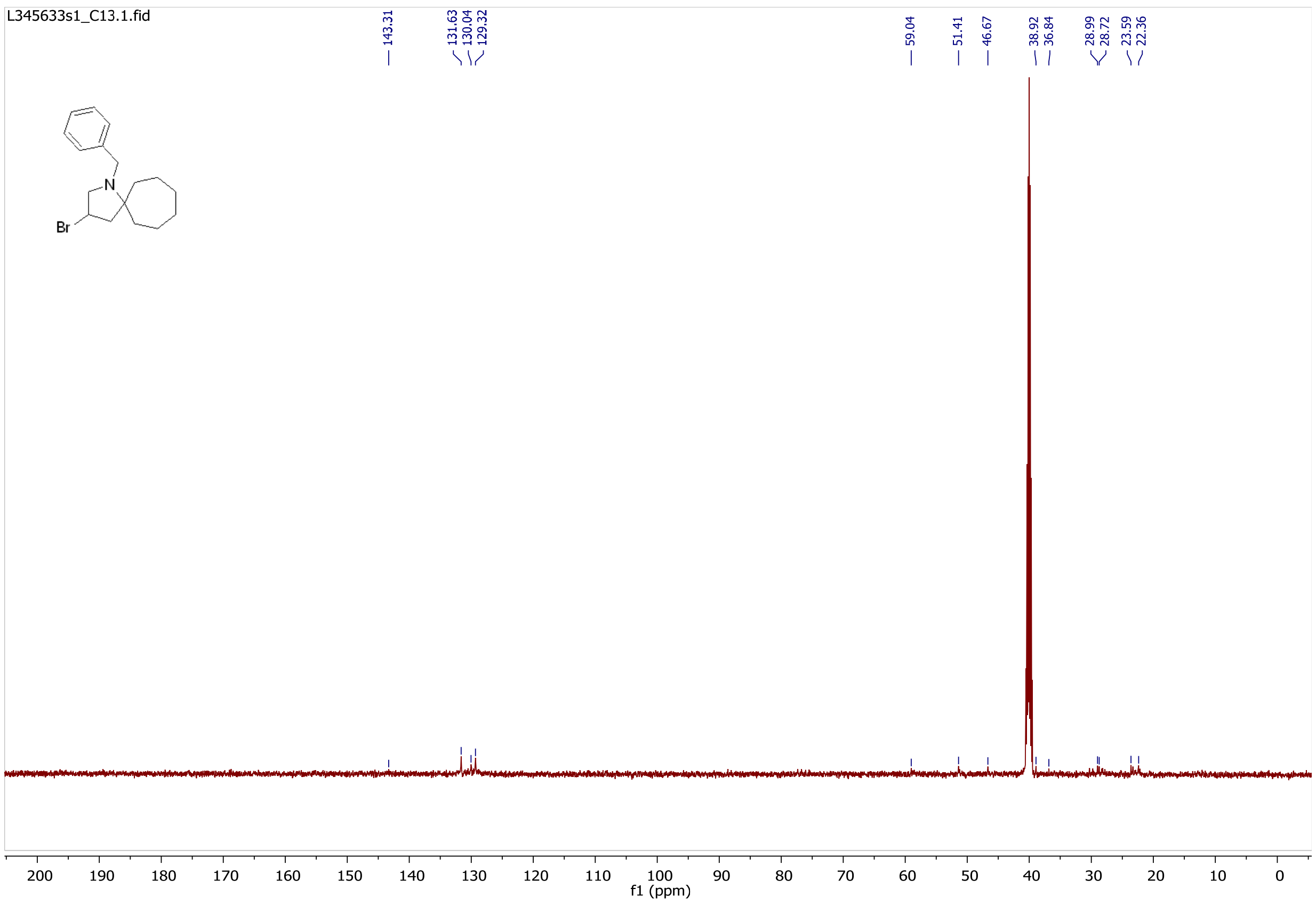


Figure S120. ${ }^{1} \mathrm{H}$ NMR spectrum of the compound $\mathbf{7 h}$.

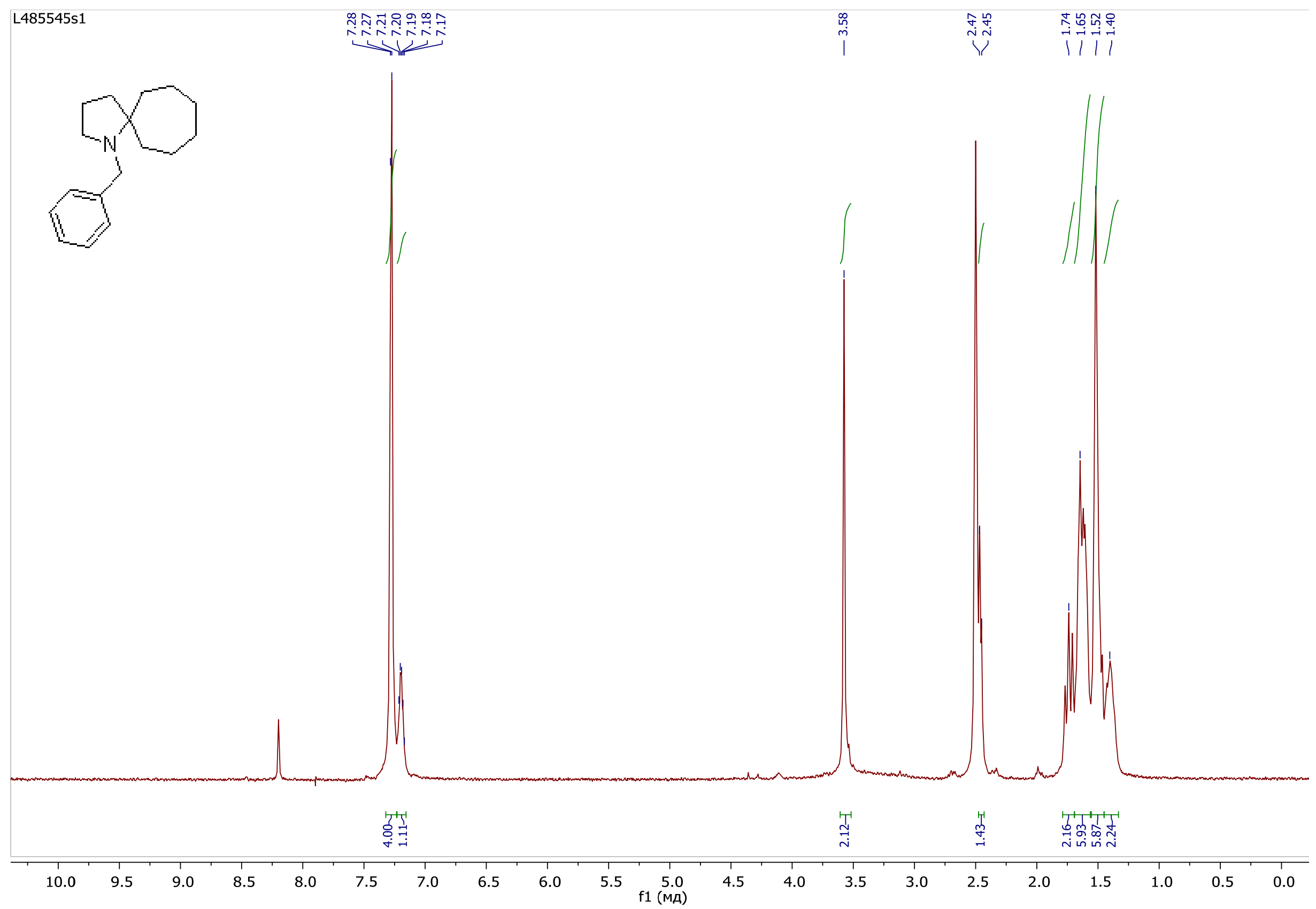


Figure S121. ${ }^{13} \mathrm{C}$ NMR spectrum of the compound $\mathbf{7 h}$.

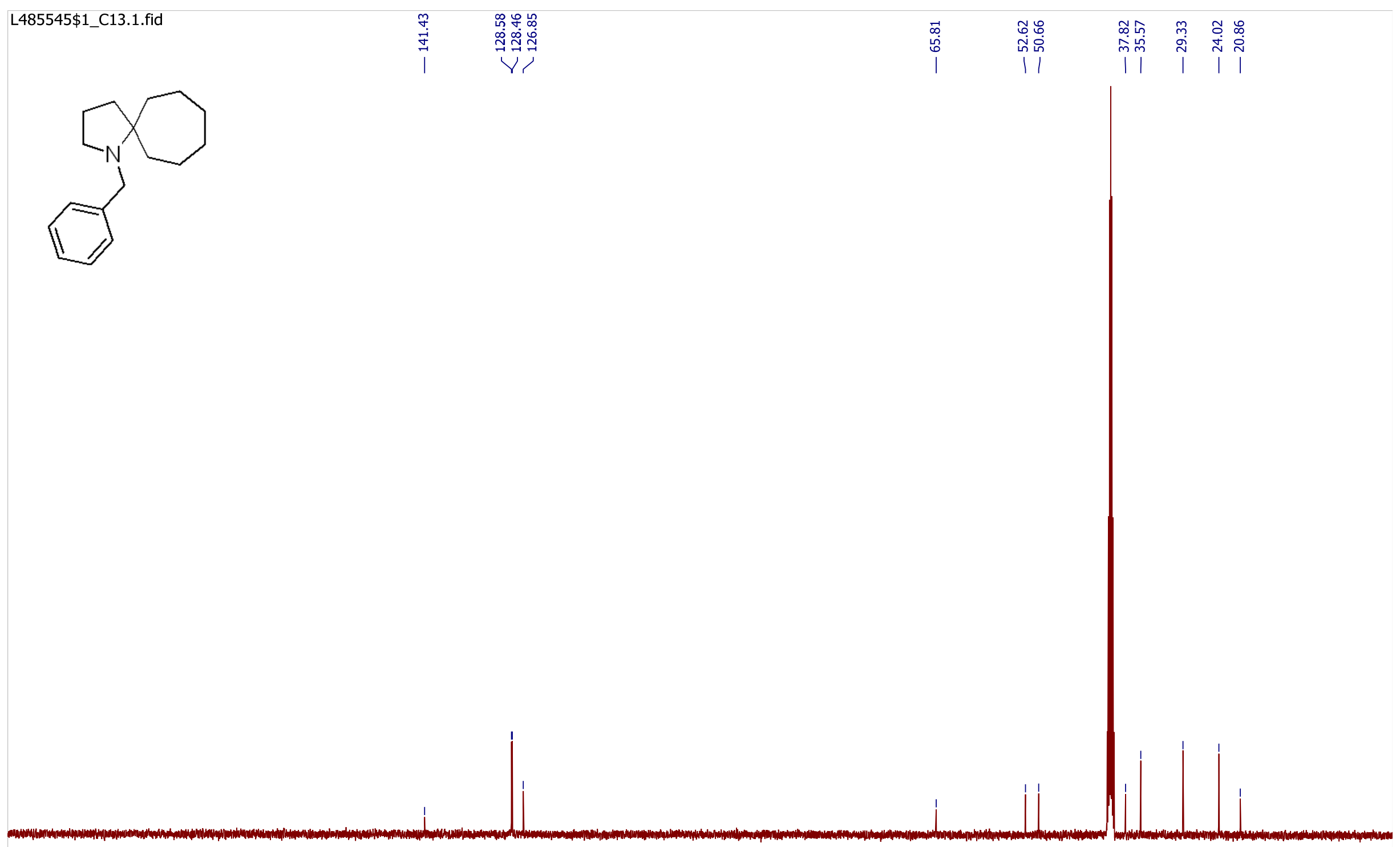

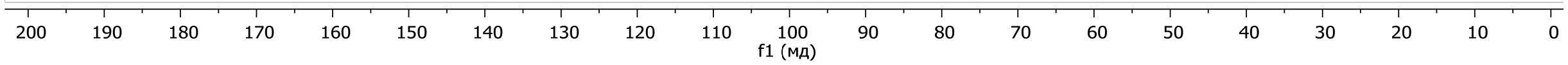


Figure S122. ${ }^{1} \mathrm{H}$ NMR spectrum of the compound $\mathbf{1 h} * \mathbf{H C l}$.

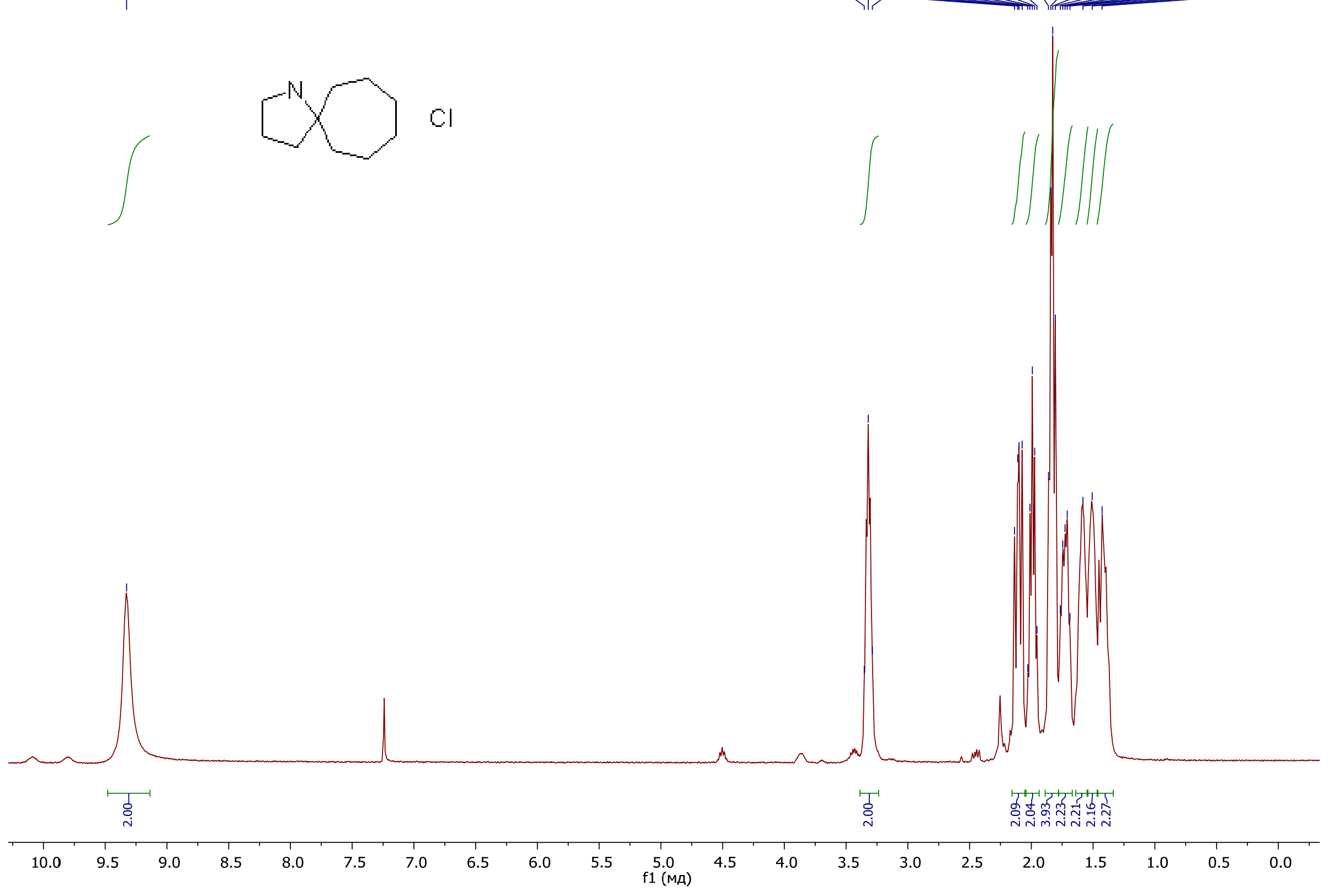

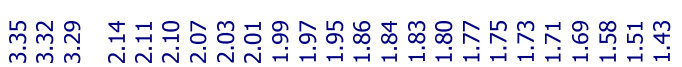

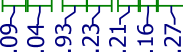


Figure S123. ${ }^{13} \mathrm{C}$ NMR spectrum of the compound $\mathbf{1 h} * \mathbf{H C l}$.

CI
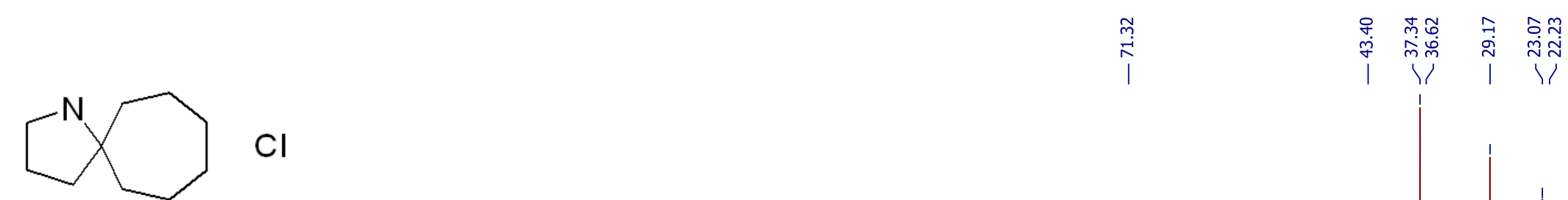
Synthesis of 7-oxa-1-azaspiro[4.4]nonane hydrochloride (1i*HCl). Approach I.

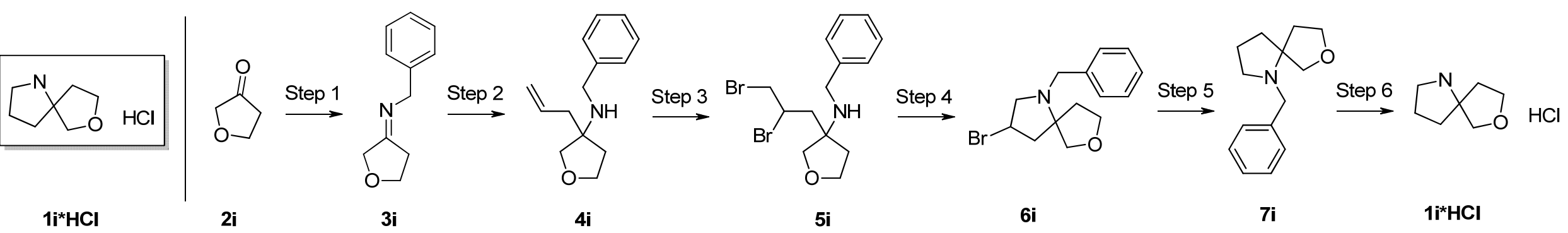

Scheme S13.

Figure S124. ${ }^{1} \mathrm{H}$ NMR spectrum of the compound $7 \mathbf{i}$.

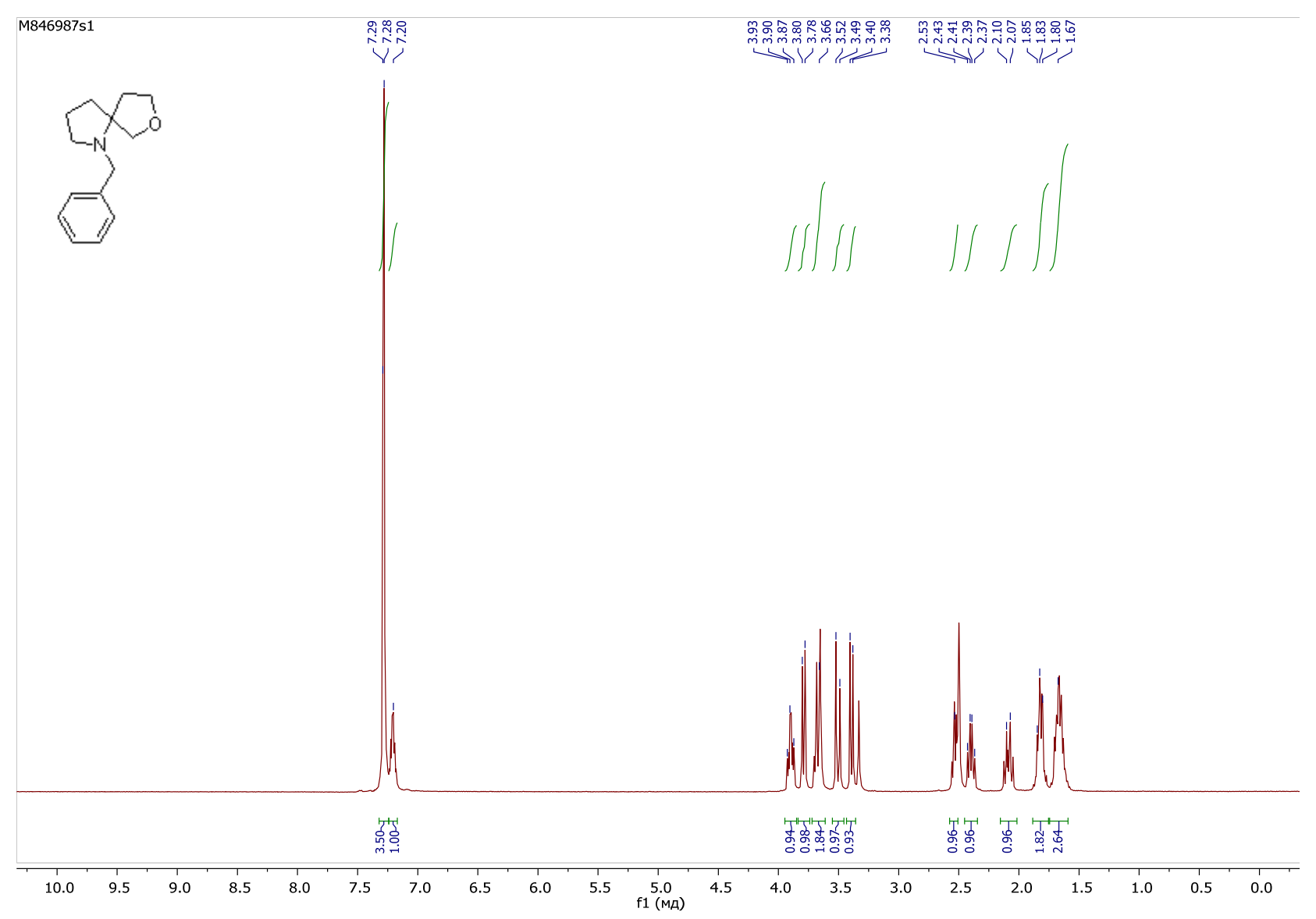


Figure S125. ${ }^{13} \mathrm{C}$ NMR spectrum of the compound $7 \mathbf{i}$.

줄

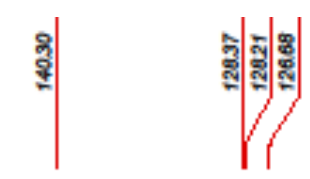

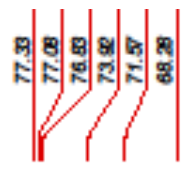

웅

용 연

m846987C13.fid

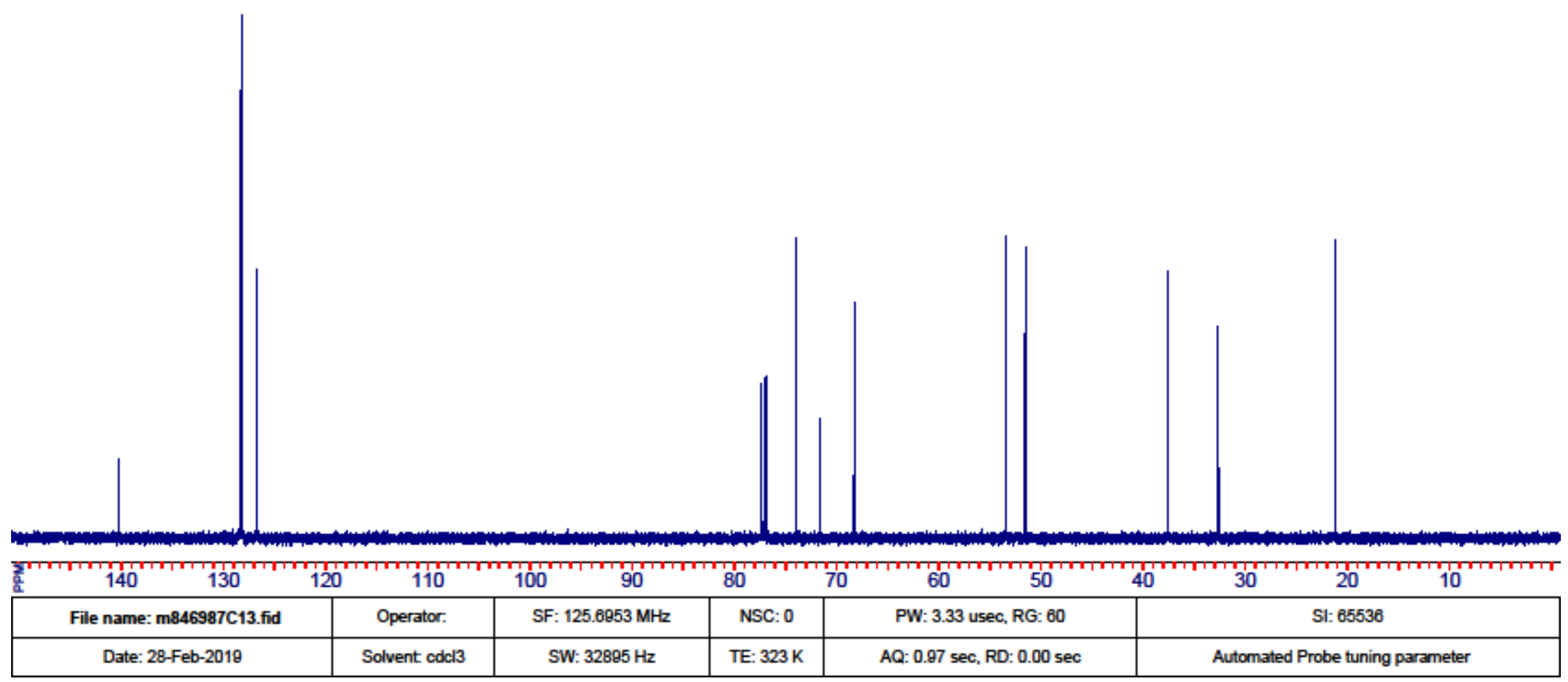


R349149

STANDARD PROTON PARAMETERS

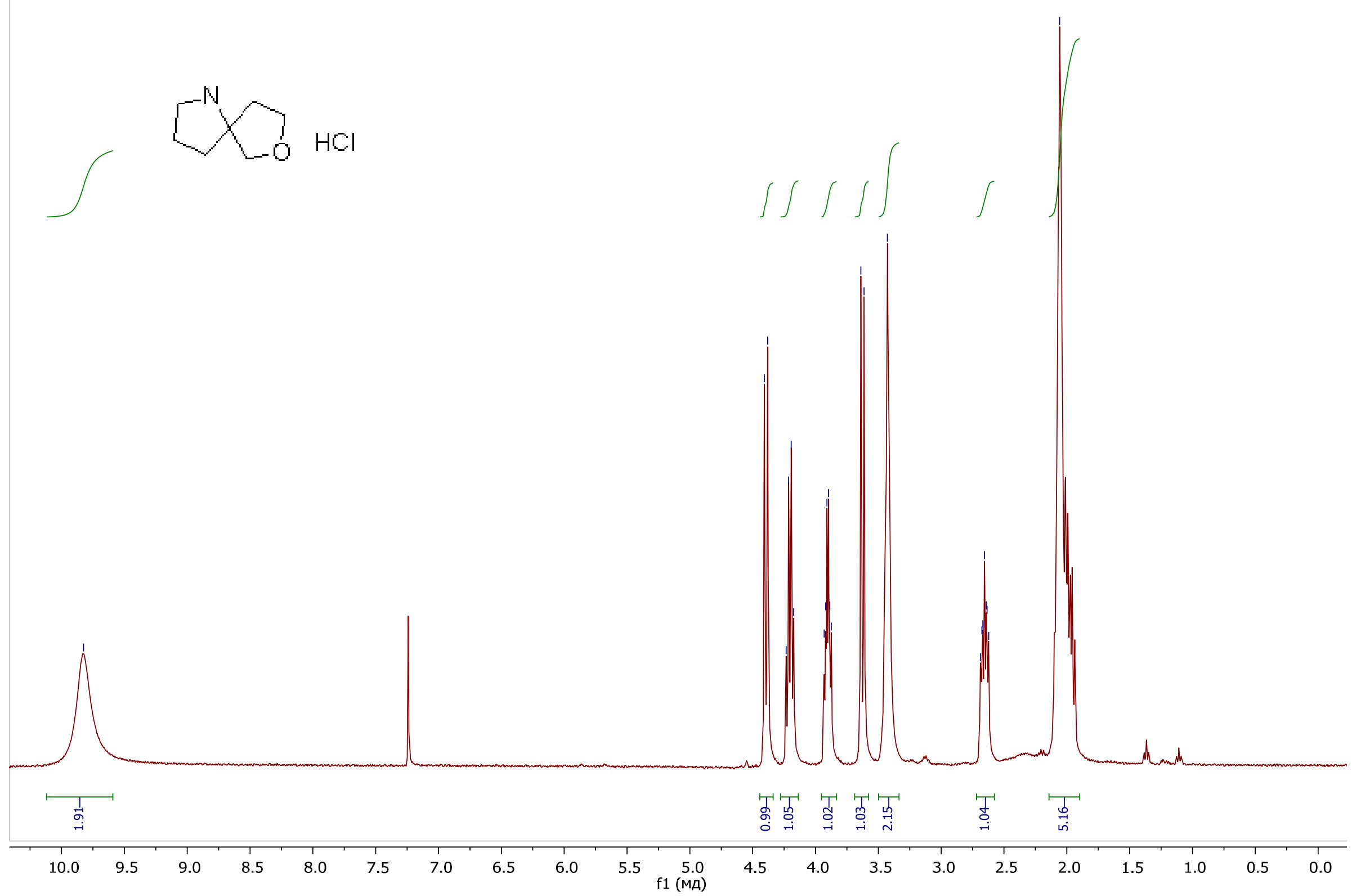

Figure S126. ${ }^{1} \mathrm{H}$ NMR spectrum of the compound $1 \mathbf{1} * \mathbf{H C l}$.

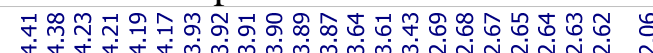

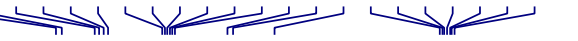


Figure S127. ${ }^{13} \mathrm{C}$ NMR spectrum of the compound $1 \mathbf{i}^{*} \mathbf{H C l}$.

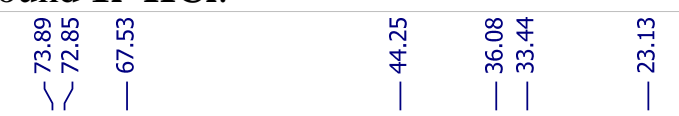

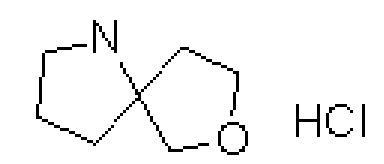

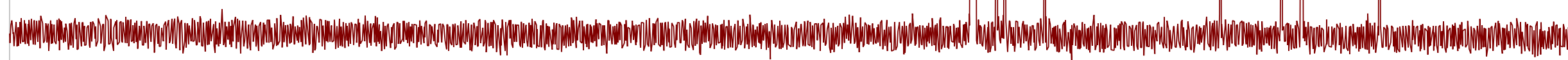

\begin{tabular}{|c|c|c|c|c|c|c|c|c|c|c|c|c|c|c|c|c|c|c|c|c|}
\hline 1 & 1 & 11 & 1 & 11 & 1 & 11 & 11 & 1 & 11 & 190 & 1 & T & 7 & 16 & 1 & 1 & 30 & 20 & 10 & $\begin{array}{l}1 \\
0\end{array}$ \\
\hline 200 & 190 & 180 & 170 & 160 & 150 & 140 & 130 & 120 & 110 & $\begin{array}{r}100 \\
\text { f1 }(\text { (MA) }\end{array}$ & 90 & 80 & 70 & 60 & 50 & 40 & 30 & 20 & 10 & 0 \\
\hline
\end{tabular}


Synthesis of 7-oxa-1-azaspiro[4.5]decane (1j). Approach I.

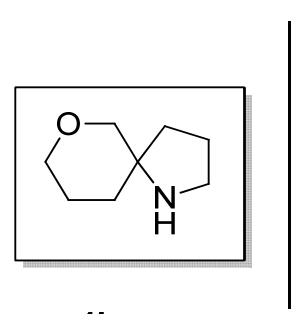

$1 \mathbf{i}$

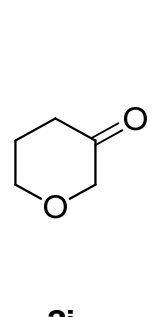

2i $\stackrel{\text { Step 1 }}{\longrightarrow}$

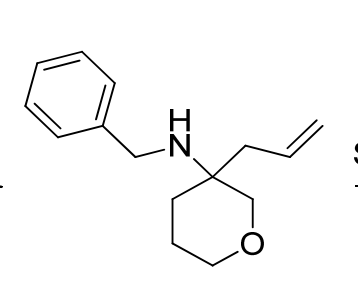

$4 \mathbf{i}$

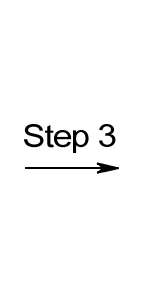

Scheme S14.

Figure S128. ${ }^{1} \mathrm{H}$ NMR spectrum of the compound $\mathbf{4 j}$.

M846986s1
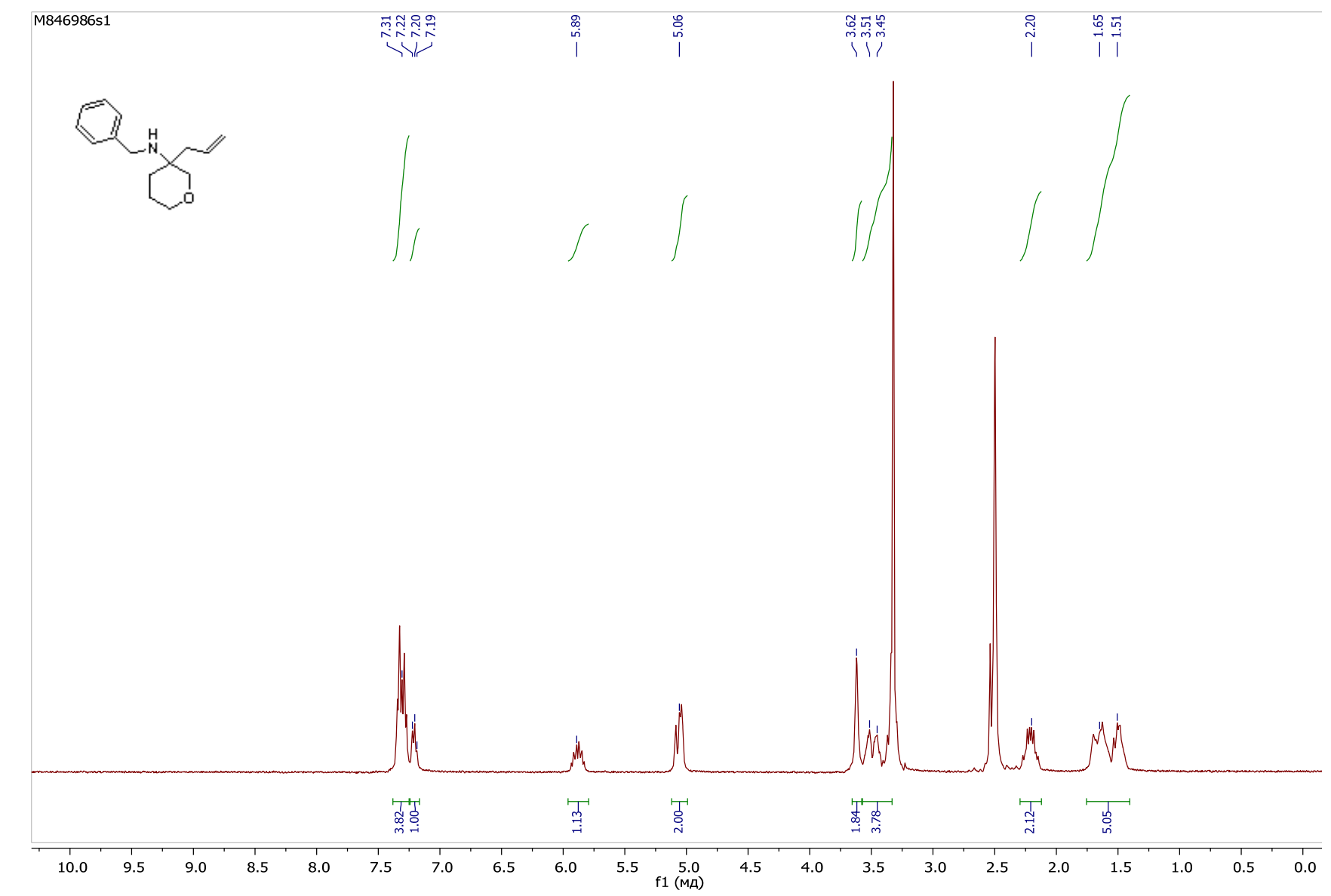
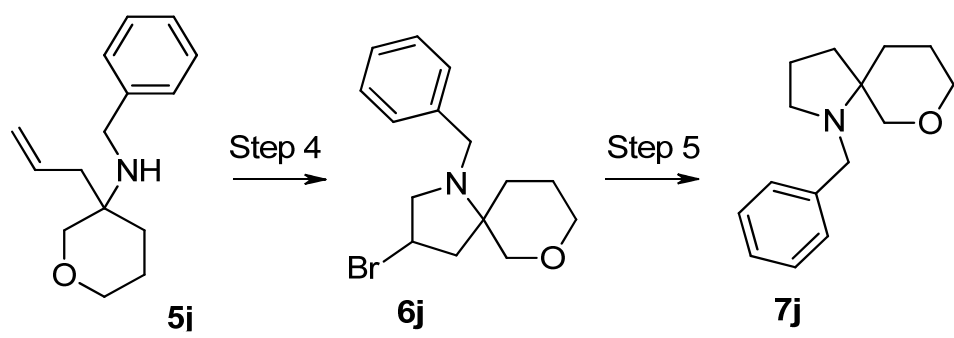

$\stackrel{\text { Step } 6}{\longrightarrow}$

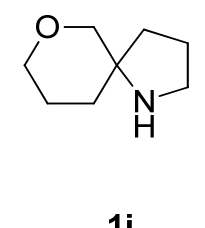


M846986s1_C13.1.fid

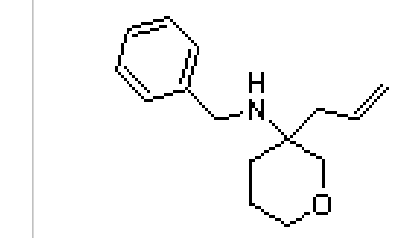

Figure S129. ${ }^{13} \mathrm{C}$ NMR spectrum of the compound $\mathbf{4 j}$.

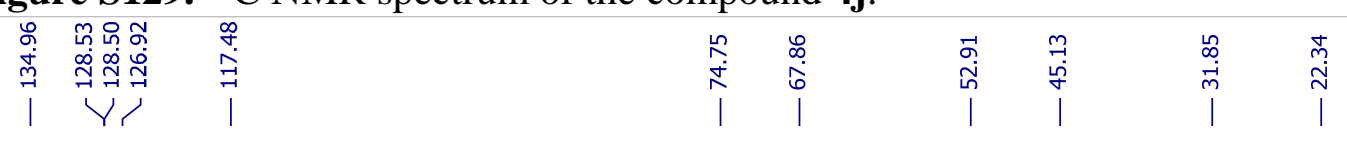


Figure S130. ${ }^{1} \mathrm{H}$ NMR spectrum of the compound $\mathbf{7 j}$.

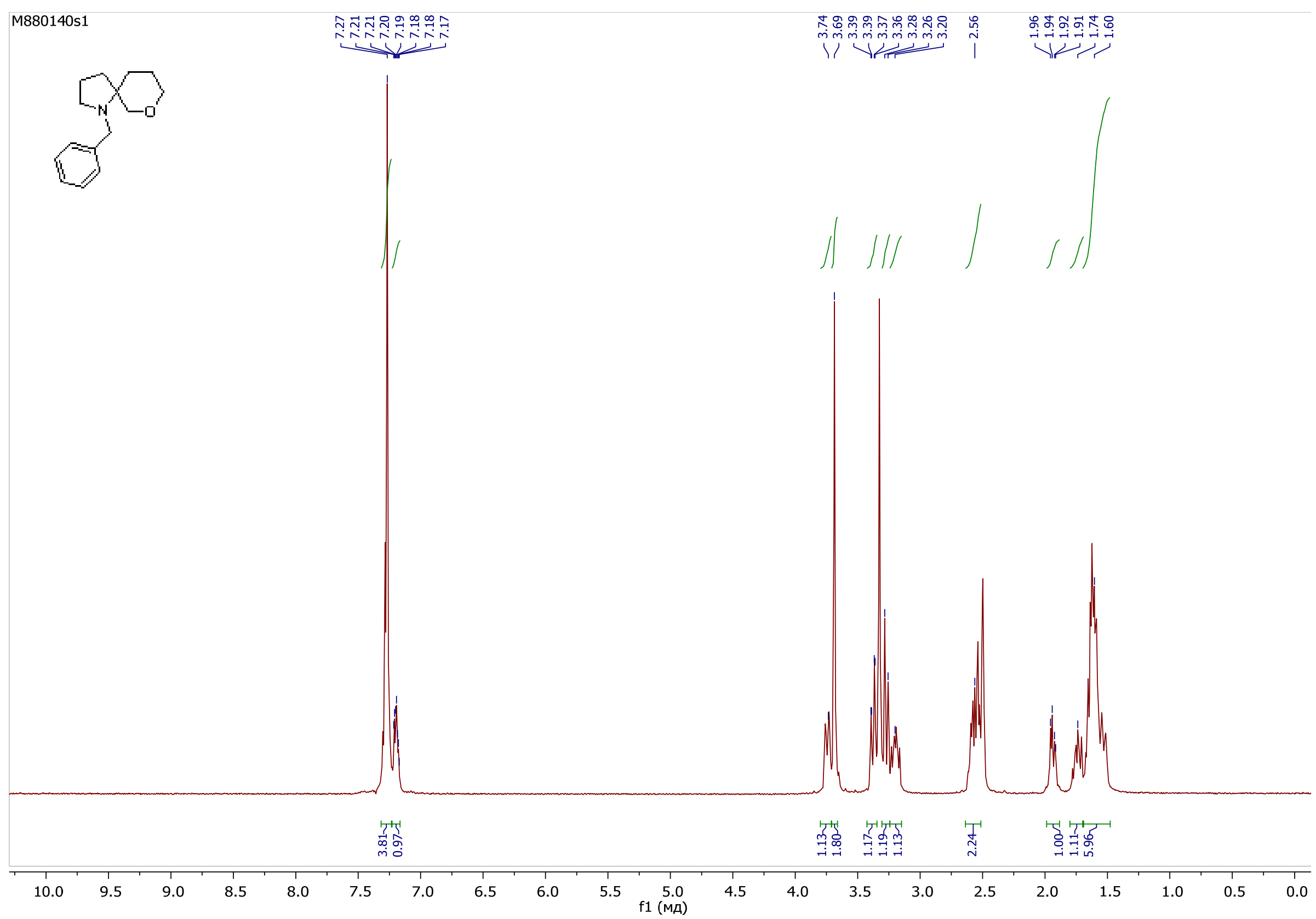


Figure S131. ${ }^{13} \mathrm{C}$ NMR spectrum of the compound $\mathbf{7 j}$.

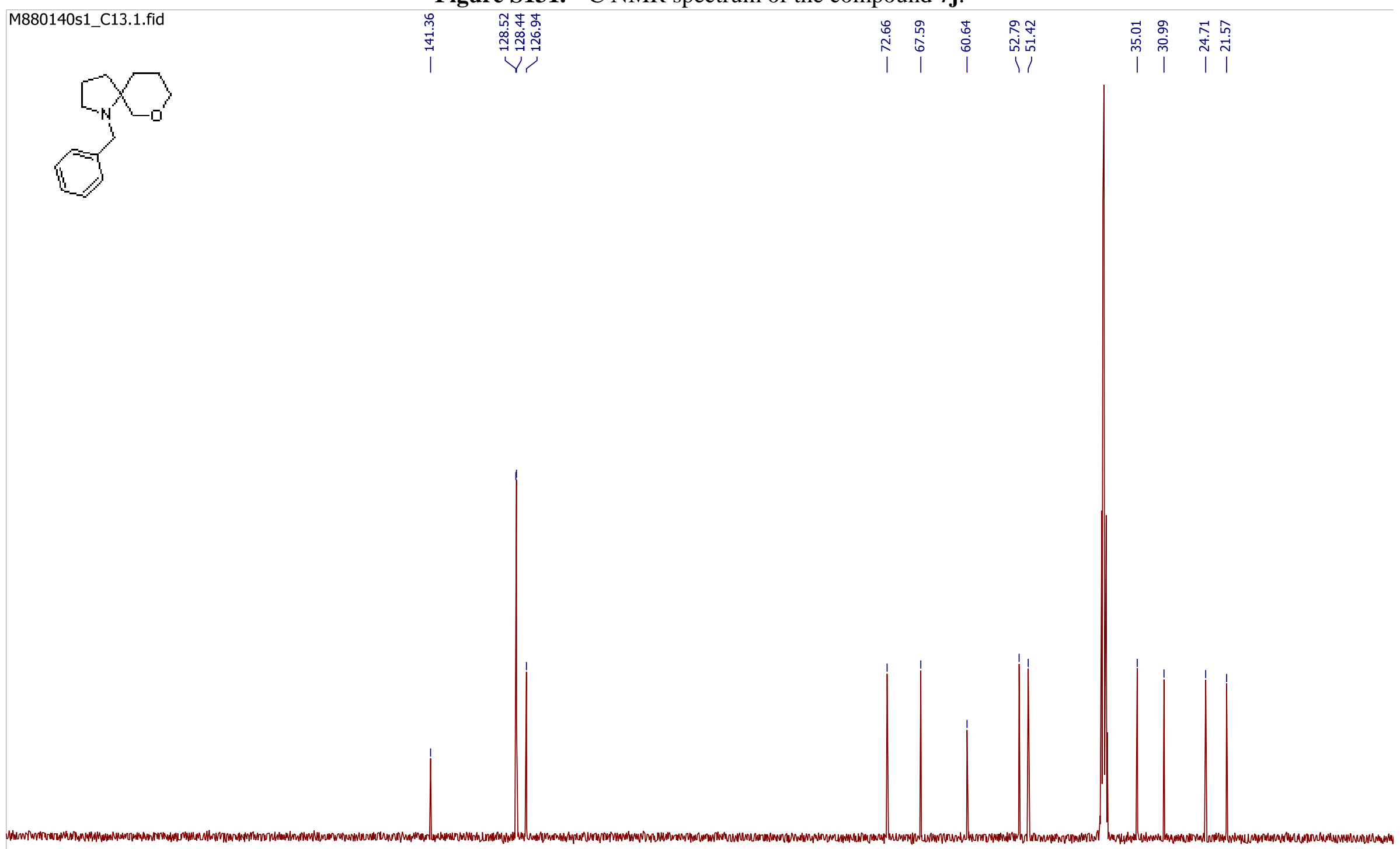

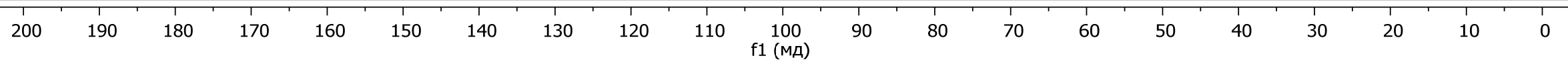


Figure S132. ${ }^{1} \mathrm{H}$ NMR spectrum of the compound $\mathbf{1 j}$.

品 N<smiles>C1CNC2(C1)CCCOC2</smiles>

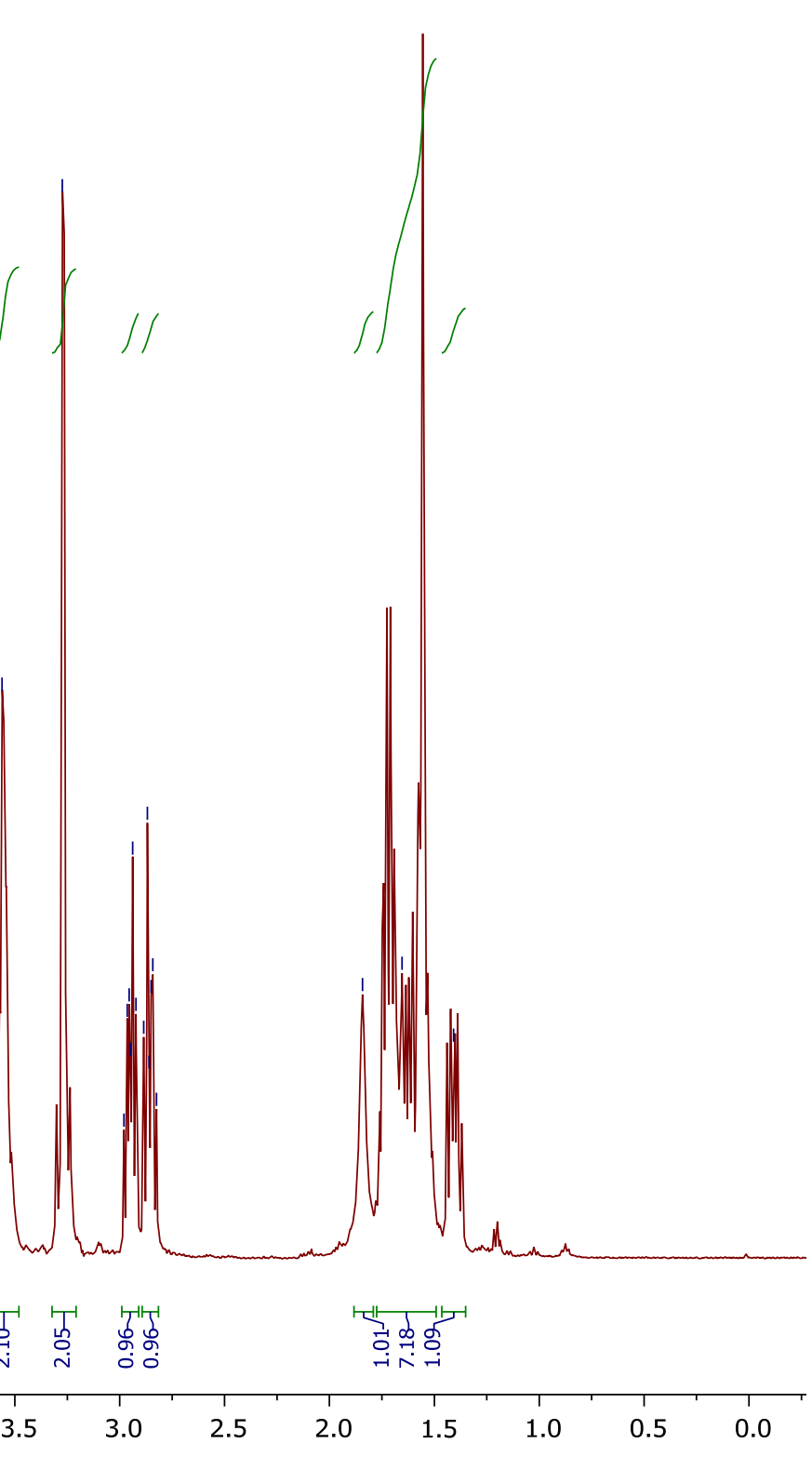


Figure S133. ${ }^{13} \mathrm{C}$ NMR spectrum of the compound $\mathbf{1 j}$.

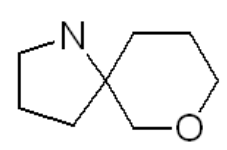

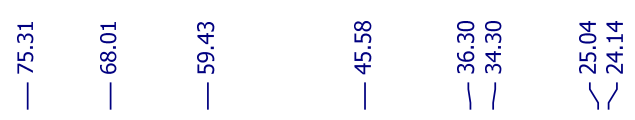

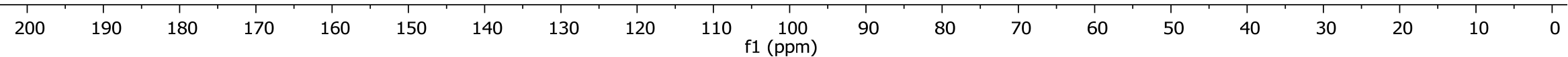


Figure S134. Mass spectrum of the compound $\mathbf{1 j}$.

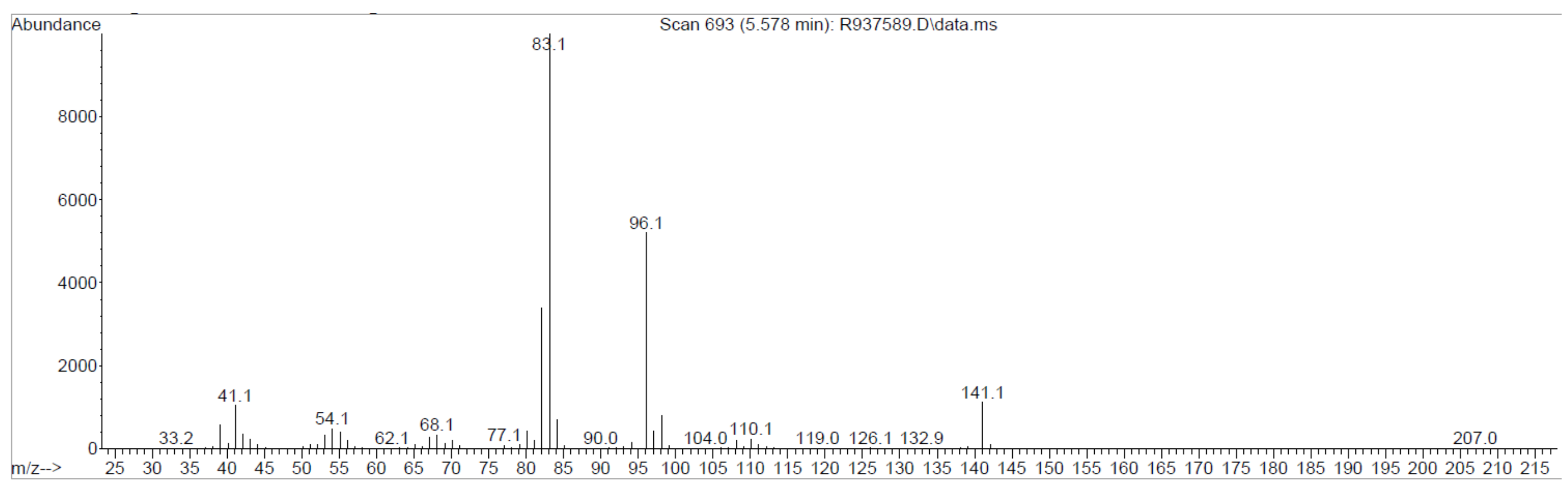


Synthesis of 7-thia-1-azaspiro[4.4]nonane hydrochloride (1k*HCl). Approach III.

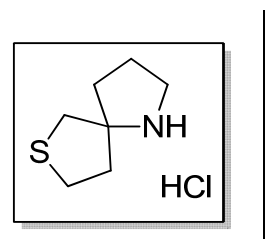

$1 k^{*} \mathrm{HCl}$

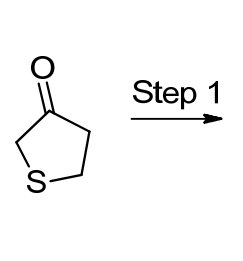

2k

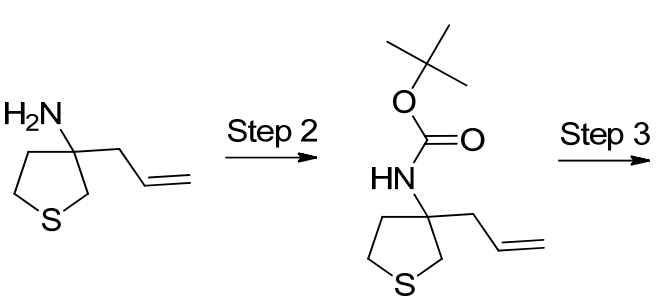

16k

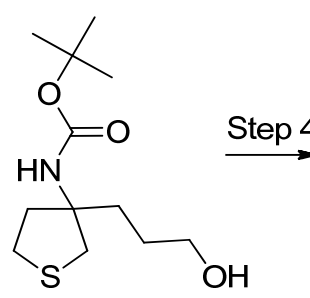

$18 \mathrm{k}$

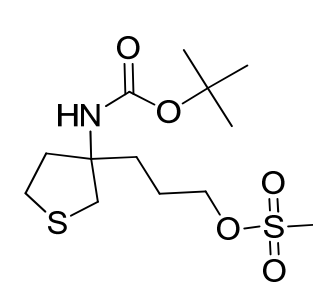

$19 k$

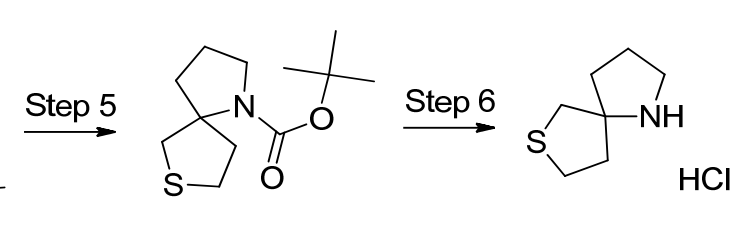

20k

$1 k^{*} \mathrm{HCl}$

\section{Scheme S15.}

Figure S135. ${ }^{1} \mathrm{H}$ spectrum of the compound $\mathbf{1 6 k}$.

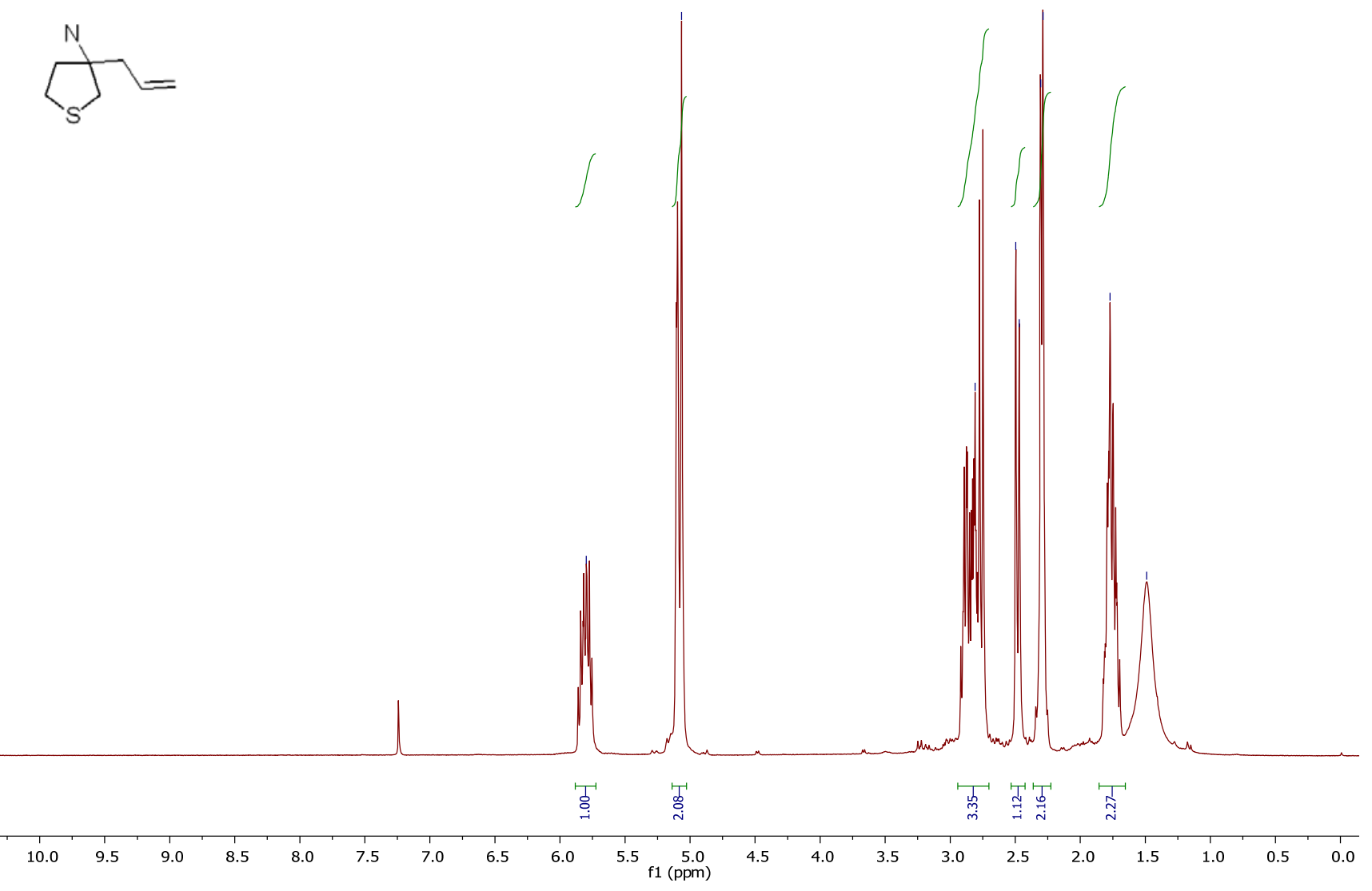


Figure S136. ${ }^{1} \mathrm{H}$ spectrum of the compound 16k.

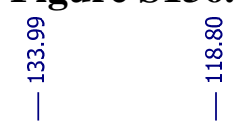

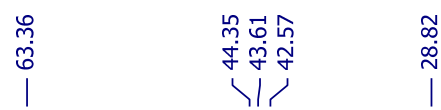

\rangle$_{S}^{N}=$

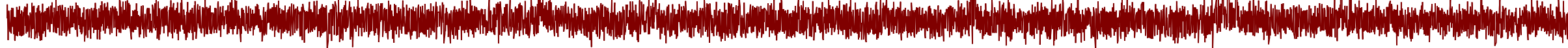

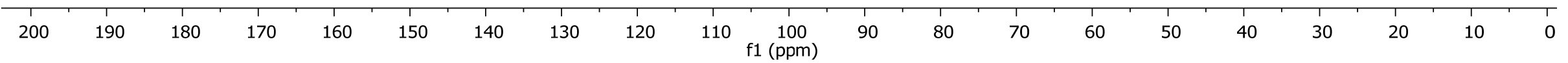


Figure S137. Mass spectrum of the compound 16k.

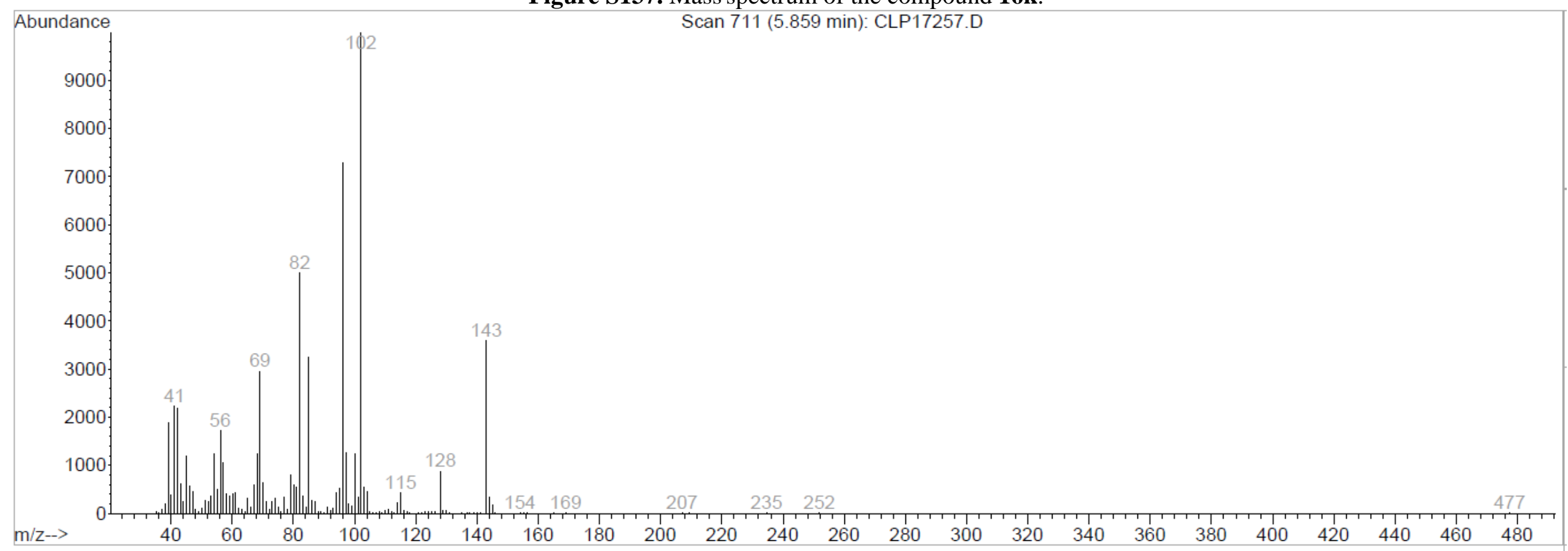


Figure S138. ${ }^{1} \mathrm{H}$ spectrum of the compound $\mathbf{1 7 k}$. in

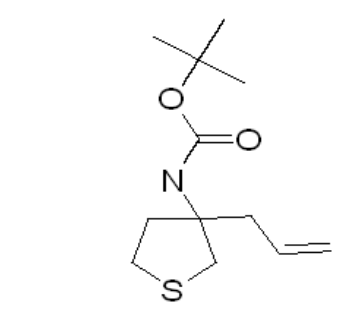

।
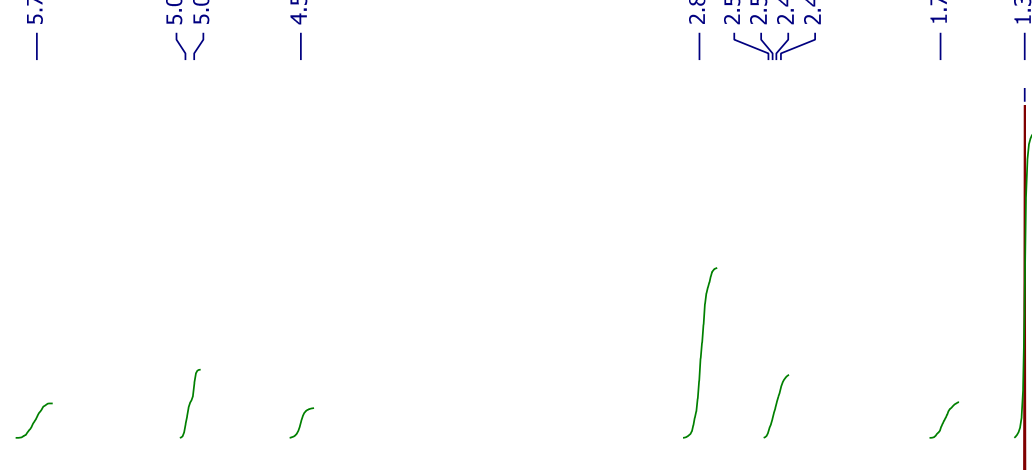
Figure S139. ${ }^{13} \mathrm{C}$ spectrum of the compound $\mathbf{1 7 k}$.

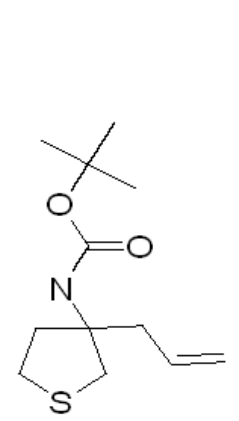

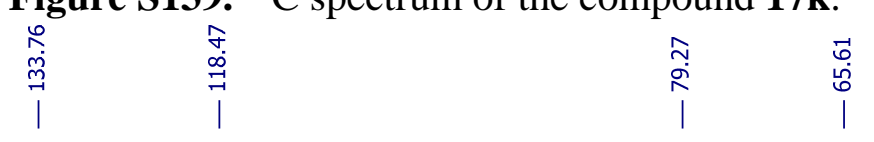
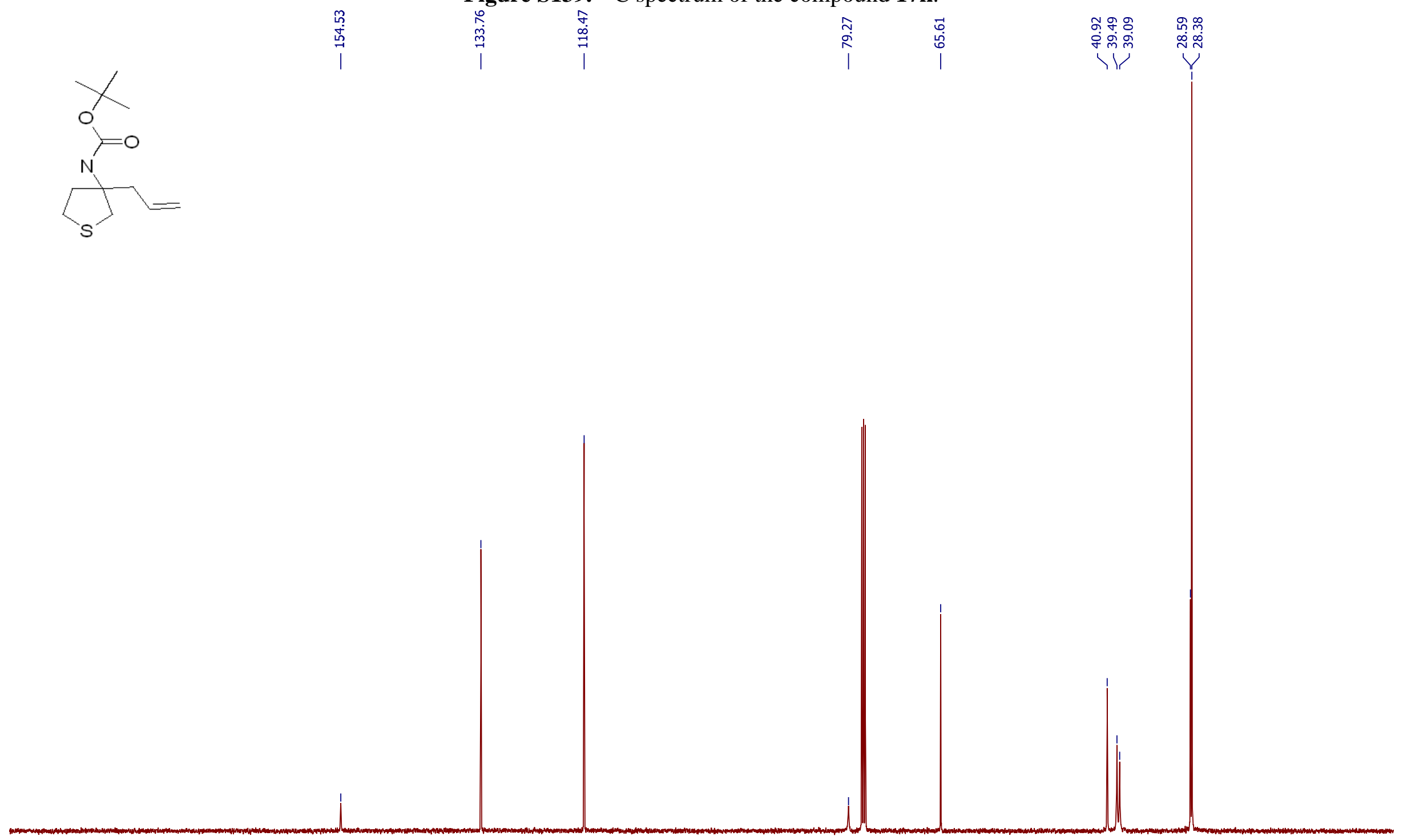
Figure S140. Mass spectrum of the compound 17k.

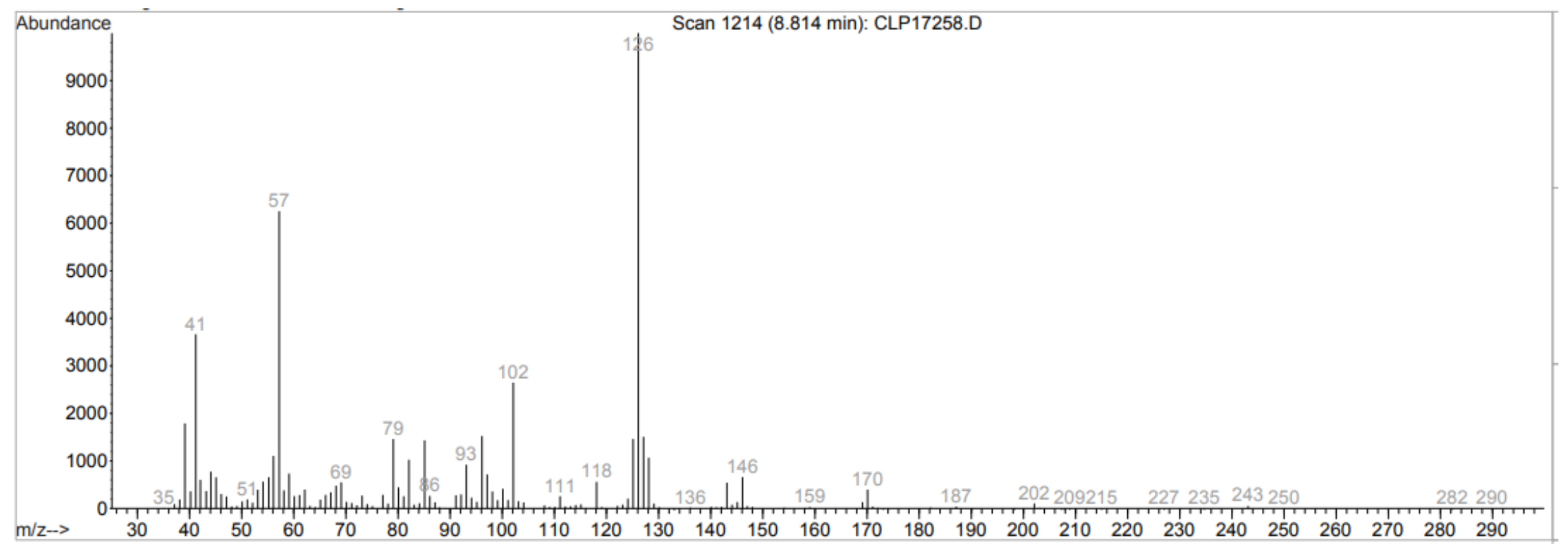


Figure S141. ${ }^{1} \mathrm{H}$ spectrum of the compound $\mathbf{1 8 k}$.
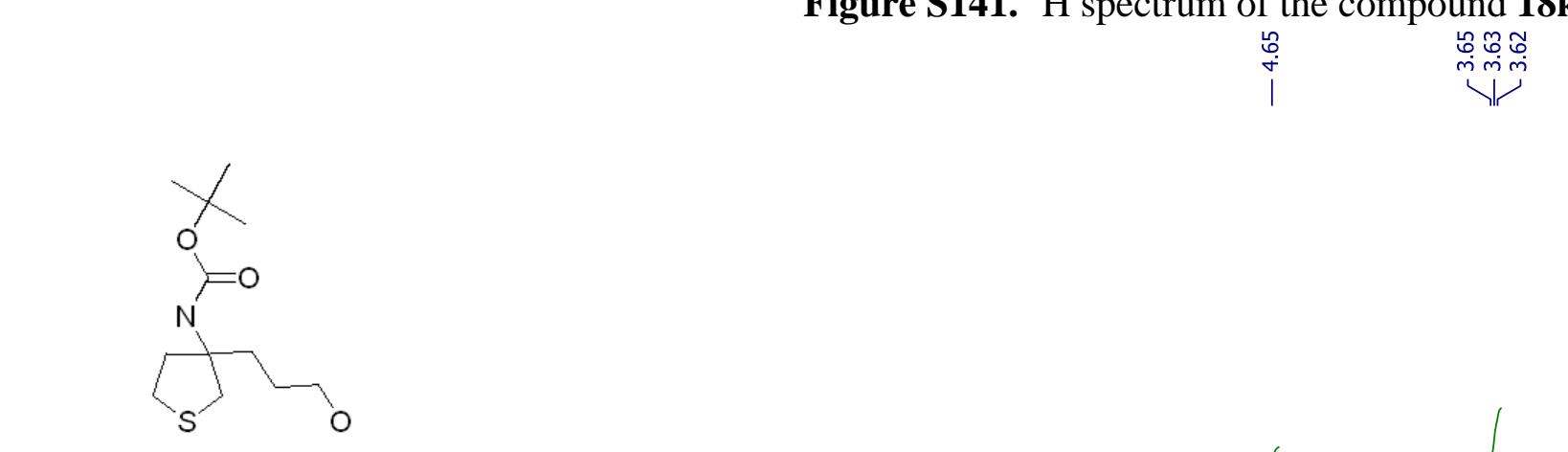

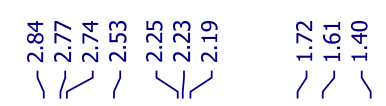
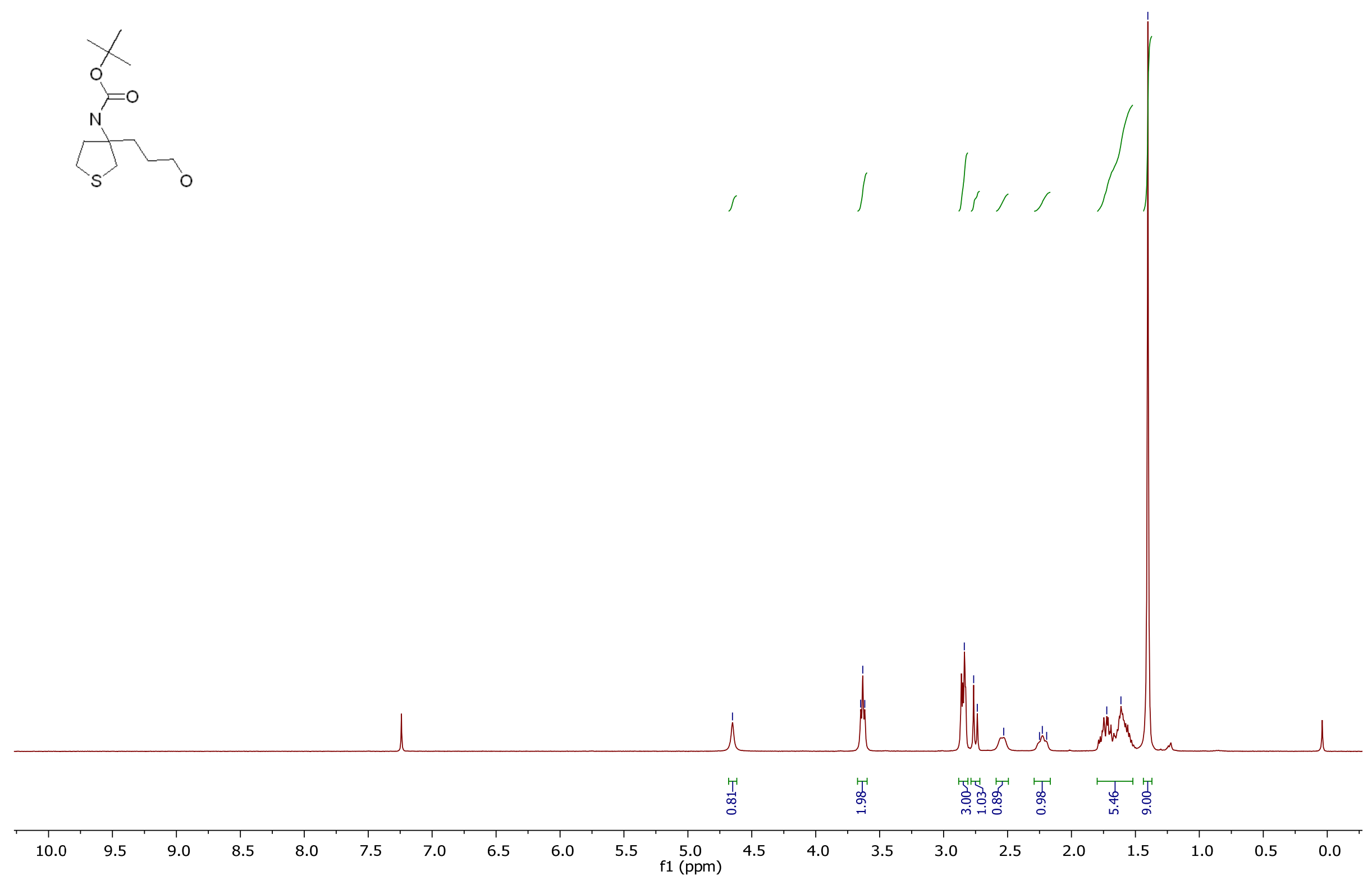
Figure S143. ${ }^{1} \mathrm{H}$ spectrum of the compound 19k.

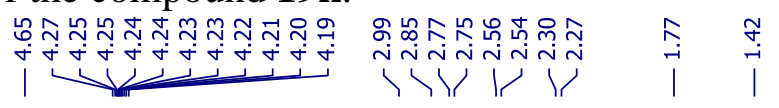
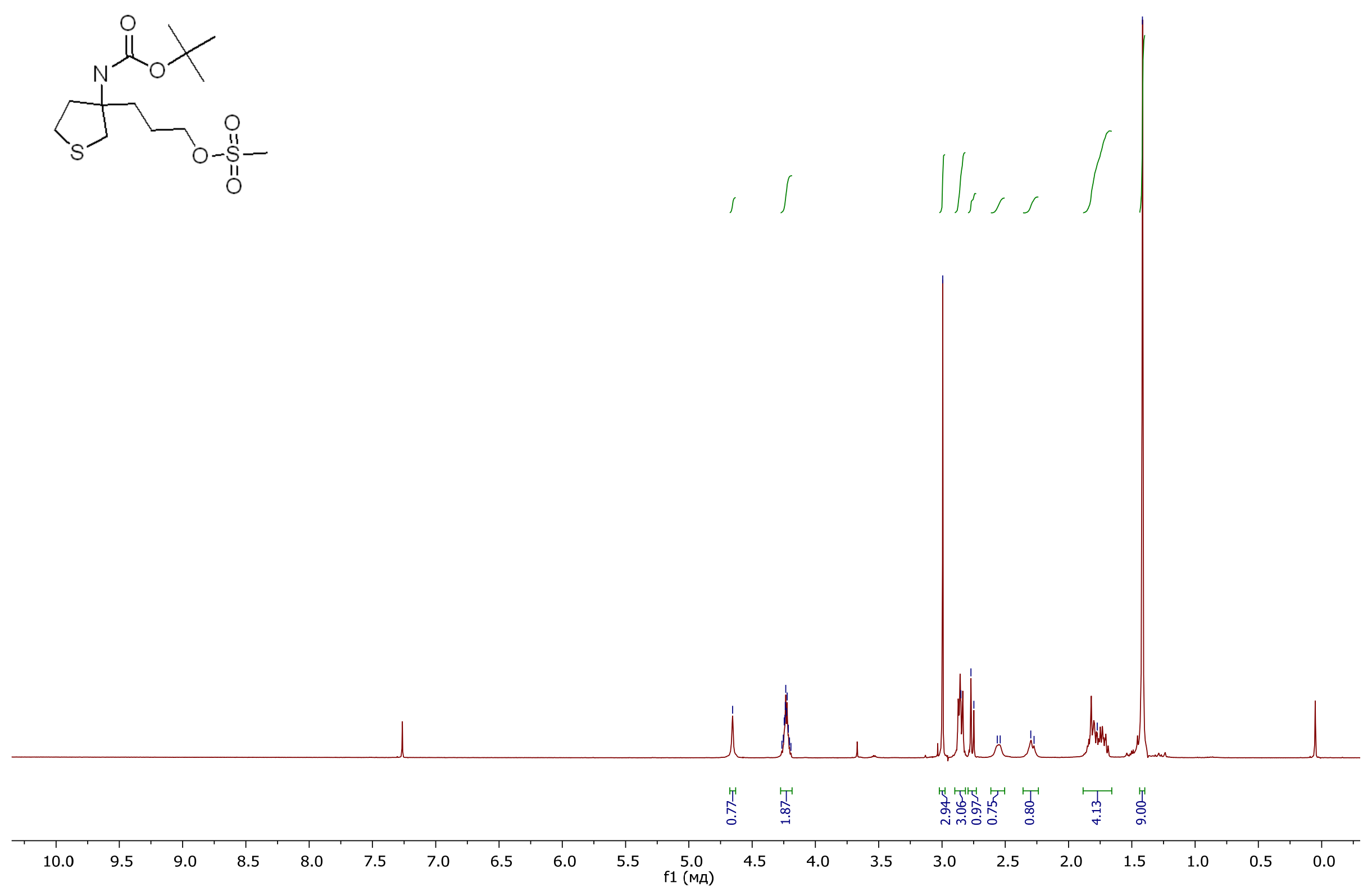
Figure S144. ${ }^{13} \mathrm{C}$ spectrum of the compound 19k.

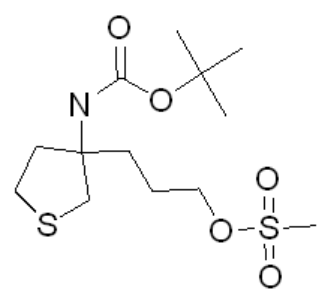

$$
\text { II }
$$

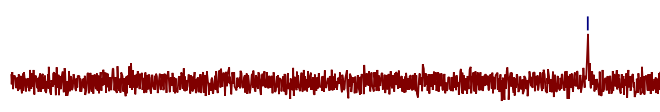
0 
Figure S145. ${ }^{1} \mathrm{H}$ spectrum of the compound 20k.

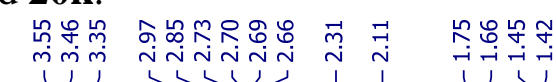
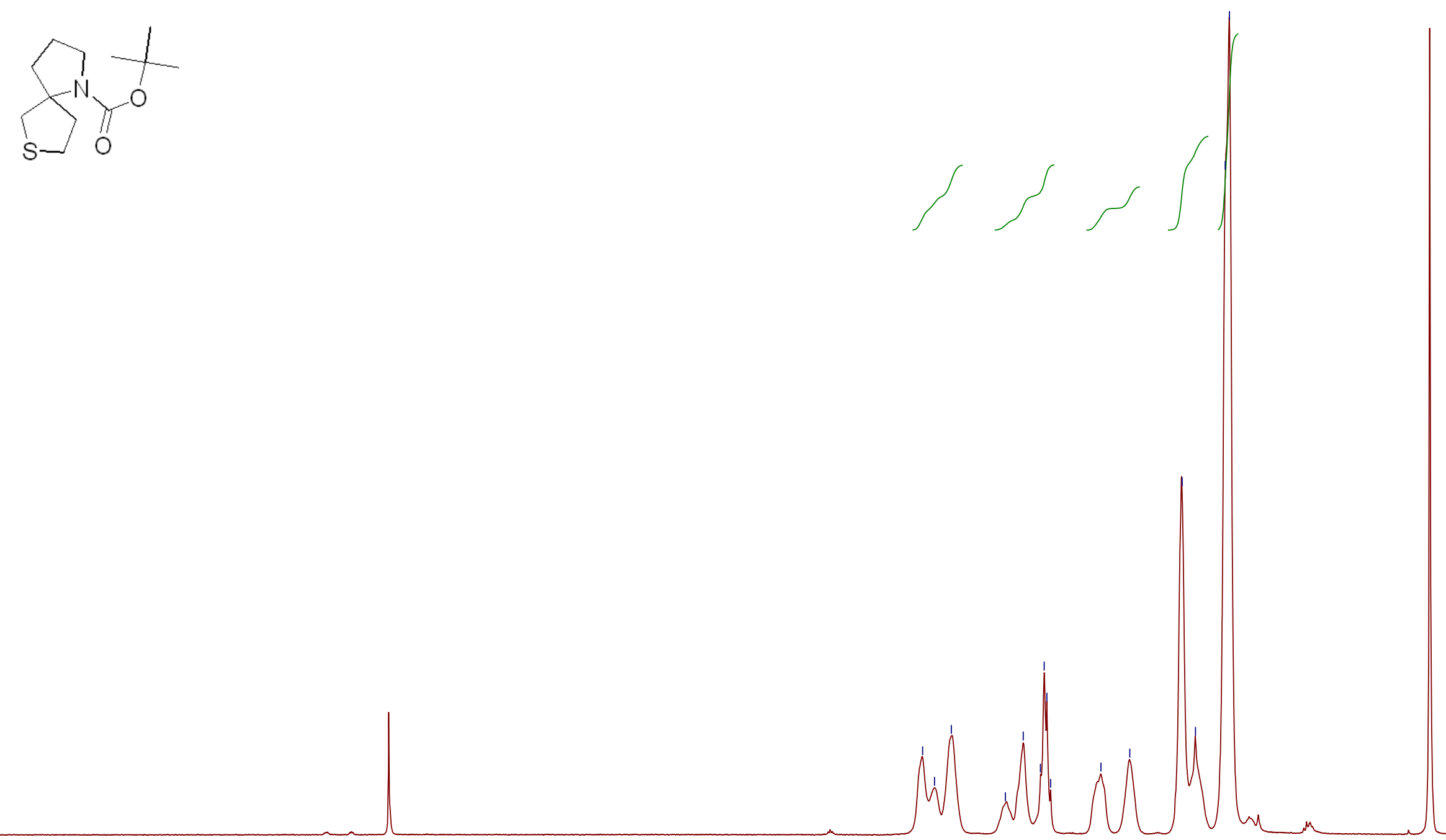

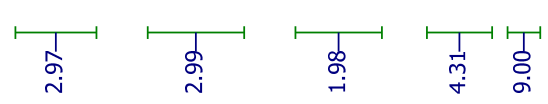


Figure S146. ${ }^{13} \mathrm{C}$ spectrum of the compound 20k.

î.

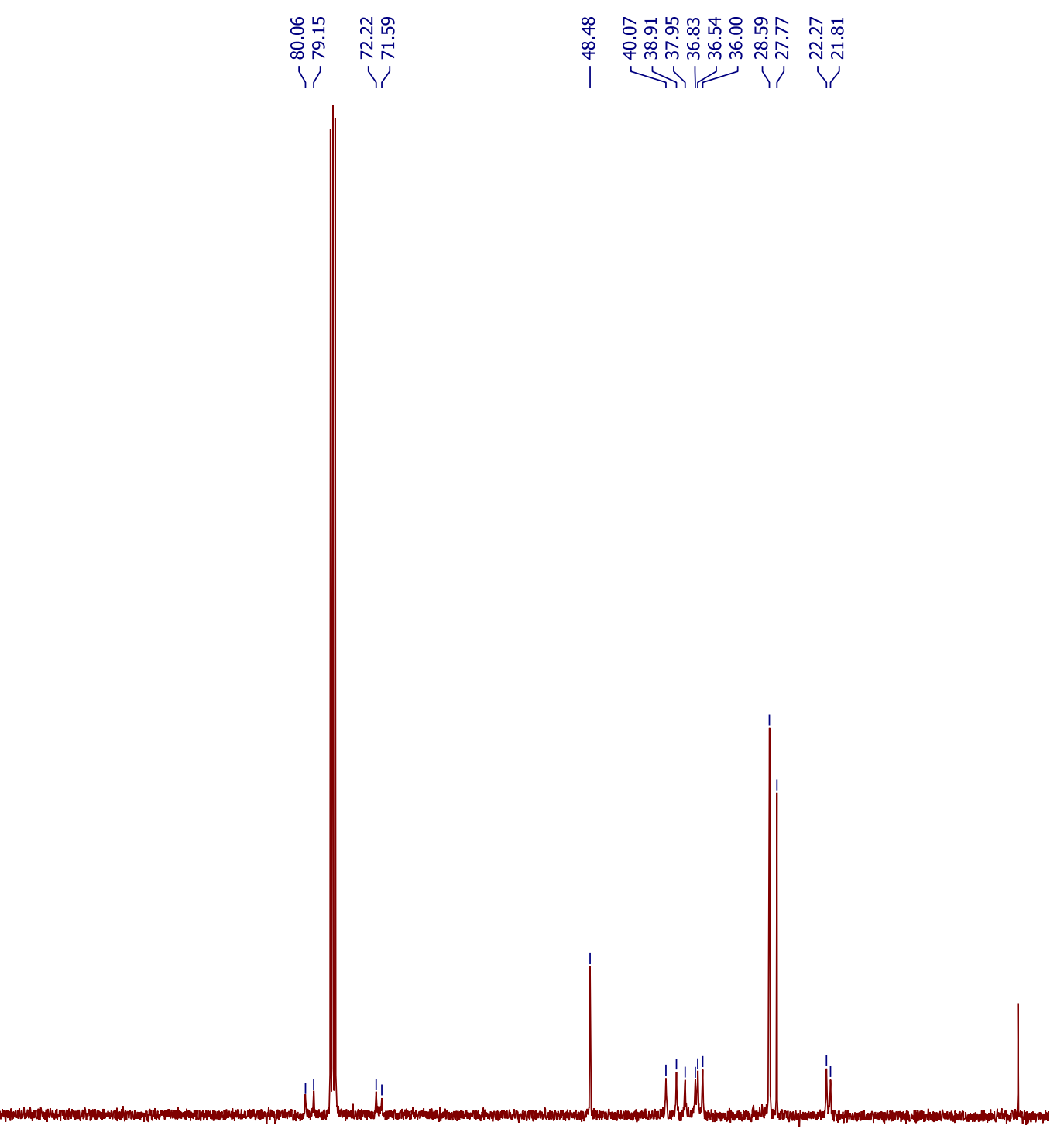

$\underbrace{\substack{0 \\ 0}}_{\substack{0 \\ 0}}$

$\sum_{S-1}^{N} m_{0}^{1}$

\)

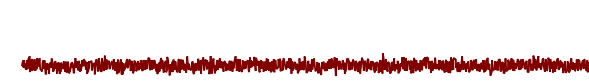


Figure S147. Mass spectrum of the compound 20k.

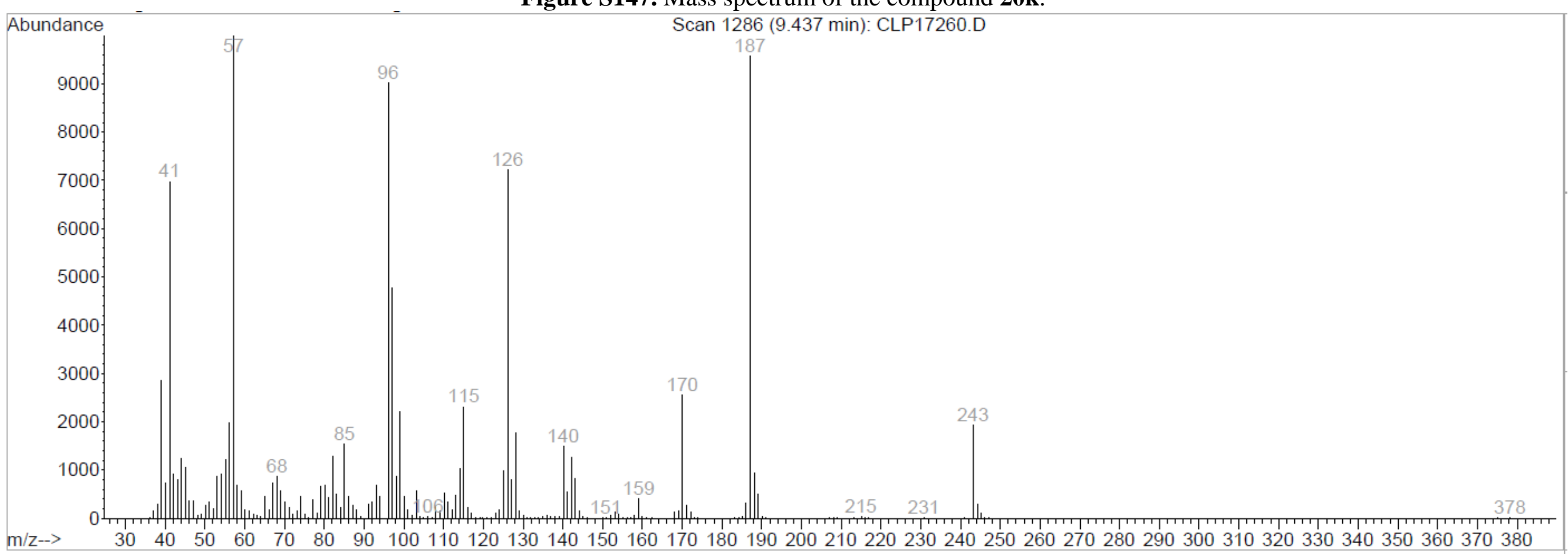


Figure S148. ${ }^{1} \mathrm{H}$ spectrum of the compound $1 \mathbf{k}^{*} \mathbf{H C l}$.

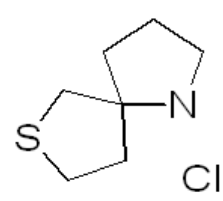

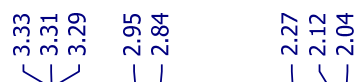
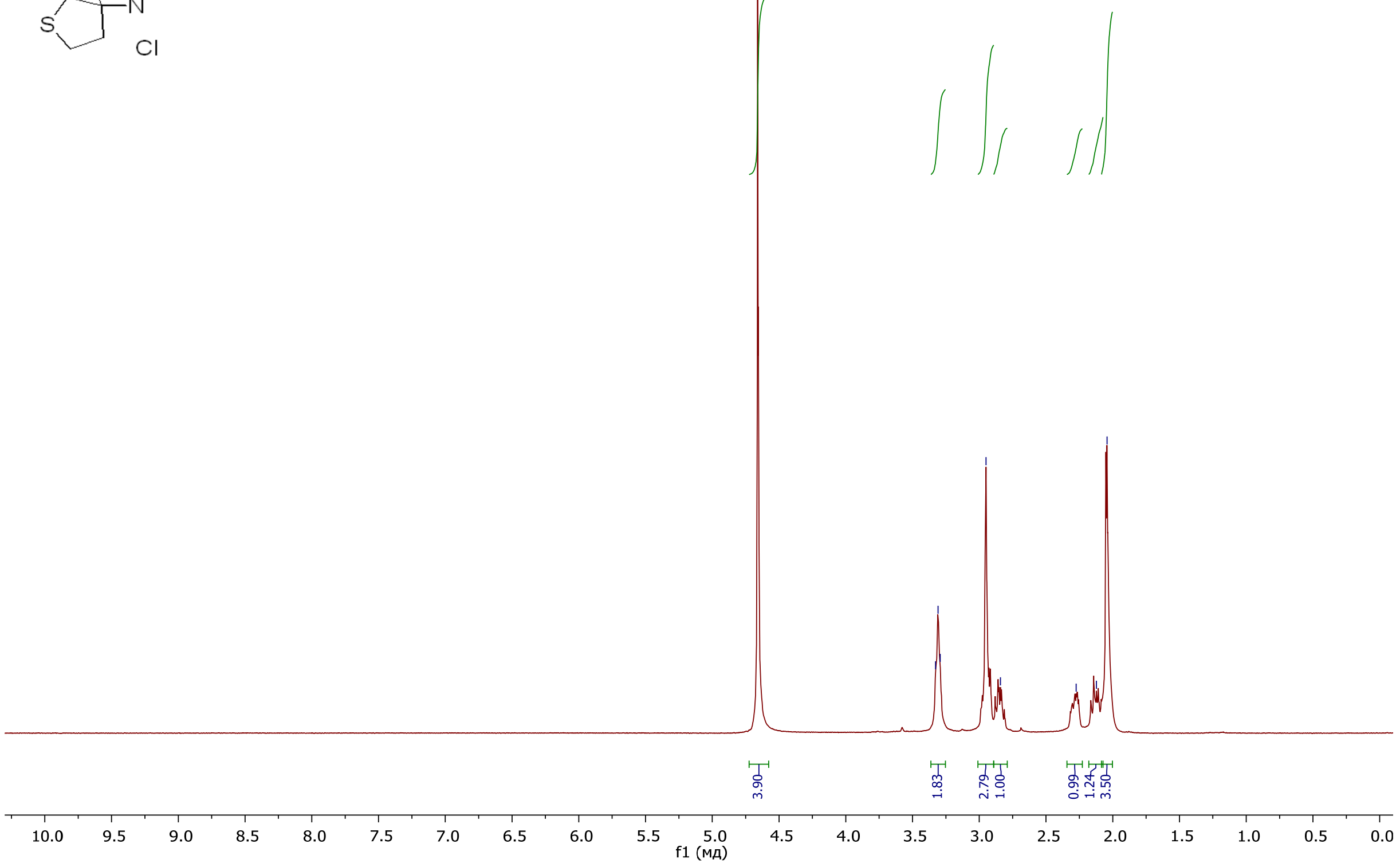
Figure S149. ${ }^{13} \mathrm{C}$ spectrum of the compound $\mathbf{1} \mathbf{k}^{*} \mathbf{H C l}$.

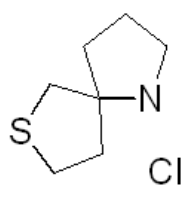

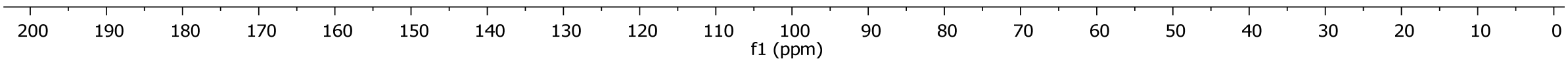


Synthesis of 7-thia-1-azaspiro[4.4]nonane 7,7-dioxide hydrochloride (11*HCl). Approach III.

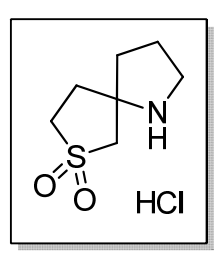

$1 I^{*} \mathrm{HCl}$

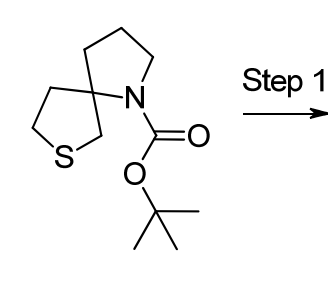

20k

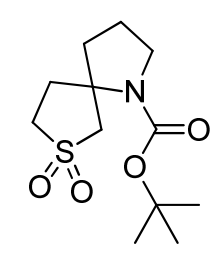

201

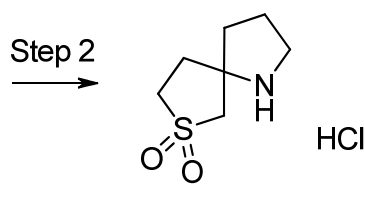

$1 I^{*} \mathrm{HCl}$

Scheme S16.

Figure S150. ${ }^{1} \mathrm{H}$ spectrum of the compound 201.

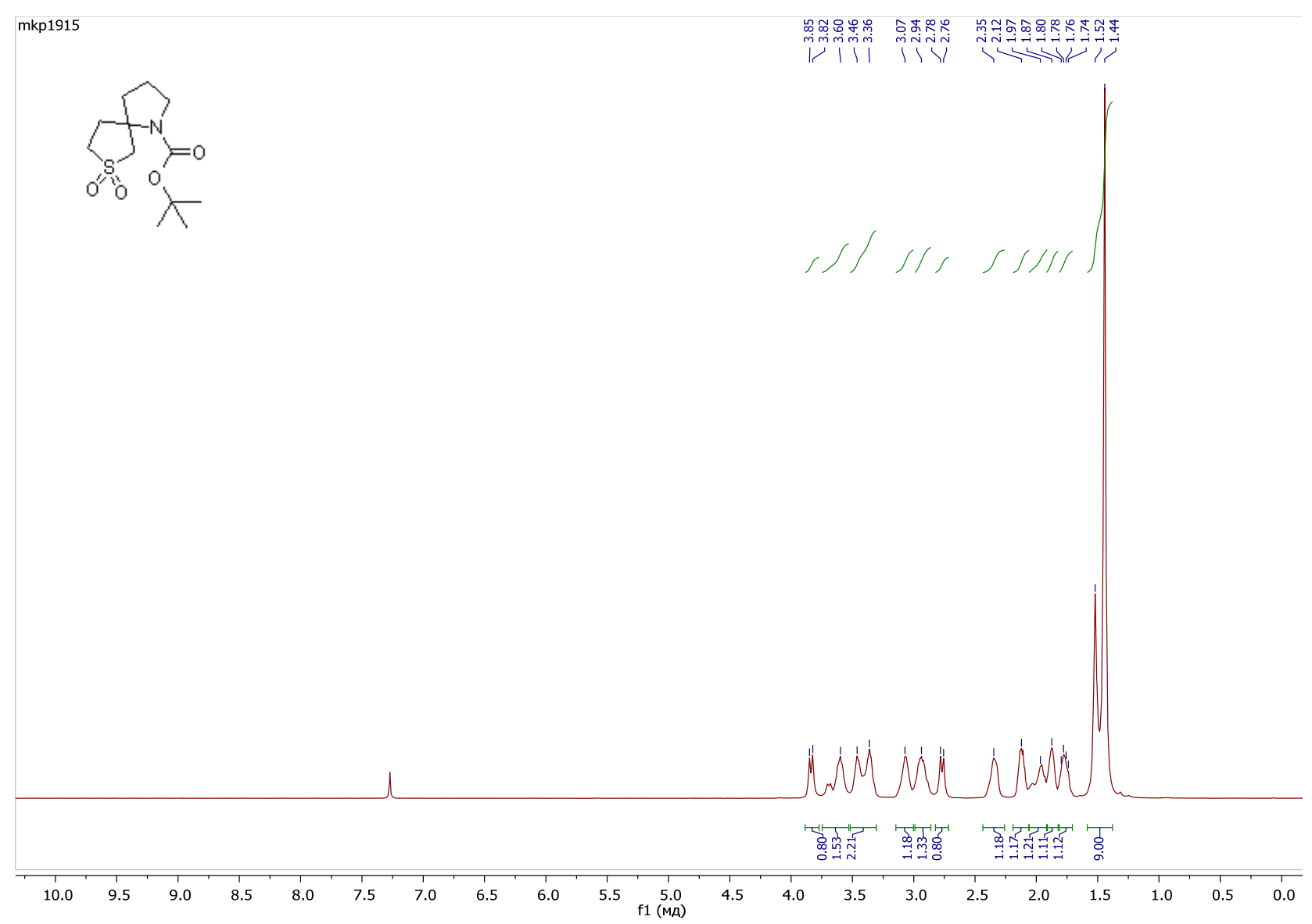


Figure S151. ${ }^{13} \mathrm{C}$ spectrum of the compound 201.

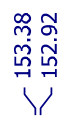
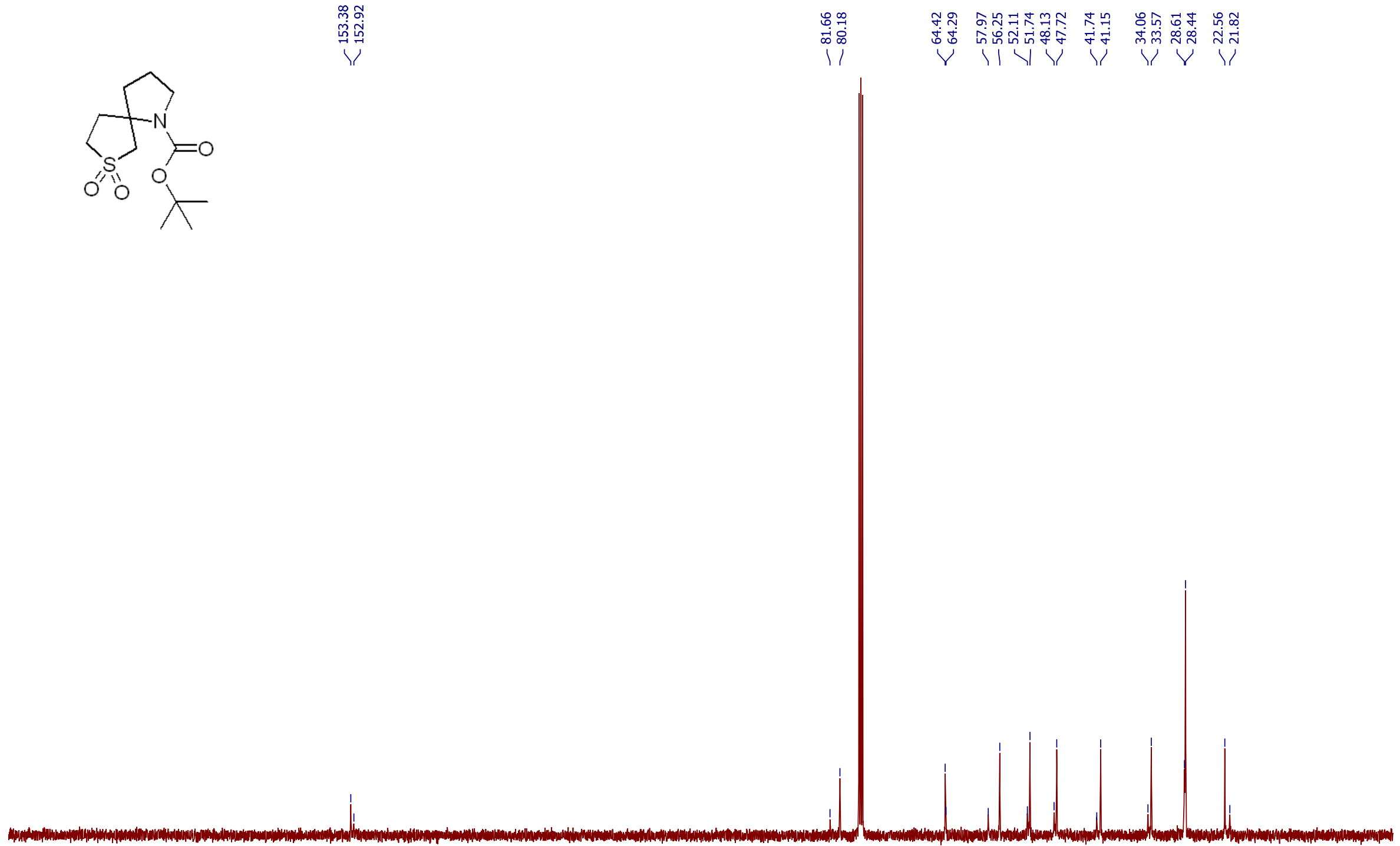

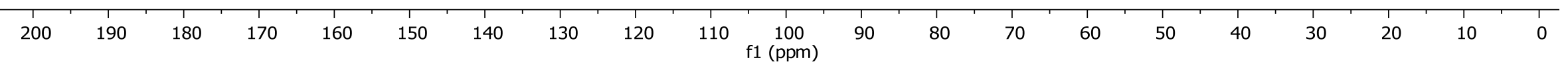


Figure S152. ${ }^{1} \mathrm{H}$ spectrum of the compound $\mathbf{1 1 *} \mathbf{H C l}$.

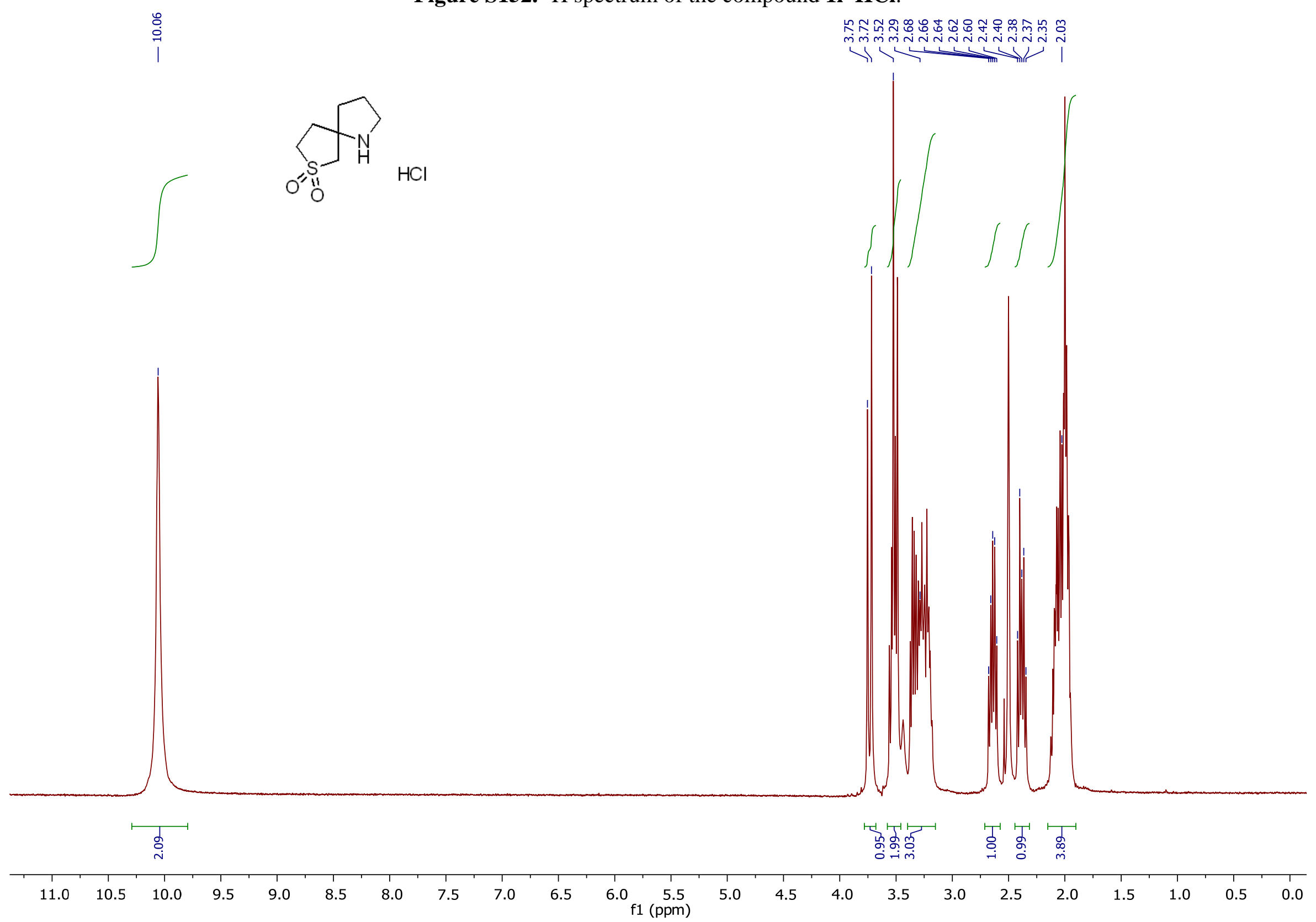


Figure S153. ${ }^{13} \mathrm{C}$ spectrum of the compound $\mathbf{1 1 *} \mathbf{H C l}$.

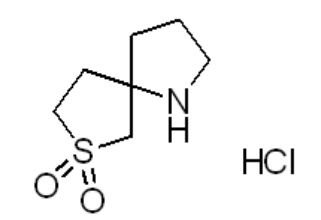

$$
\mathrm{Cl}
$$


Synthesis of 7-thia-1-azaspiro[4.5]decane hydrochloride (1m*HCl). Approach II.

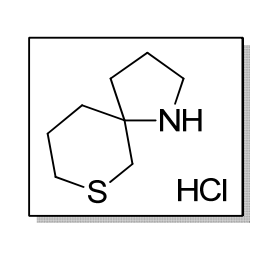

$1 \mathrm{~m} * \mathrm{HCl}$

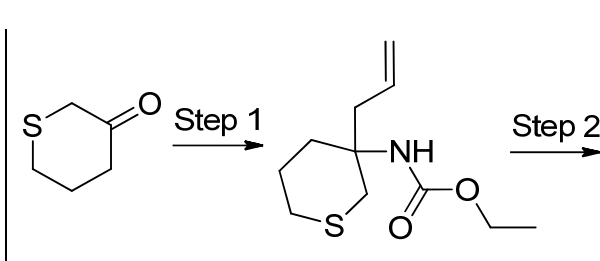

$2 m$

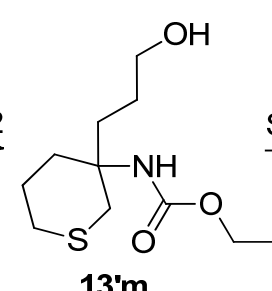

13 'm

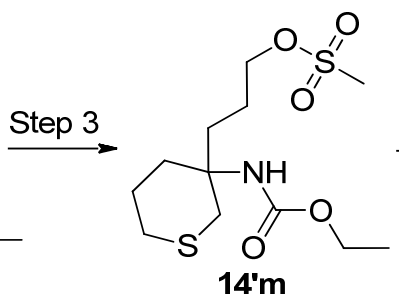

14 'm

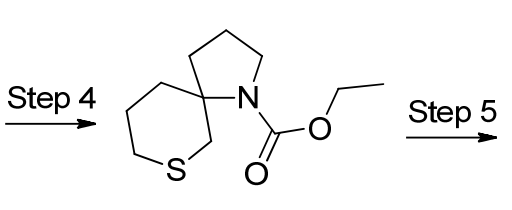

$15 ' \mathrm{~m}$

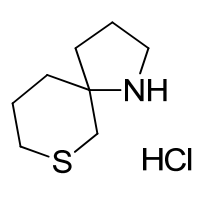

$1 \mathrm{~m} * \mathrm{HCl}$

Figure S154. ${ }^{1} \mathrm{H}$ NMR spectrum of the compound $\mathbf{1 2 m}$.

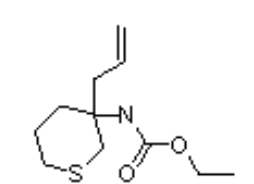

TR spectrum of the compound $\mathbf{1 2 m}$.

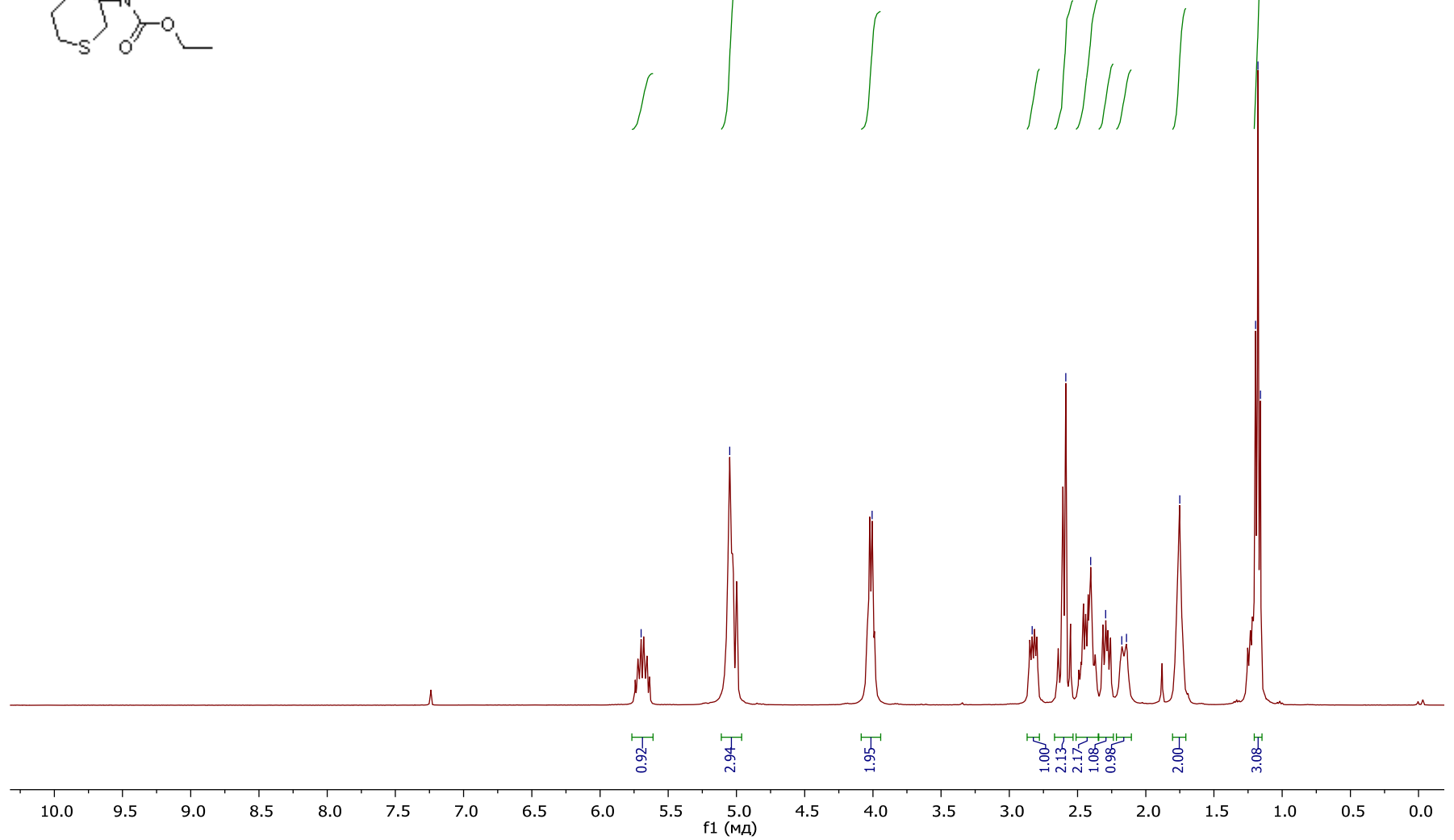


Figure S155. ${ }^{13} \mathrm{C}$ NMR spectrum of the compound $12 \mathrm{~m}$.

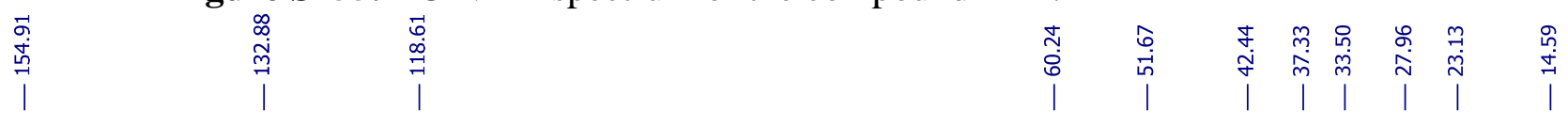
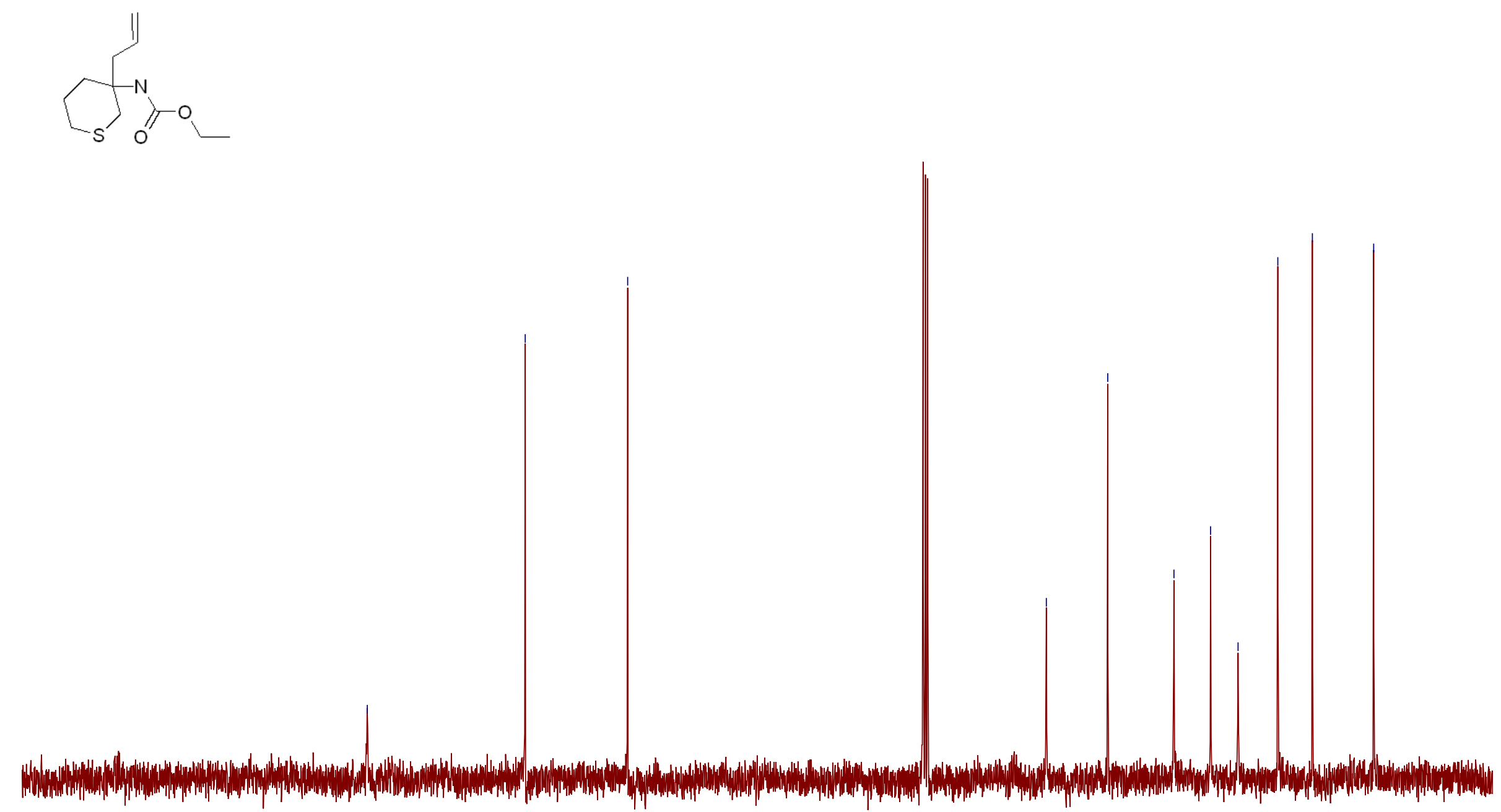

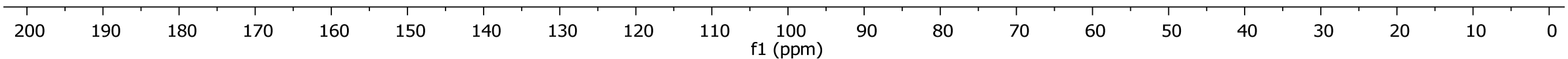


Figure S156. Mass spectrum of the compound 12m.

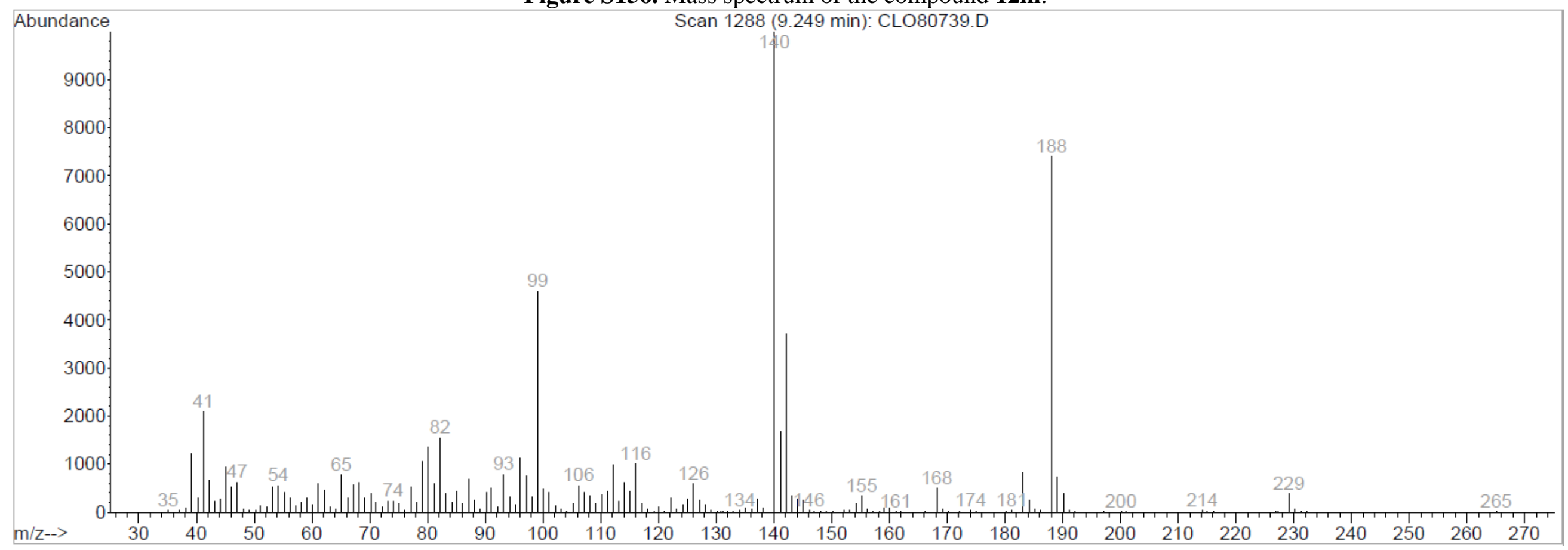


Figure S157. ${ }^{1} \mathrm{H}$ NMR spectrum of the compound $\mathbf{1 3 m}$.

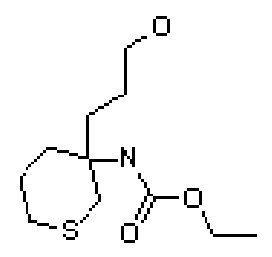
|
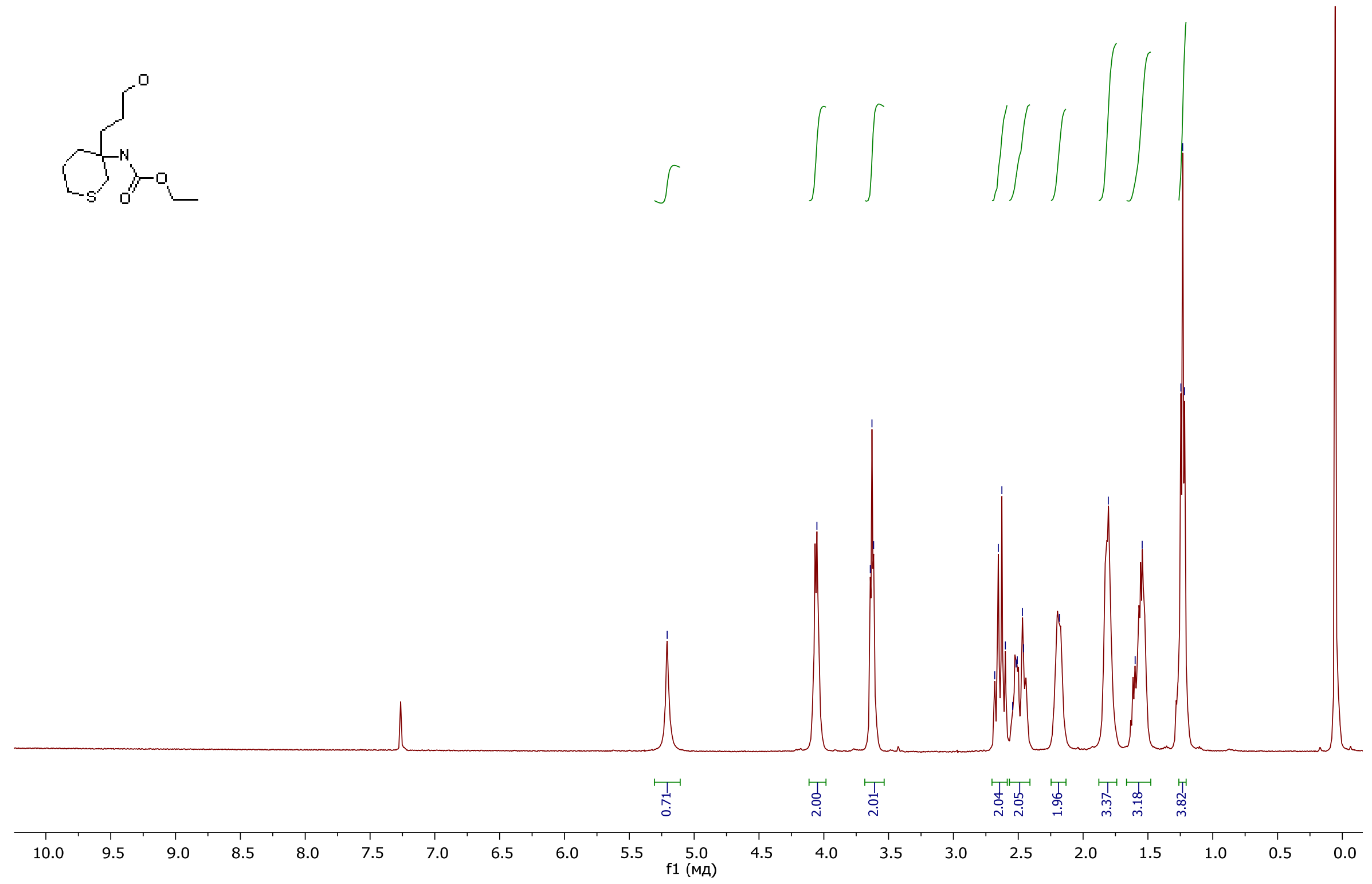
Figure S158. ${ }^{13} \mathrm{C}$ NMR spectrum of the compound $\mathbf{1 3 m}$.
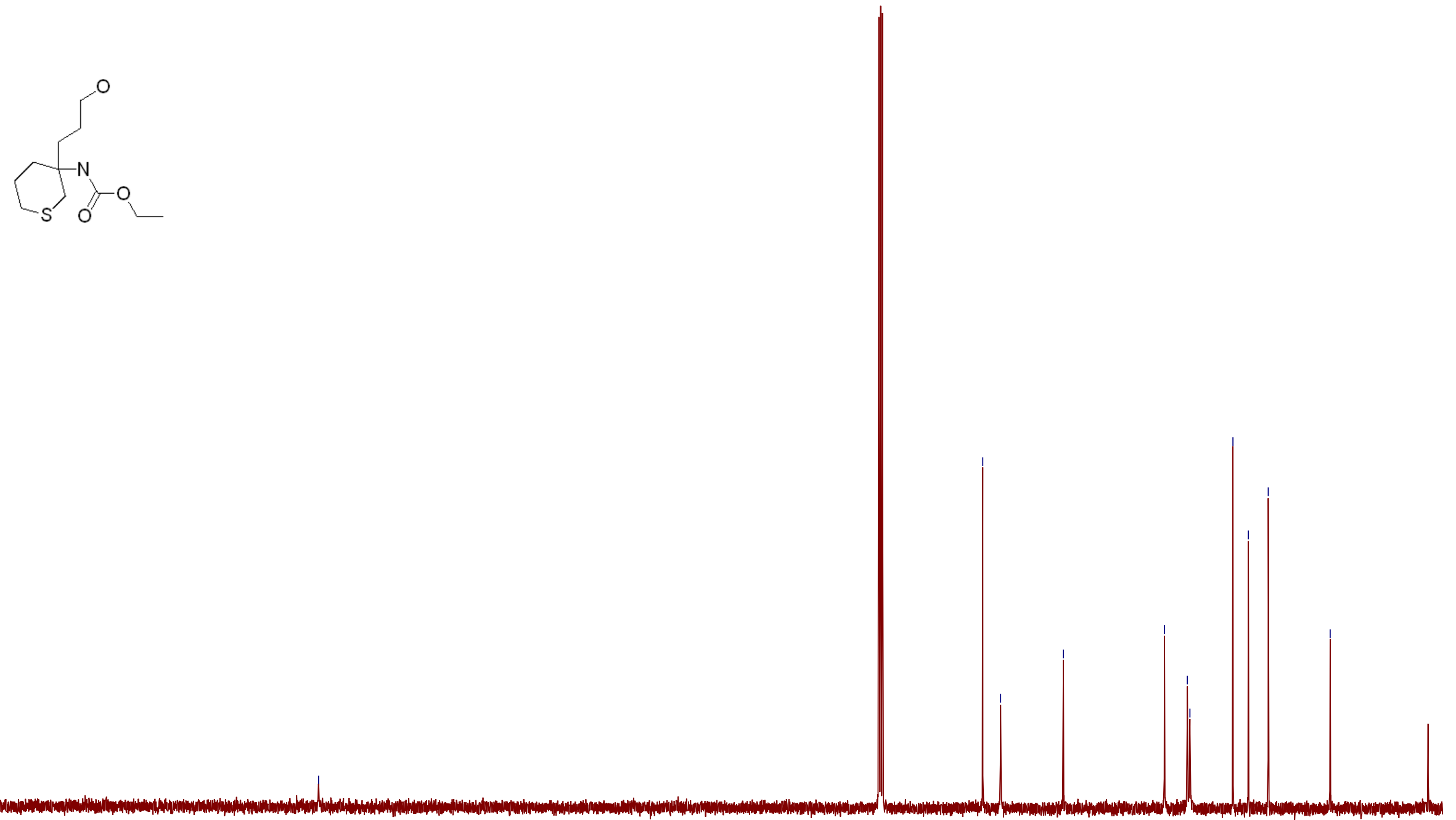
Figure S159. Mass spectrum of the compound 13m.

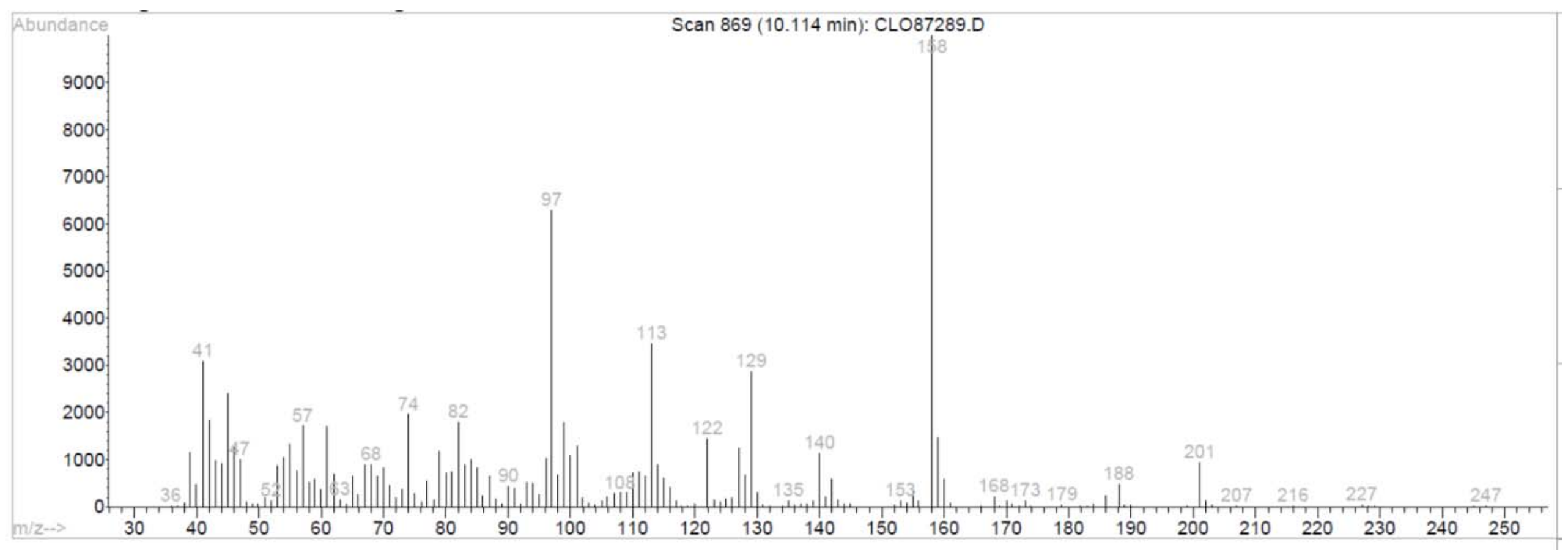


Figure S160. ${ }^{1} \mathrm{H}$ NMR spectrum of the compound $14 \mathbf{m}$.

i
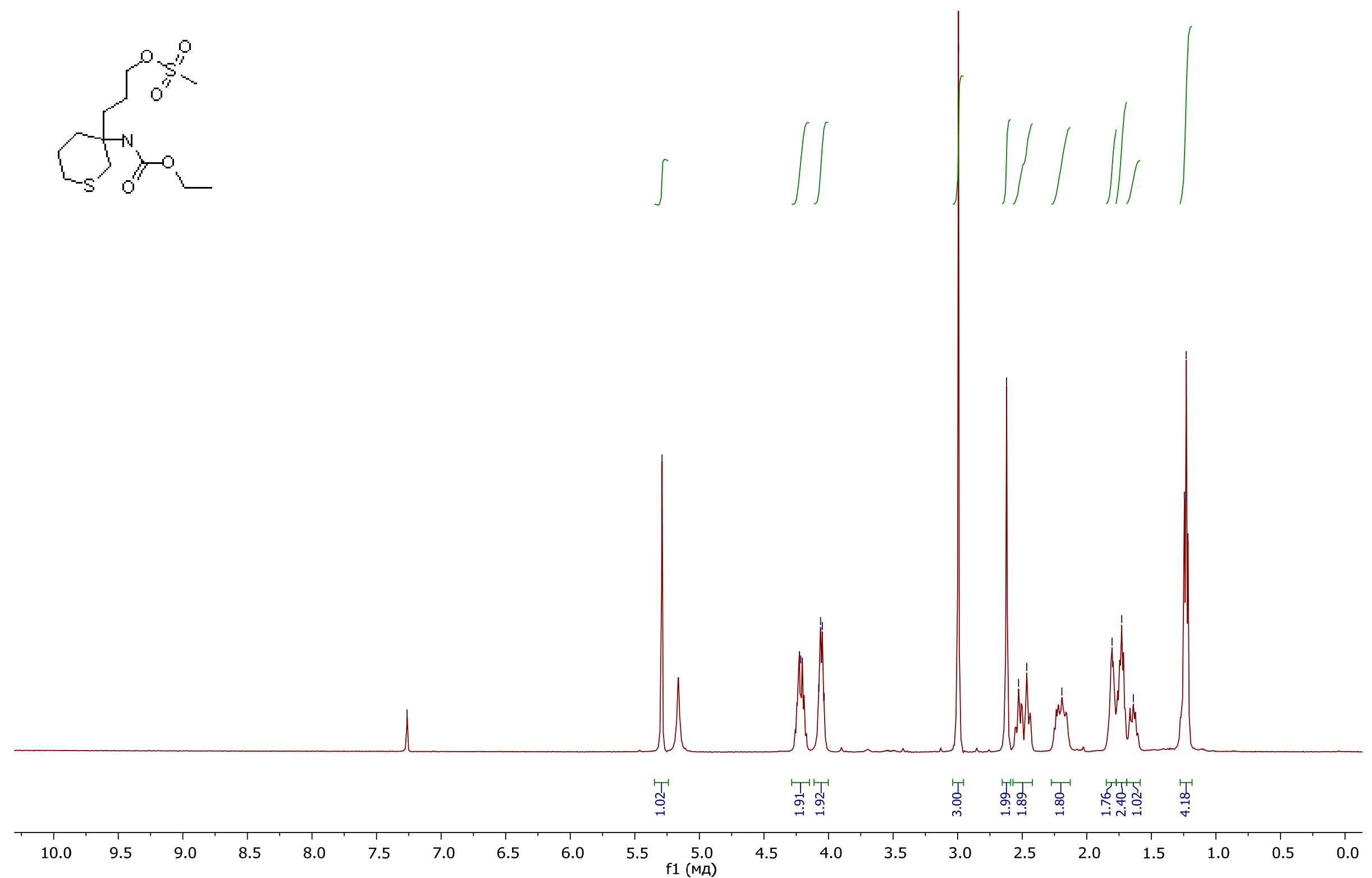
Figure S161. ${ }^{13} \mathrm{C}$ NMR spectrum of the compound $\mathbf{1 4 m}$.

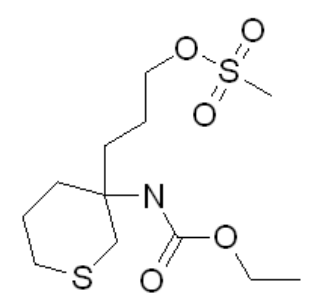


Figure S162. Mass spectrum of the compound $\mathbf{1 4 m}$.

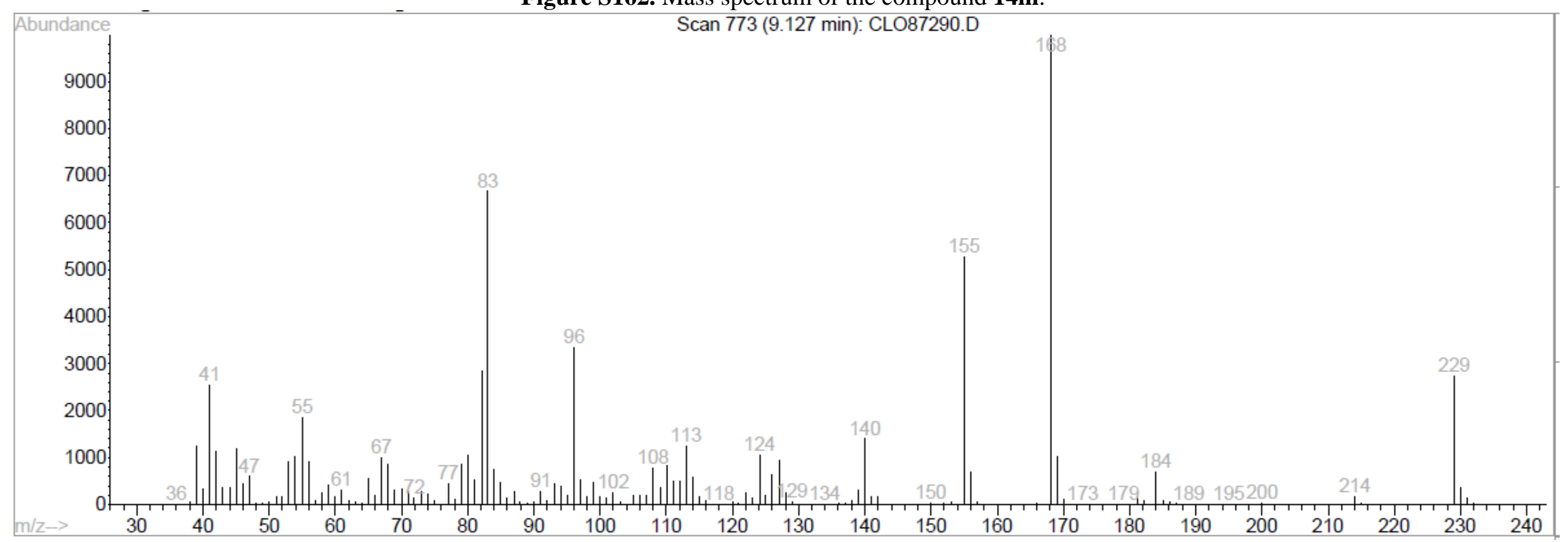


Figure S163. ${ }^{1} \mathrm{H}$ NMR spectrum of the compound $\mathbf{1 5 m}$.

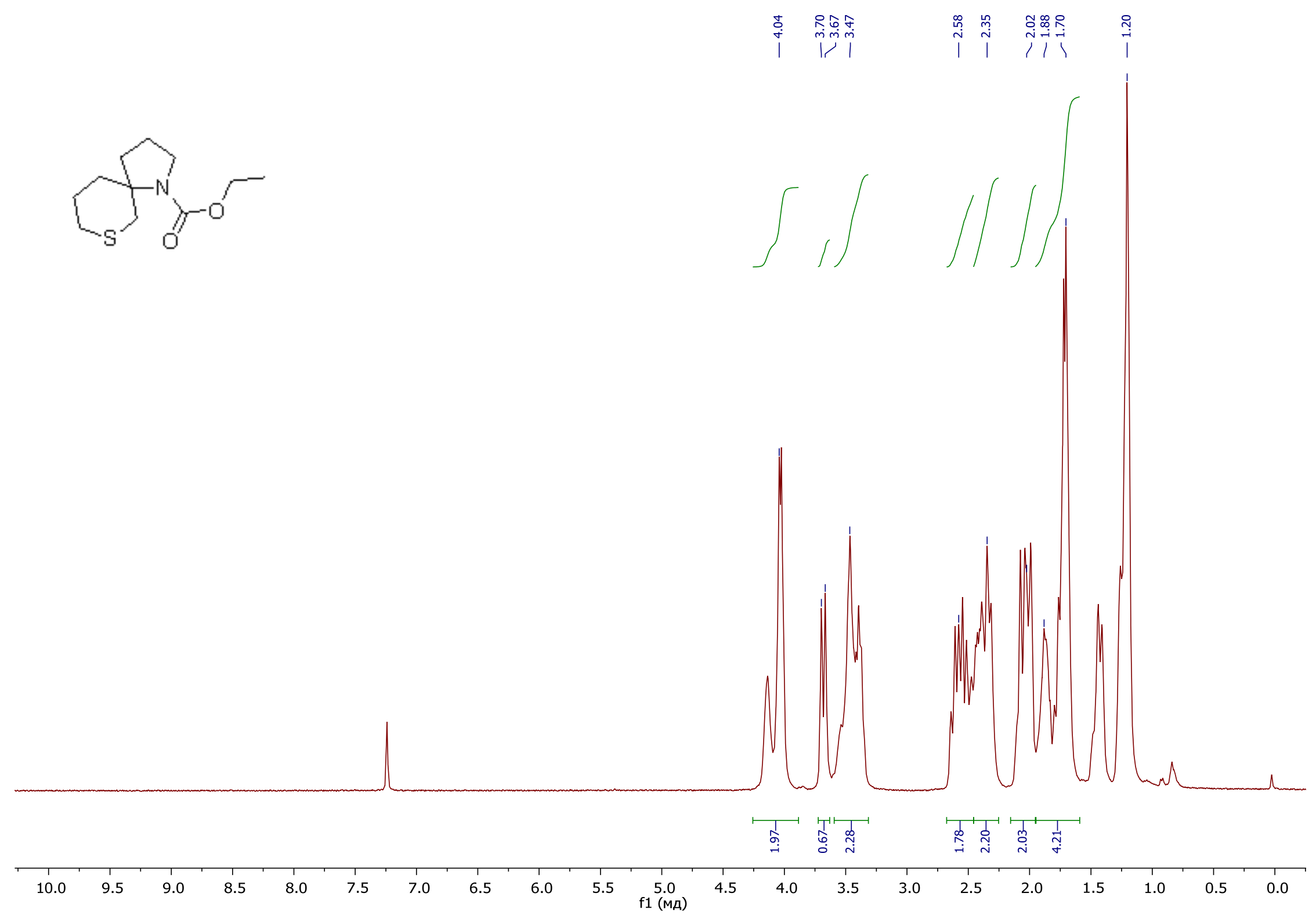


Figure S164. ${ }^{13} \mathrm{C}$ NMR spectrum of the compound $15 \mathrm{~m}$.
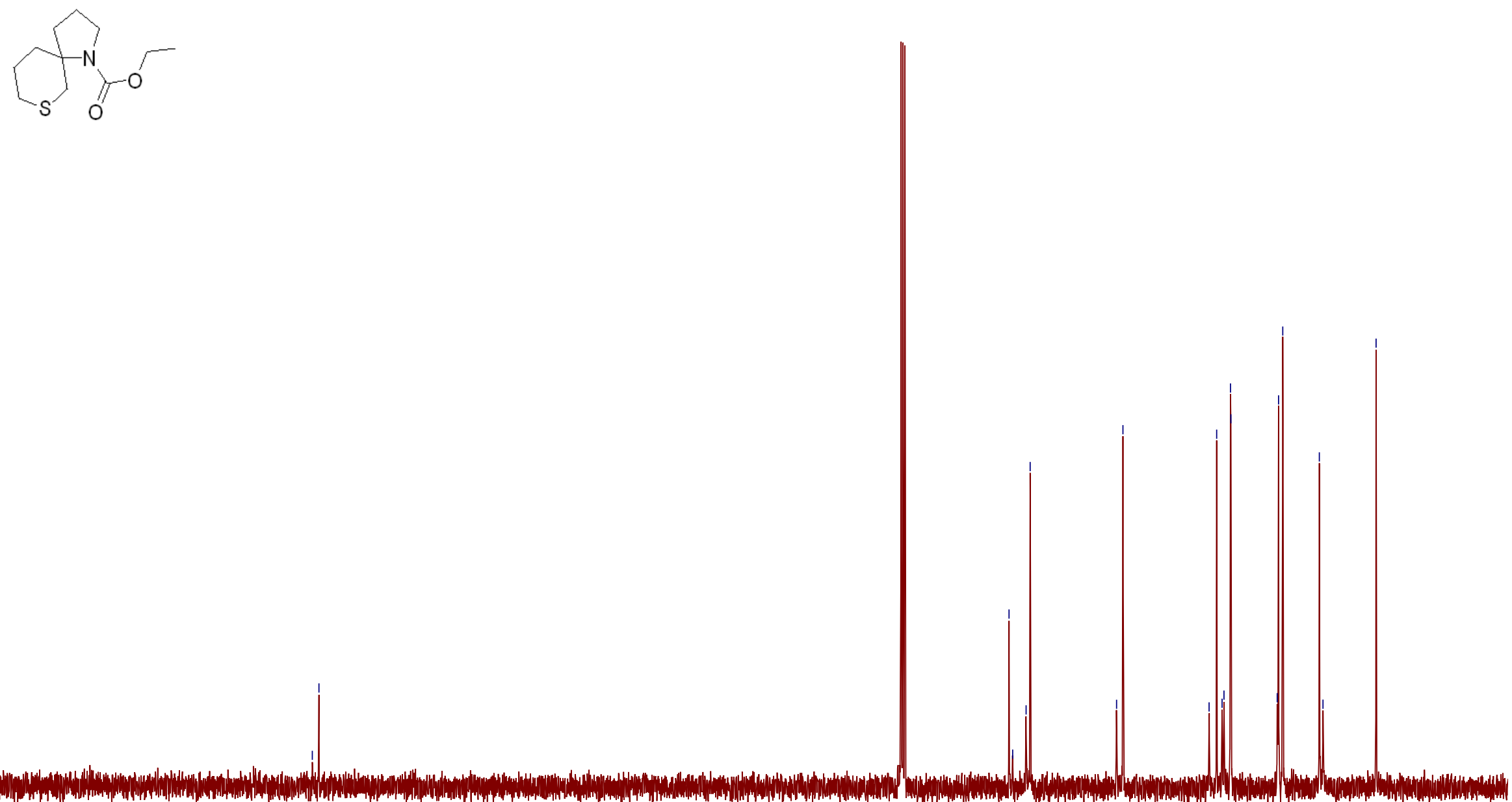
Figure S165. Mass spectrum of the compound $\mathbf{1 5 m}$.

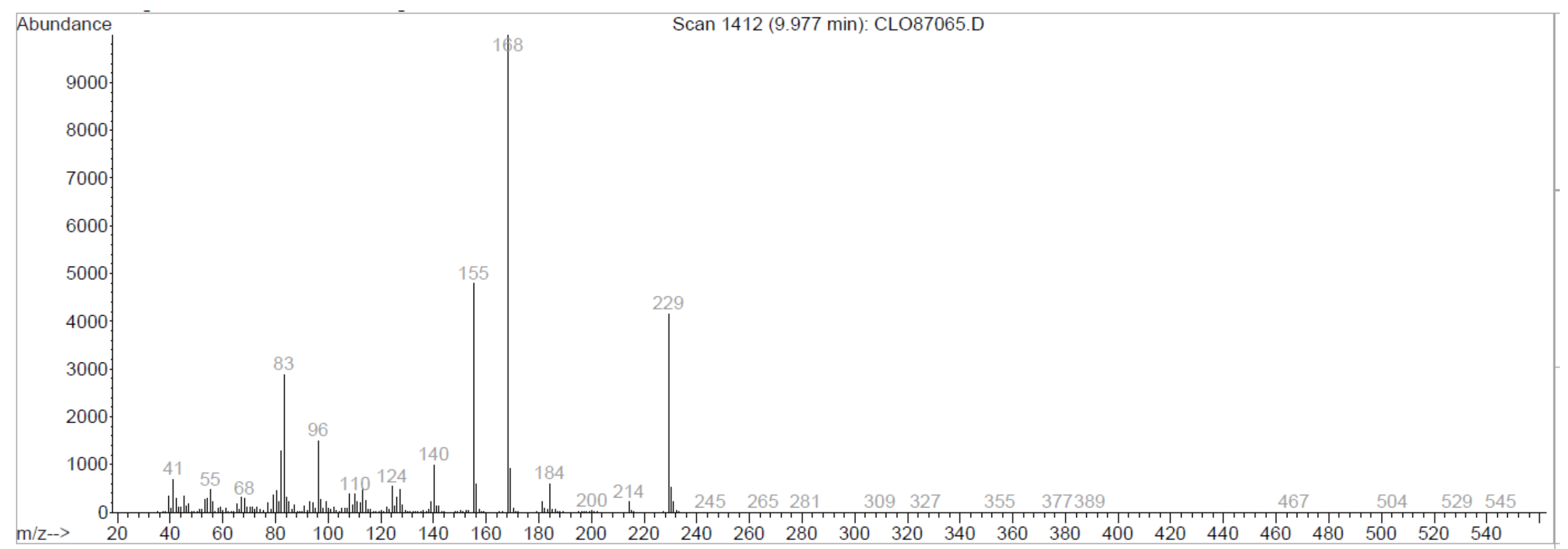


Figure S166. ${ }^{1} \mathrm{H}$ NMR spectrum of the compound $1 \mathbf{m} * \mathbf{H C l}$.

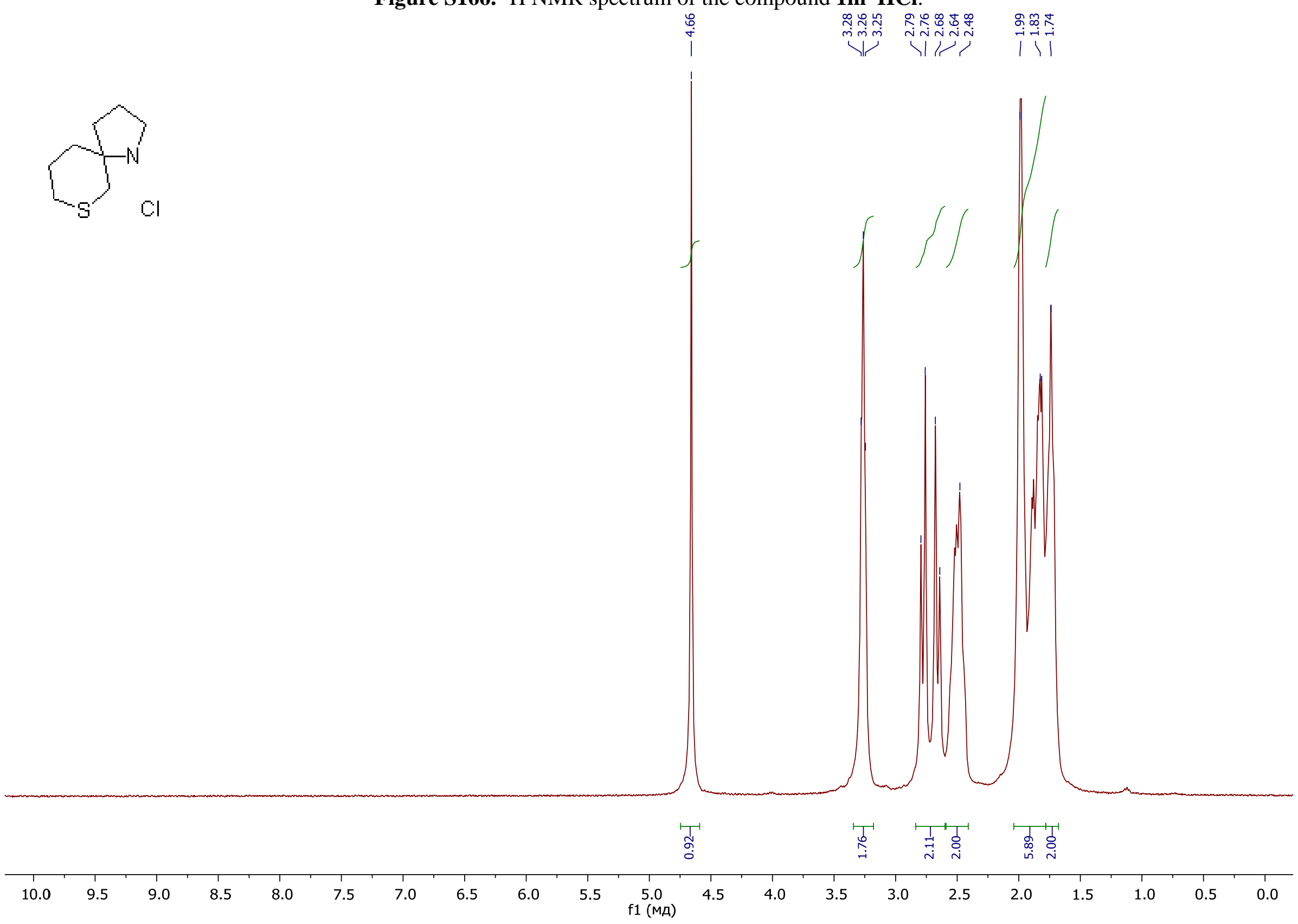


Figure S167. ${ }^{13} \mathrm{C}$ NMR spectrum of the compound $\mathbf{1 m} * \mathbf{H C l}$.

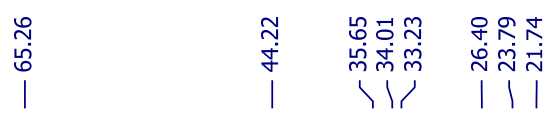

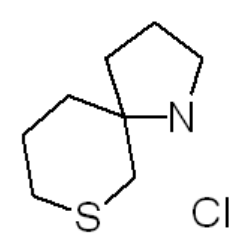


Synthesis of benzyl 7-thia-1-azaspiro[4.5]decane 7,7-dioxide hydrochloride (1n*HCl). Approach II.

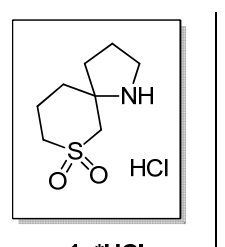

$1 n^{*} \mathrm{HCl}$

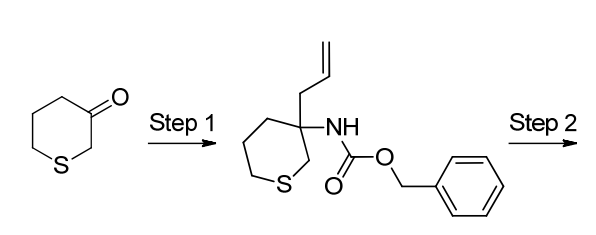

$8 m$

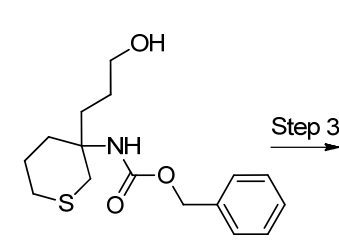

$9 m$

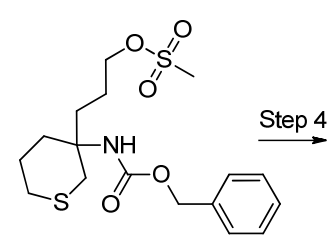

$10 \mathrm{~m}$

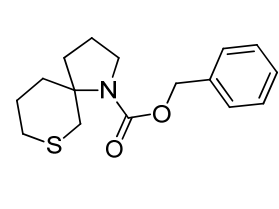

$11 \mathrm{~m}$

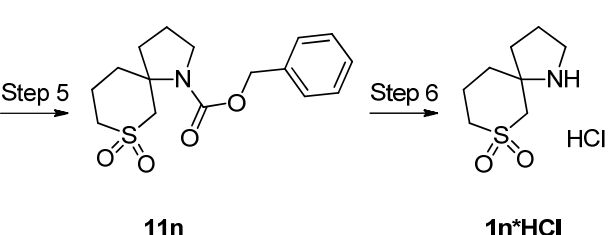

$11 \mathrm{n}$

$1 n^{*} \mathrm{HCl}$

Scheme S18.

Figure S168. ${ }^{1} \mathrm{H}$ NMR spectrum of the compound $\mathbf{8 m}$.

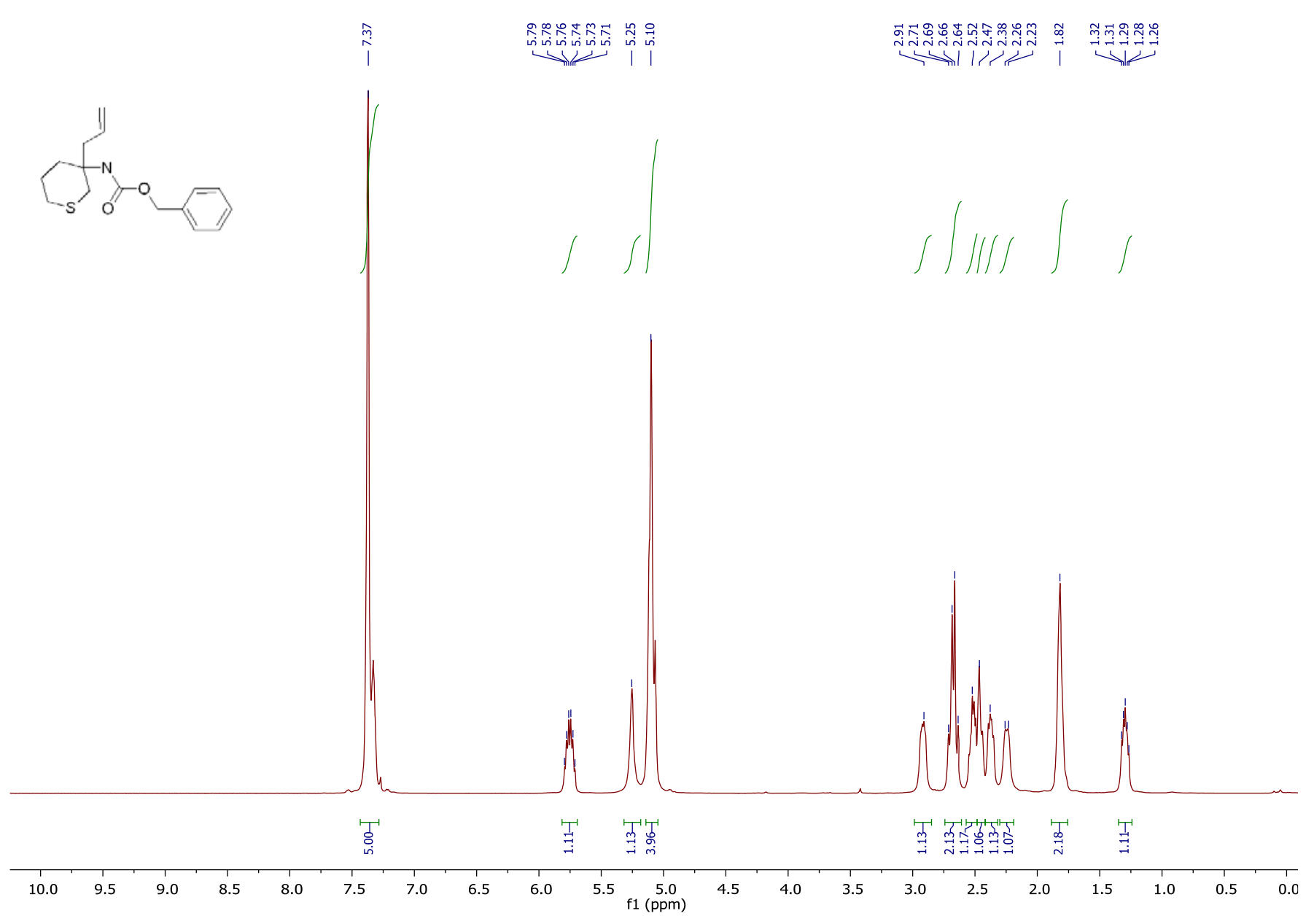


Figure S169. ${ }^{13} \mathrm{C}$ NMR spectrum of the compound $\mathbf{8 m}$.

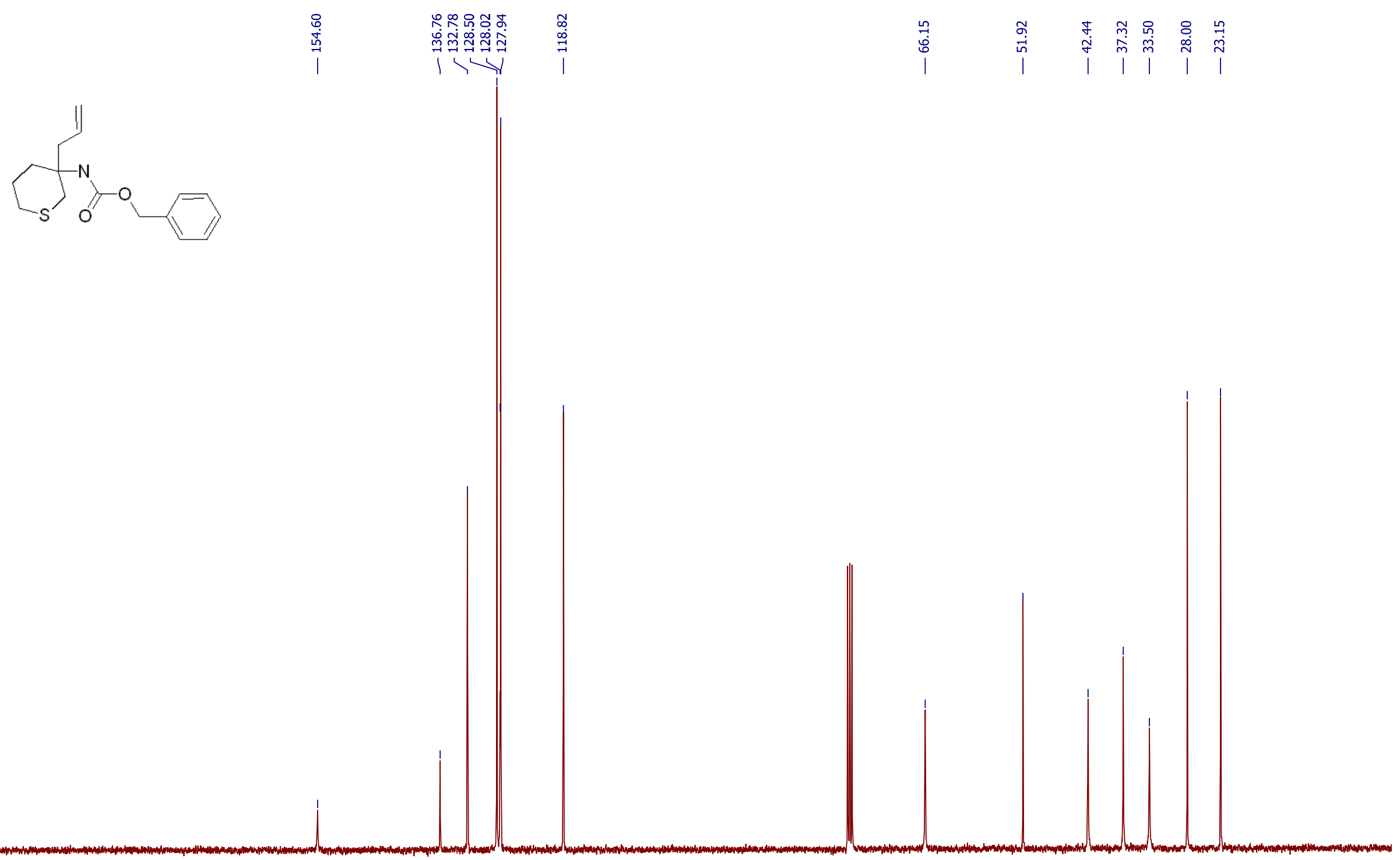


Figure S170. Mass NMR spectrum of the compound $\mathbf{8 m}$.

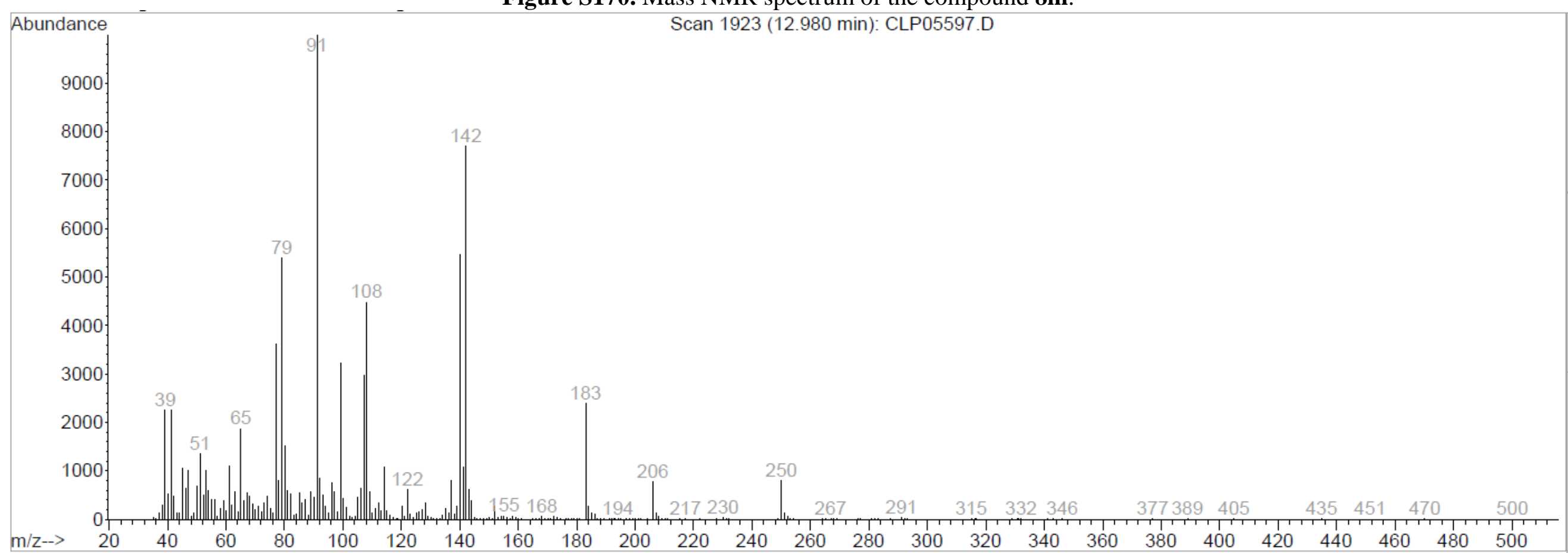


Figure S171. ${ }^{1} \mathrm{H}$ NMR spectrum of the compound $\mathbf{9 m}$.

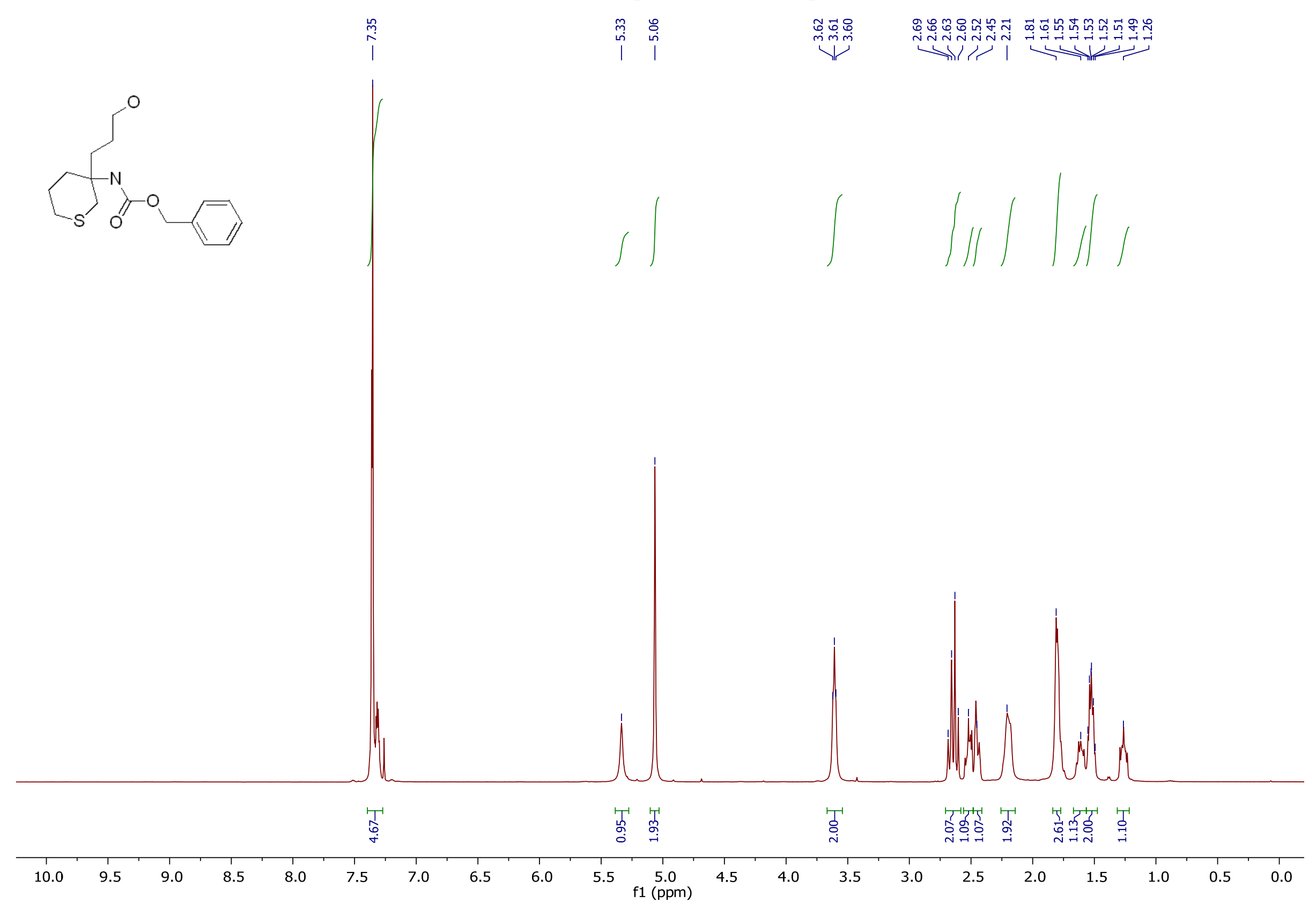


Figure S172. ${ }^{13} \mathrm{C}$ NMR spectrum of the compound $\mathbf{9 m}$.
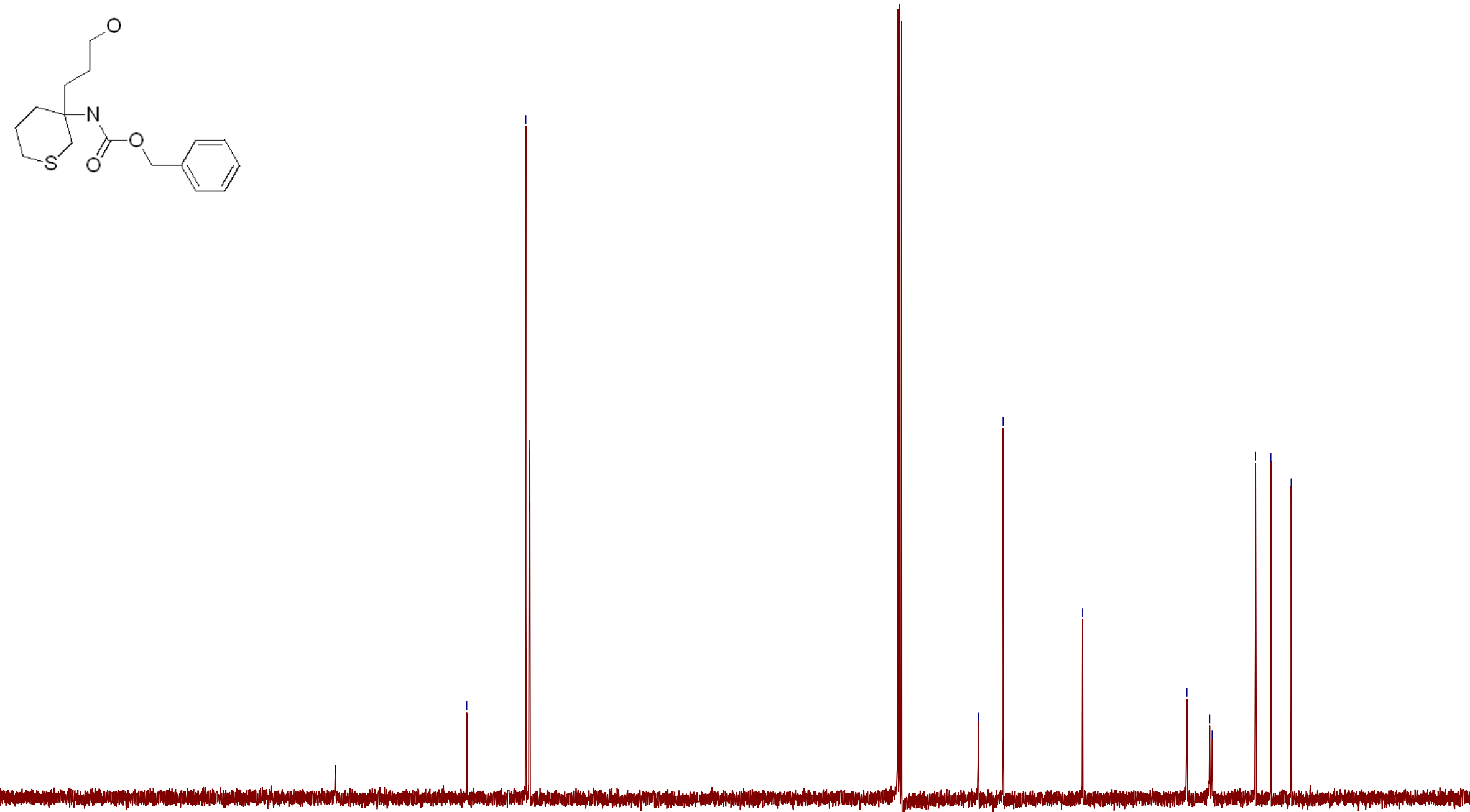

\begin{tabular}{|c|c|c|c|c|c|c|c|c|c|c|c|c|c|c|c|c|c|c|c|}
\hline 200 & 190 & 180 & 170 & 160 & 150 & 140 & 130 & 120 & 110 & 100 & 90 & 80 & 70 & 60 & 50 & 40 & 30 & 20 & 10 \\
\hline
\end{tabular}


Figure S173. ${ }^{1} \mathrm{H}$ NMR spectrum of the compound $10 \mathrm{~m}$.

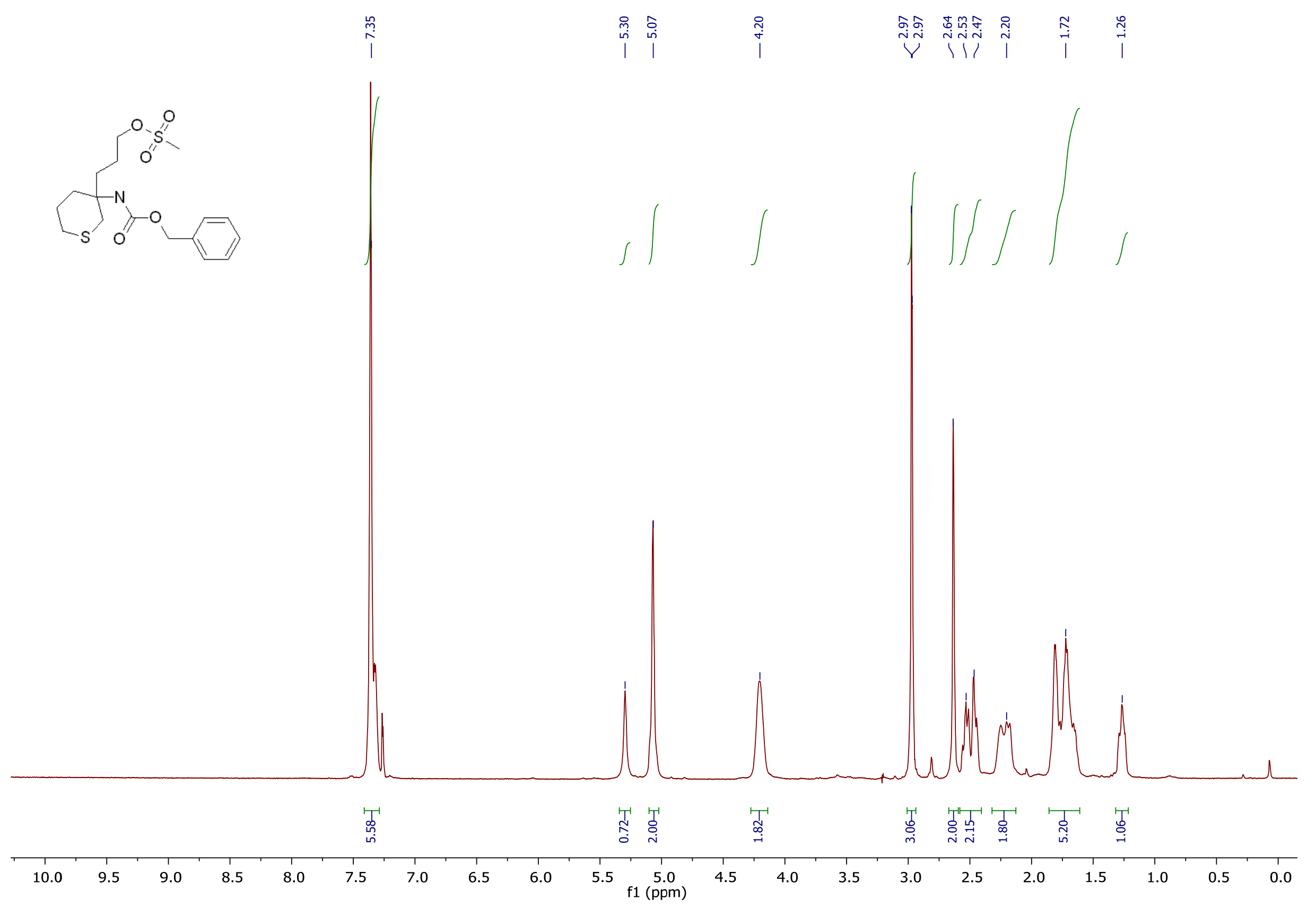


Figure S174. ${ }^{13} \mathrm{C}$ NMR spectrum of the compound $10 \mathrm{~m}$.

\begin{tabular}{|c|c|c|c|c|}
\hline 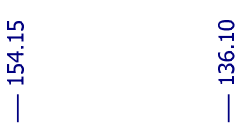 & 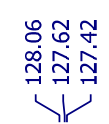 & 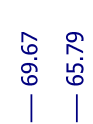 & 总 & 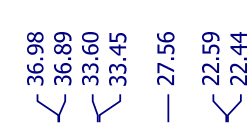 \\
\hline
\end{tabular}
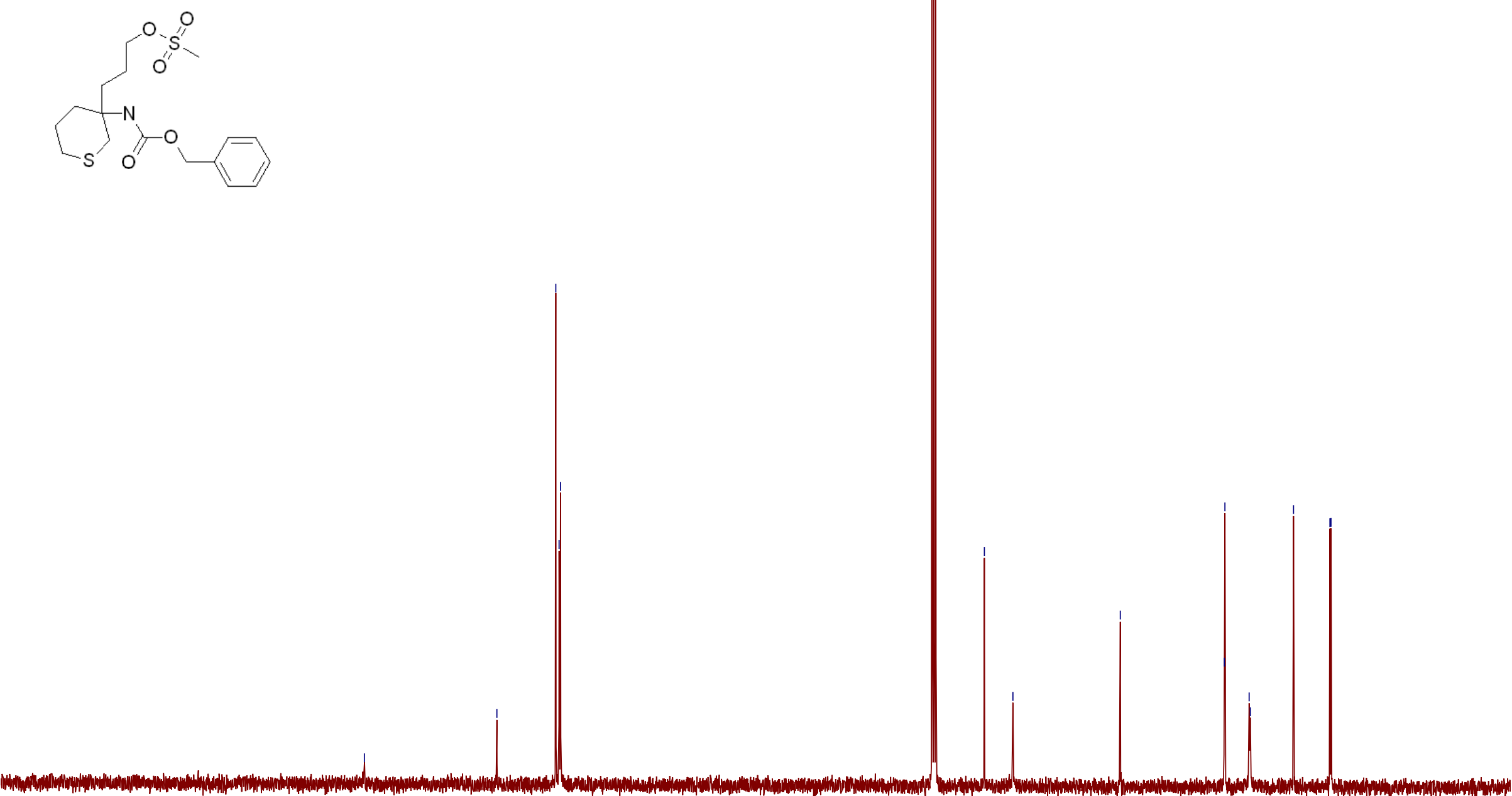

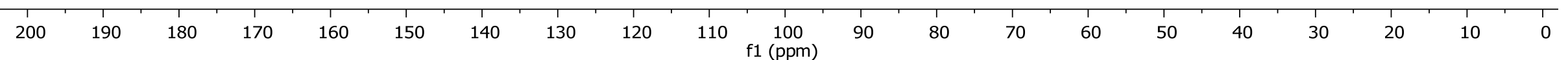


Figure S175. ${ }^{1} \mathrm{H}$ NMR spectrum of the compound $\mathbf{1 1 m}$.

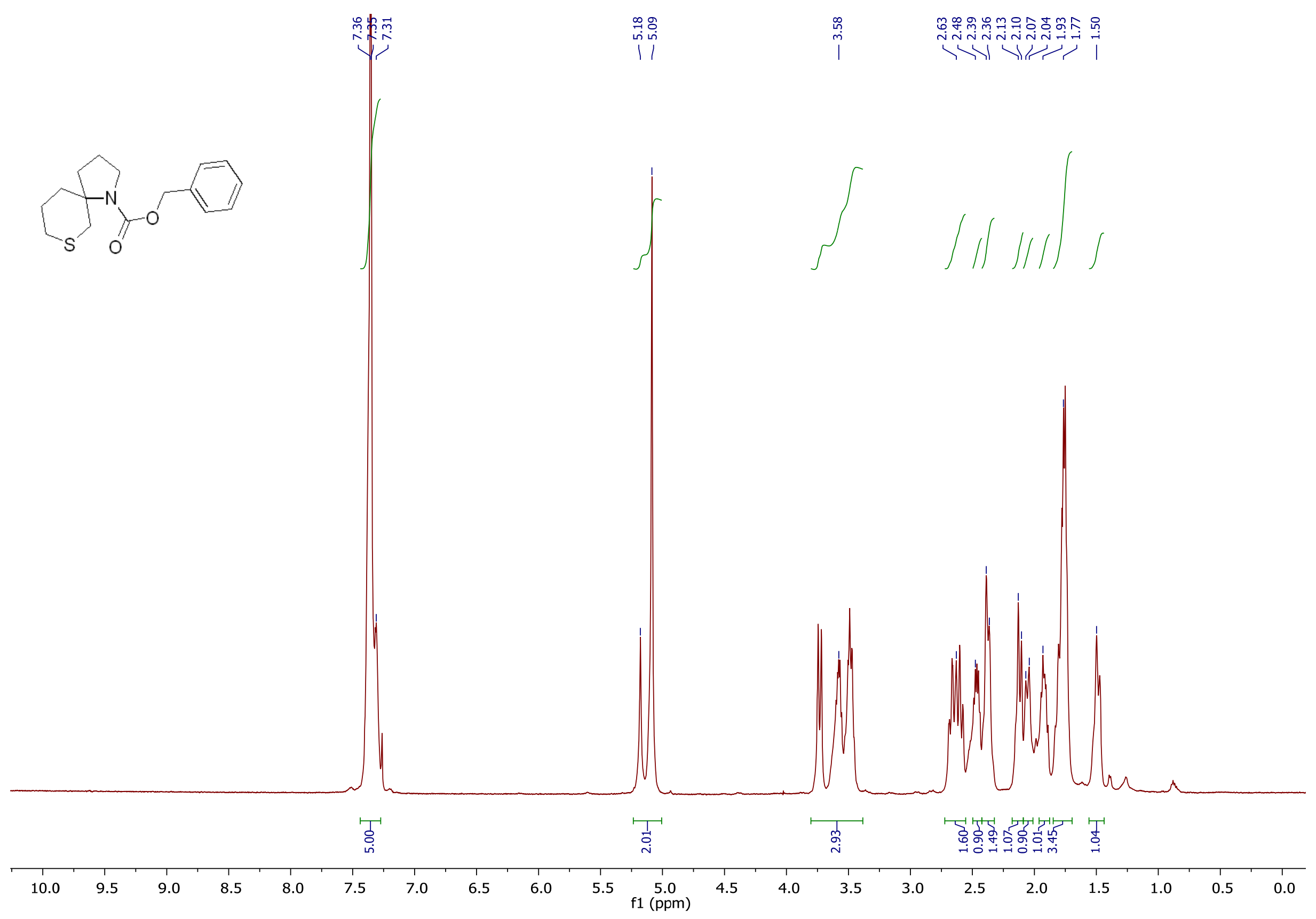


Figure S176. ${ }^{13} \mathrm{C}$ NMR spectrum of the compound $11 \mathrm{~m}$.

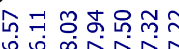

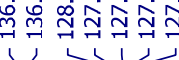

กิน

$\checkmark \mathrm{V}$

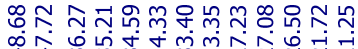

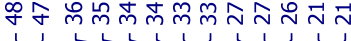

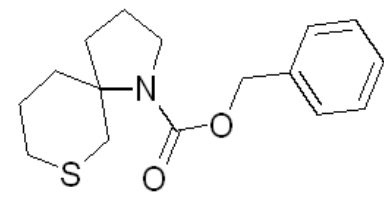

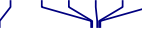

,

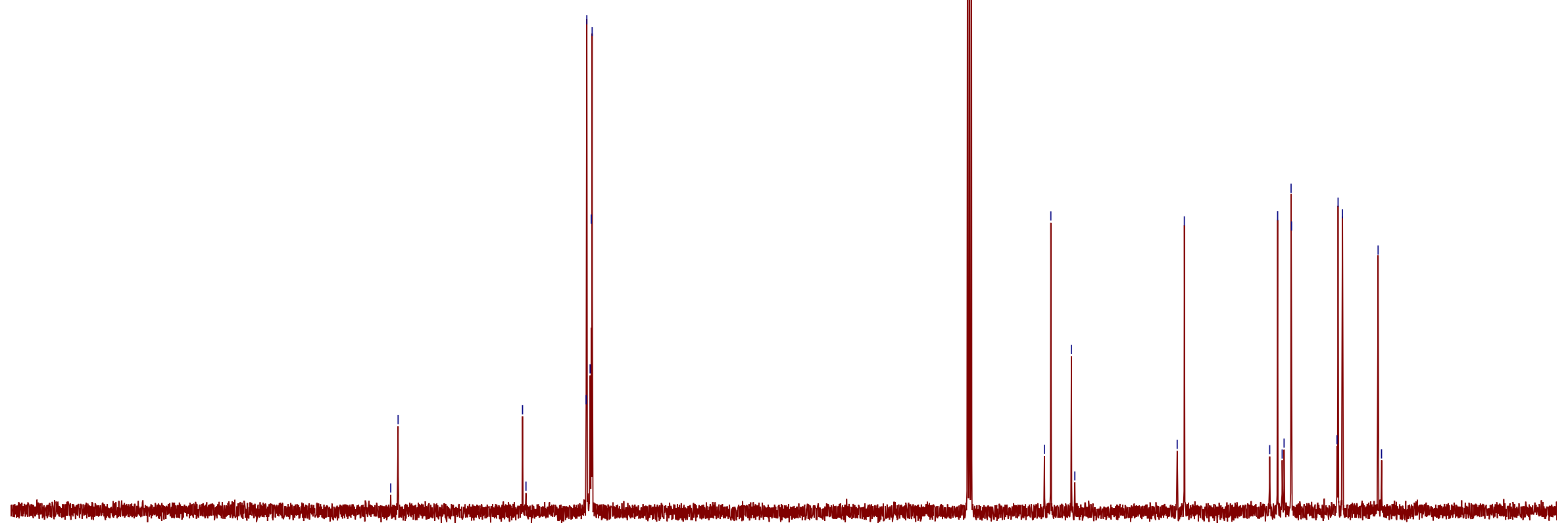

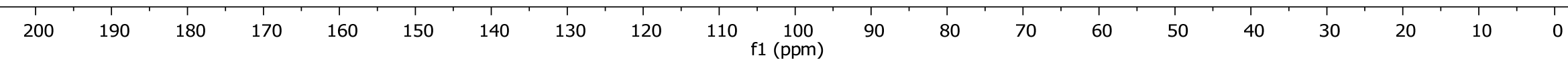


Figure S177. ${ }^{1} \mathrm{H}$ NMR spectrum of the compound $\mathbf{1 1 n}$.

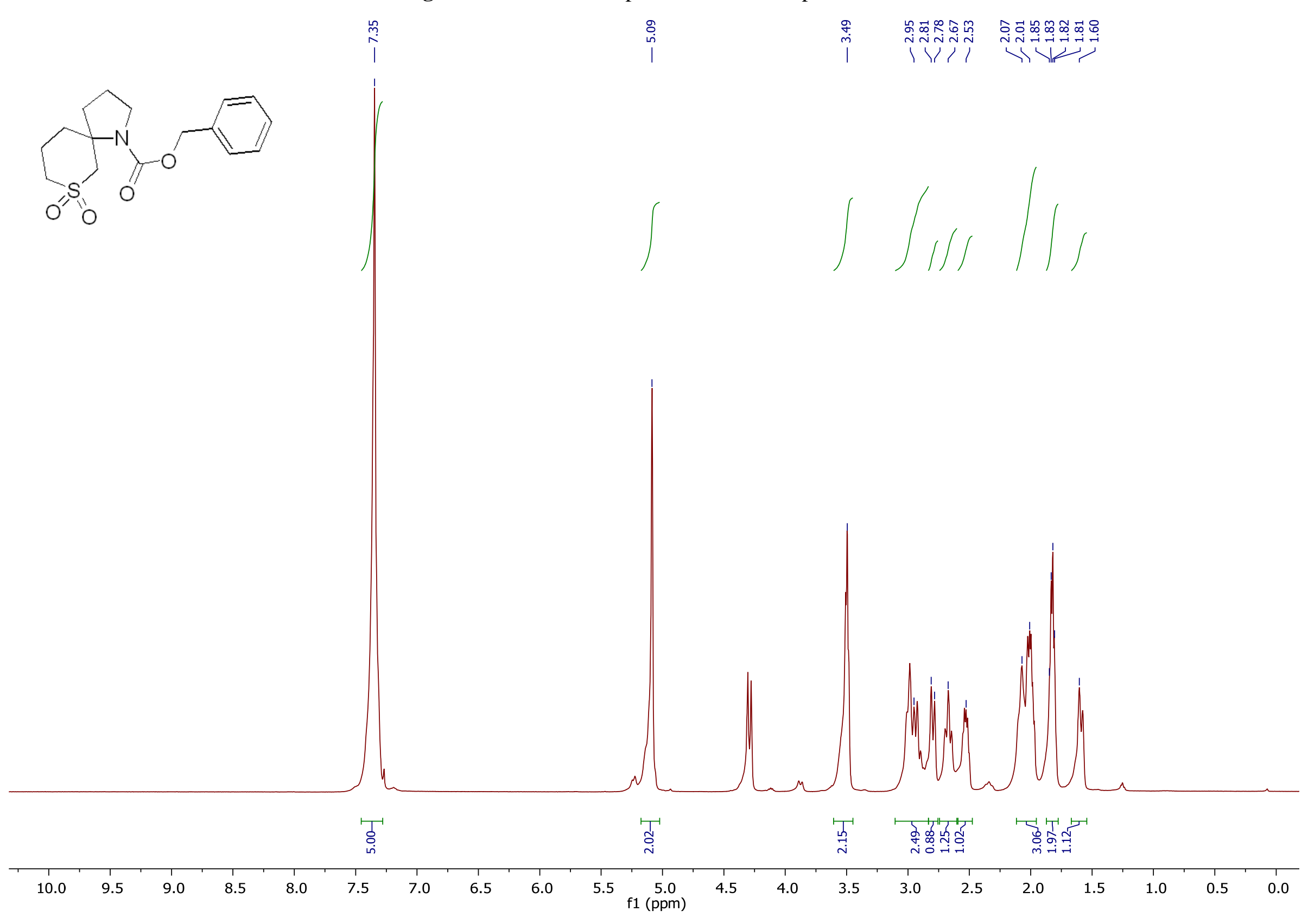


Figure S178. ${ }^{13} \mathrm{C}$ NMR spectrum of the compound $11 n$.

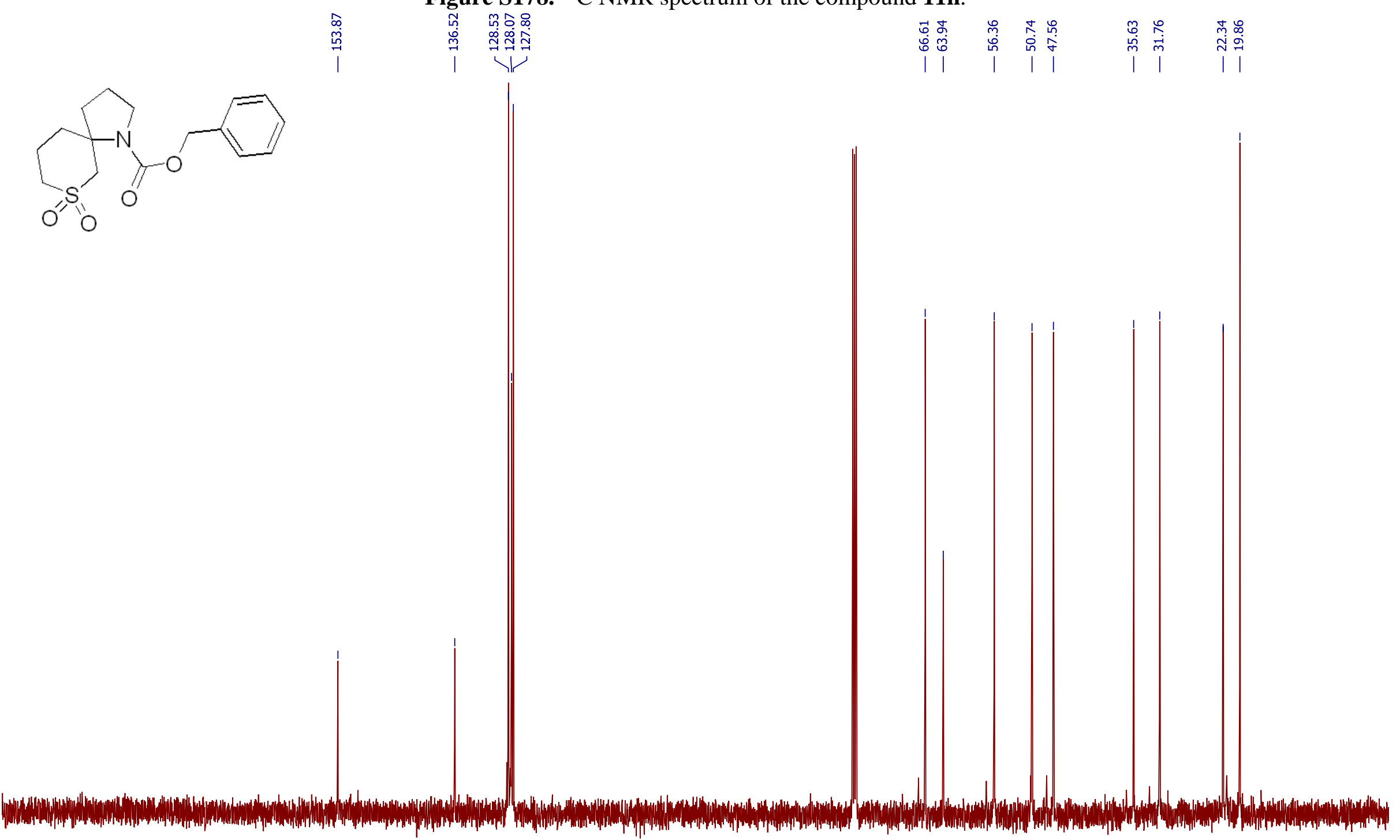

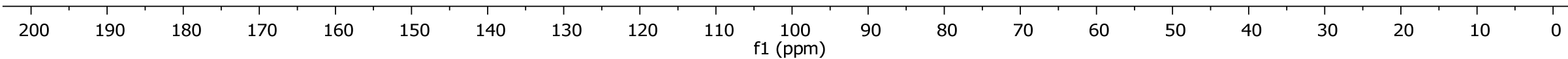


Figure S179. ${ }^{1} \mathrm{H}$ NMR spectrum of the compound $\mathbf{1 n} * \mathbf{H C l}$.

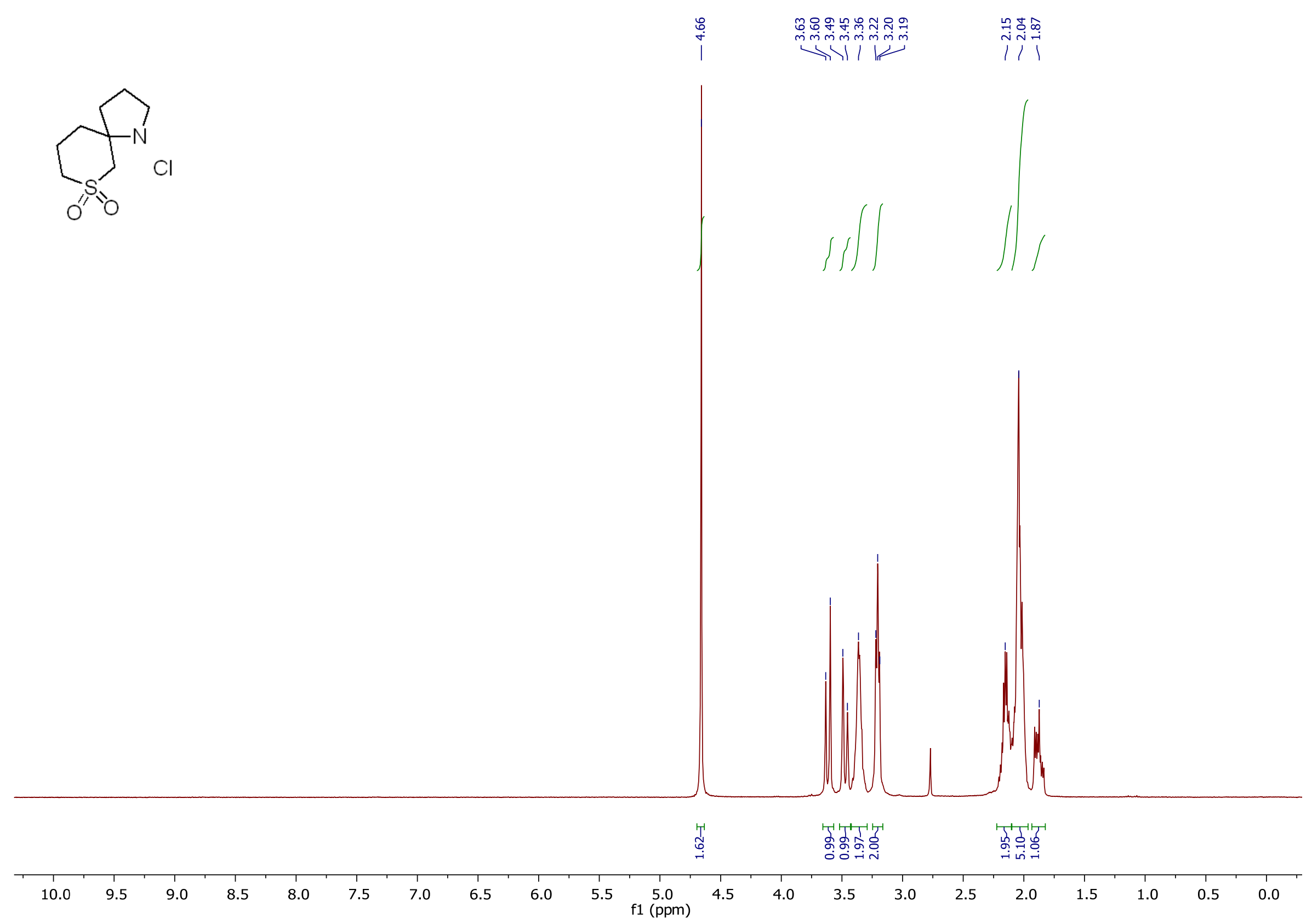


Figure S180. ${ }^{13} \mathrm{C}$ NMR spectrum of the compound $1 \mathbf{n} * \mathbf{H C l}$.

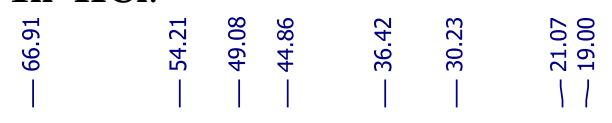

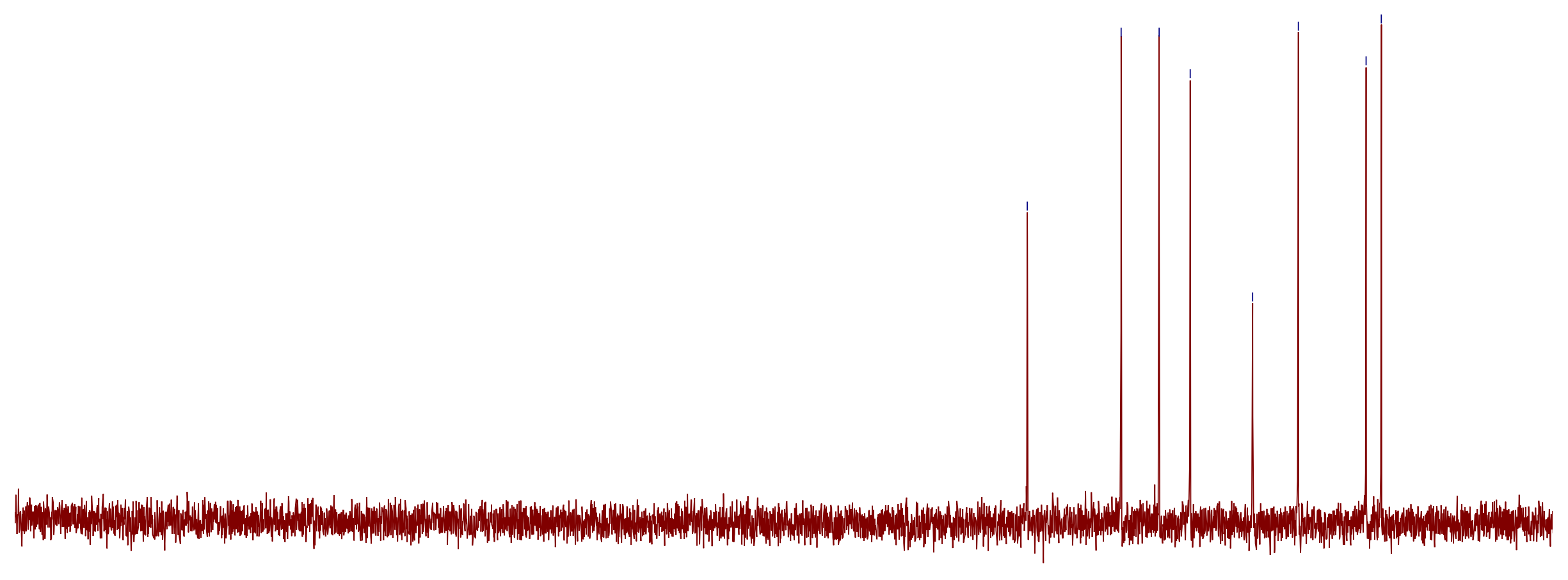

\begin{tabular}{|c|c|c|c|c|c|c|c|c|c|c|c|c|c|c|c|c|c|c|c|}
\hline 200 & $\begin{array}{l}1 \\
190\end{array}$ & 180 & 170 & 160 & $\begin{array}{l}1 \\
150\end{array}$ & 140 & 130 & 120 & 110 & 100 & 90 & 80 & 70 & 60 & 50 & & 30 & 20 & 10 \\
\hline
\end{tabular}


Synthesis of 8,8-difluoro-1-azaspiro[4.5]decane hydrochloride (10*HCl). Approach II.

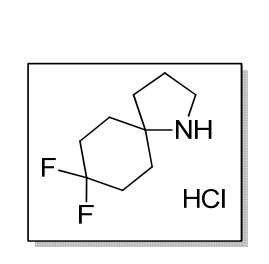

$10 * \mathrm{HCl}$

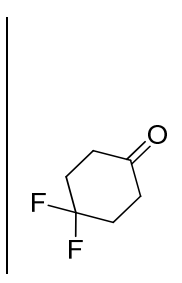

20

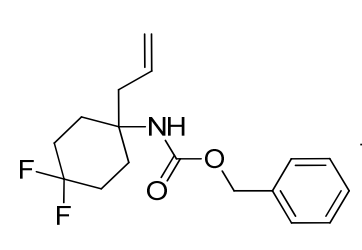

80

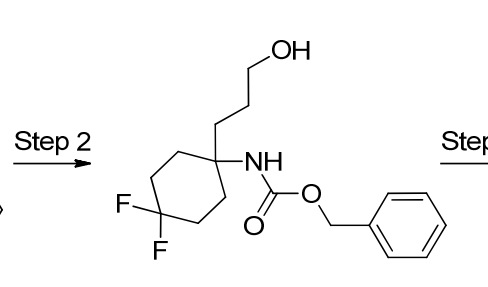

90

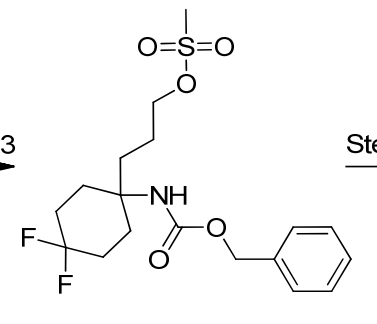

100

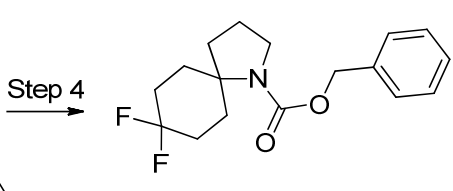

110

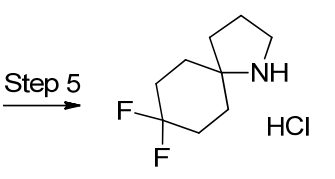

10* $\mathrm{HCl}$

Scheme S19.

Figure S181. ${ }^{1} \mathrm{H}$ NMR spectrum of the compound $\mathbf{8 0}$.

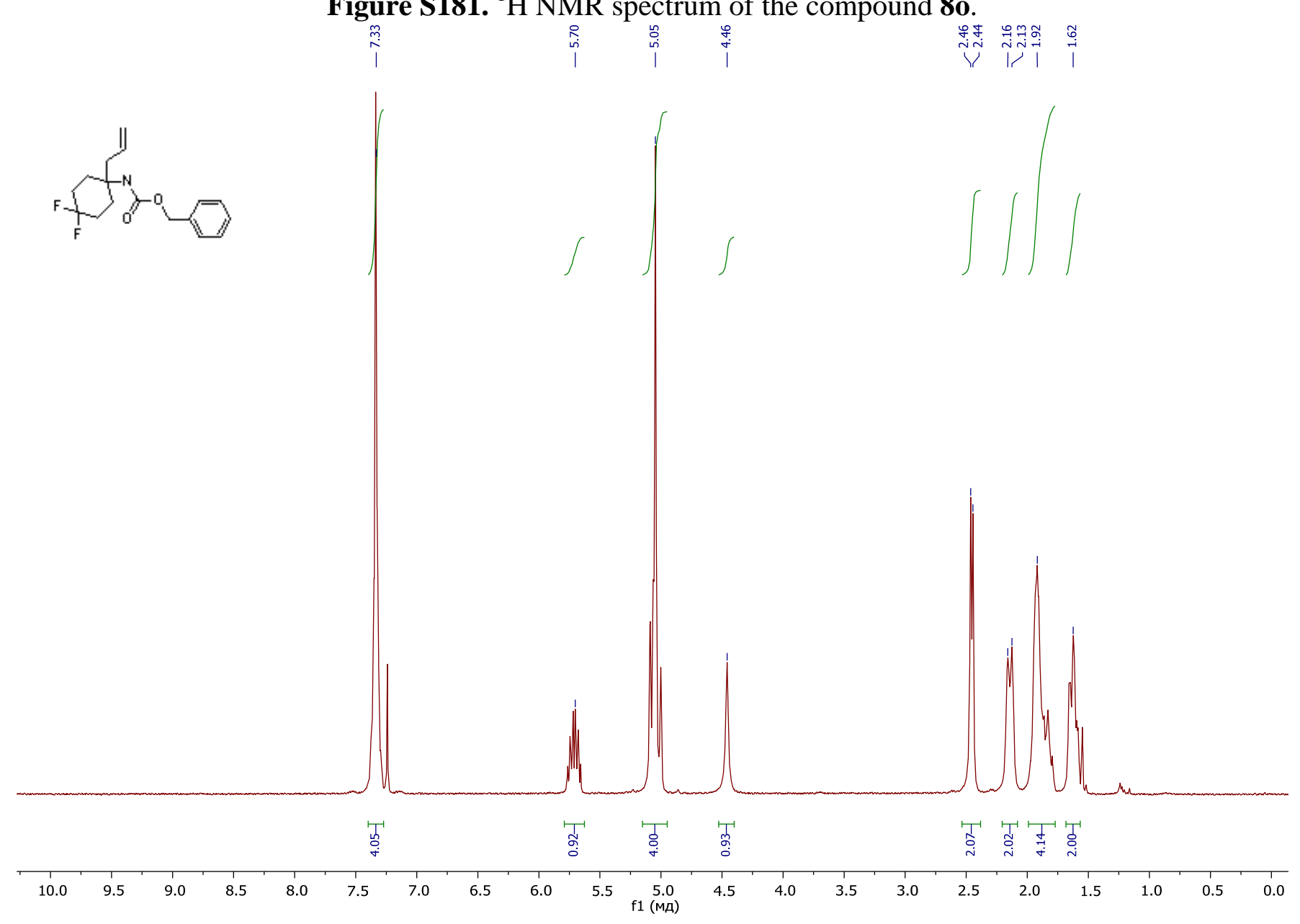


Figure S182. ${ }^{13} \mathrm{C}$ NMR spectrum of the compound $\mathbf{8 0}$. 每

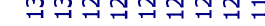

144111

๙ิ่

मे

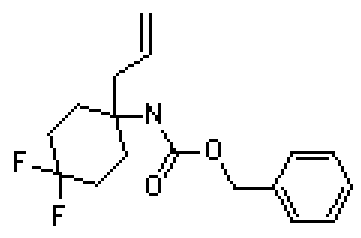

(Im)

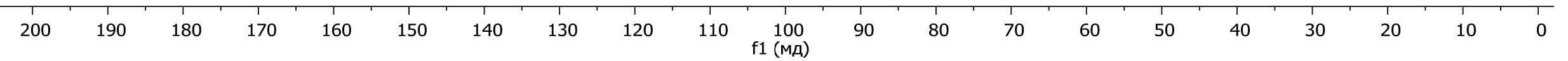


Figure S183. ${ }^{19}$ F NMR spectrum of the compound 80.

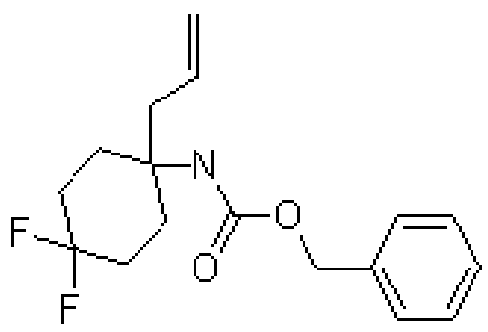
范

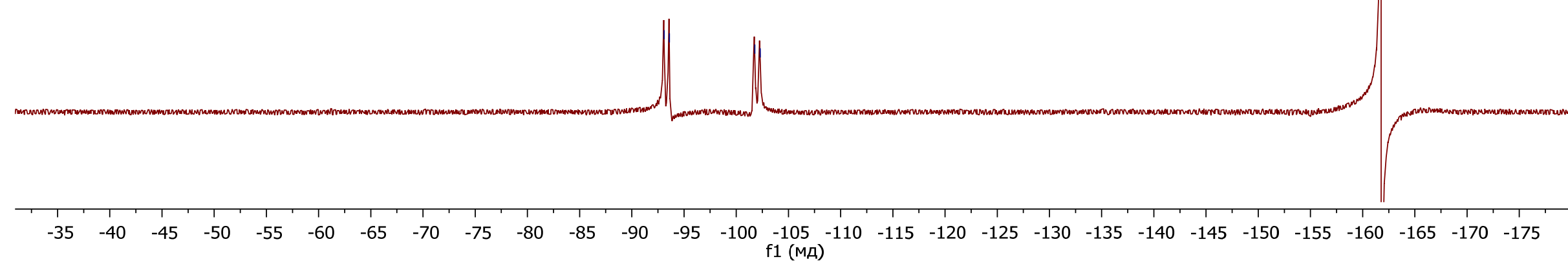


Figure S184. ${ }^{1} \mathrm{H}$ NMR spectrum of the compound 90.

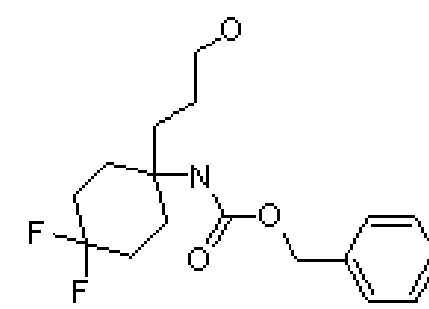

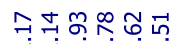

|गरा।
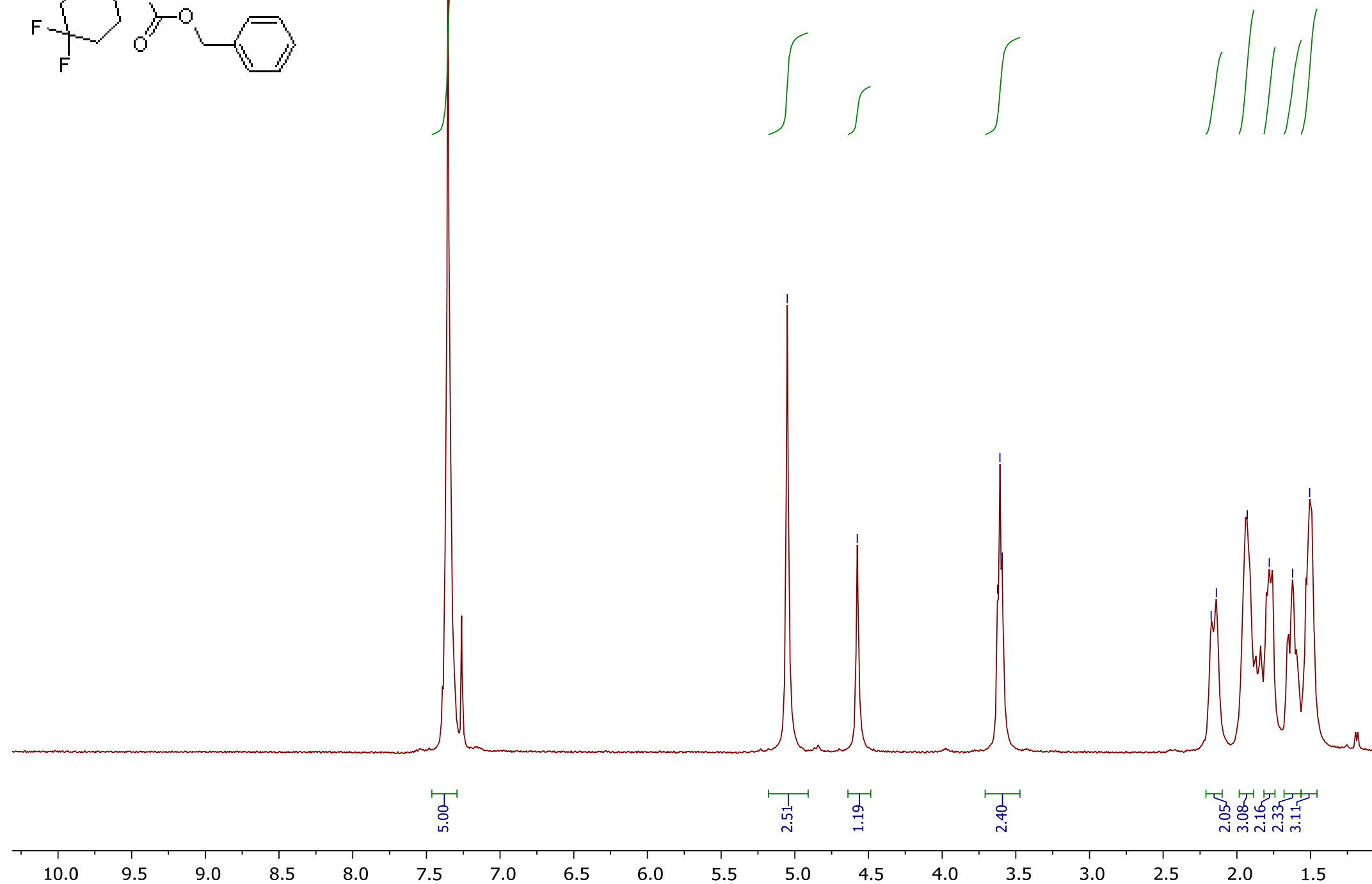

\section{客}
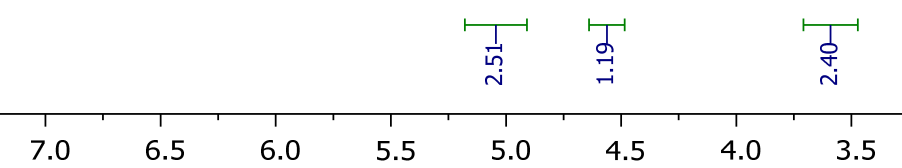
inini 


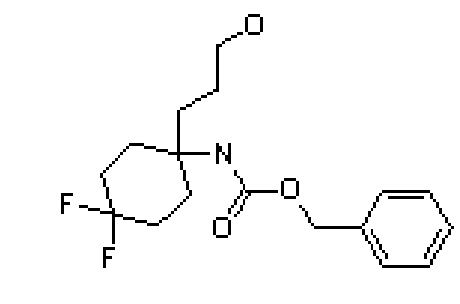

Figure S185. ${ }^{13} \mathrm{C}$ NMR spectrum of the compound 9o. 훙

苞

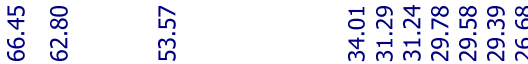

(

| | |

4 -
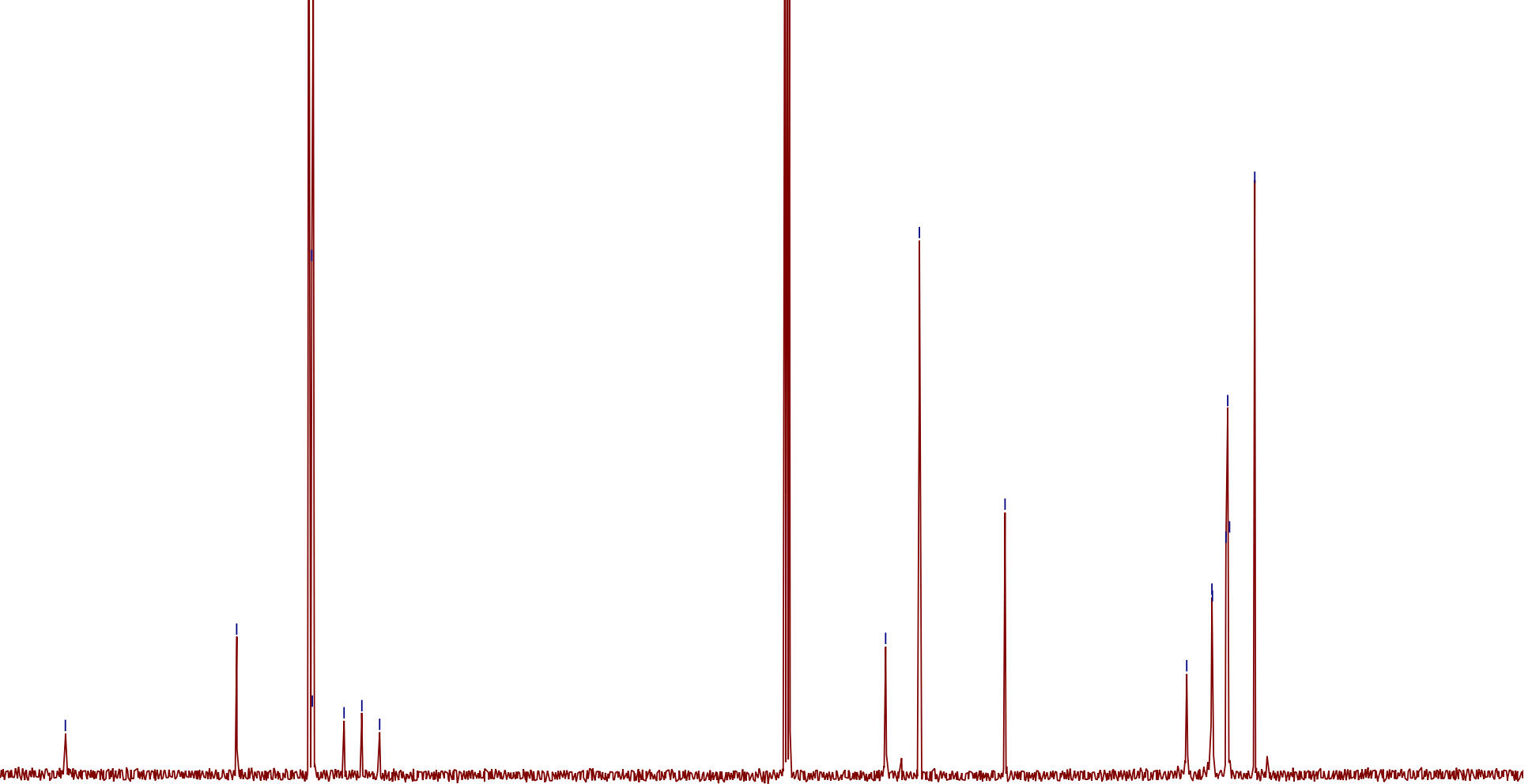
Figure S186. ${ }^{19}$ F NMR spectrum of the compound 90.

車
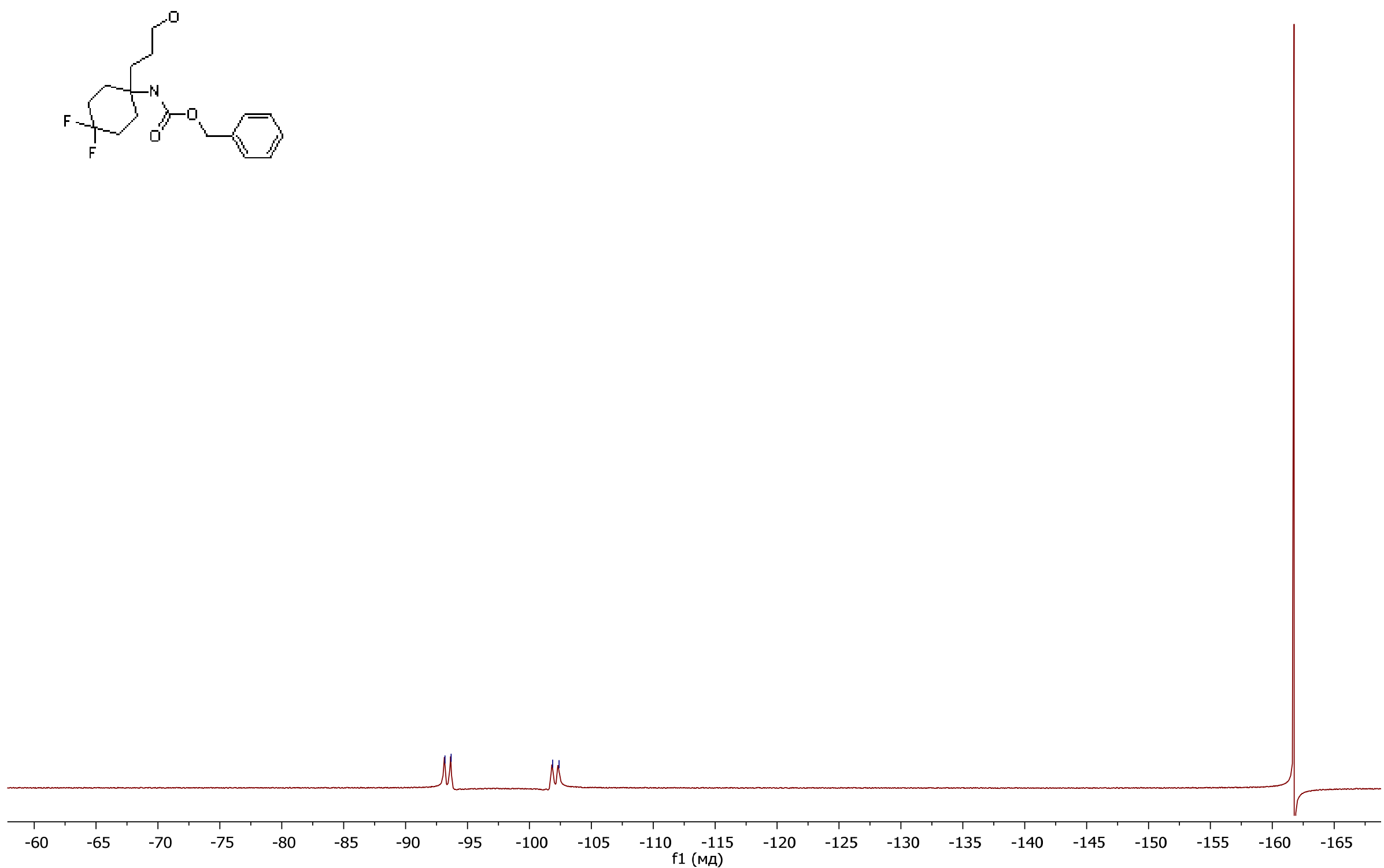
Figure S187. ${ }^{1} \mathrm{H}$ NMR spectrum of the compound $\mathbf{1 0 0}$.

în
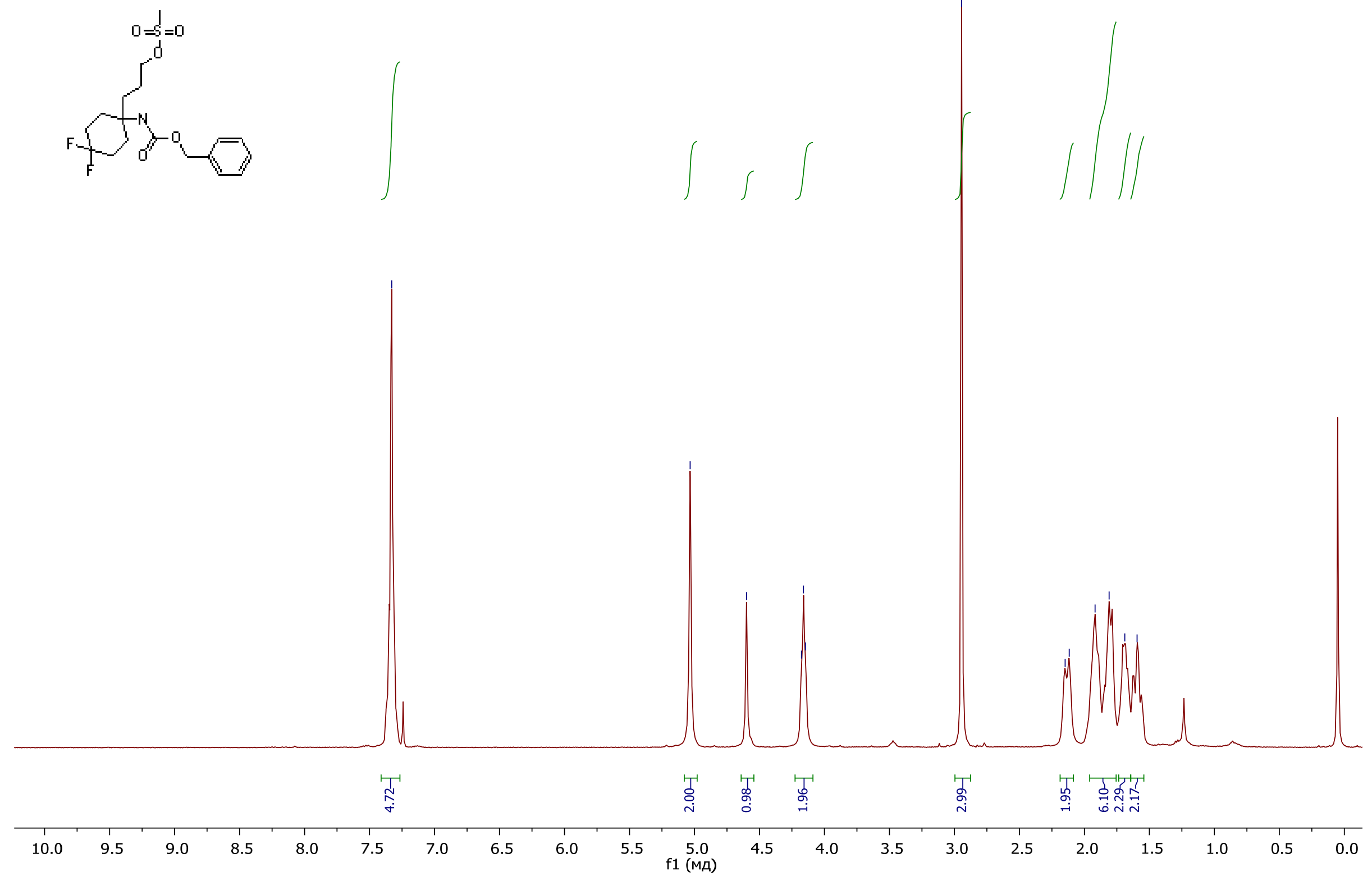
Figure S188. ${ }^{13} \mathrm{C}$ NMR spectrum of the compound 100.

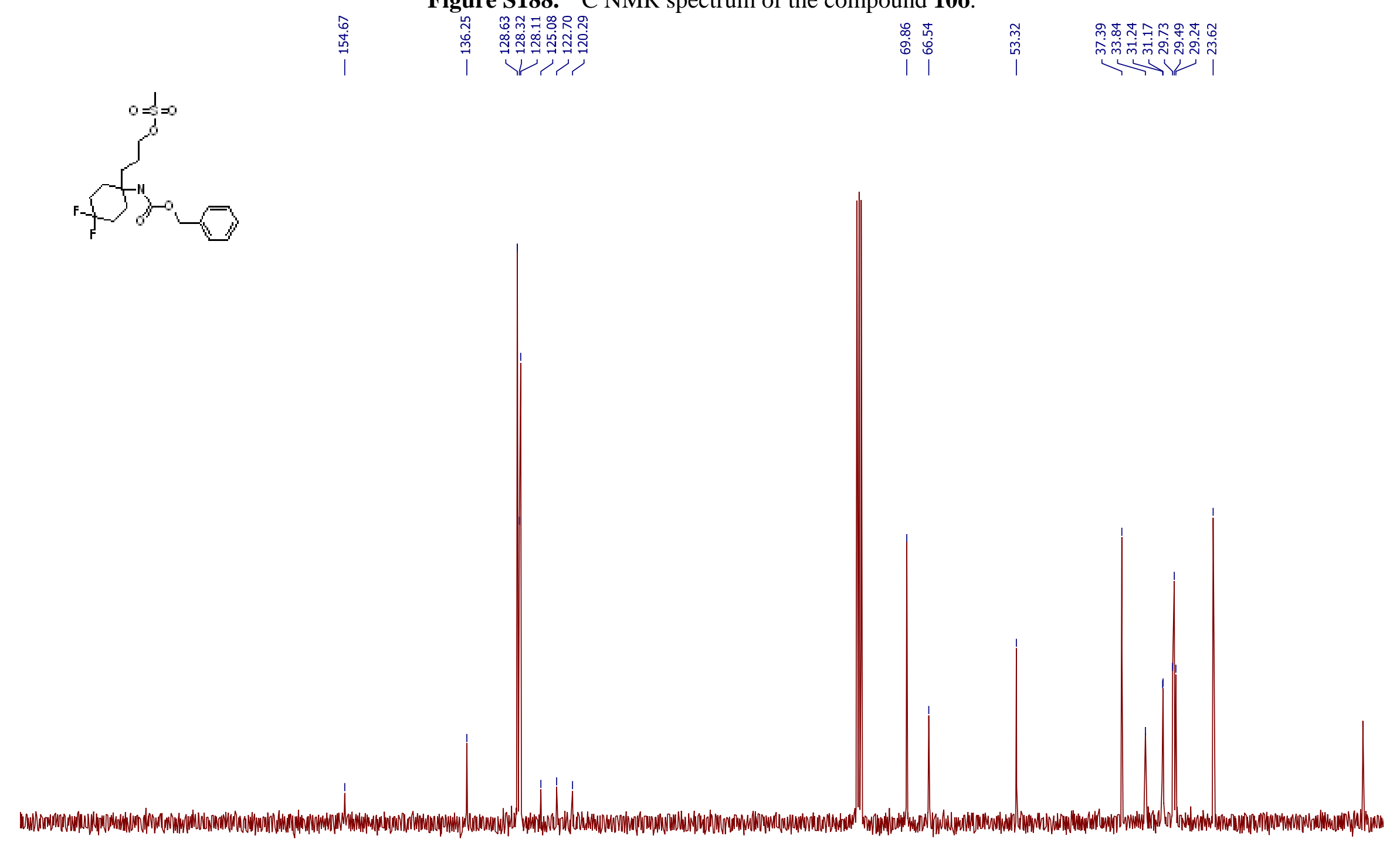

\begin{tabular}{|c|c|c|c|c|c|c|c|c|c|c|c|c|c|c|c|c|c|c|c|c|}
\hline 200 & 19 & 180 & 170 & 160 & 150 & 140 & 130 & 120 & 110 & $\begin{array}{c}100 \\
\mathrm{f} 1(\mathrm{MA})\end{array}$ & 90 & 80 & 70 & 60 & 50 & 40 & 30 & 20 & 10 & 0 \\
\hline
\end{tabular}


Figure S189. ${ }^{19} \mathrm{~F}$ NMR spectrum of the compound $\mathbf{1 0 0}$.

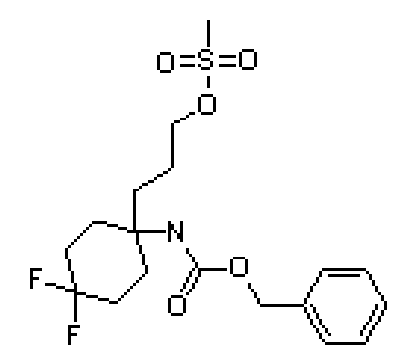

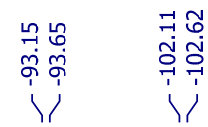

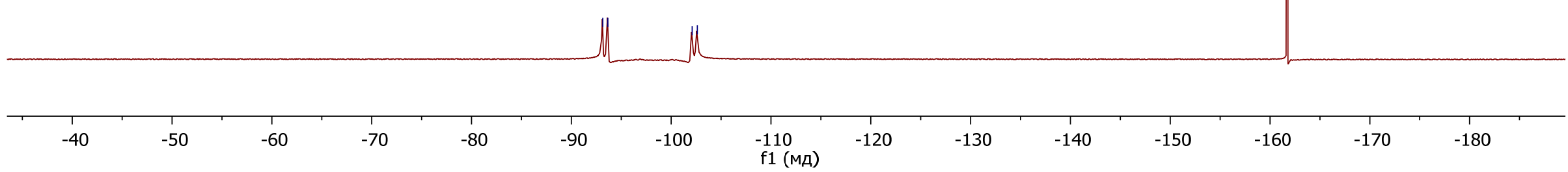


Figure S190. ${ }^{1} \mathrm{H}$ NMR spectrum of the compound $\mathbf{1 1 0 .}$

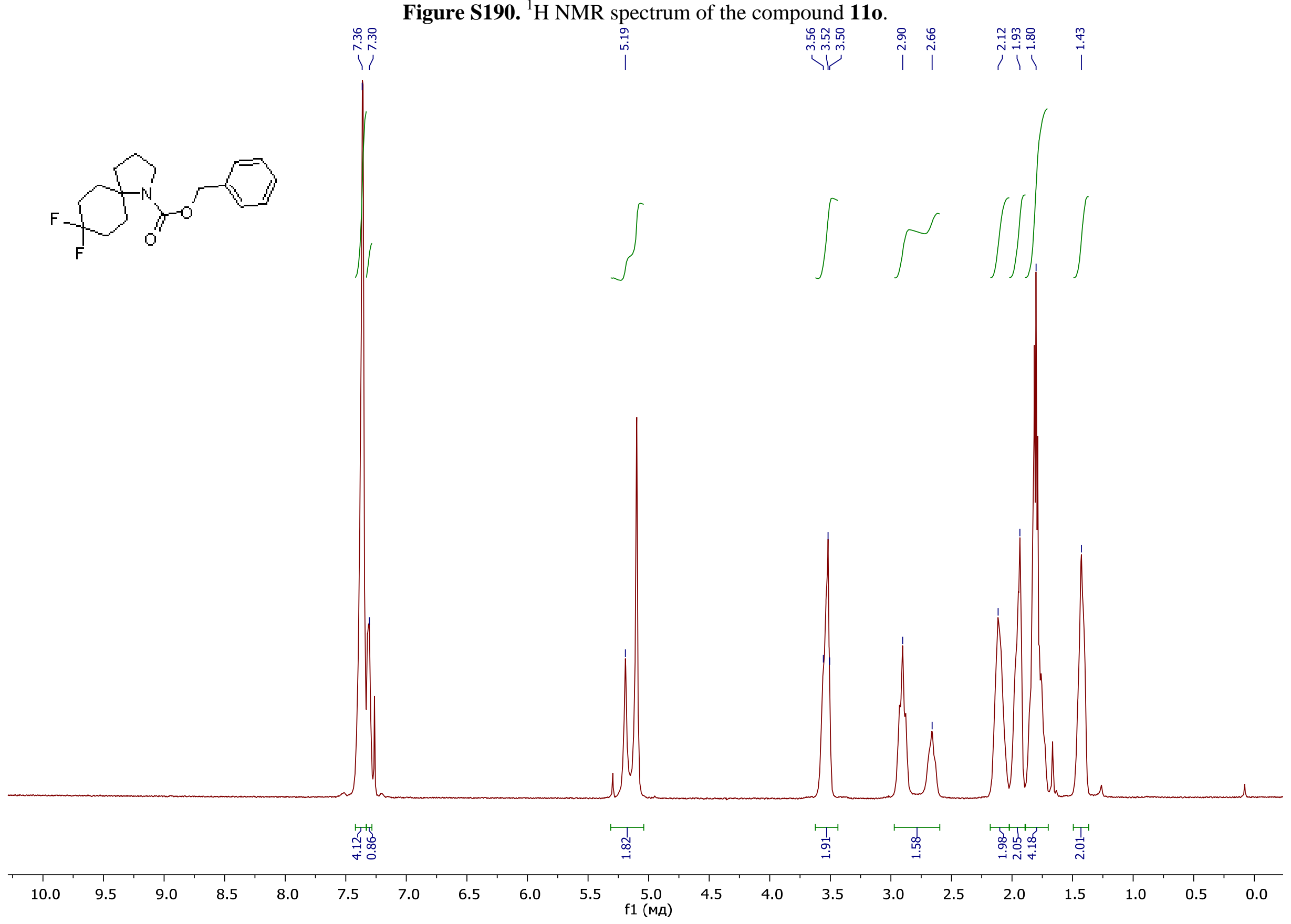




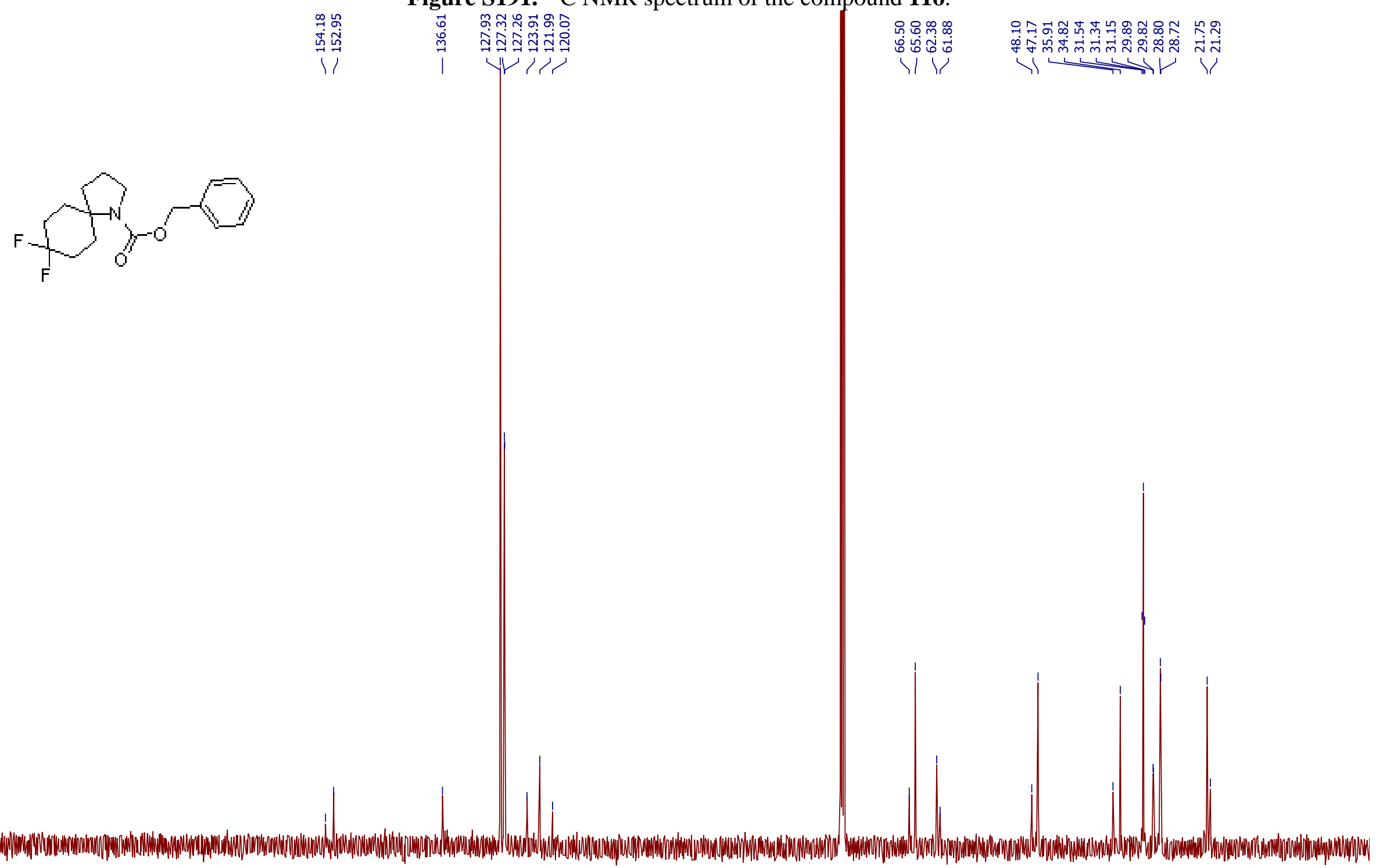

Figure S191. ${ }^{13} \mathrm{C}$ NMR spectrum of the compound 110. 
Figure S192. ${ }^{19}$ F NMR spectrum of the compound $\mathbf{1 1 0 .}$

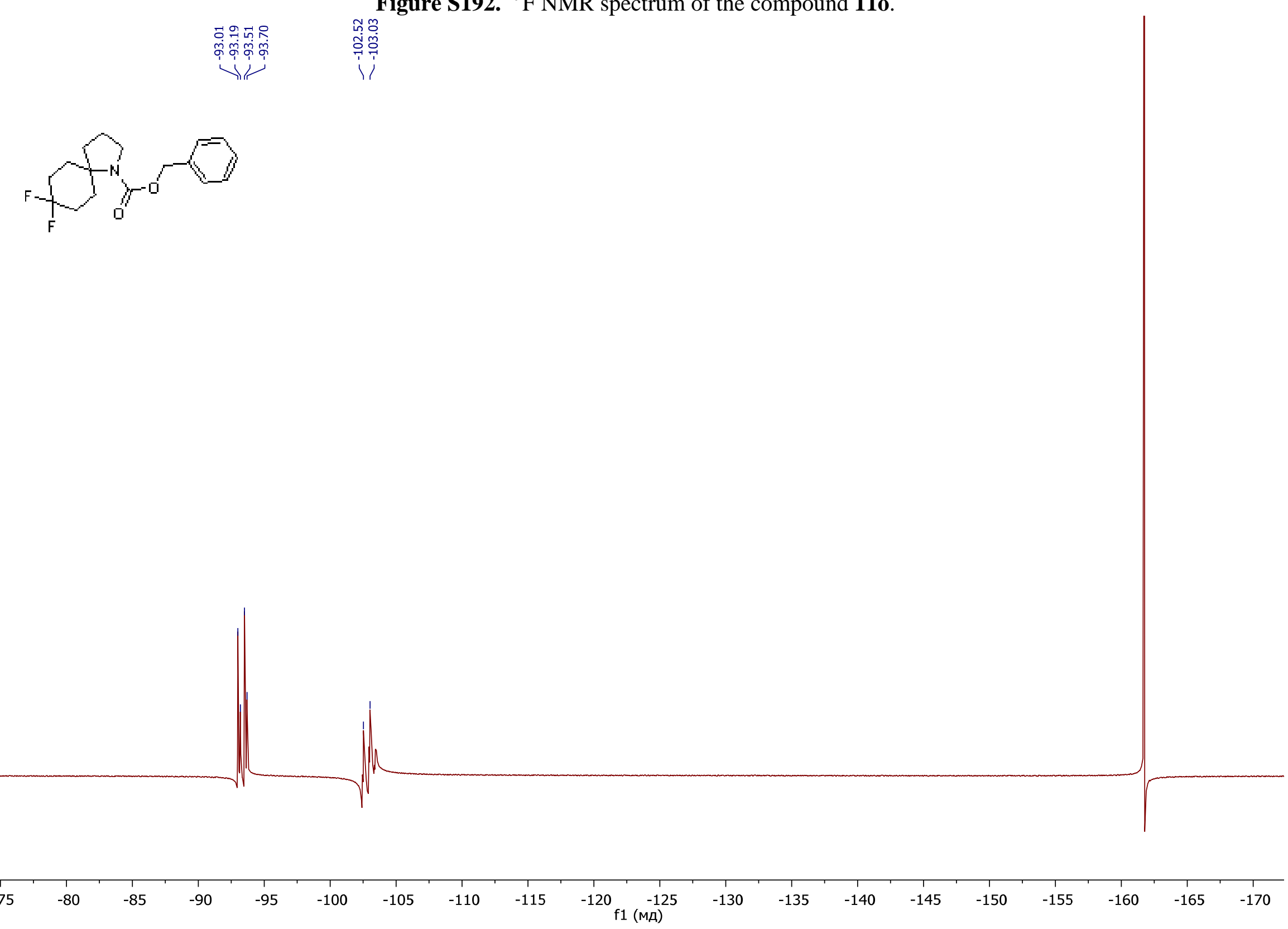


Figure S193. Mass spectrum of the compound 110.

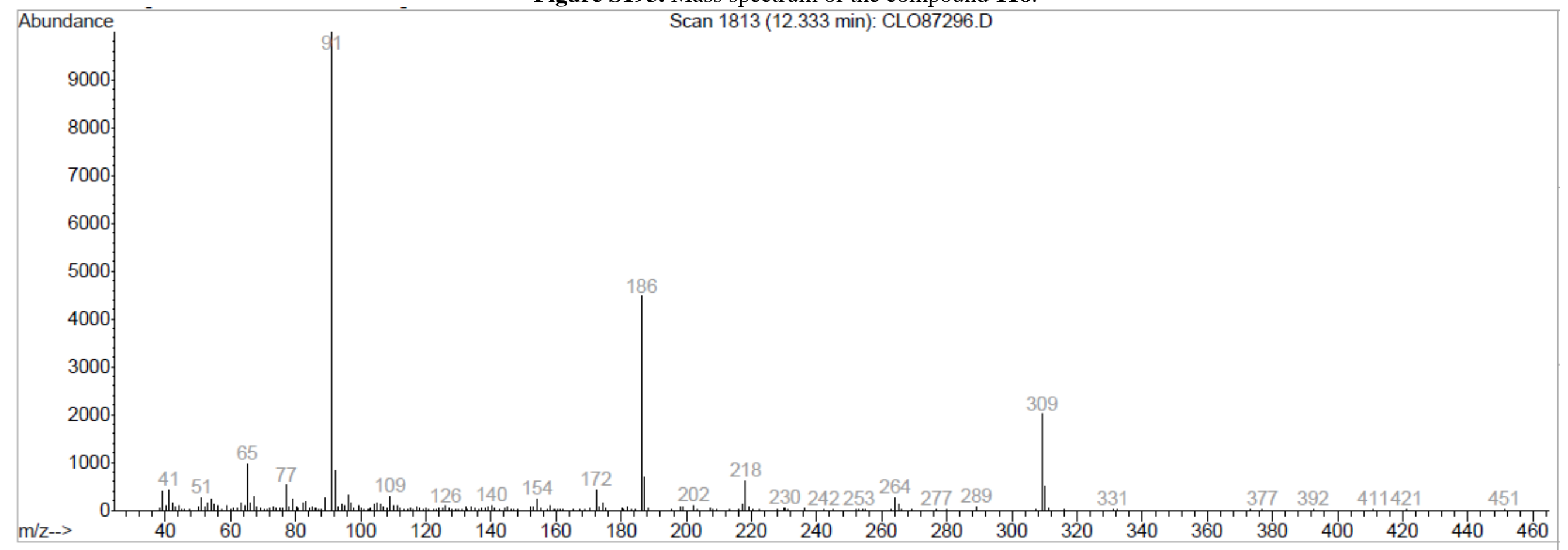


Figure S194. ${ }^{1} \mathrm{H}$ NMR spectrum of the compound 1 10 $^{*} \mathbf{H C l}$.

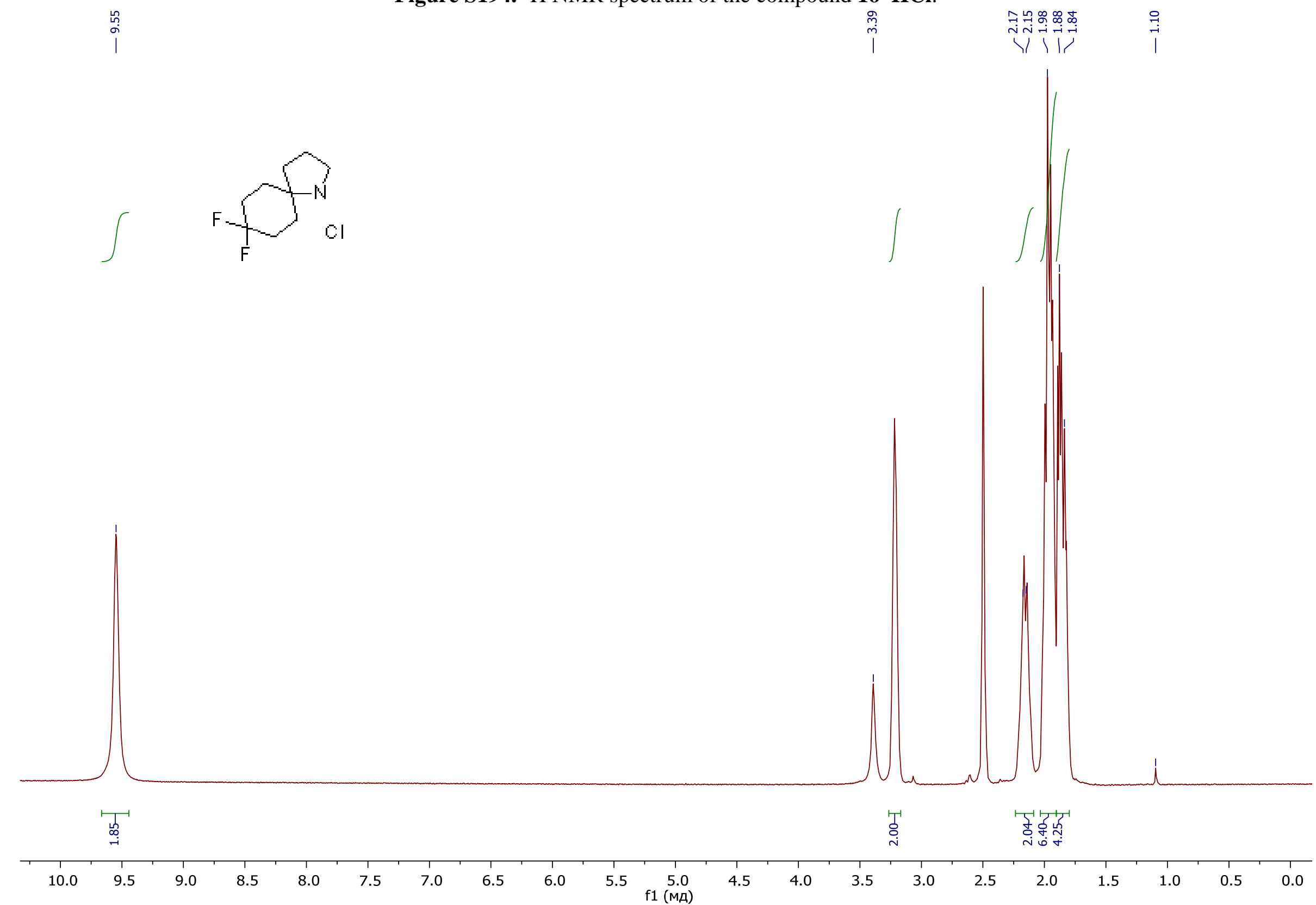


Figure S195. ${ }^{13} \mathrm{C}$ NMR spectrum of the compound 1 10 $^{*} \mathbf{H C l}$.

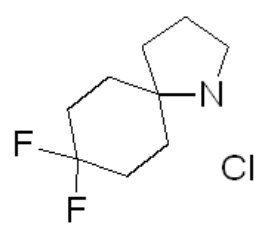

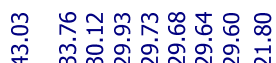

i

I

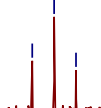

\begin{tabular}{|c|c|c|c|c|c|c|c|c|c|c|c|c|c|c|c|c|c|c|c|c|}
\hline 200 & 190 & 180 & 170 & 160 & 150 & 140 & 130 & 120 & 110 & $\begin{array}{c}100 \\
\mathrm{f} 1(\mathrm{ppm})\end{array}$ & 90 & 80 & 70 & 60 & 50 & 40 & 30 & 20 & 10 & 0 \\
\hline
\end{tabular}


Figure S196. ${ }^{19} \mathrm{~F}$ NMR spectrum of the compound $1 \mathbf{1 0}^{*} \mathbf{H C l}$.

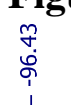
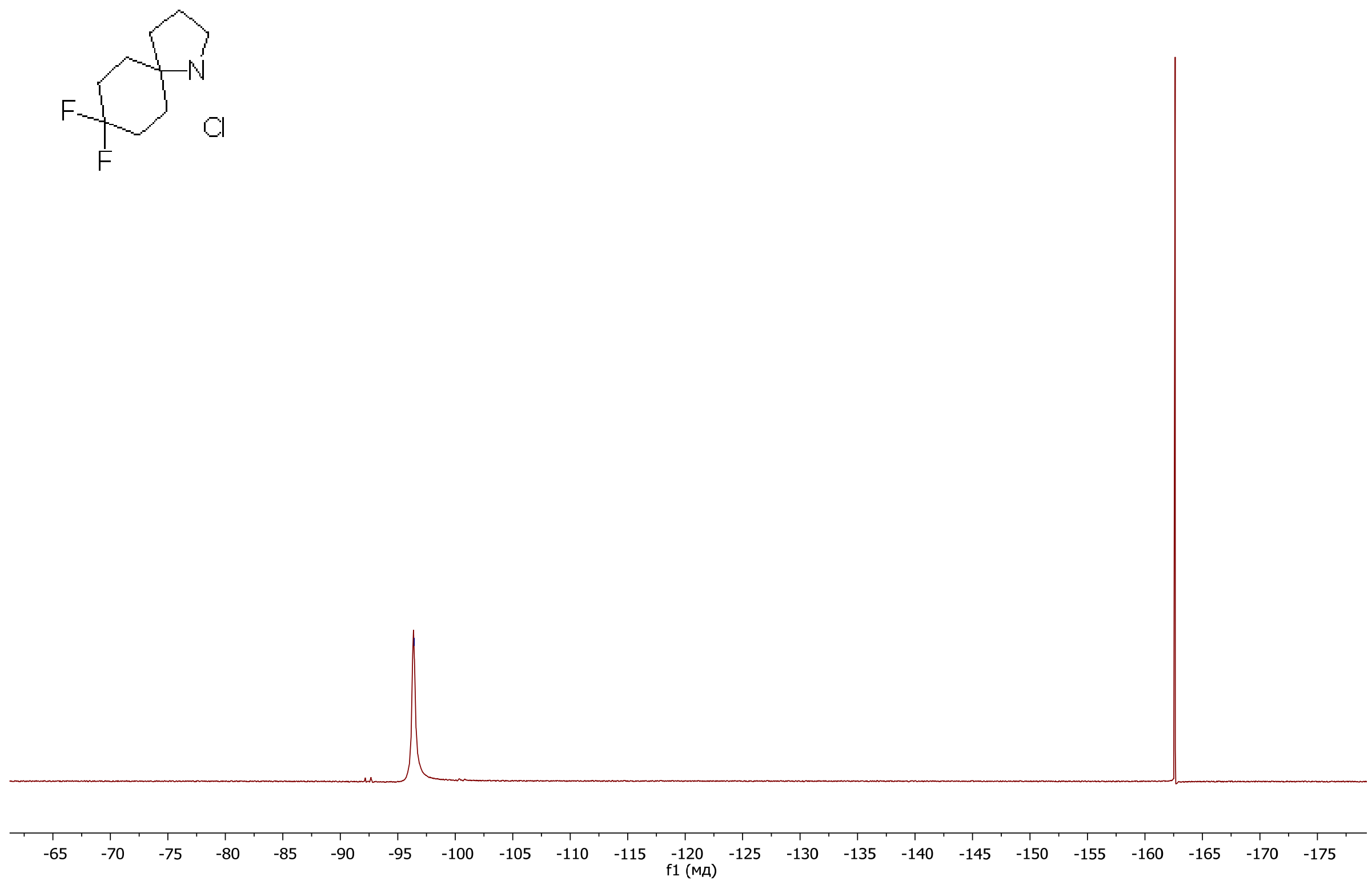
Figure S197. Mass spectrum of the compound 10*HCl.

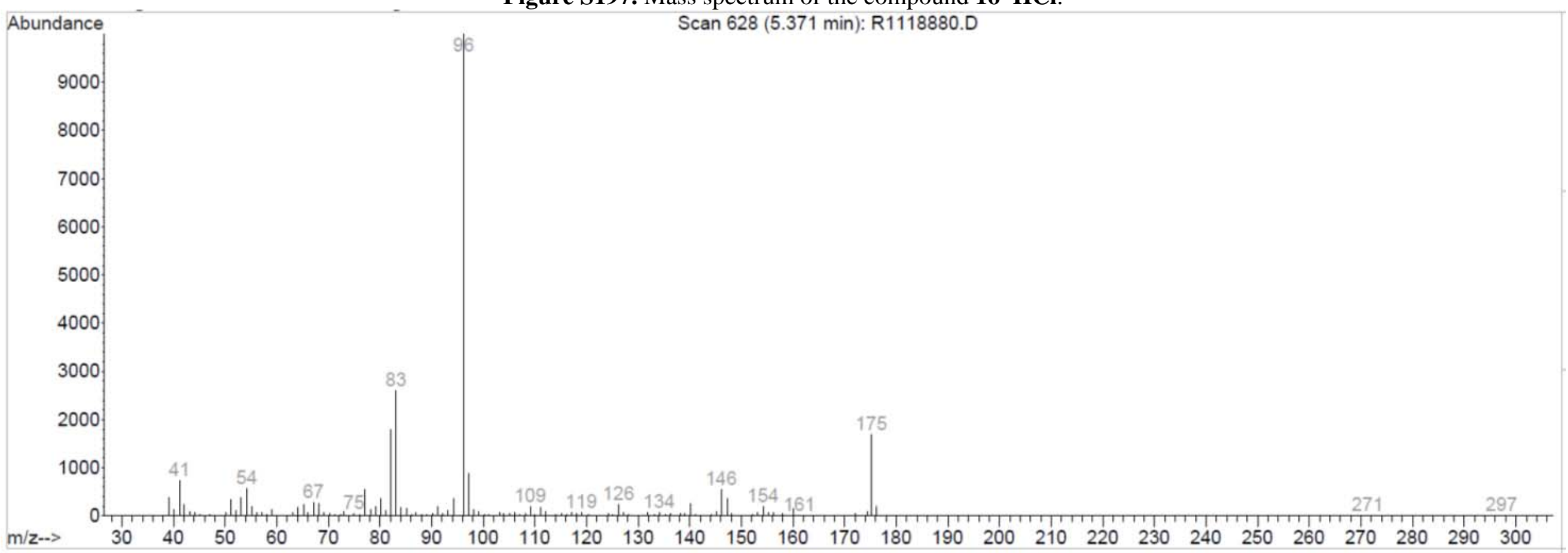


Synthesis of tert-butyl 1,8-diazaspiro[4.5]decane-8-carboxylate (1p). Approach III.

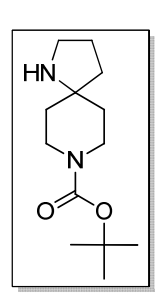

$1 \mathrm{p}$

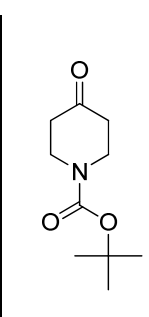

$2 p$

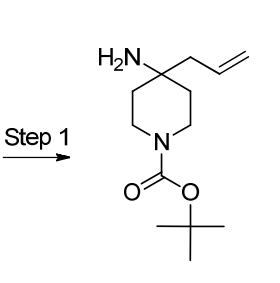

$16 p$

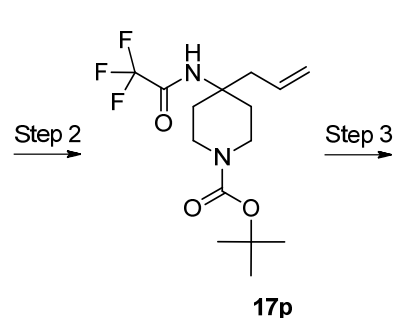

$17 \mathrm{p}$

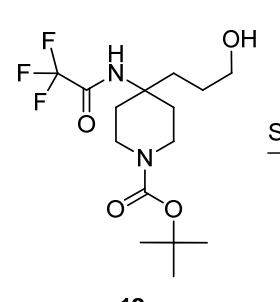

Scheme S20.

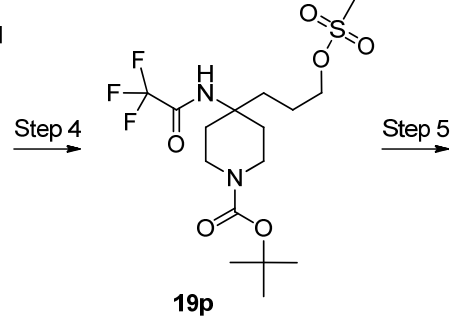

$19 p$

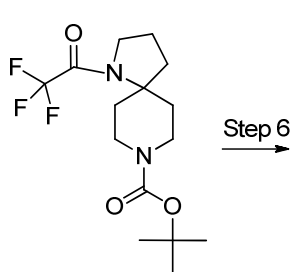

20p

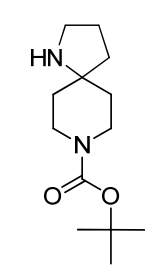

1p

Figure S198. ${ }^{1} \mathrm{H}$ spectrum of the compound $\mathbf{1 6 p}$.
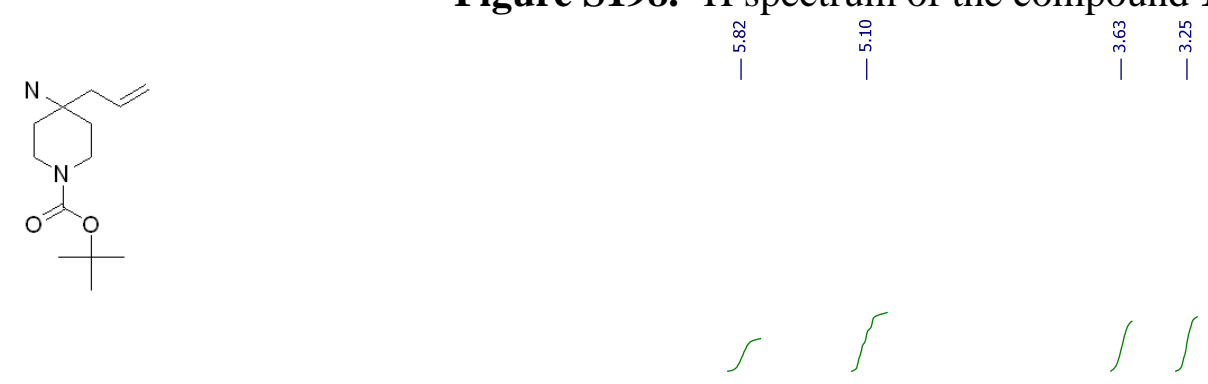

号

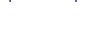

(n)
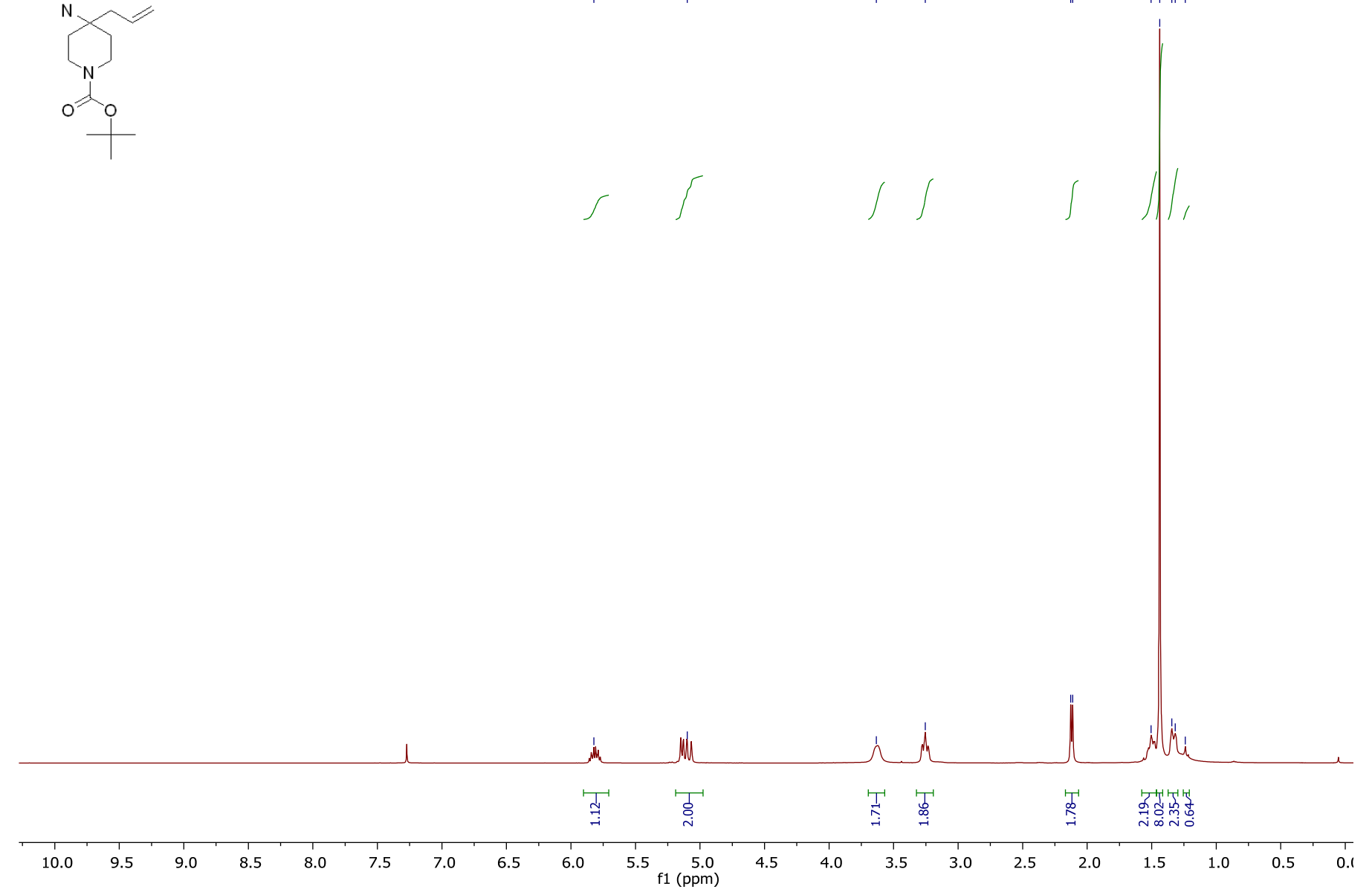
Figure S199. ${ }^{13} \mathrm{C}$ spectrum of the compound $\mathbf{1 6 p}$.

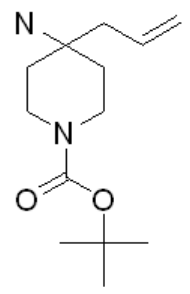

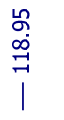

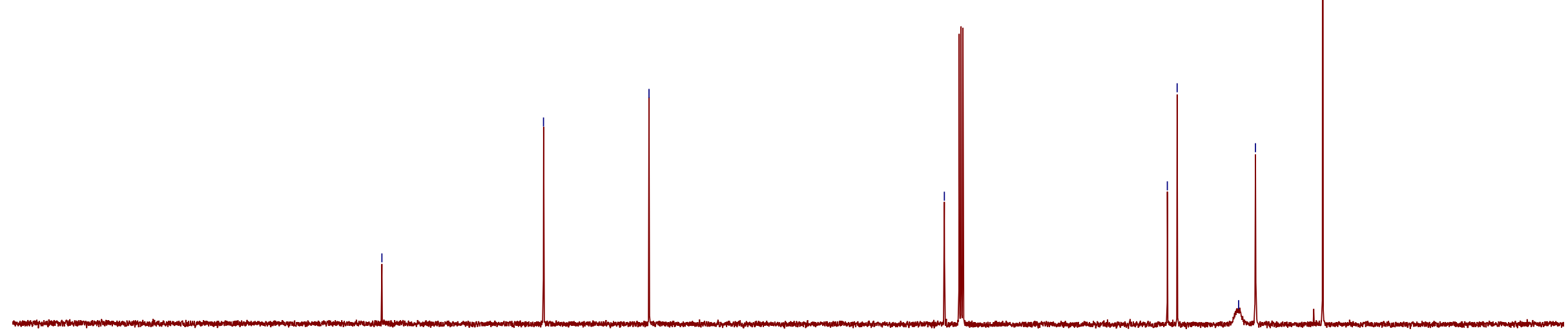


Figure S200. Mass spectrum of the compound 16p.

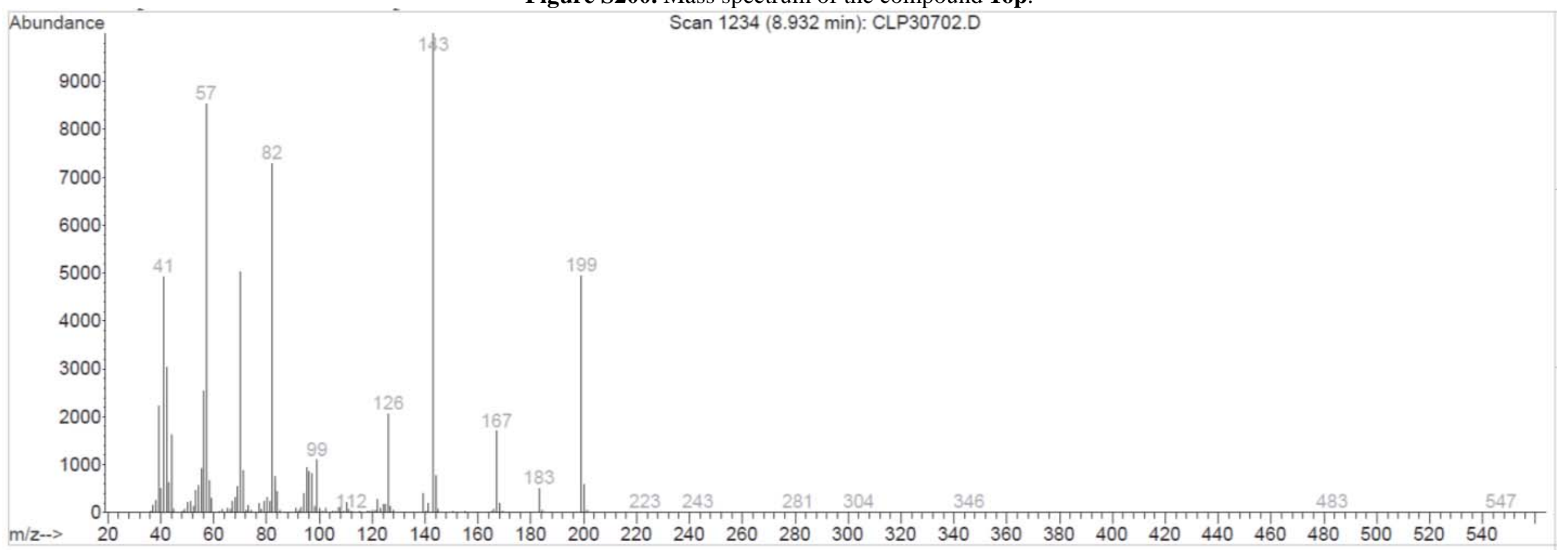


Figure S201. ${ }^{1} \mathrm{H}$ spectrum of the compound 17p.

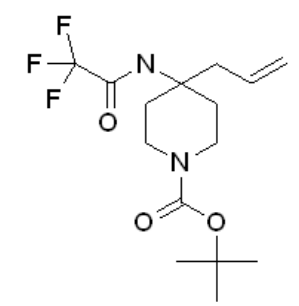

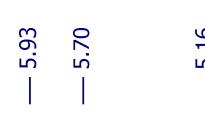

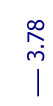

$\overbrace{\substack{\infty \\ \text { minj }}}^{\infty}$

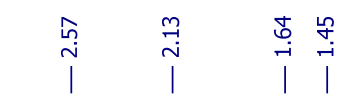
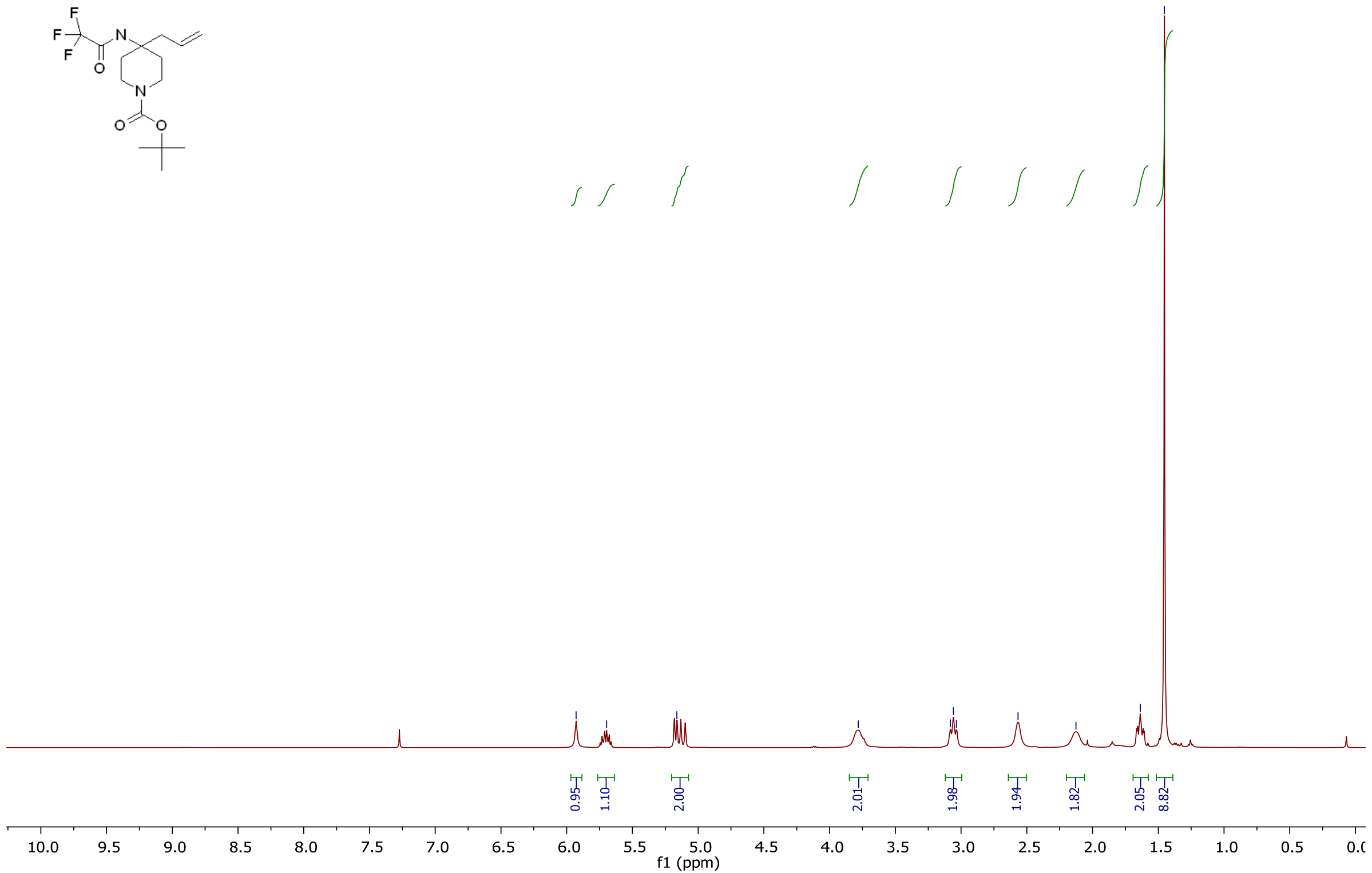
Figure S202. ${ }^{13} \mathrm{C}$ spectrum of the compound $\mathbf{1 7 p}$.

덩엉뭉웅

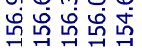

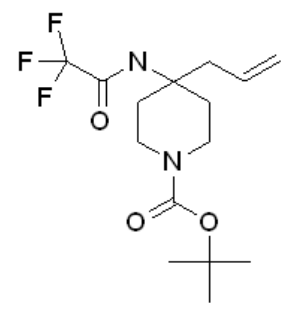

ิㅗㄹ

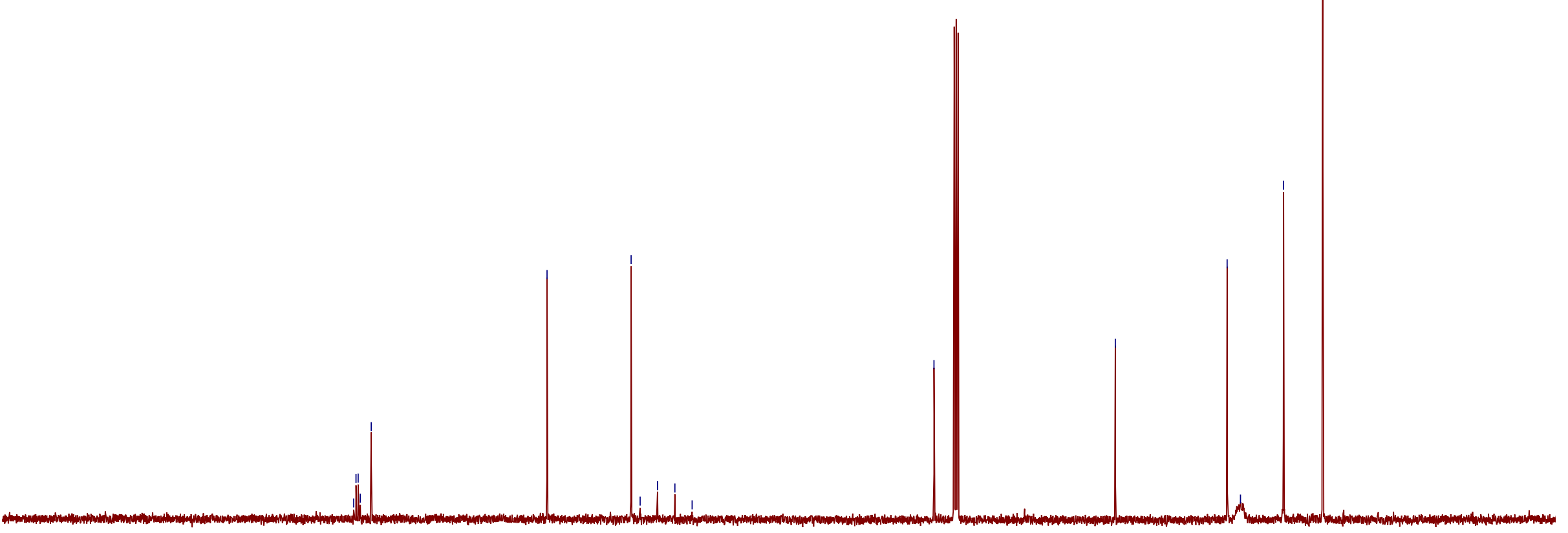

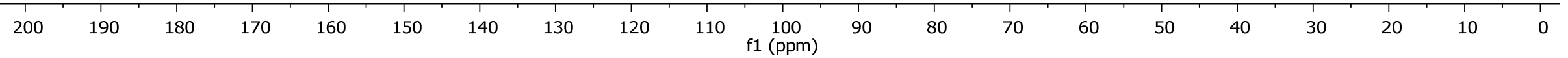


Figure S203. ${ }^{19} \mathrm{~F}$ spectrum of the compound $\mathbf{1 7} \mathbf{p}$.

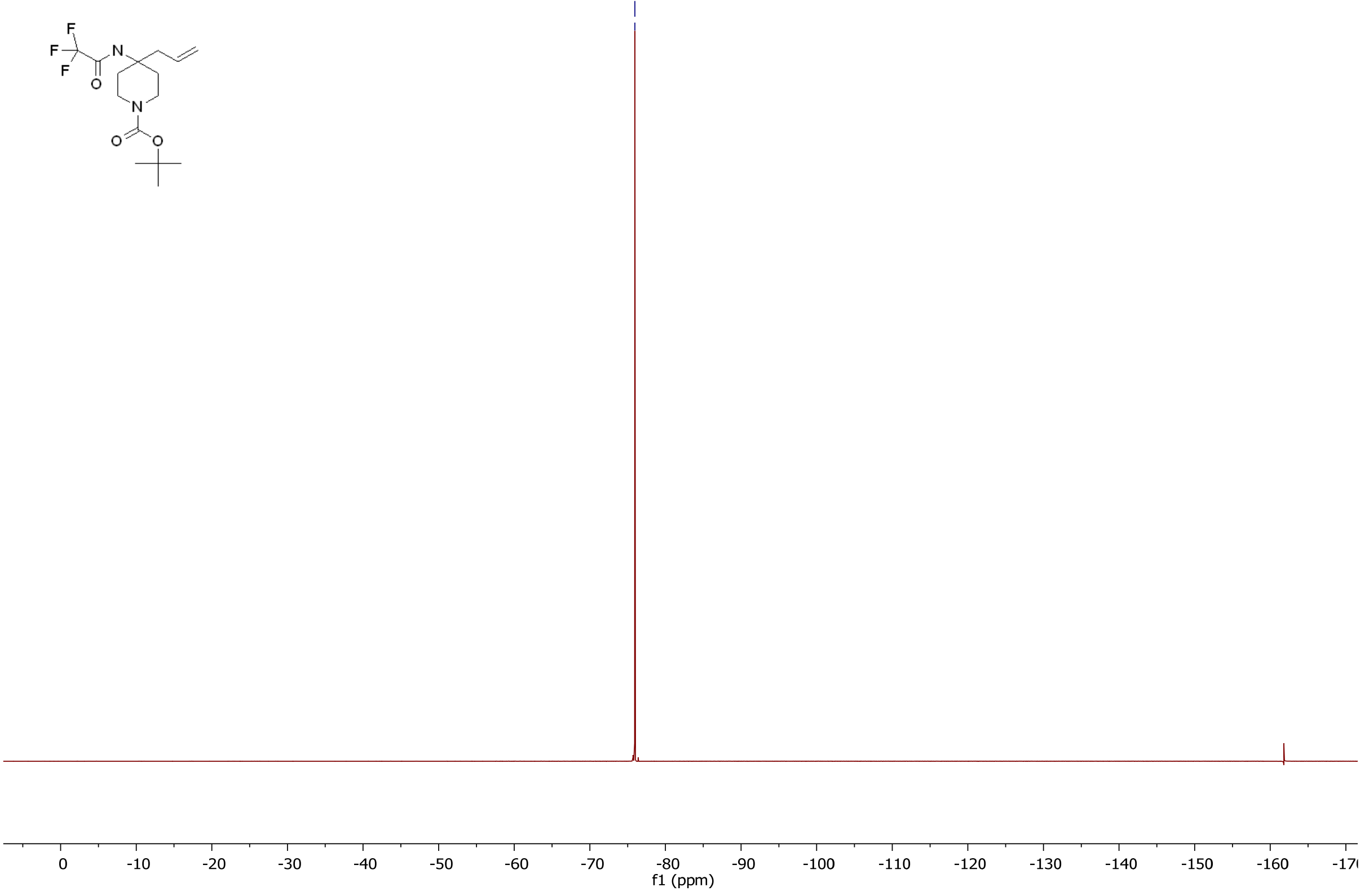


Figure S204. ${ }^{1} \mathrm{H}$ spectrum of the compound 18p.

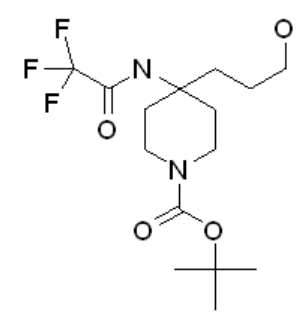

chn

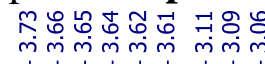

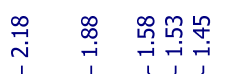
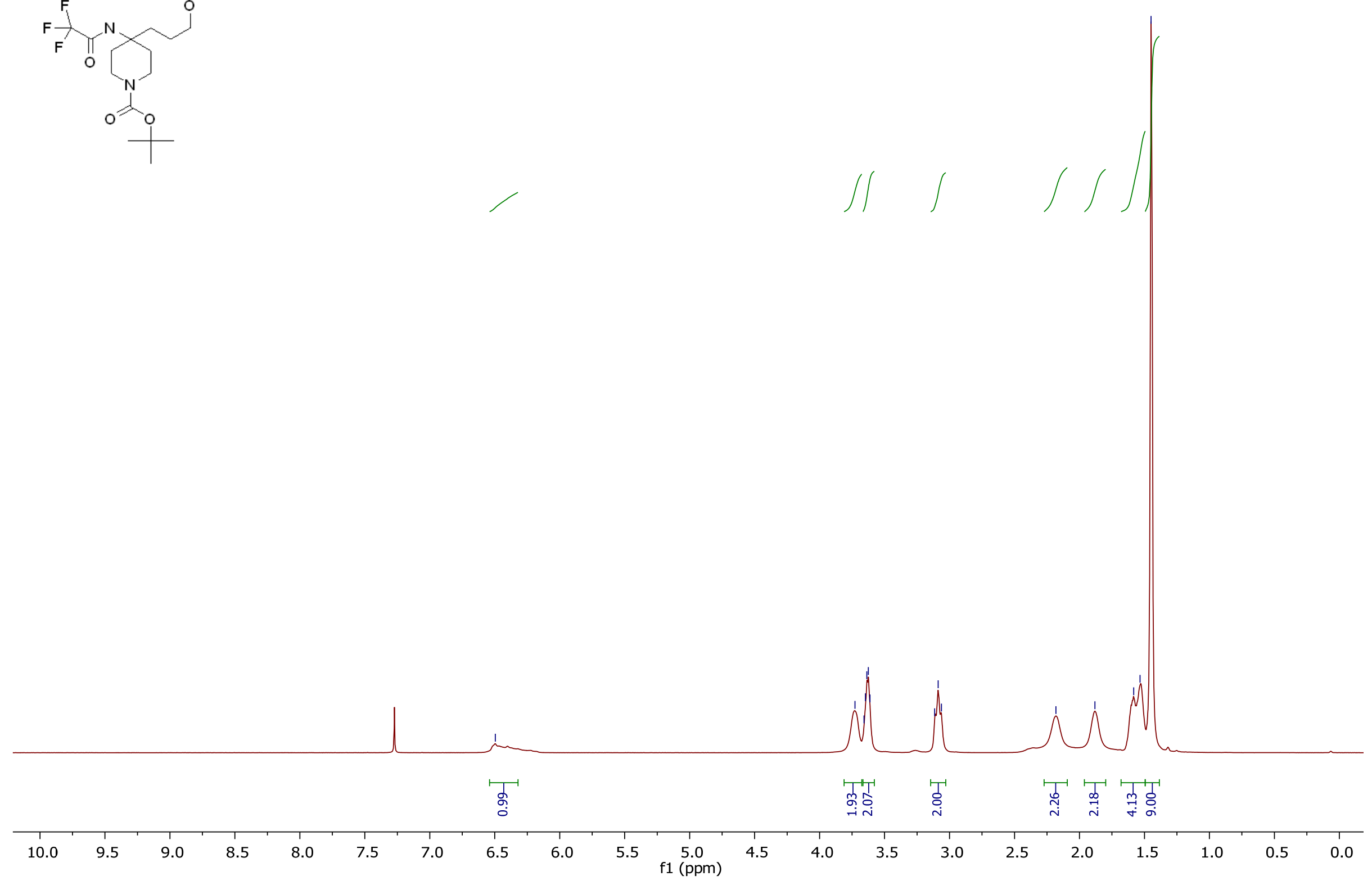
Figure S205. ${ }^{13} \mathrm{C}$ spectrum of the compound 18p.

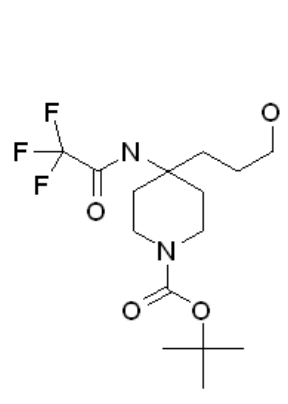

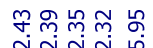

บู่

m.

य$$
\text { (1) }
$$

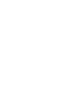


Figure S206. ${ }^{19} \mathrm{~F}$ spectrum of the compound 18p.

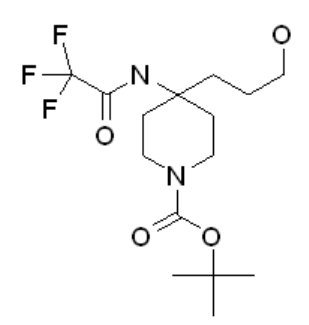

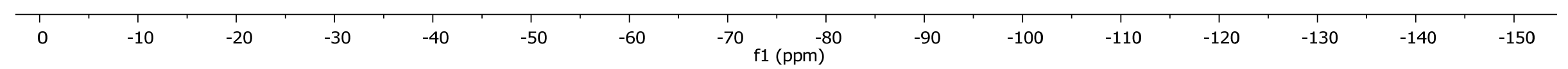


Figure S207. Mass spectrum of the compound 18p.

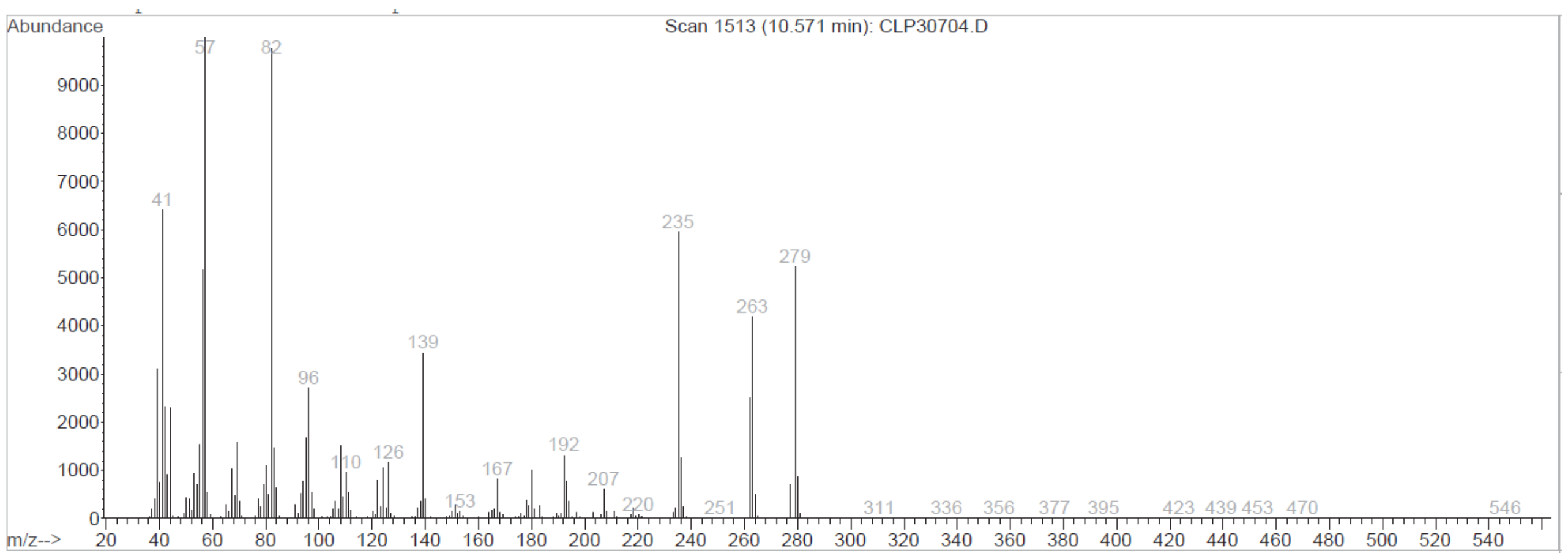


Figure S208. ${ }^{1} \mathrm{H}$ spectrum of the compound 19p.

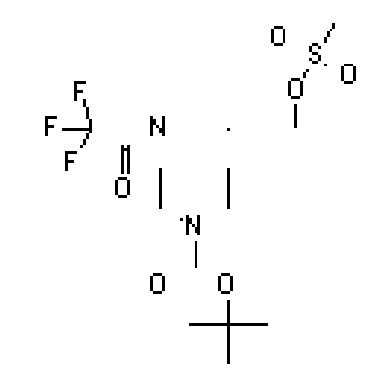

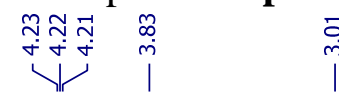$$
\text { 落 }
$$$$
\stackrel{\substack{0 \\ 0 \\ 1}}{1}
$$
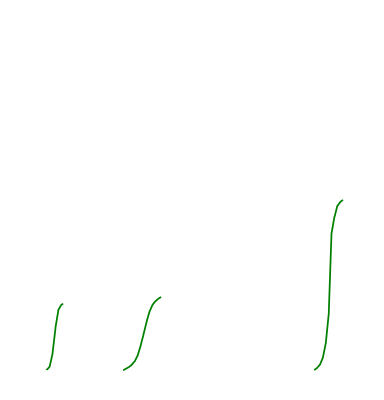

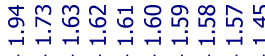
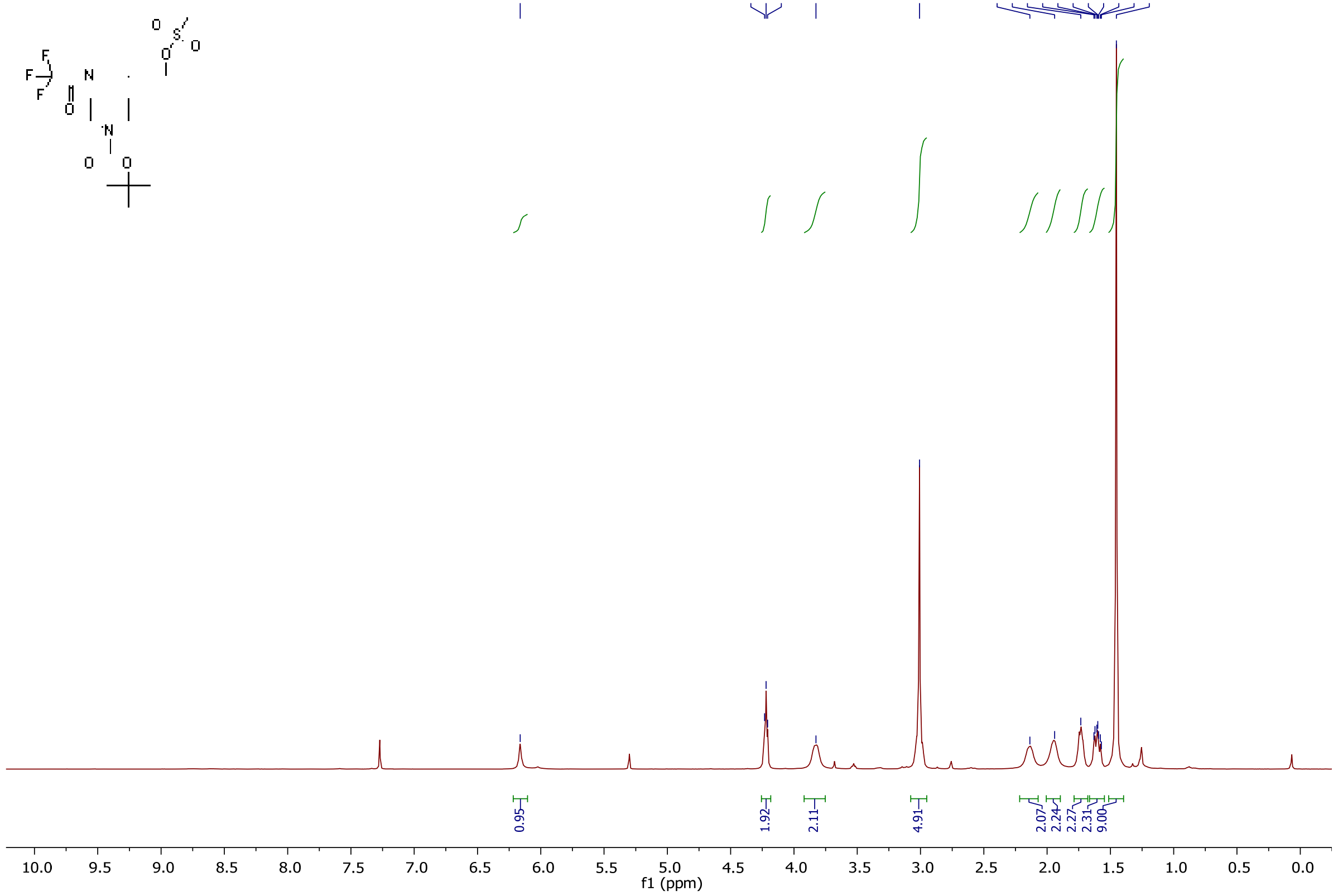
Figure S209. ${ }^{13} \mathrm{C}$ spectrum of the compound 19p.

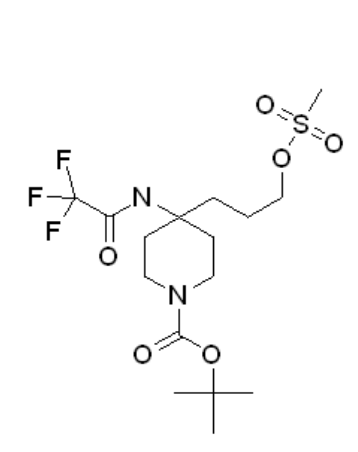

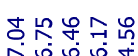

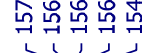

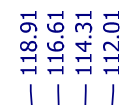

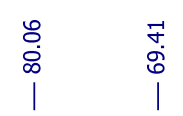

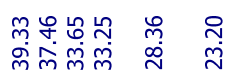

$11<1 \mid$

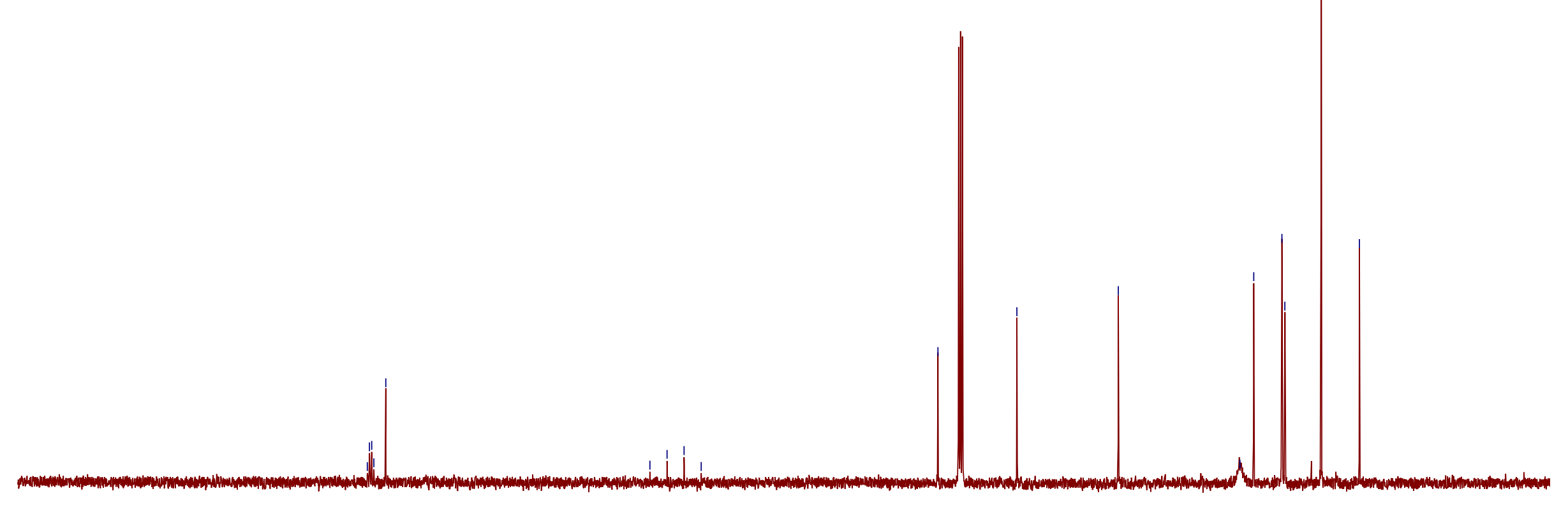


Figure S210. ${ }^{19} \mathrm{~F}$ spectrum of the compound 19p.

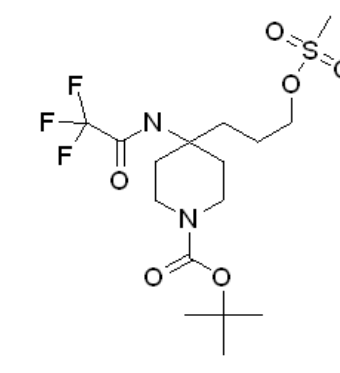

官

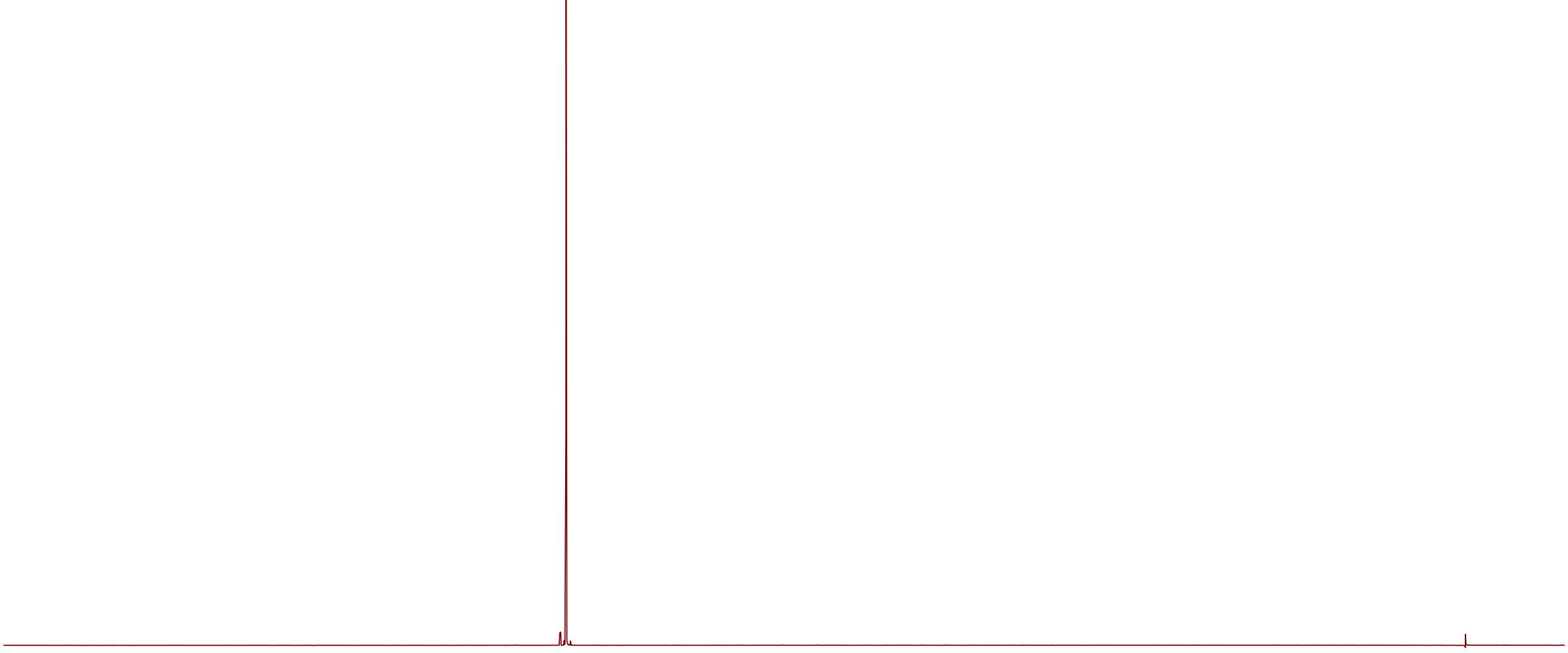

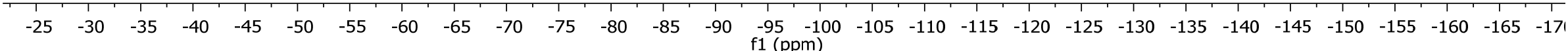

Figure S211. ${ }^{1} \mathrm{H}$ spectrum of the compound 20 p. 


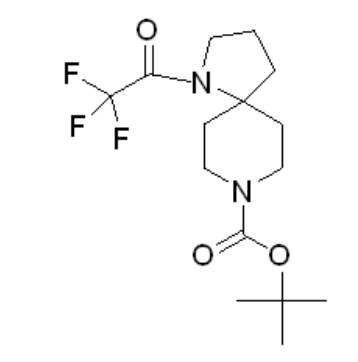

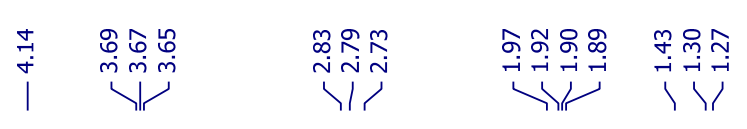
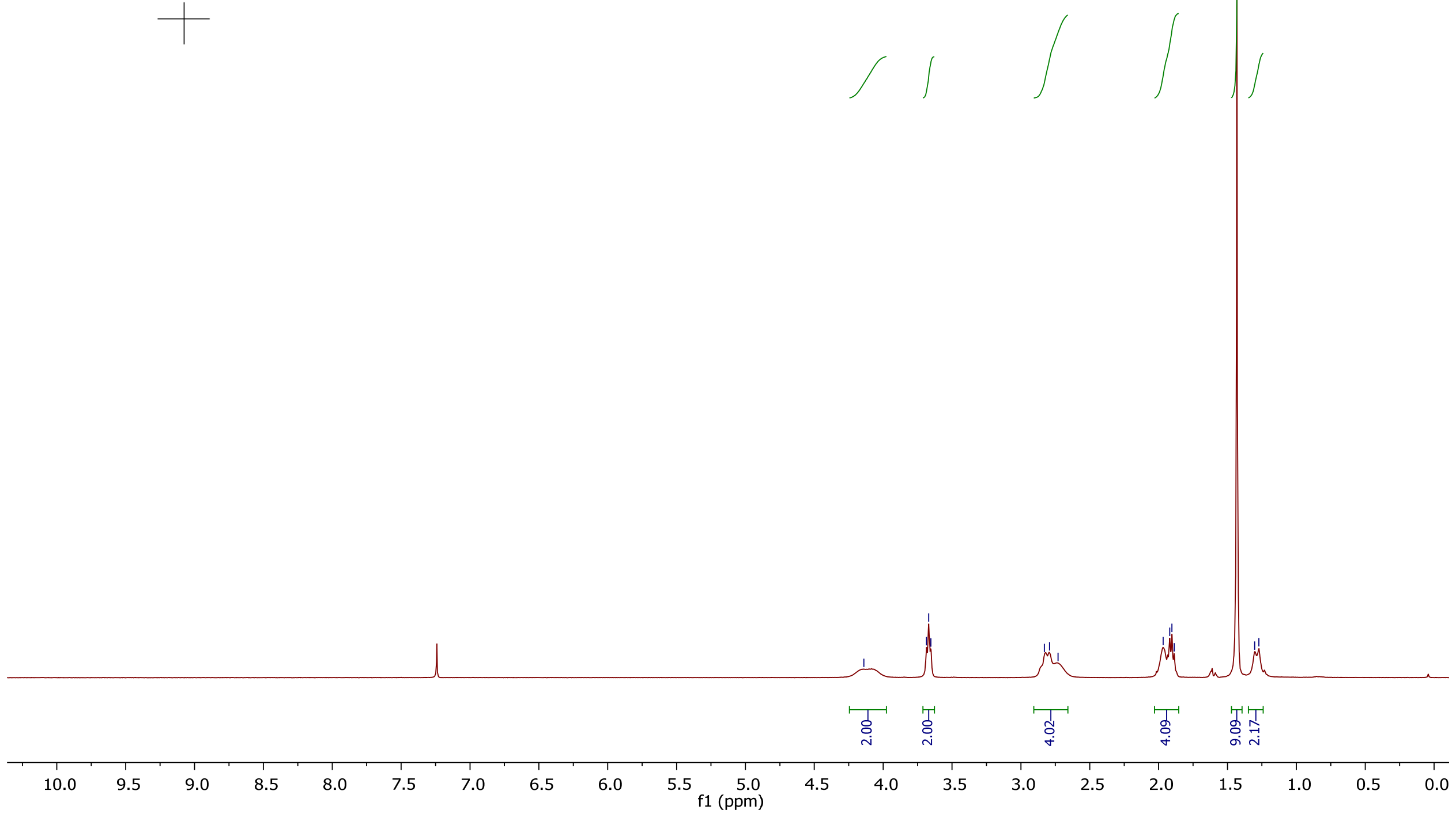
Figure S212. ${ }^{13} \mathrm{C}$ spectrum of the compound 20p.

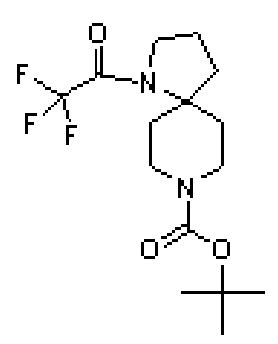

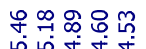

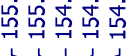

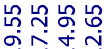

윜ㅋㅋ혁

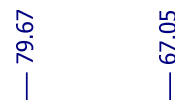

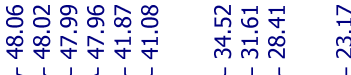

स 1111

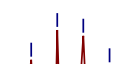

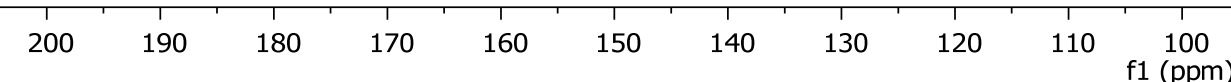

90

80

70

60

50

40

30 
Figure S213. ${ }^{19} \mathrm{~F}$ spectrum of the compound 20p.

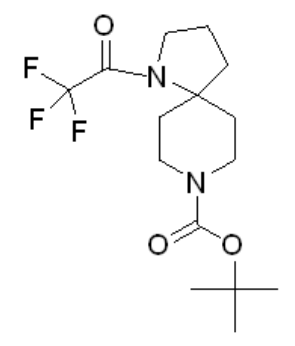

$\stackrel{\infty}{\stackrel{\infty}{i}}$

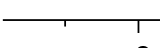


Figure S214. ${ }^{1} \mathrm{H}$ spectrum of the compound $\mathbf{1 p}$.
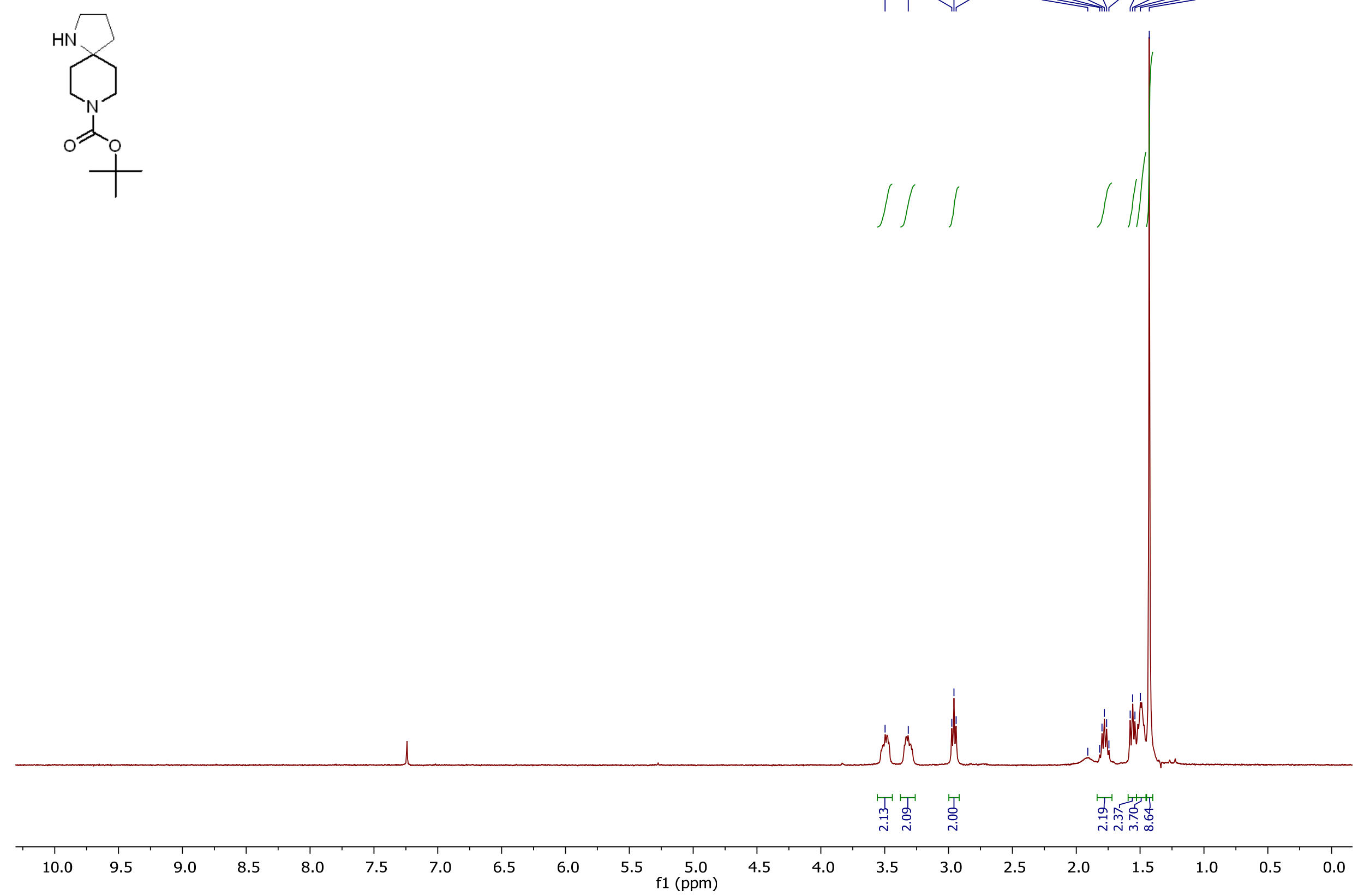
Figure S215. ${ }^{13} \mathrm{C}$ spectrum of the compound $\mathbf{1 p}$.

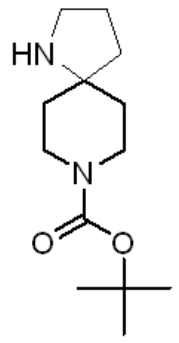

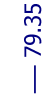

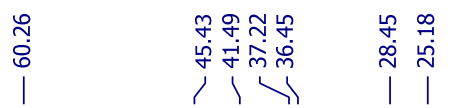

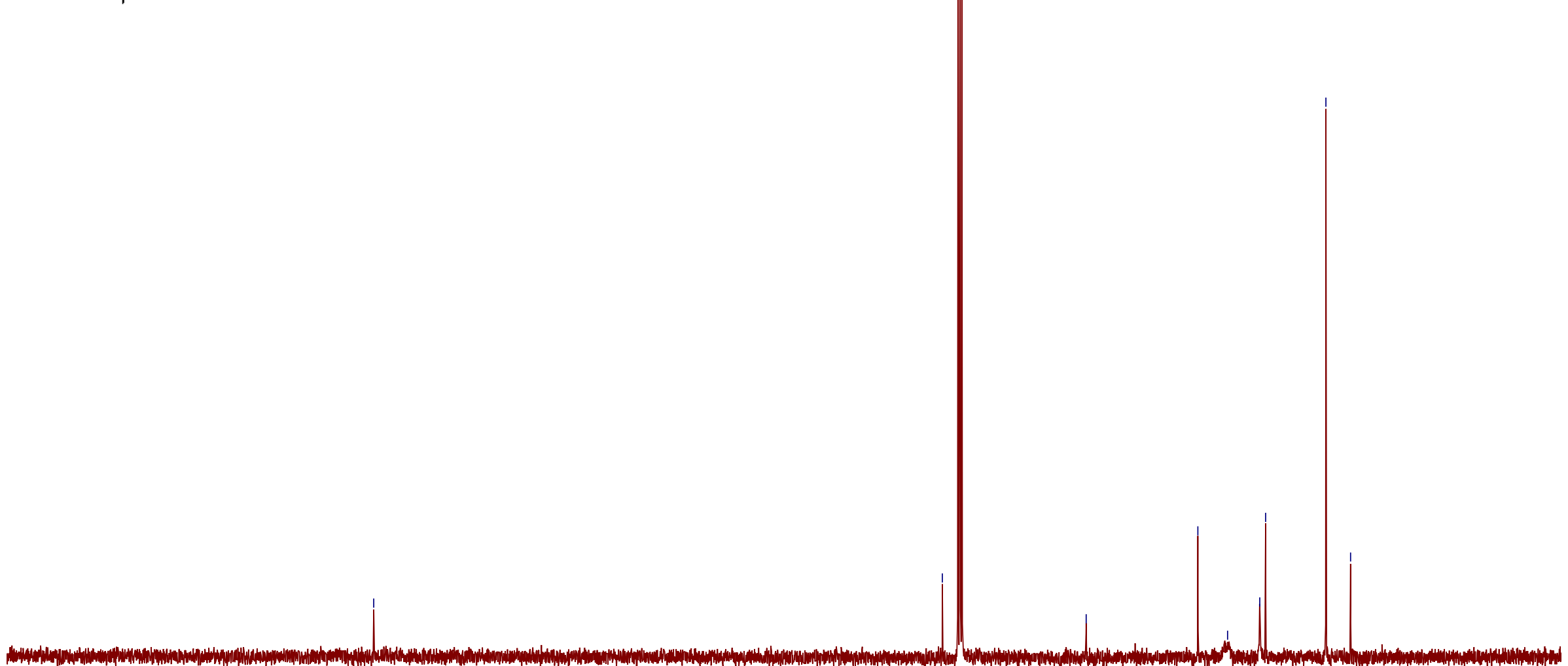


Figure S216. Mass spectrum of the compound 1p.

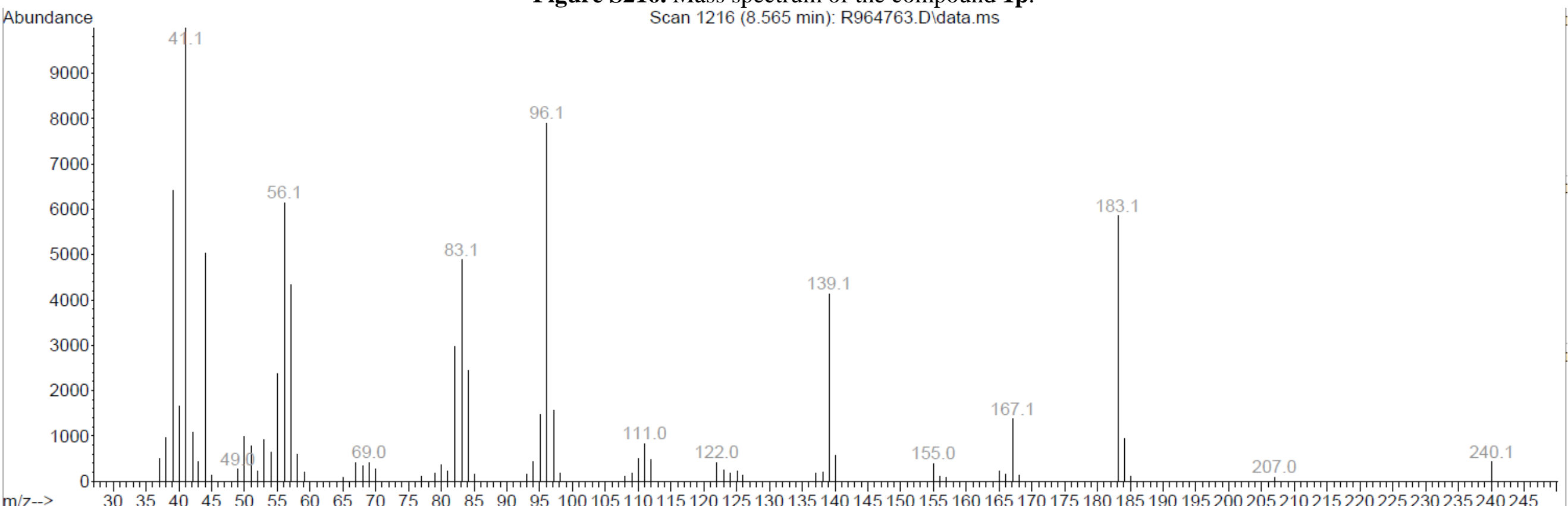


Synthesis of tert-butyl 1,7-diazaspiro[4.5]decane-7-carboxylate (1r). Approach III.

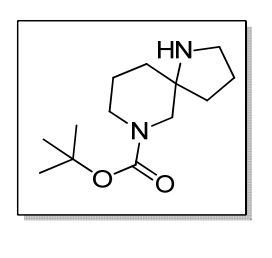

$1 r$

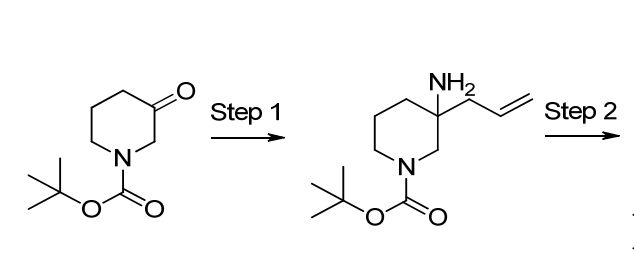

$16 r$

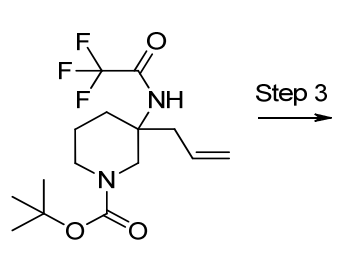

$17 r$

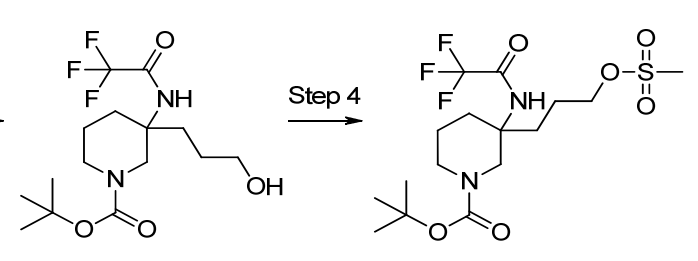

$18 r$

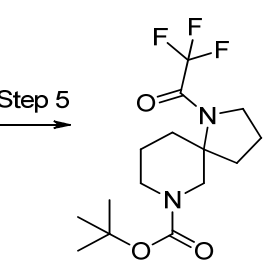

20r

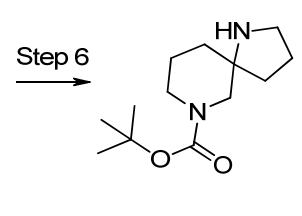

$1 \mathbf{r}$

Scheme S21.

Figure S217. ${ }^{1} \mathrm{H}$ spectrum of the compound $\mathbf{1 6 r}$.

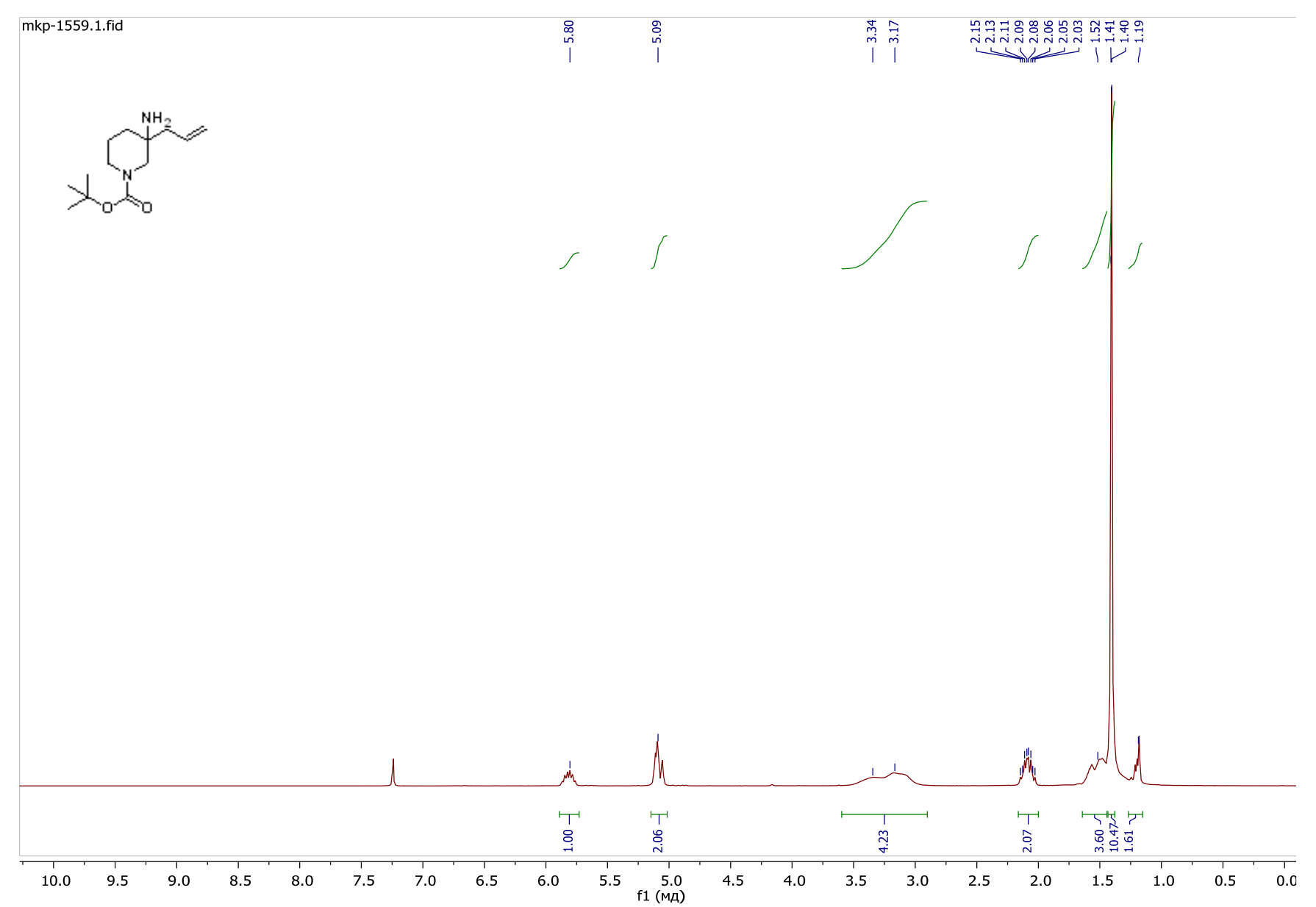


Figure S218. ${ }^{13} \mathrm{C}$ spectrum of the compound $\mathbf{1 6 r}$.

mkp-1559_C13.1.fid

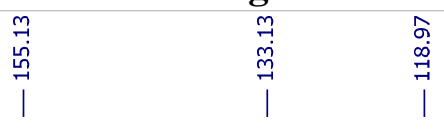
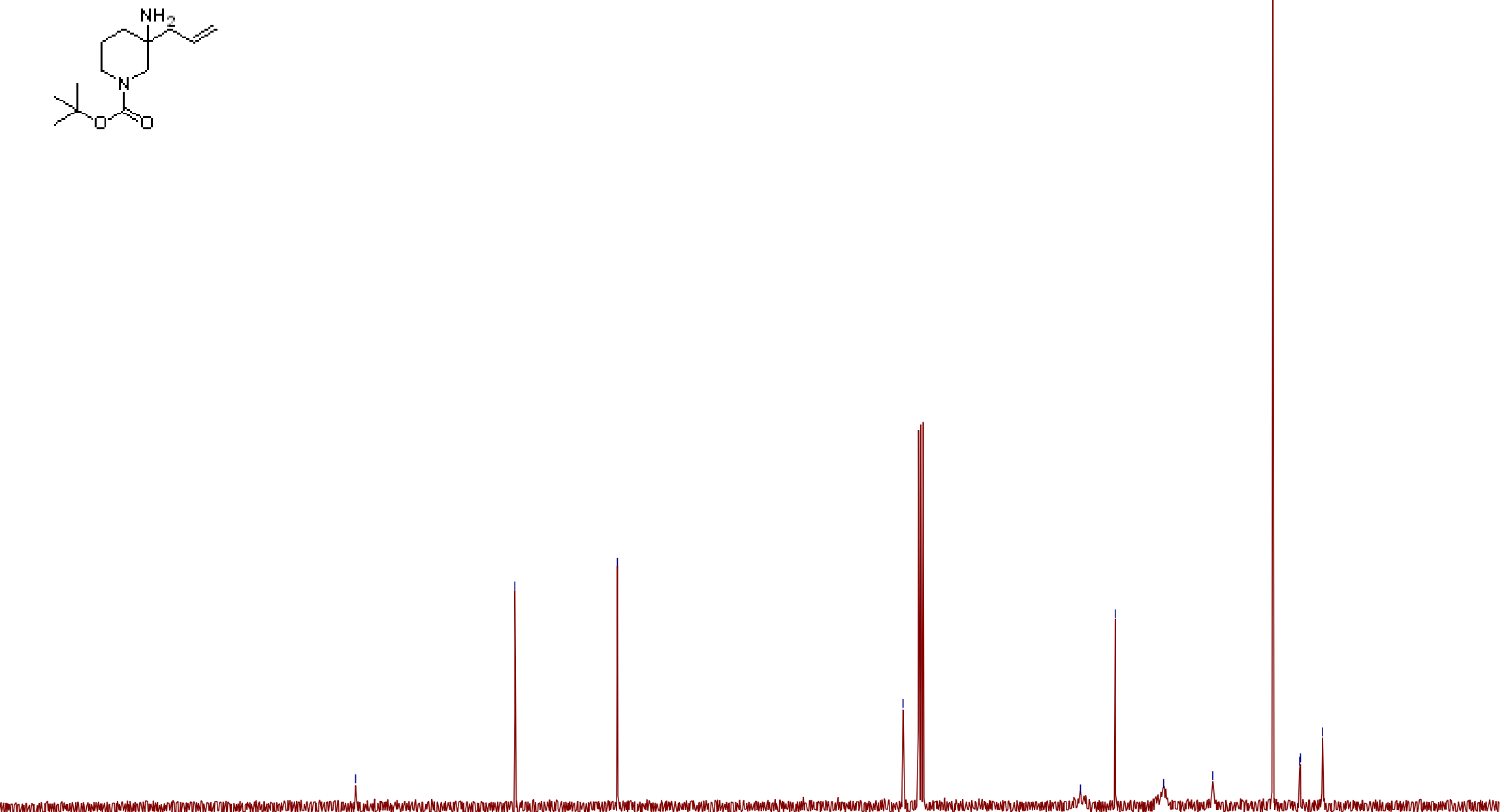
mkp-1160

Combined from individual shim mapping experiments new experiment

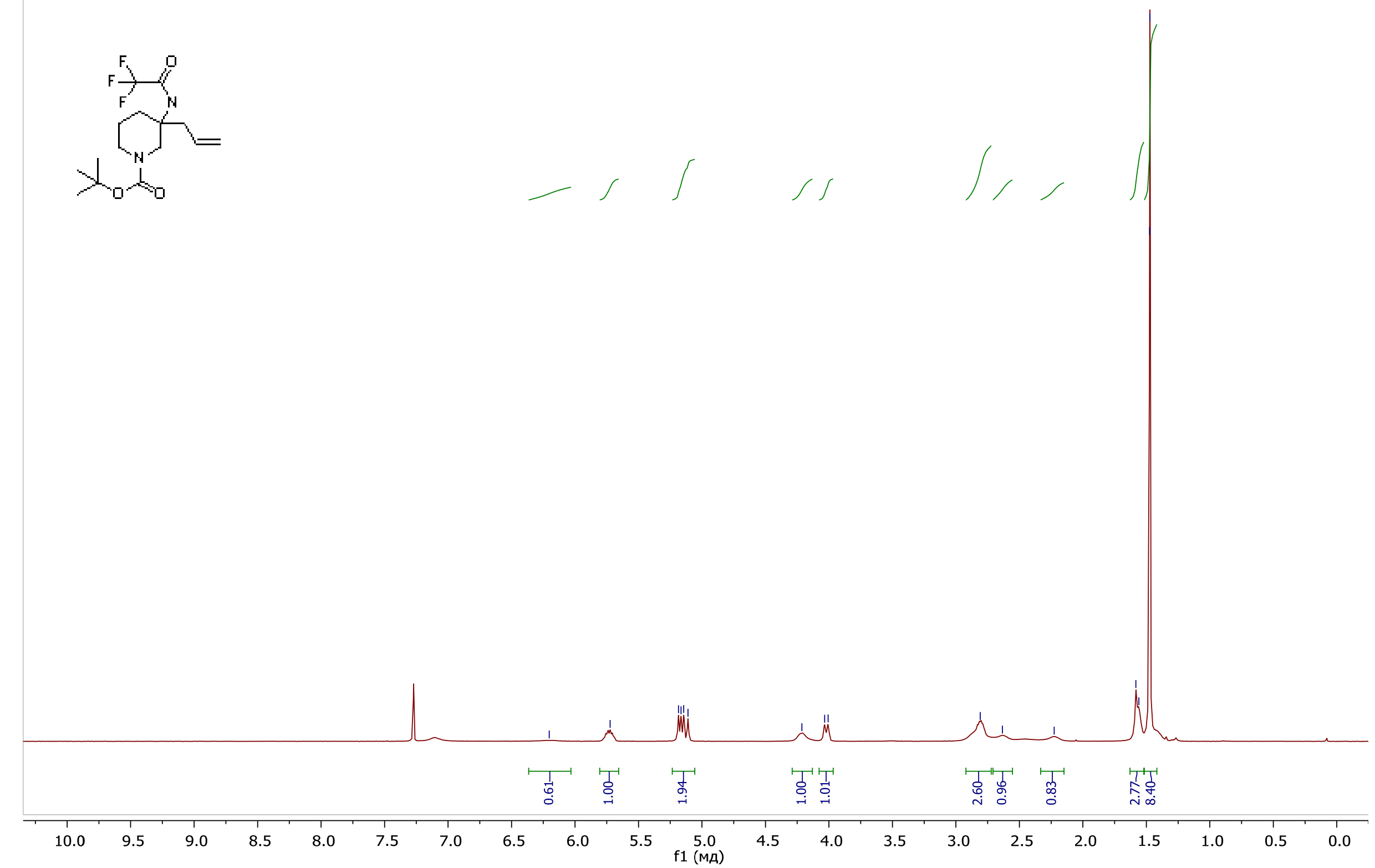

Figure S219. ${ }^{1} \mathrm{H}$ spectrum of the compound $\mathbf{1 7}$.

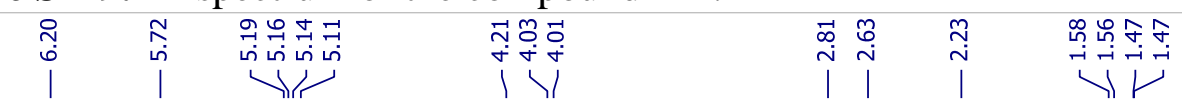


Figure S220. ${ }^{13} \mathrm{C}$ spectrum of the compound $\mathbf{1 7 r}$.

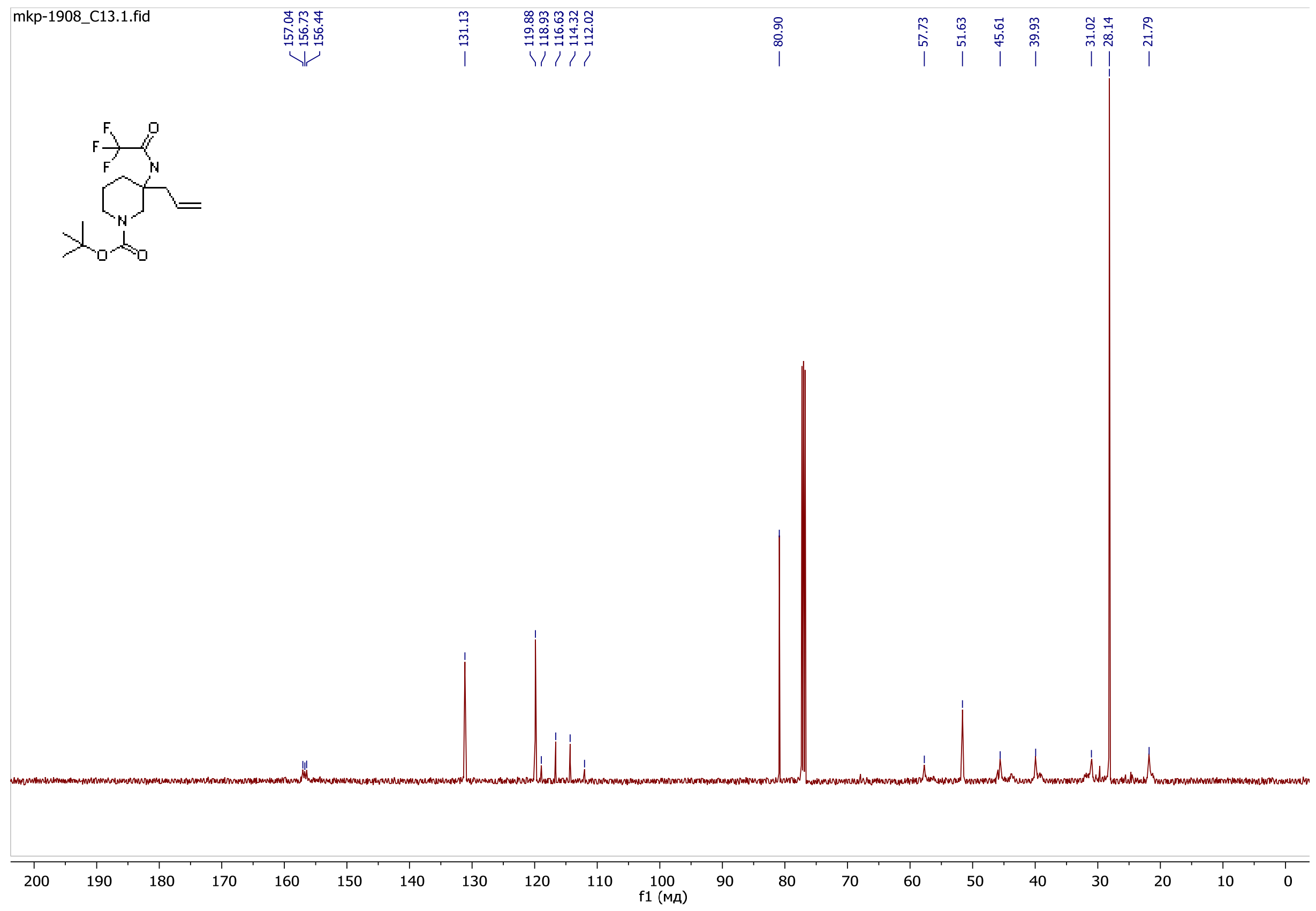


Figure S221. ${ }^{19} \mathrm{~F}$ spectrum of the compound 17r.

mkp-b-800_F19

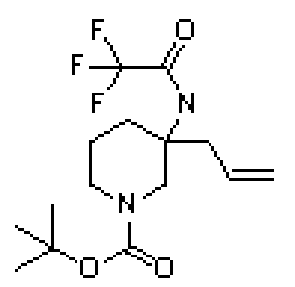

空苍

i
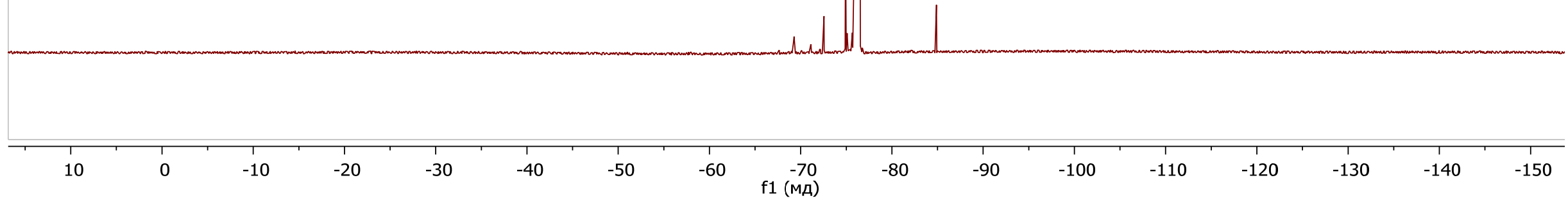
mkp-1196

new experiment

Combined from individual shim mapping experiments
Figure S222. ${ }^{1} \mathrm{H}$ spectrum of the compound 18r.

它
नें लंm लिं

।

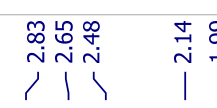
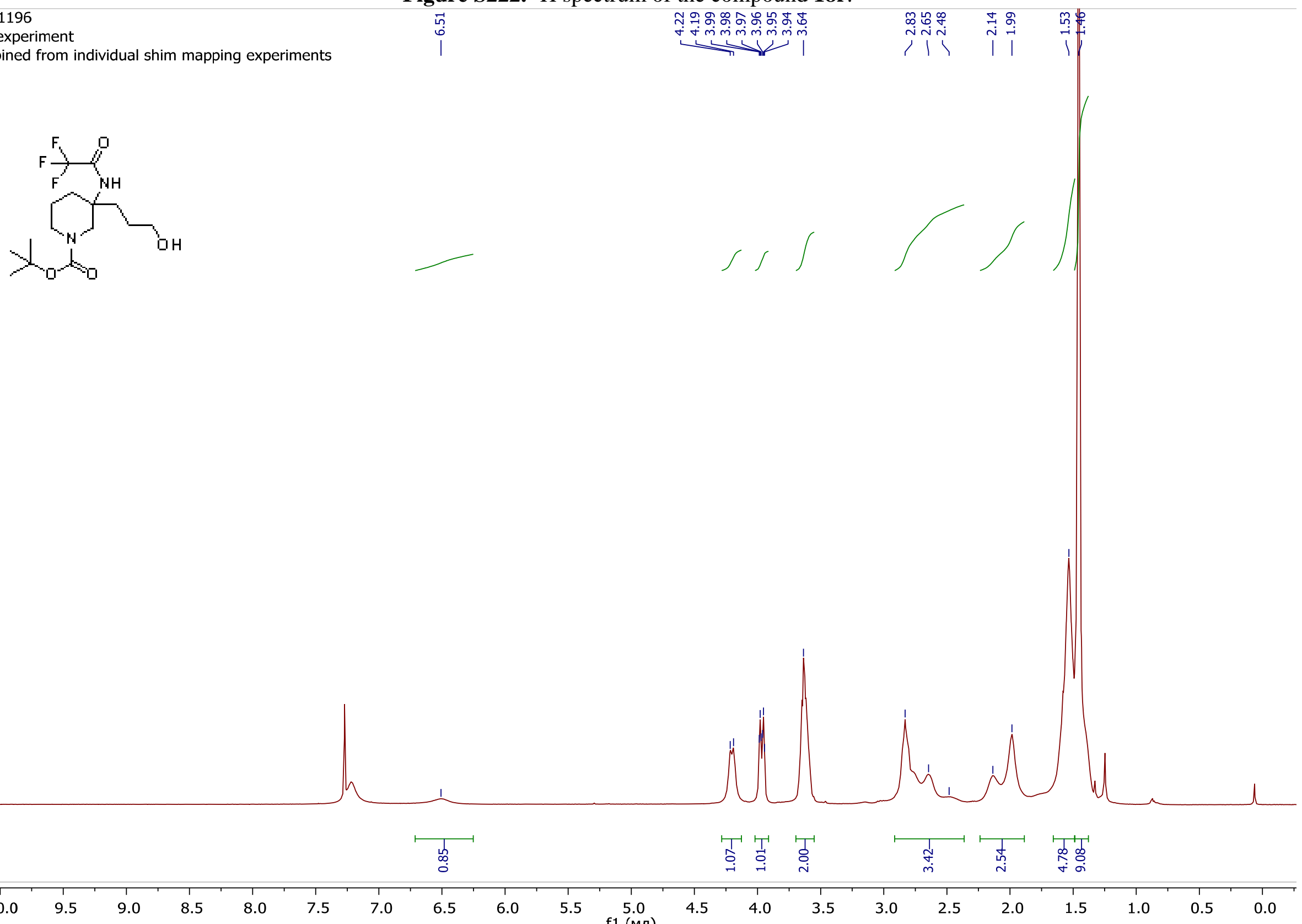
Figure S223. ${ }^{13} \mathrm{C}$ spectrum of the compound $\mathbf{1 8 r}$.

mkp-1196_C13

Automated Probe tuning parameter

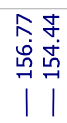

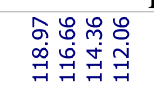

|1।

$$
\begin{gathered}
\infty \\
\infty \\
\infty \\
\infty \\
\mid \\
\mid
\end{gathered}
$$

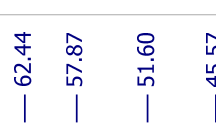

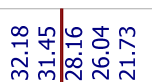

1ैं⿰

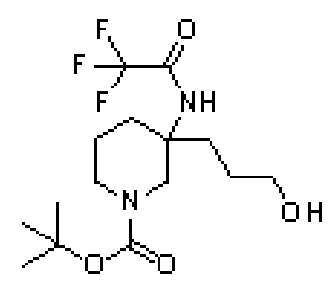

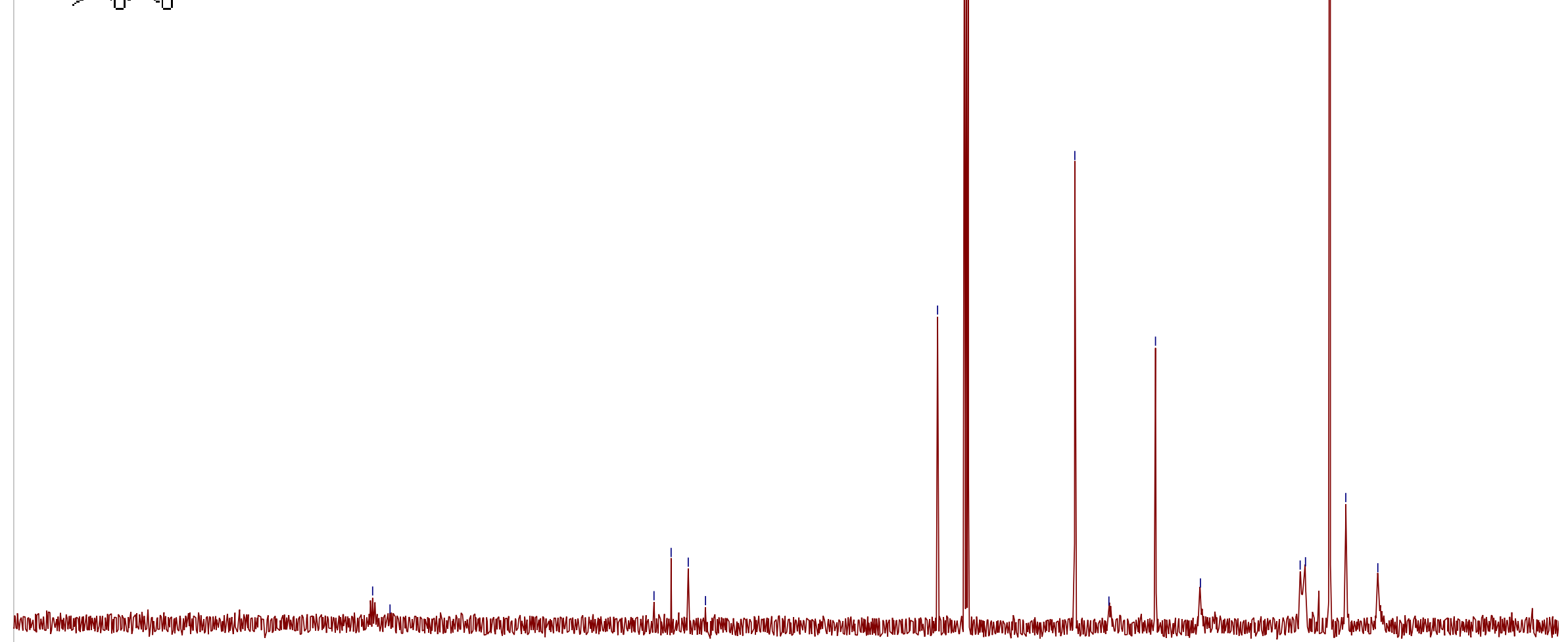

100
$\mathrm{f} 1$ (Мд)


Figure S224. ${ }^{19} \mathrm{~F}$ spectrum of the compound 18r.

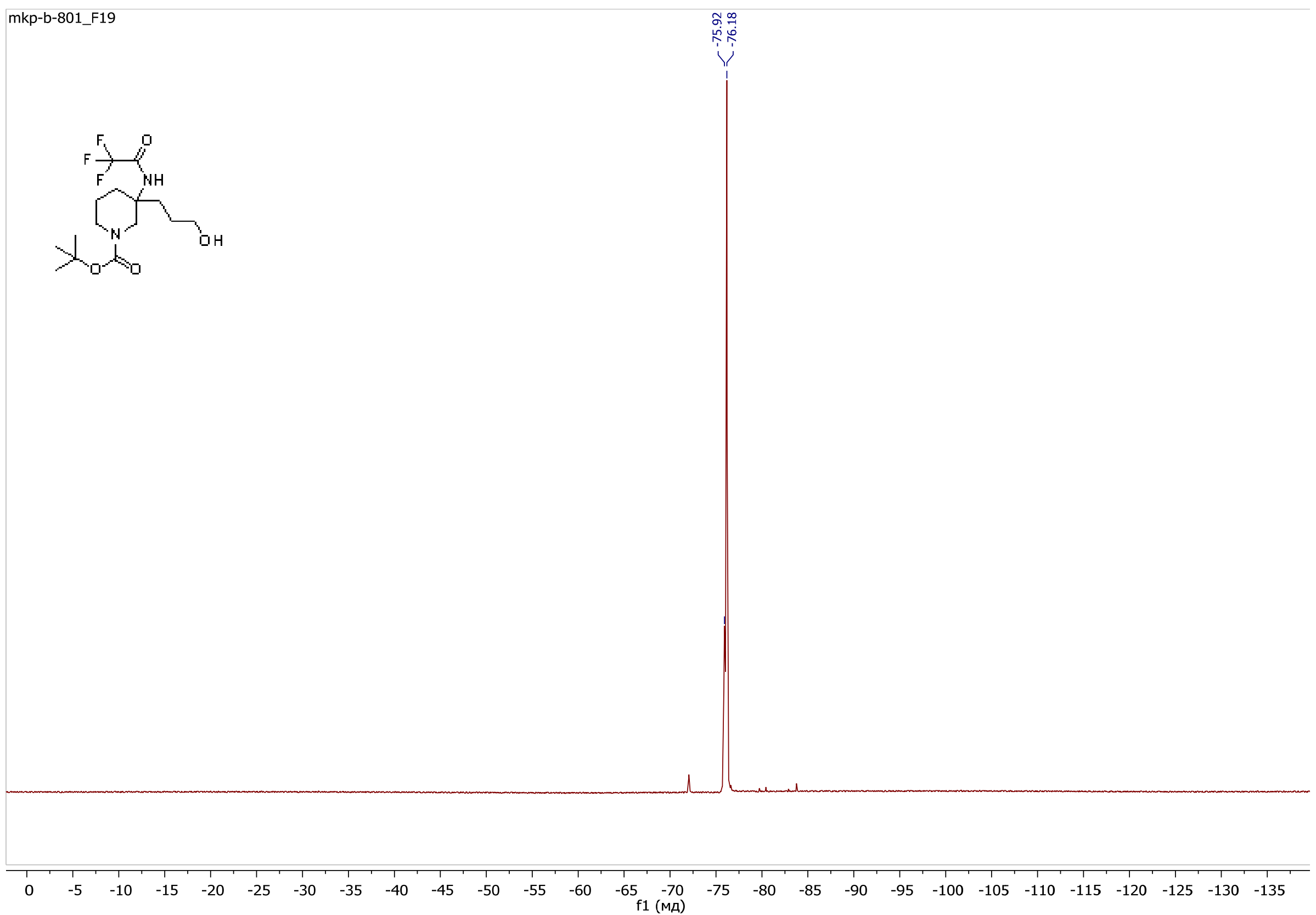


Figure S225. ${ }^{1} \mathrm{H}$ spectrum of the compound $19 r$.

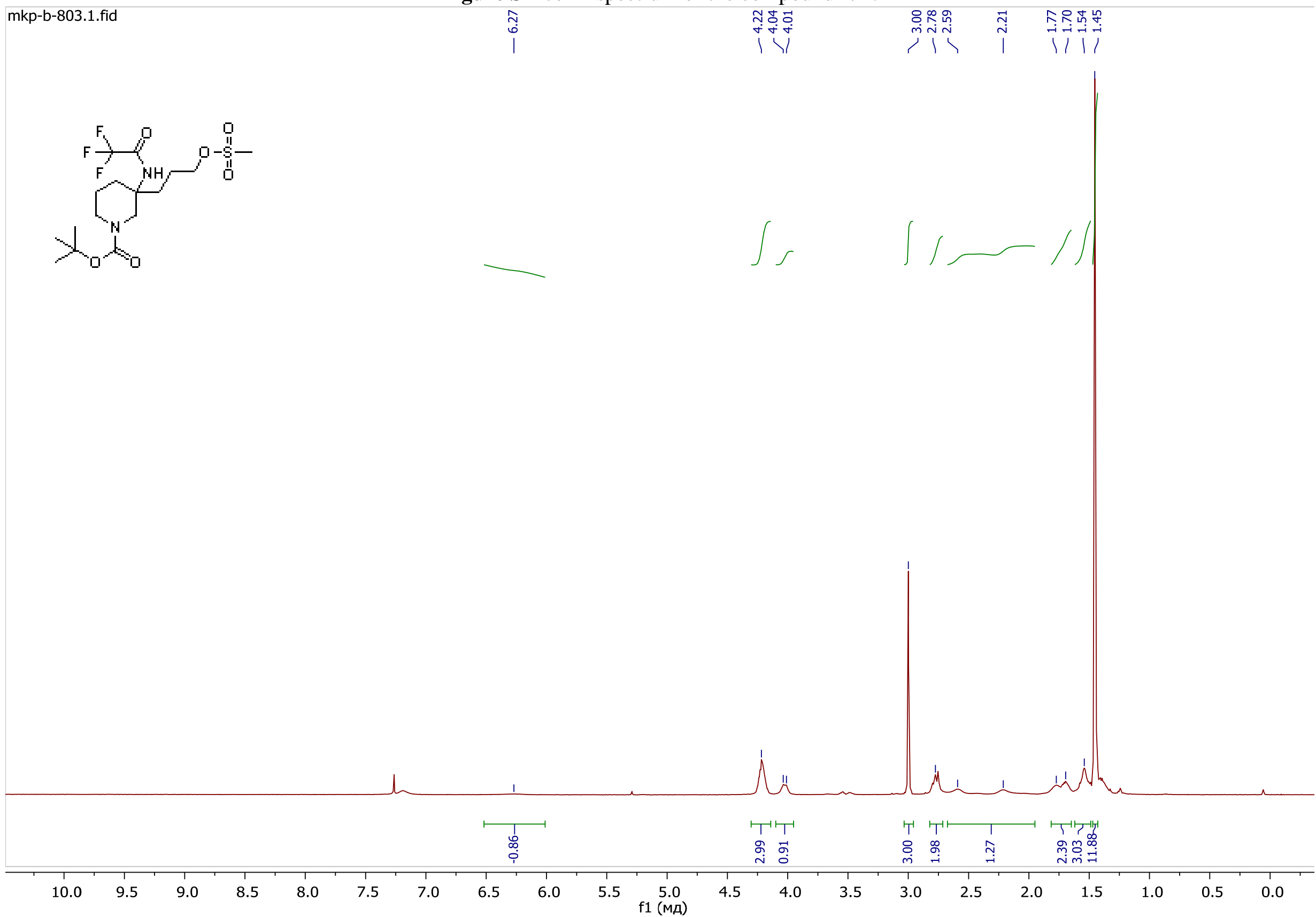


Figure S226. ${ }^{13} \mathrm{C}$ spectrum of the compound $19 \mathbf{r}$.

mkp-b-803_C13

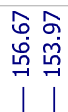<smiles>CC(C)(C)OC(=O)N1CCCC(CCCOS(C)(=O)=O)(NC(=O)C(F)(F)F)C1</smiles>

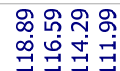

|111

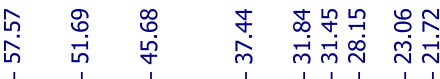

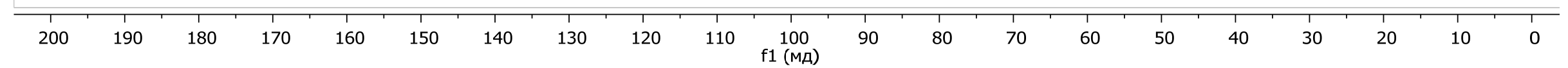


Figure S227. ${ }^{19} \mathrm{~F}$ spectrum of the compound 19r.

mkp-b-803_F19

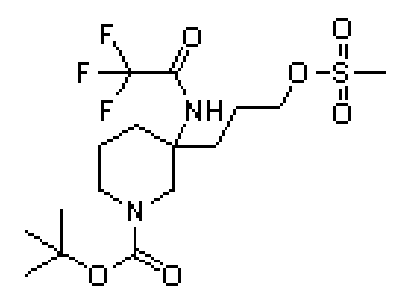

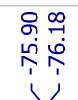

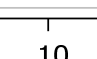

$-10$

$-20$

$-30$

$-40$

$-50$

$-60$ $f 1($ (мд)

$-80$

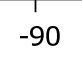

$-100$

$-110$

$-120$

$-130$

$-140$ $-15$ 
Figure S228. ${ }^{1} \mathrm{H}$ spectrum of the compound 20r.

mkp-b-802.1.fid I
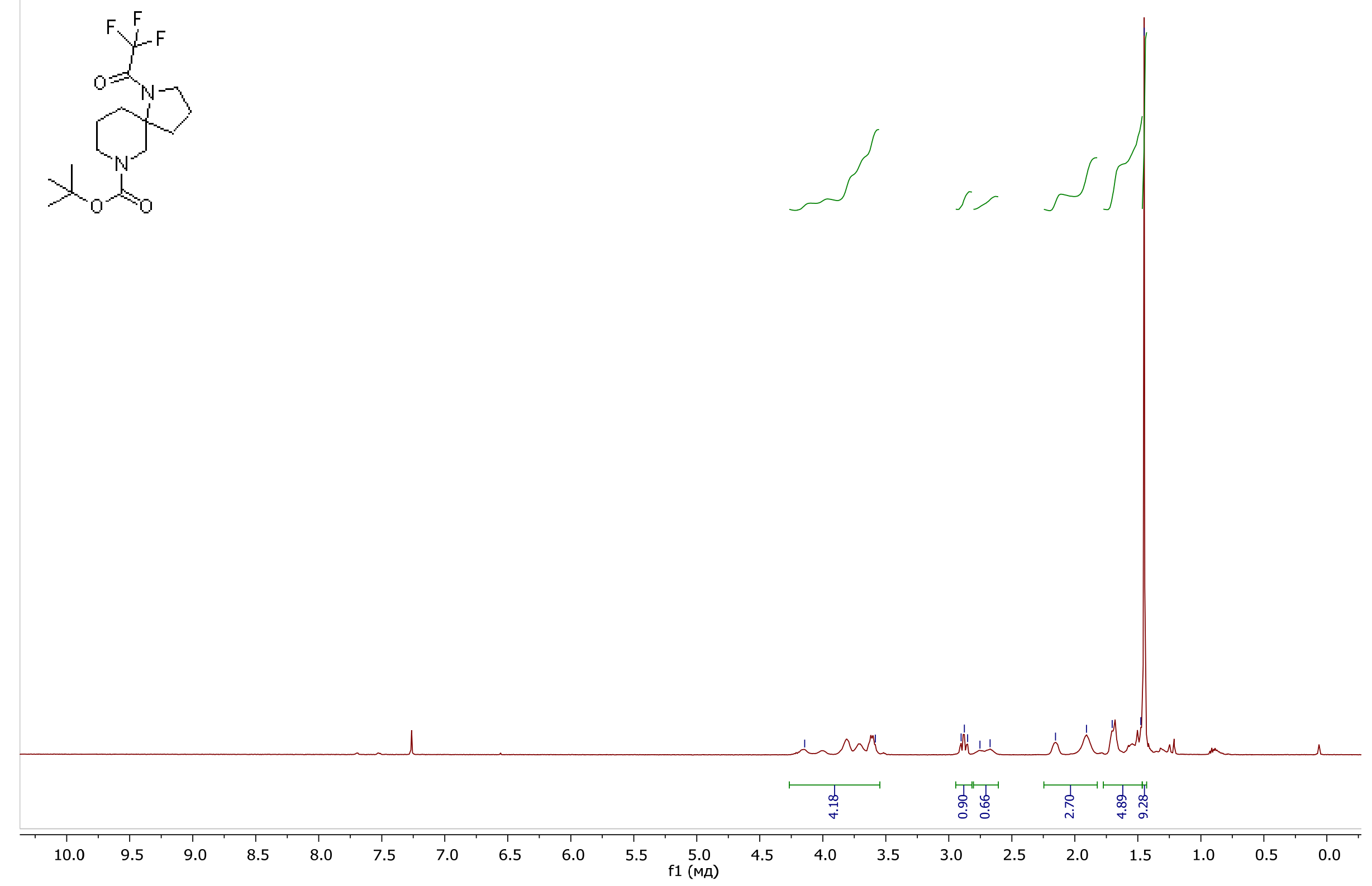
mkp-1911_C13.1.fid

후응

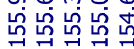

WN

Figure S229. ${ }^{13} \mathrm{C}$ spectrum of the compound 20r.

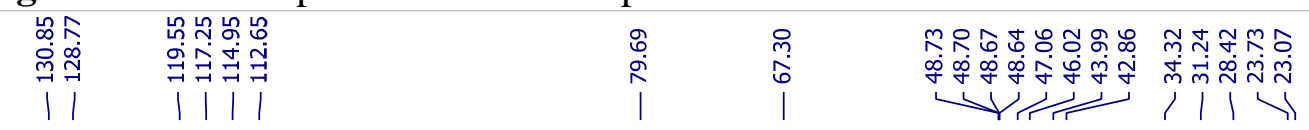<smiles>CC(C)(C)OC(=O)N1CCCC2(CCCN2C(=O)C(F)(F)F)C1</smiles>

प1।

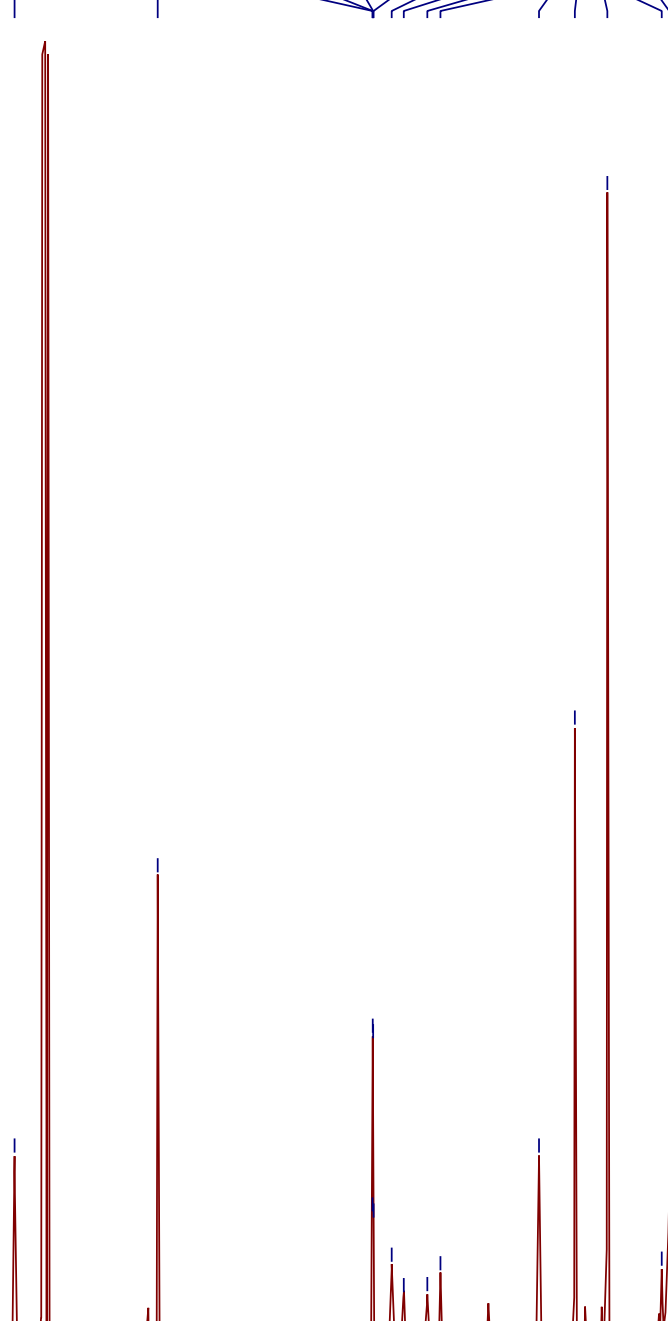

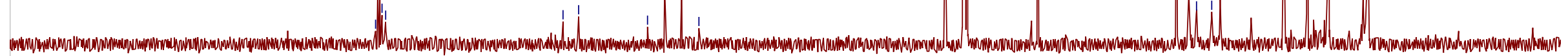

\begin{tabular}{|c|c|c|c|c|c|c|c|c|c|c|c|c|c|c|c|c|c|c|c|c|}
\hline 200 & $\begin{array}{c}1 \\
190\end{array}$ & $\begin{array}{c}1 \\
180\end{array}$ & 170 & 160 & $\begin{array}{l}1 \\
150\end{array}$ & 140 & 130 & 120 & 110 & $\begin{array}{c}1 \\
100\end{array}$ & 90 & 80 & 70 & 60 & 50 & 40 & 30 & 20 & 10 & 0 \\
\hline & & 100 & & 100 & 100 & & 130 & & & f1 (Mд) & 90 & 00 & 10 & 00 & 50 & 40 & 30 & 20 & 10 & 0 \\
\hline
\end{tabular}


Figure S230. ${ }^{19} \mathrm{~F}$ spectrum of the compound 20r.

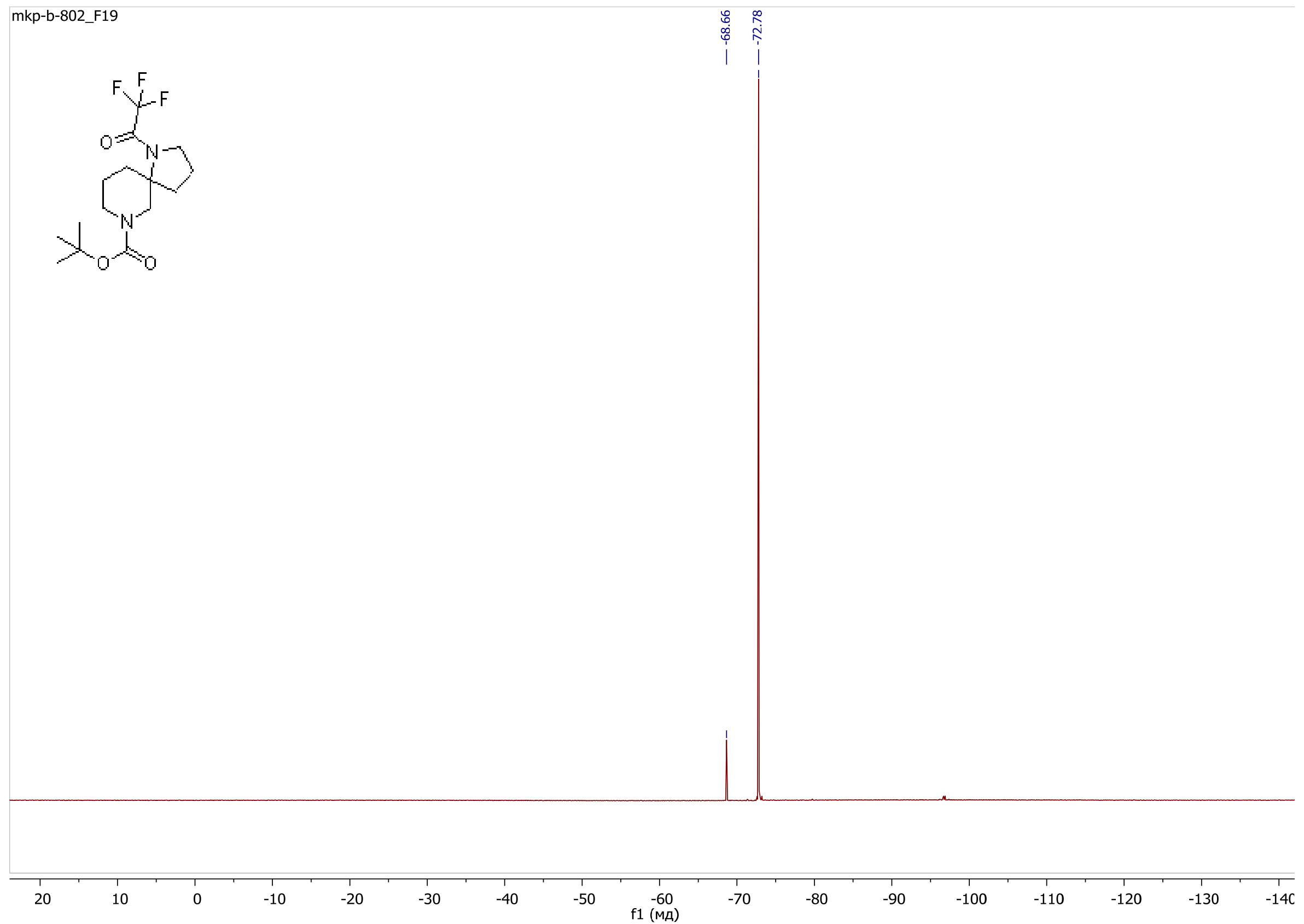


Figure S231. Mass spectrum of the compound 20r.

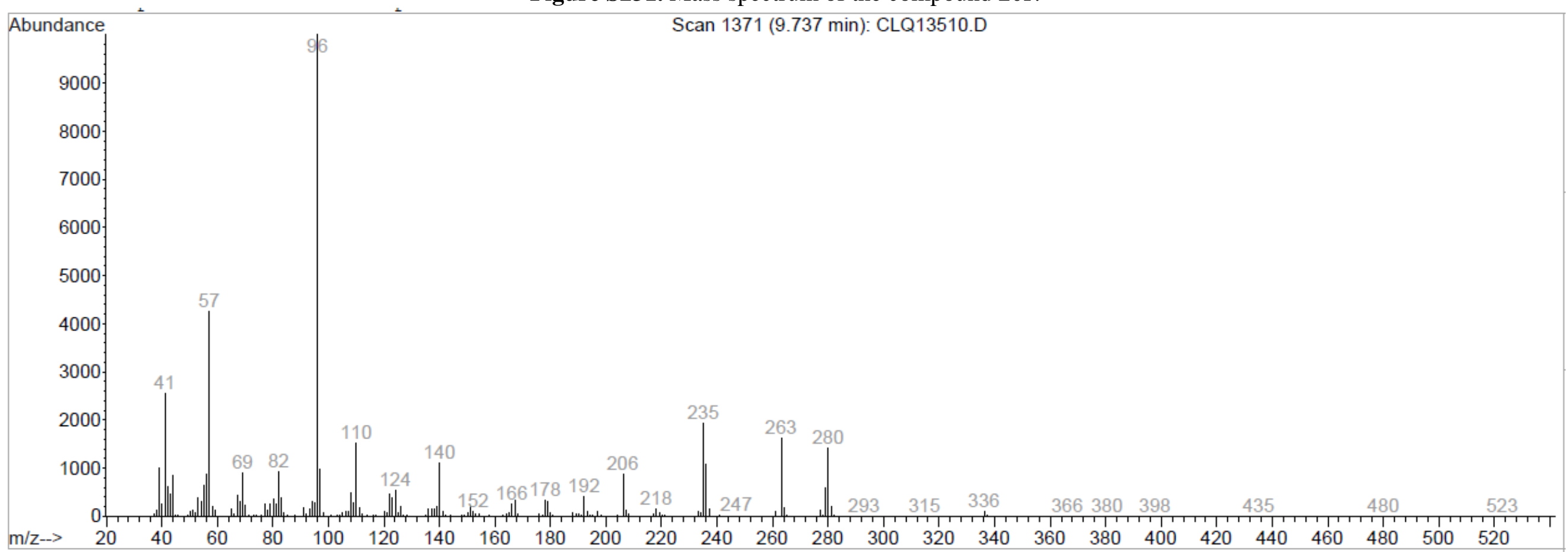


Figure S232. ${ }^{1} \mathrm{H}$ spectrum of the compound $1 \mathbf{r}$.

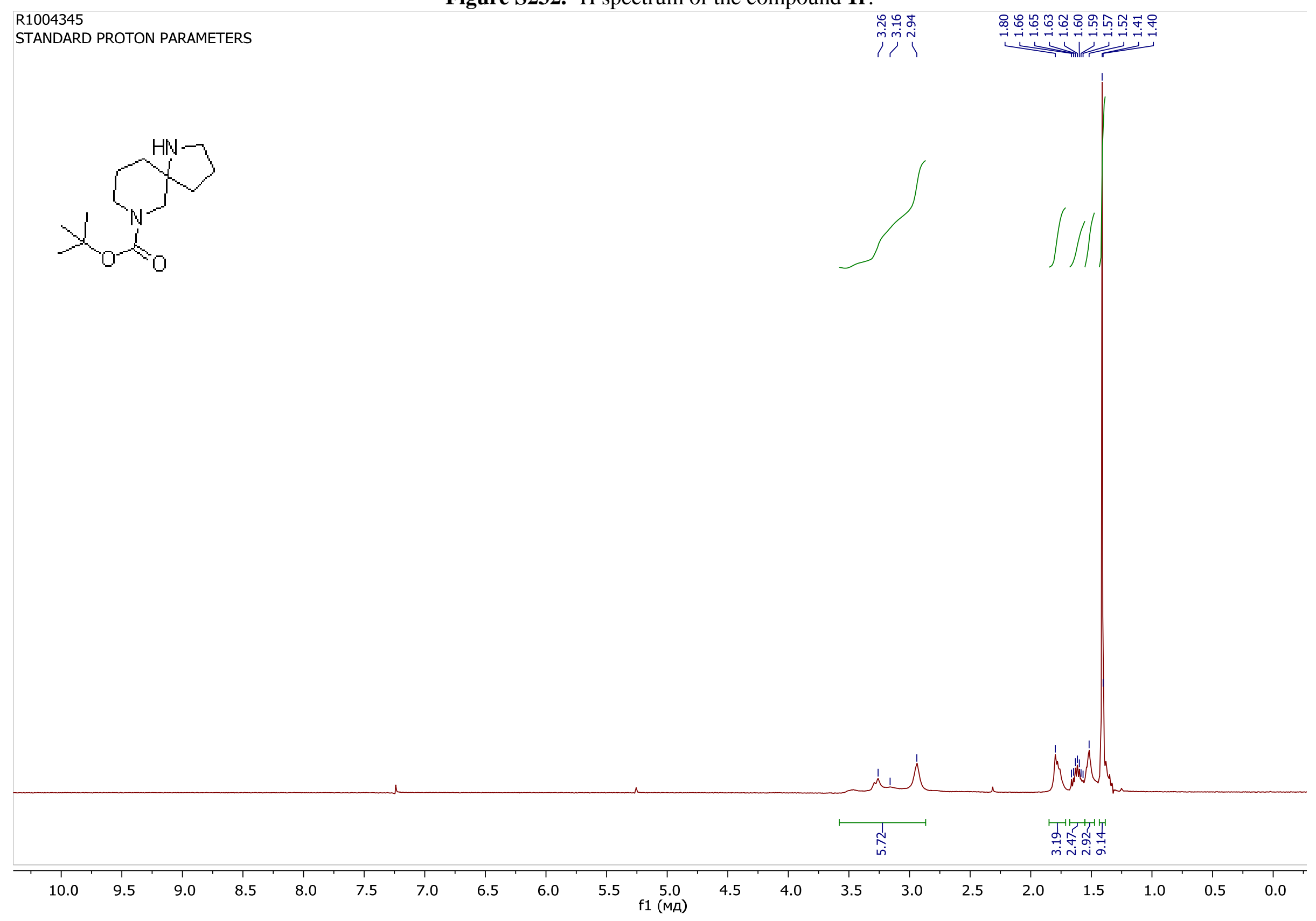


Figure S233. ${ }^{13} \mathrm{C}$ spectrum of the compound $\mathbf{1 r}$.

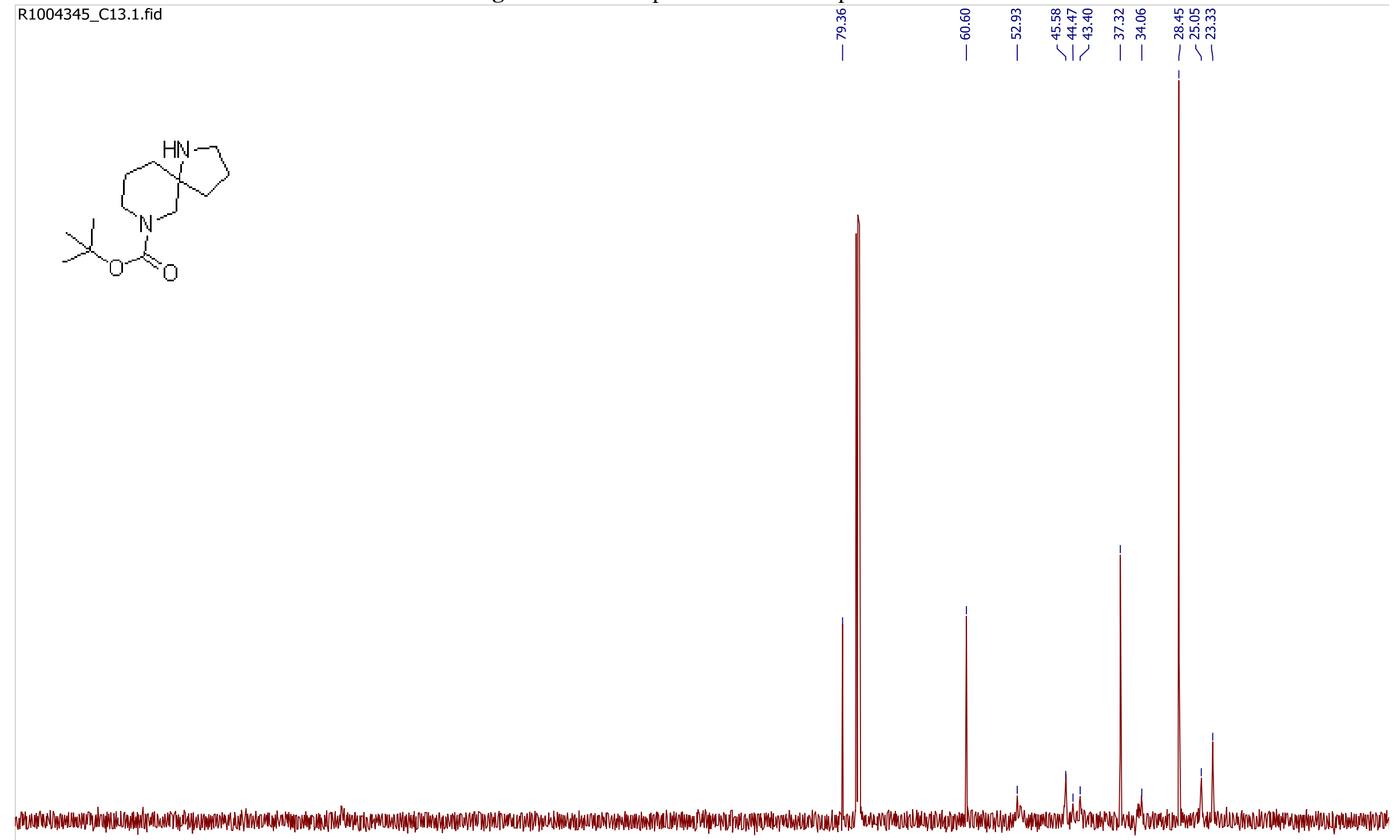

\begin{tabular}{|c|c|c|c|c|c|c|c|c|c|c|c|c|c|c|c|c|c|c|c|c|}
\hline 200 & $\begin{array}{c}1 \\
190\end{array}$ & 180 & $\begin{array}{c}1 \\
170\end{array}$ & 160 & $\begin{array}{c}1 \\
150\end{array}$ & $\begin{array}{c}1 \\
140\end{array}$ & 130 & 120 & 110 & $\begin{array}{c}100 \\
\text { f1 (MA) }\end{array}$ & 90 & 80 & 70 & 60 & 50 & 40 & 30 & 20 & 10 & $\begin{array}{l}1 \\
0\end{array}$ \\
\hline
\end{tabular}

